\title{
Measuring and modelling the dynamics of carbon and nitrogen mineralization from diverse plant residues in soil - plant systems
}

\author{
Dissertation \\ to obtain the Ph. D. degree \\ in the International Ph. D. Program for Agricultural Sciences in Goettingen (IPAG) \\ at the Faculty of Agricultural Sciences, \\ Georg-August-University Göttingen, Germany
}

presented by

Nguyen, Trung Hai

born in Thua Thien Hue, Vietnam 
D7

1. Name of supervisor: Prof. Dr. Anthony Whitbread

2. Name of co-supervisor: Prof. Dr. Klaus Dittert

Date of dissertation: 03.05.0216 


\section{Preface}

This thesis has been submitted in partial fulfilment of the requirements for the degree "Doktor der Agrarwissenschaften" (Dr. sc. agr. / Ph.D in Agricultural Sciences) by the Faculty of Agricultural Sciences at the Georg-August University of Göttingen, Germany on the $1^{\text {st }}$ April 2016.

Date of oral examination: $3^{\text {rd }}$ May 2016

Examination Committee:

First supervisor: Prof. Dr. Anthony Whitbread

Second supervisor: Prof. Dr. Klaus Ditter

External examiner: Dr. Marife Corre 


\section{Table of Contents}

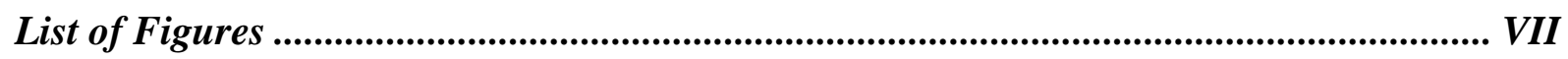

List of Tables ............................................................................................................................ IX

Chapter 1: General introduction ............................................................................................. 1

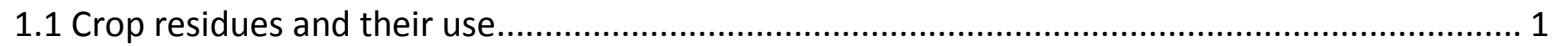

1.1.1 Global production estimates of crop residue from arable lands .................................. 1

1.1.2. The application of plant residues and their roles..................................................... 2

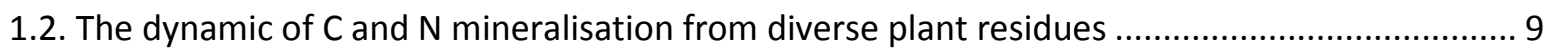

1.2.1. General conceptual ...................................................................................... 9

1.2.2. Factors affecting the dynamic of $\mathrm{C}$ and $\mathrm{N}$ mineralisation ............................................. 10

1.3. The application of model in representing the $\mathrm{C}$ and $\mathrm{N}$ dynamics in soil - plant - atmosphere

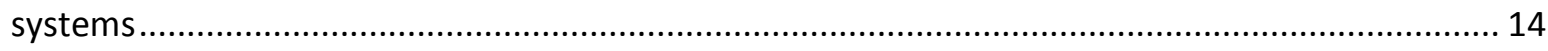

1.3.1. Overview of some Soil Organic Matter (SOM) models ........................................... 14

1.3.2. Description of using model - SOILN in APSIM....................................................... 17

1.3.3. The application of SOILN in representing the dynamic of $\mathrm{C}$ and $\mathrm{N}$................................ 18

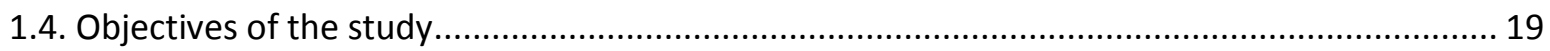

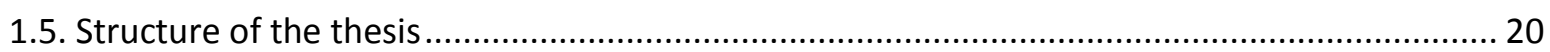

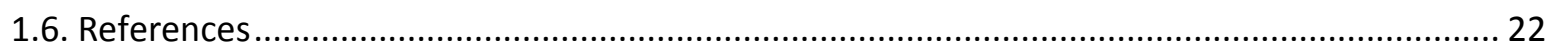

Chapter 2. Evaluating the effect of residue quality on $C$ and $N$ mineralization in soils under controlled conditions ........................................................................................... 27

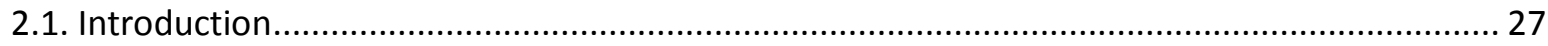

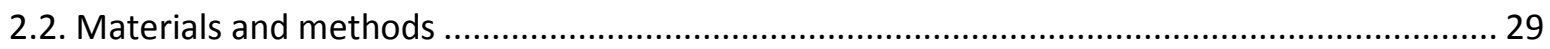

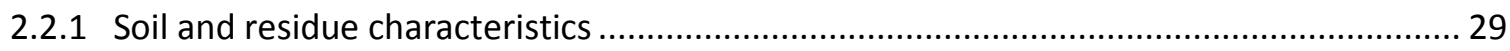

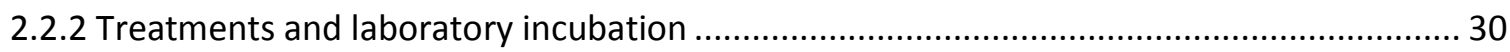

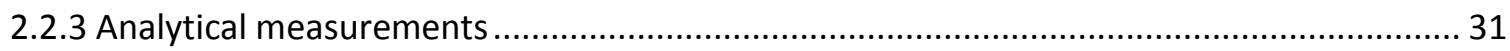

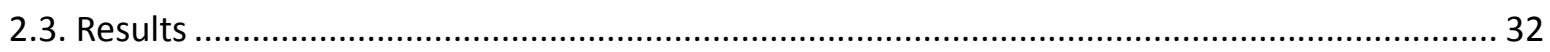

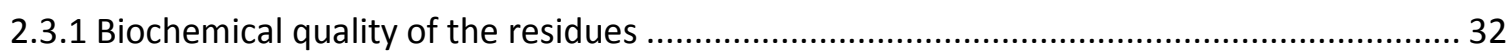

2.3.2 Carbon and nitrogen mineralisation of added residues from different soil types.............. 33

2.3.3 Carbon and nitrogen mineralisation from different residue application methods ............40

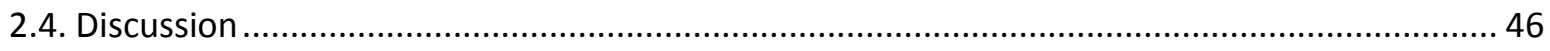

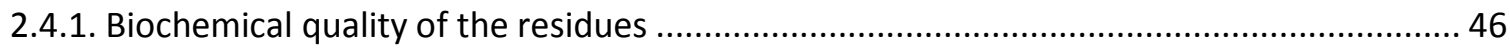

2.4.2. Carbon and nitrogen mineralisation of added residues from different soil types.............46

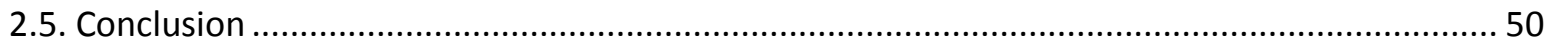

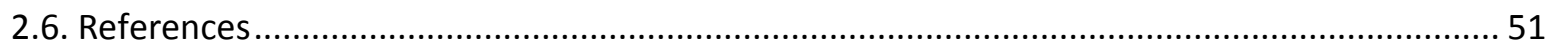


Chapter 3. Modelling carbon and nitrogen mineralisation from diverse plant residues in

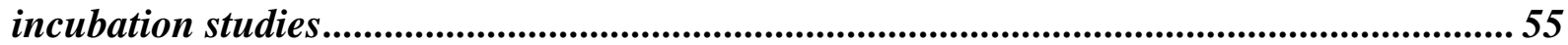

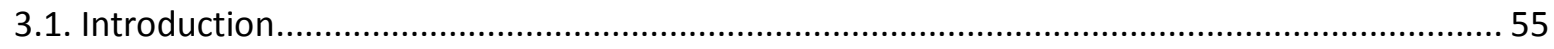

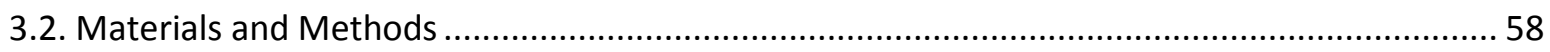

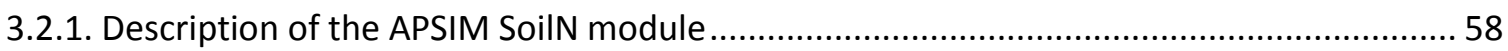

3.2.2. Process for initialising SOILN to simulate diverse residues .............................................. 59

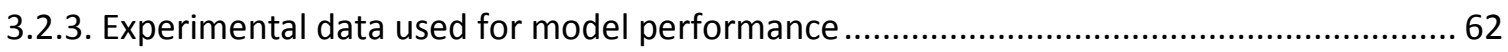

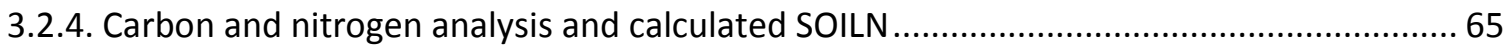

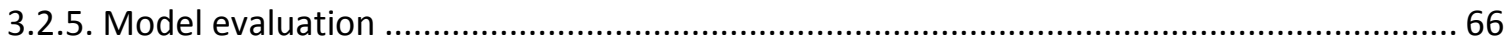

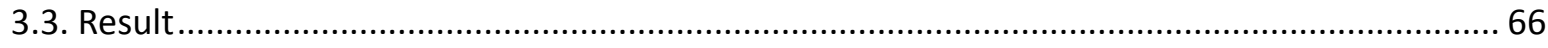

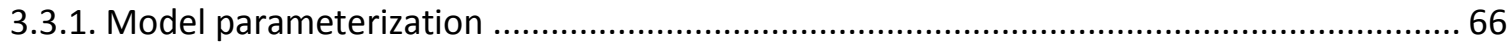

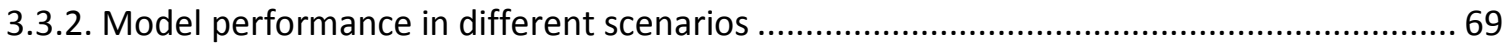

3.3.3. Simulation $\mathrm{C}$ and $\mathrm{N}$ dynamic from SOILN model by using modified parameters................ 74

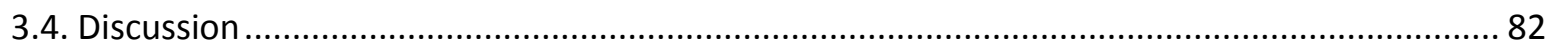

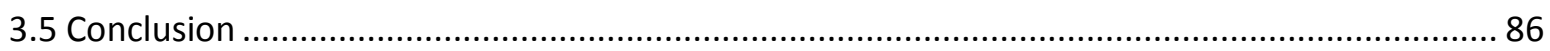

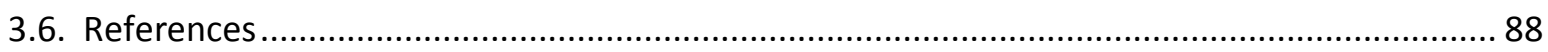

APPENDIX

Chapter 4. Carbon and nitrogen mineralisation and $\mathrm{N}$ recovery from ${ }^{15} \mathrm{~N}$ labelled plant residues under controlled conditions....................................................................................94

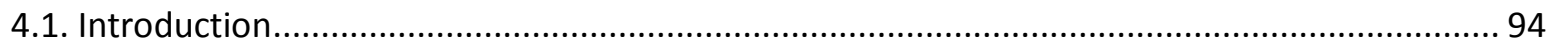

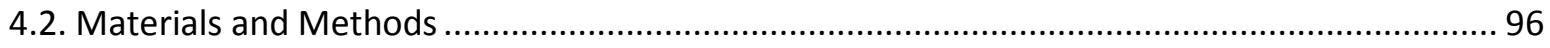

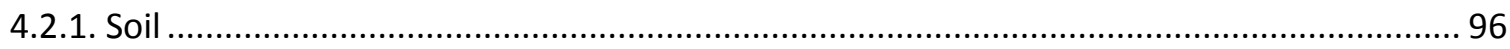

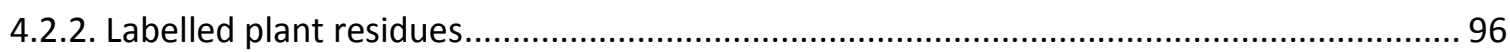

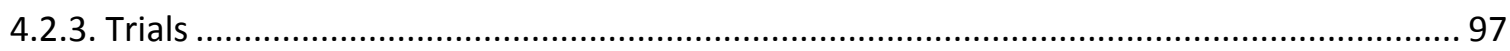

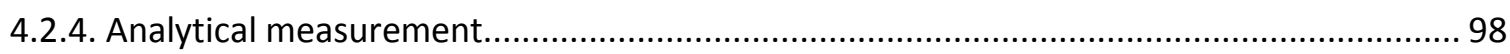

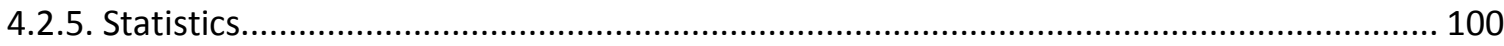

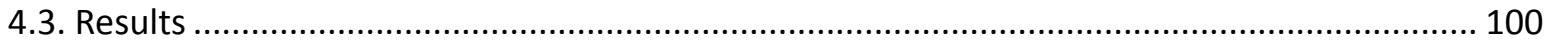

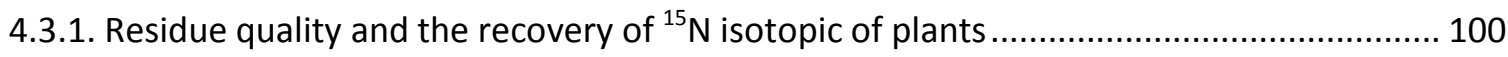

4.3.2. Gas fluxes and net $\mathrm{N}$ mineralisation from incubation trial ........................................... 102

4.3.3. Dry matter of wheat plant from different applications and residues quality................... 104

4.3.4. $\mathrm{N}$ recovery from added labelled residues to plant.......................................................... 107

4.3.5. Net $\mathrm{N}$ mineralisation from different residue types and application ................................. 110

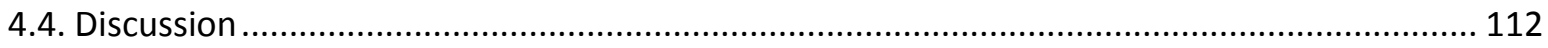

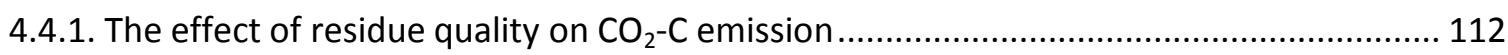

4.4.2. $\mathrm{N}$ mineralisation/immobilisation in the different conditions ......................................... 112

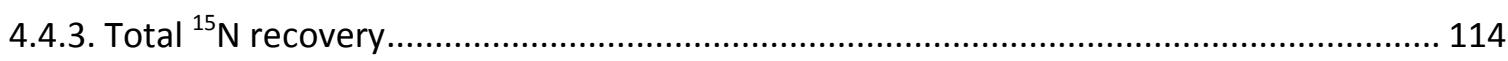


Chapter 5. General discussion and conclusion ........................................................ 119

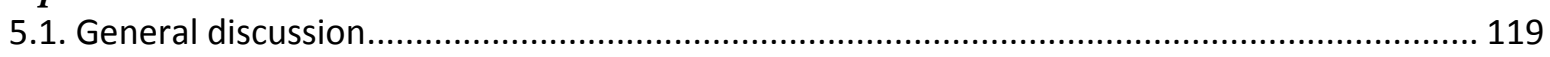

5.1.1. Residue quality and decomposition ............................................................... 119

5.1.2. Potential application of soil organic matter models ............................................. 121

5.2. Conclusions and recommendations .................................................................. 123

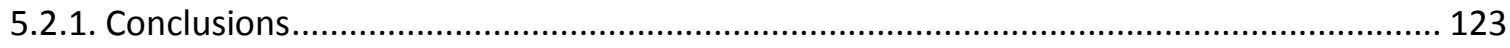

5.2.2. Suggestions for future research related to the findings of this thesis......................... 124

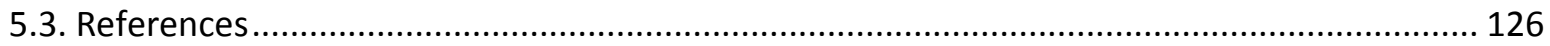

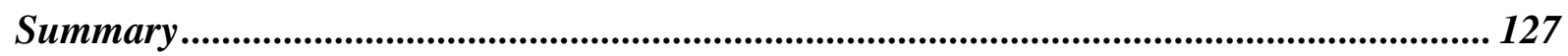

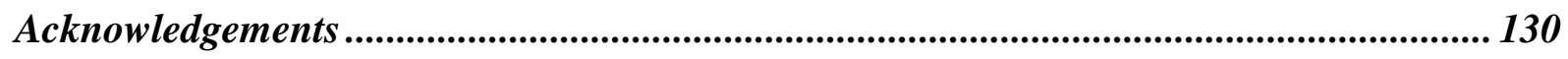

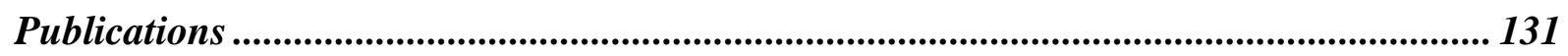

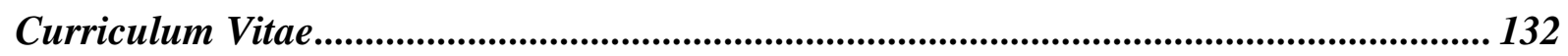

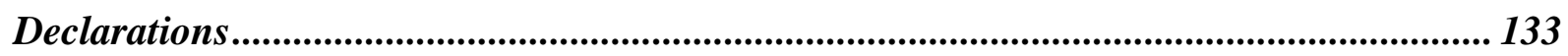




\section{List of Figures}

Figure 1.1. The implication of plant residues

Figure 1.2. The impact of plant residues on soil processes 7

Figure 1.3. Total $\mathrm{N}$ content from added residues of different continents since 1960 to $2050 . .8$

Figure 1.4. Total $\mathrm{CO}_{2}$ emission equivalent in gigagrams from added residues of different continents since 1960 to 2050 .

Figure 1.5. Total $\mathrm{N}_{2} \mathrm{O}$ emission in gigagrams from added residues of different continents since 1960 to 2050 .

Figure 1.6. The framework of SOILN module and the transformation occurring in each layer.

Figure 2.1. Linear regression between $\mathrm{C}: \mathrm{N}$ ratio of residue and some carbon distribution pools of residue.

Figure 2.2. Cumulative $\mathrm{CO}_{2}-\mathrm{C}$ release from only residues in clay, sand and subsoil 35

Figure 2.3. The relationships between net $C$ release as percentage of total $C$ input from only added residues and soil types after 7, 28 and 63 days of incubation.

Figure 2.4. Net $\mathrm{N}$ mineralisation from only residues in clay, sand and subsoil ...... 38

Figure 2.5. The relationship between overall C:N ratio of residues and net carbon mineralised and net $\mathrm{N}$ mineralised in clay soil and sand soil at 7 days, 28 days and 63 days ........

Figure 2.6. Cumulative $\mathrm{CO}_{2}-\mathrm{C}$ release from only residues in incorporated application, and mulched application .

Figure 2.7. Net $\mathrm{N}$ mineralisation from only residues in incorporated application, and mulched application.

Figure 2.8. The relationship between overall $\mathrm{C}: \mathrm{N}$ ratio of residues and net $\mathrm{C}$ release and net $\mathrm{N}$ mineralised of different residue materials at 7 days, 28 daysand 63 days. 42

Figure 2.9. The relationship between different biochemical components and carbon mineralised and net $\mathrm{N}$ mineralised of different residue materials at 7 days, 28 days and 63 days.

Figure 3.1. The framework of SOILN in relationship with other essential modules in APSIM

Figure 3.2. Cumulative $\mathrm{CO}_{2}-\mathrm{C}$ release and Net $\mathrm{N}$ mineralised from unamended soil by individual fitting 3 parameters.

Figure 3.3. Scatter plots of the observation vs. measurement of cumulative $\mathrm{CO}_{2}$-C release from 20 residues applied in scenario 1 and scenario 2 and 3

Figure 3.4. Scatter plots of the observation vs. measurement of net $\mathrm{N}$ mineralised from 20 residues applied in scenario 1 and scenario 2 and scenario 3 
Figure 3.5. Cumulative $\mathrm{CO}_{2}-\mathrm{C}$ release and Net $\mathrm{N}$ mineralized from residues in soil type 1 by using modified parameters. .75

Figure 3.6. Cumulative $\mathrm{CO}_{2}-\mathrm{C}$ release and $\mathrm{Net} \mathrm{N}$ mineralized from residues in soil type 2 by using modified parameters.

Figure 3.7. Cumulative $\mathrm{CO}_{2}-\mathrm{C}$ release and Net $\mathrm{N}$ mineralized from residues in soil type 4 and soil type 3 by using modified parameters.

Figure 3.8. Sensitivity analysis to the variation of ef_biom, ef_fom and ef_hum parameters applied to mucuna residue (\#4) in soil type 2 .

Figure 4.1. Cummulative $\mathrm{CO}_{2}-\mathrm{C}$ emissions from added residues in incubation trial. 102

Figure 4.2. The relationship between lignin content and $\mathrm{CO}_{2}$ gas flux emission of different residue materials at 7 days, 28 days, 56 days and 119 days. 103

Figure 4.3. Net $\mathrm{N}$ mineralisation from added residues in incubation trial.. 104

Figure 4.4. Dry matter of wheat at 6 WAP and at 12 WAP of different treatments from mulched (a) and incorporated (b) application in 3 consecutive seasons. 106

Figure 4.5. ${ }^{15} \mathrm{~N}$ recovery from different added residues to plant in various harvesting time and residues application in the first season, second season and third season..... 108

Figure 4.6. Total ${ }^{15} \mathrm{~N}$ recovery from different added residues to plant in different residues applications at 6 WAP and at 12 WAP... 109

Figure 4.7. Relationship between total $15 \mathrm{~N}$ derived from residue and lignin content from incorporated (a) and mulched (b) application at 6 WAP and at 12 WAP 110

Figure 4.8. Net $\mathrm{N}$ mineralisation from added residues in pot trial when incorporated with soil (a) or placed on the surface (b).

Figure 5.1. Decision tree of plant residues application as determined by their litter quality .... 


\section{List of Tables}

Table 1.1. Plant residue production of some main countries and of the world in 2000 and 2014

Table 2.1. Some chemical and textural properties of soils used in 3 incubation experiments.

Table 2.2. Chemical properties of residues used

Table 3.1. Chemical properties of residues used in this study .64

Table 3.2. Soil characteristics and soil organic matter in first $10 \mathrm{~cm}$ layer 65

Table 3.3a. Value of some modification parameters of SOILN. .68

Table 3.3b. Statistical analysis of model performance from unamended soil 69

Table 3.4a. Statistical analysis of cumulative $\mathrm{CO}_{2}-\mathrm{C}$ release from different dataset in the best scenario performance.

Table 3.4b. Statistical analysis of net $\mathrm{N}$ mineralisation from different dataset in the best scenario performance

Table 3.5a. Statistical analysis of cumulative $\mathrm{CO}_{2}-\mathrm{C}$ release from added residues in different scenarios.

Table 3.5b. Statistical analysis of net $\mathrm{N}$ mineralized from added residues in different scenarios

Table 4.1. Some biochemical quality of using plant residues

Table 4.2. The recovery of ${ }^{15} \mathrm{~N}$ isotopic in atom percent excess (APE) of wheat plant from different ${ }^{15} \mathrm{~N}$ labelled residues in 3 consecutive seasons at 6 and 12 weeks after planting of 2 different residue applications

Table 5.1. Different categories of organic materials based on biochemical quality and their effects on nitrogen supply and soil organic matter 121 


\section{Chapter 1: General introduction}

\subsection{Crop residues and their use}

\subsubsection{Global production estimates of crop residue from arable lands}

Plant residue is defined as the non-edible plant parts left in the field after plants have been harvested (Lal, 2005) and thrashed or left after pastures are grazed (Kumar and Goh, 1999). Such materials have been considered as waste materials and usually have been burned directly on the field, especially in developing countries. However, it has become increasingly apparent that crop residues are an important natural resource for maintaining agricultural productivity, environmental improvement and an important raw material for energy generation or other industrial activities. Estimate of the amount of plant residue produced by different crops are usually computed on the basis of data on the area and productivity and it differs widely depending on plant characteristics (Lal, 2005, Lal, 1995). Using straw/grain ratio of some main crops adapted from Lal (2005), the annual residue production in general has increased since 2000 in which cereal crops as maize, rice, wheat contribute the most (Table 1.1)

Table 1.1. Plant residue production (in 1000 tones) of some main countries and of the world in 2000 and 2014

\begin{tabular}{|c|c|c|c|c|c|c|c|c|c|c|c|c|}
\hline \multirow{2}{*}{ Area } & \multicolumn{6}{|c|}{2000} & \multicolumn{6}{|c|}{2014} \\
\hline & Maize & Peas & Potatoes & Rice & Sugar cane & Wheat & Maize & Peas & Potatoes & Rice & Sugar cane & Wheat \\
\hline Argentina & 16781 & 11 & 555 & 1355 & 4600 & 24220 & 33000 & 54 & 466 & 2373 & 6149 & 20895 \\
\hline Australia & 406 & 456 & 300 & 1651 & 9541 & 33162 & 390 & 293 & 293 & 1229 & 7630 & 37955 \\
\hline Brazil & 31879 & 4 & 640 & 16635 & 81926 & 2492 & 79878 & 4 & 922 & 18263 & 184289 & 9393 \\
\hline China & 106000 & 1020 & 16569 & 281862 & 16570 & 149454 & 215646 & 1575 & 24022 & 309761 & 31403 & 189313 \\
\hline France & 16018 & 1937 & 1609 & 174 & 0 & 56030 & 1854 & 512 & 2014 & 125 & 0 & 58450 \\
\hline Germany & 3324 & 409 & 3424 & 0 & 0 & 32432 & 5142 & 155 & 2902 & 0 & 0 & 41677 \\
\hline India & 12043 & 815 & 6250 & 191197 & 74831 & 114553 & 23670 & 600 & 11599 & 235800 & 88036 & 141725 \\
\hline USA & 251852 & 158 & 5823 & 12987 & 9029 & 90959 & 361091 & 778 & 5014 & 15039 & 7001 & 83093 \\
\hline World Total & 592479 & 10716 & 81900 & 898348 & 313972 & 878536 & 1021617 & 11333 & 96269 & 1111434 & 474998 & 1093450 \\
\hline
\end{tabular}

(These calculations are done by using straw/grain ratio adapted from Lal (2005) multiple by grain production calculated from Food and Agriculture Organisation of the United Nations, 2013). 


\subsubsection{The application of plant residues and their roles}

Plant residues nowadays are used in plenty of aspects not only in agricultural activities such as an important animal feed source, retaining on the field as an organic fertilizer. They are also a potential source of feedstock for industrial activities such as bioenergy production and raw materials in paper production (Figure 1.1).

Plant residues in soil quality enhancement

The use of plant residues as a means of maintaining and increasing soil fertility as well as in nutrient providing has been applied widely, especially in organic farming systems and in organic agriculture. According to Food and Agriculture Organization of the United Nations, the total $\mathrm{N}$ content from added residues have increased significantly since 1950 in which Asia has contributed the largest amount, following by Americas and Europe (Figure 1.3) and this trend will continue till 2050. For example, the total amount of $\mathrm{N}$ from plant residues in 2012 from over the world accounted for over 32 million tons in which Asia accounted almost half of this number, following by Americas (over a quarter) and Europe (15\%). In addition to the $N$, plant residues are also a source of other macronutrients $(P, K)$ and micronutrients $(S$, $\mathrm{Cu}, \mathrm{Zn}, \mathrm{Mo}$ ) needed for crop growth and humification of residue (Chen and Avnimelech, 1986). Lal (1995) reported that three principal plant nutrients (N, P, K) contributed from major cereals plant and leguminous plant residues in the USA were about $58 \%$ of the total fertilizer use. On the global scale, this figure was about $65 \%$ of the world annual consumption of fertilizer. In systems where plant residues are managed well, they add soil organic matter, which improves the quality of the seedbed and increases the water infiltration and retention capacity of the soil, buffers the $\mathrm{pH}$ and facilitates the availability of nutrients; they also sequester $\mathrm{C}$ in the soil, provide nutrients for soil biological activity and plant uptake, capture the rainfall on the surface and thus increase infiltration and the soil moisture content, provide a cover to protect the soil from being eroded and reduce evaporation and avoid desiccation from the soil surface (Bot and Benites, 2005). According to Shaver et al. (2013), increasing of crop residue accumulation will have the indirect effect of increased sorptivity via improvements in soil aggregation, bulk density, and porosity that are conductive to water 
infiltration. Moreover, organic matter intimately mixed with mineral soil materials has a considerable influence in increasing moisture holding capacity, especially in the topsoil. When calculated the cumulative daily losses of water over 100 days simulation, Lascano and Baumhardt (1996) found the reduction losses of water due to soil evaporation in the presence of wheat straw in cotton systems compared with conventional cotton. When expressed water use efficiency as the ratio of lint yield to the total evaporation, the efficiency of cotton in the wheat -straw systems increased by over $35 \%$ compared to the conventional cotton. van S. J. Donk (2010) reported that the residue-covered soil held approximately $60 \mathrm{~mm}$ more water in the first $1.8 \mathrm{~m}$ compared to the bare soil when carried out in the plot treatments of corn field. The effect of crop residues in mitigation greenhouse gases emission also mentioned in several researches. Gattinger et al. (2012) found a positive difference in soil organic carbon concentration, stocks and $\mathrm{C}$ sequestration rates when compared organic and non-organic farming systems in the top soil. In particular, organic farming practice led to soil organic carbon stocks in the upper $20 \mathrm{~cm}$ of soil over a period of 14 years were around 4 $\mathrm{Mg} \mathrm{C} \mathrm{ha-1} \mathrm{higher} \mathrm{than} \mathrm{in} \mathrm{non-organic} \mathrm{systems.} \mathrm{The} \mathrm{mean} \mathrm{difference} \mathrm{of} \mathrm{net} \mathrm{C}$ sequestration in the top soil between organic and non-organic farming was about $0.5 \mathrm{Mg} \mathrm{C}^{-1}$ per year (Gattinger et al., 2012). In the global scale, the total net $\mathrm{C}$ sequestration was about $0.4 \mathrm{Gt} \mathrm{C}$ per year when switching to organic agriculture, approximately offsetting $3 \%$ of current total greenhouse gas emissions or $25 \%$ of total current agricultural emissions and equaling approximately $25 \%$ of the annual technical agricultural mitigation potential. The authors also predicted that until 2030 the cumulative mitigation would contribute $13 \%$ to the cumulative reductions. In dryland ecosystems such as West Asia and Africa, Lal (2002) recommended several strategies for increasing soil C sequestration which were including residues management, cover crops. Tuomisto et al. (2012) reported that organic farming in Europe had generally lower environmental impacts per unit of area than conventional farming. Food and Agriculture Organization of the United Nations (2013) predicted that the total amount of $\mathrm{CO}_{2}$ emission and $\mathrm{N}_{2} \mathrm{O}$ emission from added residues from 5 different continents and all over the world will continue to increase until 2050 (Figure 1.4 and 1.5). 


\section{Plant residues in bioenergy}

The utilization of plant residues as raw materials of bioenergy is a promising alternative to fossil resources for production of energy carriers and chemical ((Cherubini and Ulgiati, 2010; Lal, 2005; Lal, 2008; Kim and Dale, 2004). Lignocellulosic biomass which was mainly from cereals plant residues like corn stover and wheat straw has three major components: cellulose, hemicellulose and lignin. While cellulose and hemicellulose are polysaccharides that can be hydrolyzed to sugars and then fermented to ethanol, lignin may be useful for chemical extraction or energy production (Cherubini and Ulgiati, 2010) or for generating electricity and steam (Kim and Dale, 2004). According to Cherubini and Ulgiati (2010), the use of plant residues as raw materials in biorefinery is an effective option for reducing environmental concerns related to fossil resources: biorefinery systems can mitigate climate change (reduced by about 50\% of GHG emissions), reduce dependence on non-renewable fossil fuels (saved more than $80 \%$ of non-renewable energy) and enhance cleaner production chains based on local and renewable sources. Lal (2005) reported that the energy value of plant residue produced in the US was $976 \times 10^{6}$ barrels of diesel and in the global scale was $7516 \times 10^{6}$ barrels of diesel. The share of biomass energy consumption depends on economic structure, the level of income, the availability of land and other energy sources and it is widely used as household fuel in developing countries. For example, the share of biomass in energy consumption is about $47 \%$ in Asia, $25 \%$ in Africa, $19 \%$ in Latin America whereas this figure is much lower in North America (5\%), Europe $(3 \%)$ and only $1 \%$ in Oceania (Lansink et al., 2003). Johansson and Goldemberg (2002) reported that biomass consumption for energy used in developing countries accounted for $26 \%$ while this number was only $3.4 \%$ in industrialized countries. Kim and Dale (2004) estimated that about $491 \mathrm{GL}$ year $^{-1}$ of potential bioethanol was produced from plant residues and waster crops and it could replace $353 \mathrm{GL}$ of gasoline or $32 \%$ of the global gasoline consumption. Plant residues are responsible for $90 \%$ of the total potential bioethanol production. Moreover, when burning lignin - rich fermentation residues (a co-product of bioethanol made from plant residues and sugar can bagasse) it could generate about 458 TWh of electricity (approximately $3.6 \%$ of 
world electricity production) and 2.6 EJ of steam (Kim and Dale, 2004). In global scale, Asia is considered as the largest potential producer of bioethanol (about $291 \mathrm{GL}$ and mainly comes from rice straw and wheat straw) and is followed by Europe (about $70 \mathrm{GL}$ and mainly comes from wheat straw). Lal (2008) estimated that about 3 billion Mg of lignocellulosic has been produced from cereals crops per year which was equivalent to 840 billion $L$ of bioethanol or $56 \times 10^{9} \mathrm{GJ}$ of energy.

\section{Plant residues in animal feeds}

The importance of plant residues for feeding livestock, especially in smallholder farming systems in developing countries has been mentioned widely ( $E$ Owen and M C N Jayasuriya, 1989); Aregheore, 1996; Onwuka et al., 1997; Njie and Reed, 1995; Valbuena et al., 2012). Baudron et al. (2015) reported that cereals residues were a major resource for livestock feeding in Southern Africa, especially in the dry season. Parthasarathy Rao and Hall (2003) estimated that over $60 \%$ of the total livestock feed on a dry matter basis came from plant residues in India. The dependence on plant residues was higher in the more marginal and semi-arid regions in which alternative sources of feed were limited. In maize-based systems in Ethiopia, over $50 \%$ of biomass maize stover was used as livestock feed (Jaleta et al., 2015) and this figure increased to $73 \%$ in Kenya in the same scale (Castellanos-Navarrete et al., 2015).

\section{Plant residues as raw material for industry}

Using plant residues such as straw from wheat, oats or barley as potential sources of biobased raw material for industrial purposes has been applied widely (Ververis et al., 2004; Bowyer, 2001; Willke and Vorlop, 2004). Bowyer (2001) reported that panels made of straw from cereals and other plant residues are being commercially manufactured in several countries. The idea of using agricultural residues as an industrial raw material is not new. Crop residues like bagasse have long been used in making paper in China, India, Pakistan and other countries. According to Bowyer (2001) production of paper and paperboard from plant residues increased dramatically, with the percentage of pulp capacity accounted for by non-wood fiber globally about $12 \%$. Global production of fiber for the panels industry from 
wheat, barley and oats was about 738 million metric tons in 1999 in which over $40 \%$ of production from China, India, Canada and the US (Bowyer, 2001) and this figure was predicted increasing to 40 to $60 \%$. Urbaniec and Bakker (2015) mentioned that agricultural waste and agro-industrial residues were the main feedstocks biohydrogen production due to theirs abundant, low input cost and biodegradable character.

Plant residues in biodiversity improvement

In order to evaluate the effect of organic farming system on biodiversity from over 70 different researches, Hole et al. (2005) found that species abundance and/ or richness of a wide range of taxa, including birds and mammals, invertebrates and arable flora tend to be higher on organic farms than on locally representative conventional farms. Similar results were also reported in other studies (Mader, 2002; Bengtsson et al., 2005; Pacini et al., 2003). Bengtsson et al. (2005) found that organic farms had $30 \%$ higher of species richness and $50 \%$ higher abundance of organisms than conventional farms. In organic farming systems, the densities of predators such as carabid beetles and spiders were usually higher than in conventional ones. Higher amount of organic material in the soil increased soil animals such as earthworm and soil fauna (Bengtsson et al., 2005; Mader, 2002). Tuomisto et al. (2012) did not find any negative effect of organic farming on biodiversity. When evaluating the sustainability of three different farming systems (organic, integrated and convention), Pacini et al. (2003) found that the organic farming systems performed better than integrated and conventional farming systems in term of pesticide risk, herbaceous plant biodiversity and most of the other environmental indicators such as nutrient losses. Average activity density of carabids, staphylinids, and spiders in the organice plots was almost double that of the conventional plots (Mader, 2002). 


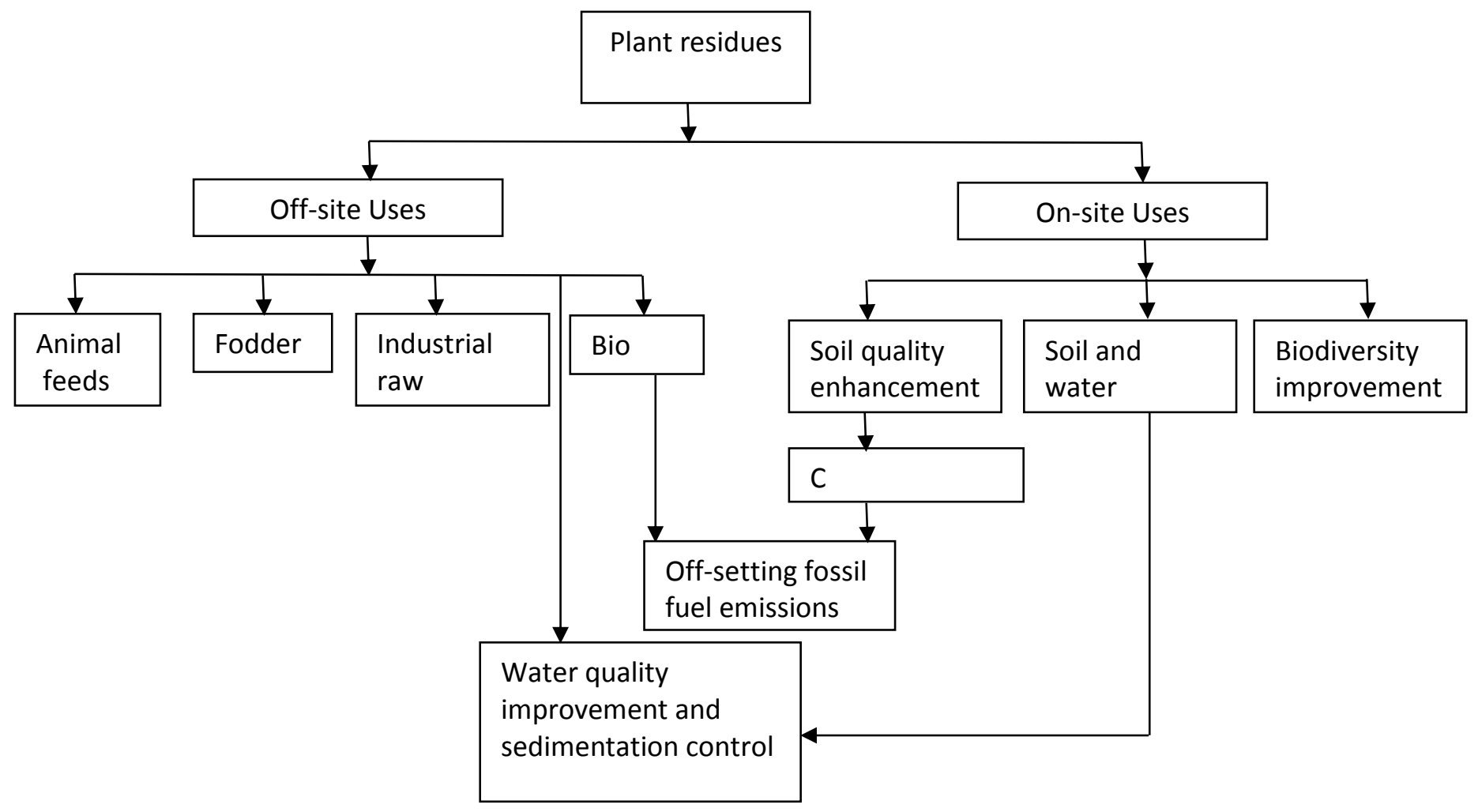

Figure 1.1. The implication of plant residues (Modified from Lal, 2005)

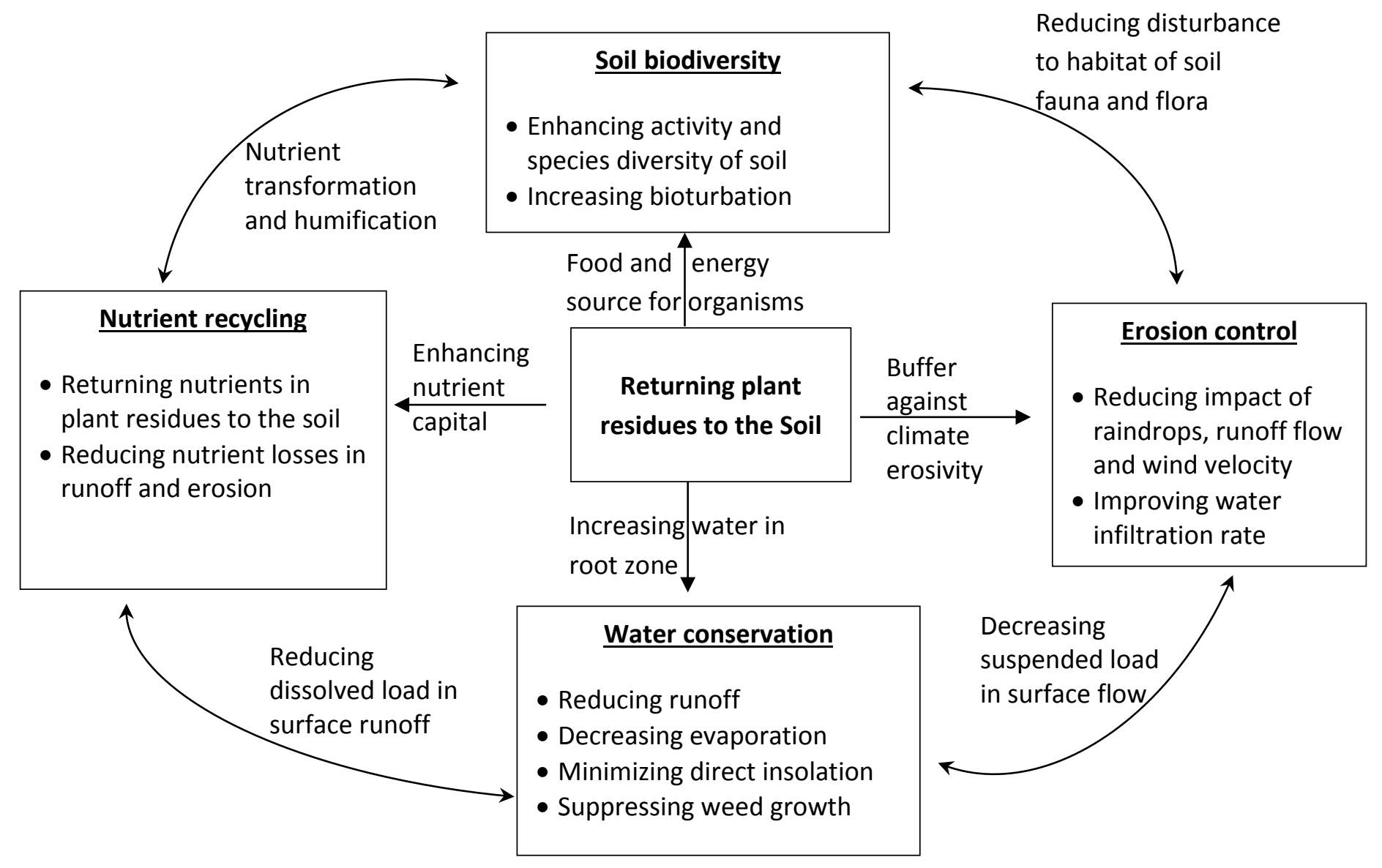

Figure 1.2. The impact of plant residues on soil processes (adopted from Lal, 2008) 


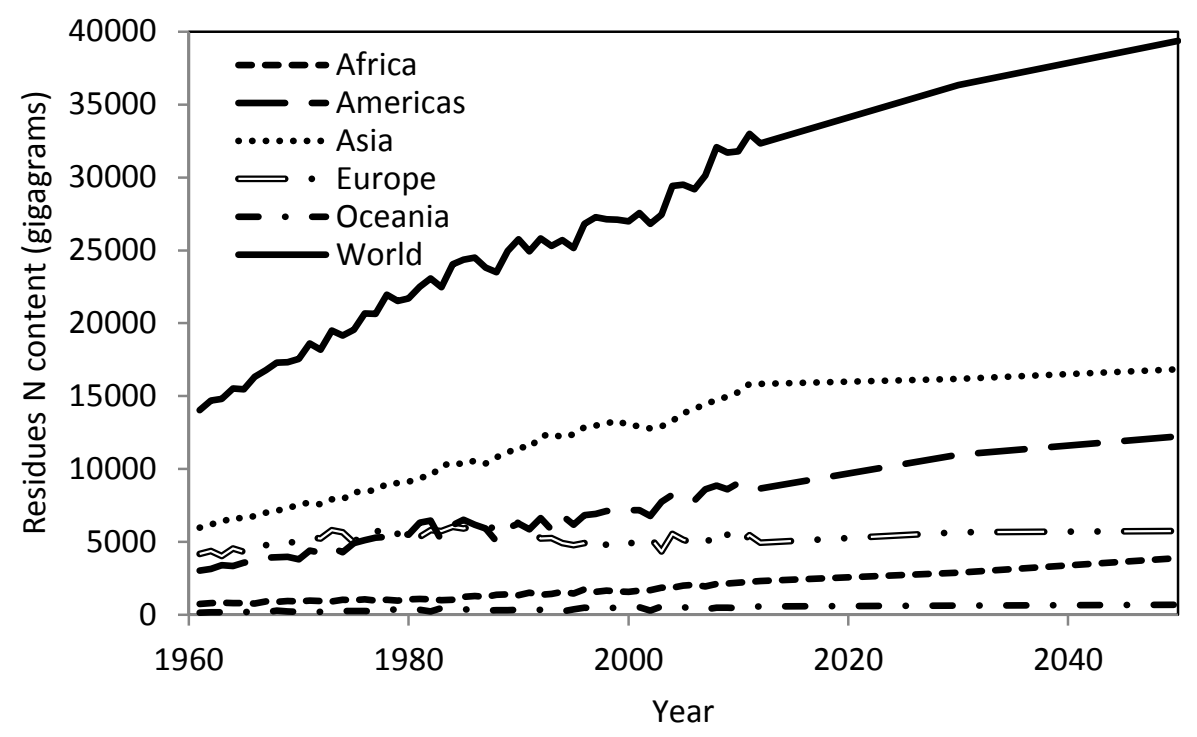

Figure 1.3. Total N content from added residues of different continents since 1960 to 2050. Source: (Food and Agriculture Organization of the United Nations, 2013)

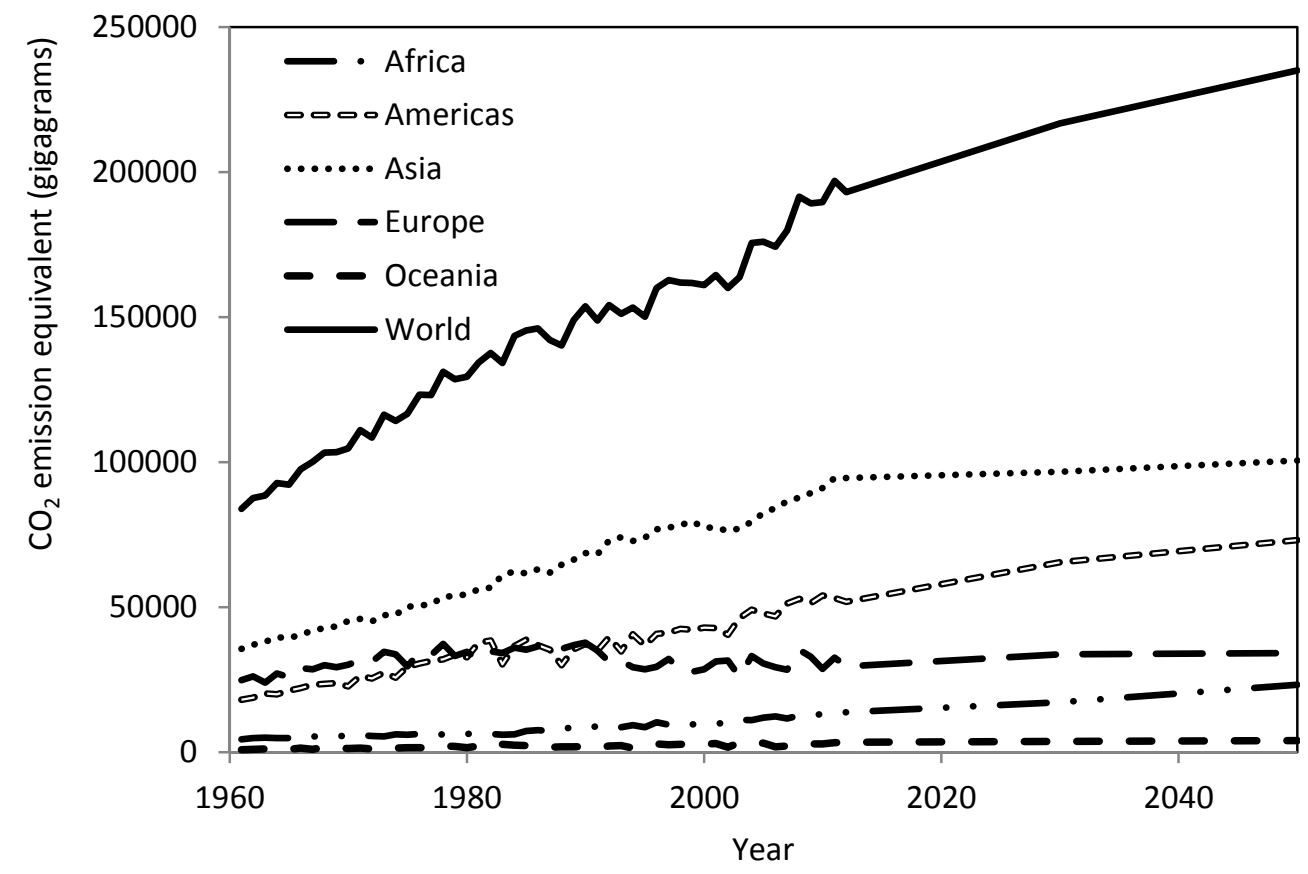

Figure 1.4. Total $\mathrm{CO}_{2}$ emission equivalent in gigagrams from added residues of different continents since 1960 to 2050. Source: (Food and Agriculture Organization of the United Nations, 2013) 


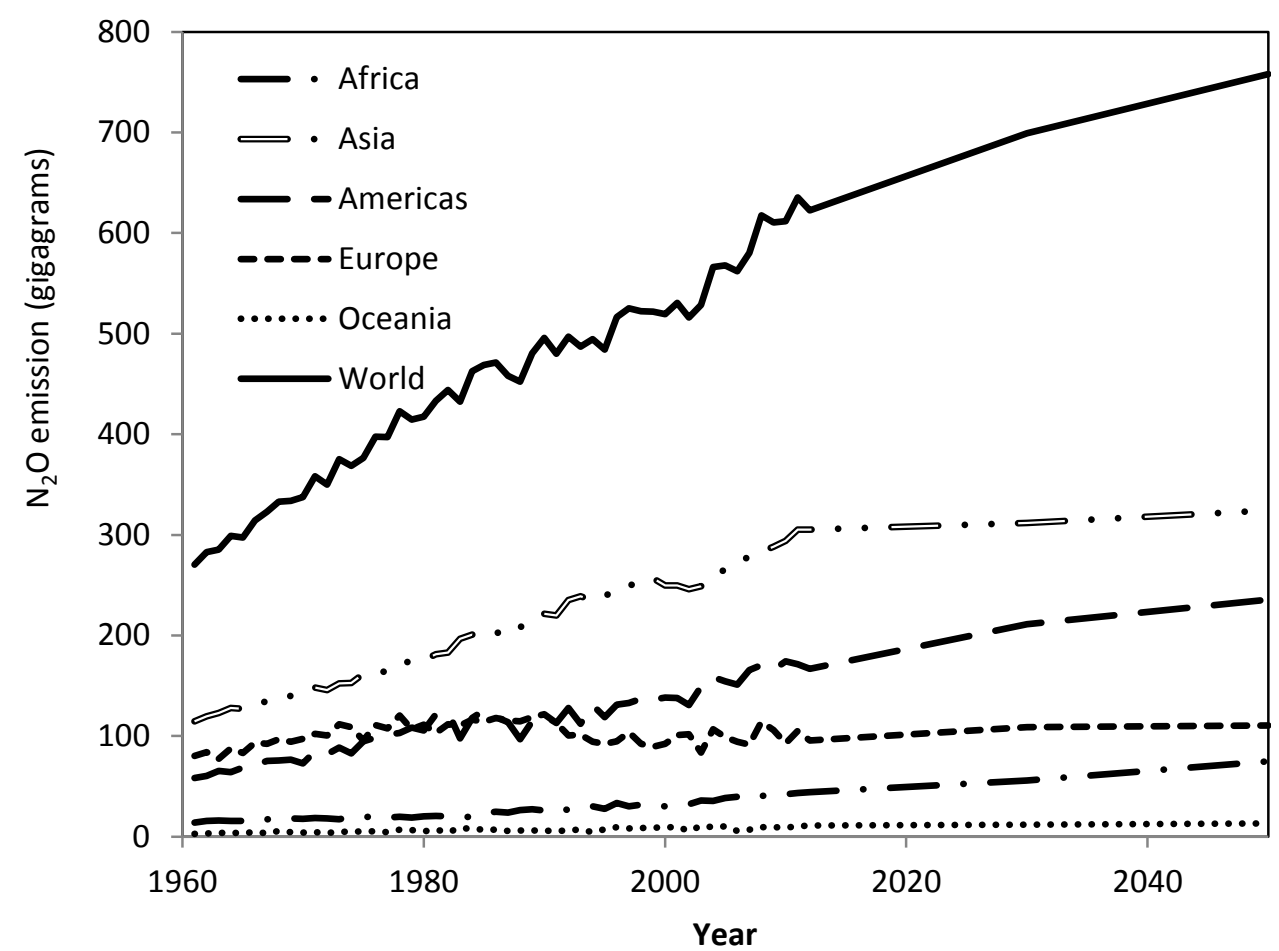

Figure 1.5. Total $\mathrm{N}_{2} \mathrm{O}$ emission in gigagrams from added residues of different continents since 1960 to 2050. Source: (Food and Agriculture Organization of the United Nations, 2013).

\subsection{The dynamic of $\mathrm{C}$ and $\mathrm{N}$ mineralisation from diverse plant residues}

\subsubsection{General conceptual}

Knowledge about the kinetics of plant residues decomposition plays an essential for management of agroecosystems. The incorporation of plant residues into soil not only represents an opportunity to limit soil organic matter depletion resulting from cultivation but also provides a valuable source of nutrients. Under normal conditions, the lost of $C$ from the system is mainly through the decomposition. In a long term experiment, a single rate constant has been usually used to describe decomposition and the change of $C$ in the soil can be expressed mathematically in one kinetic rate constant of decomposition:

$C_{t}=C_{0} e^{-k_{1} t}+C_{2} e^{-k_{2} t}$ 
Where $C_{t}$ is the amount of soil $C$ at time $t, C_{0}$ is the amount of soil $C$ at time $0, k_{1}$ is the decomposition rate constant $\left(\right.$ day $\left.^{-1}\right)$ of the total soil $\mathrm{C}$ pool before amendment of $\mathrm{C}$ added, $\mathrm{Ca}$ is the amount of $\mathrm{C}$ added (plant residue) with decomposition rate constant is $\mathrm{k} 2$.

If we ignore the dynamic nature of the system, the $\mathrm{N}$ mineralisation from a substrate can be expressed as below:

$N_{\text {mineralised }}=C_{t}(1 / Z-E / Y)$

Where $\mathrm{Z}$ is the $\mathrm{C}: \mathrm{N}$ ratio of the decomposing substrate, $\mathrm{E}$ is a microbiological efficiency factor and is estimated as a constant $(0.4), \mathrm{Y}$ is the $\mathrm{C}: \mathrm{N}$ ratio of soil organic matter.

Nevertheless, in short term experiment likely in laboratory studies, several authors suggested that plant residues should be divided into two or more pools with different decomposition rates. Therefore, the decomposition process is often considered as a first -order reaction for various $\mathrm{C}$ pools. The rapid and slow fractions can be mathematically represented as below: \%decomposed $=\%$ rapid $\left(1-\exp \left(-\mathrm{k}_{1} \mathrm{t}\right)\right)+(100-\%$ rapid $)\left(1-\exp \left(-\mathrm{k}_{2} \mathrm{t}\right)\right)$

Where \% rapid is the amount of plant residue C in the rapid pool, (100-\%rapid) is the amount of plant residue $\mathrm{C}$ in the slow pool, $\mathrm{k}_{1}$ is the rapid-likely pool rate decomposition constant, $\mathrm{k}_{2}$ is the slow-likely pool rate decomposition constant.

\subsubsection{Factors affecting the dynamic of $\mathrm{C}$ and $\mathrm{N}$ mineralisation}

The decomposition process of plant residues depends primarily on the interaction of three components: the soil organisms, its chemical composition and the physical and chemical environmental conditions.

\section{Soil organisms}

Soil organisms are responsible for the decay and cycling of both macronutrients and micronutrients, and their activity affects the structure, tilth and productivity of the soil (Bot and Benites, 2005). In natural humid and subhumid forest ecosystems without human disturbance, the living and non-living components are in dynamic equilibrium with each other. When evaluating the effect of microbial biomass on the fate of nitrogen over a period of 6 months in sandy loam soil under controlled condition, Bending et al. (1998) reported that cumulative microbial respiration during the early stages of decomposition was correlation 
with net $\mathrm{N}$ mineralisation after 2 months, at which time maximum net $\mathrm{N}$ mineralisation was recorded. Moreover, microbial respiration also effected on activities of organisms involved in immobilization of $\mathrm{N}$ and denitrification. Hassink et al. (1994) found that the differences in $\mathrm{C}$ mineralisation rate between the four grasslands could satisfactorily be explained by the differences in bacterial biomass. The fauna may contribute to $\mathrm{C}$ and $\mathrm{N}$ mineralisation in two ways: directly through their own $\mathrm{C}$ and $\mathrm{N}$ mineralisation and indirectly through their effect on the growth rate of the microbes in which the direct contribution of the fauna to $N$ mineralisation ranged from 7 to $28 \%$.

\section{Biochemical composition}

The rate of soil organic matter accumulation depends largely on the quantity and quality of organic matter input. Biochemical compositions such as $\mathrm{N}$ content, C:N ratio, water soluble, hemicellulose, lignin and polyphenol content are considered as an important factor governing the $\mathrm{C}$ and $\mathrm{N}$ mineralisation of plant residues (Fox et al., 1994; Constantinides and Fownes, 1994). Palm and Sanchez (1991) reported that polyphenolic content could control the short term $\mathrm{N}$ release and the availability from legumes. Legumes with low polyphenolic content used as green manure or mulch may release $\mathrm{N}$ rapidly and provide sufficient $\mathrm{N}$ for plant growth. Under tropical conditions, applications of readily degradable residues with low C:N ratios, such as green manure and leguminous cover crops, favor decomposition and increase the labile nitrogen pool. On the other hand, applications of plant residues with both large C:N ratios and

lignin contents such as cereal straw and grasses generally favour nutrient immobilization, organic matter accumulation and humus formation, with increased potential for improved soil structure development (Bot and Benites, 2005). When examining the correlation between $\mathrm{N}$ mineralisation and initial chemical composition of both gramineae and leguminoseae plant residues, Vahdat et al. (2011) found that lignin content was the most important factor for prediction of the net effects on soil mineral $\mathrm{N}$ dynamics $(\mathrm{r}=-0.974, \mathrm{P}<0.001)$. It is believed that lignin is a natural recalcitrant which exerts a control on the overall biodegradability of the plant residue in soil and thus may play a major role in predicting $\mathrm{N}$ mineralisation from plant residue. A negative correlation was also found between $\mathrm{N}$ mineralisation and $\mathrm{C}: \mathrm{N}$ ratio but no significant 
correlation was found between $\mathrm{N}$ mineralisation and cellulose content. However, the correlation between hemicellulose and $\mathrm{N}$ mineralisation was quite high $(r=-0.762, \mathrm{P}<0.05)$. In the woody agroforestry plant species residues, Tian et al. (1992) also found a negative correlation between decomposition rate constants and $\mathrm{C}: \mathrm{N}$ ratio, lignin content and polyphenol content. When assessing the kinetics of $\mathrm{C}$ and $\mathrm{N}$ biotransformation of different tissues of Brassica napus, Trinsoutrot et al. (2000b) found that the rate of $\mathrm{C}$ mineralisation (via ${ }^{13} \mathrm{C}$ labelled) from the residues was influenced by the biochemical composition of the tissues, in particularly by their soluble C content. As the decomposition or residues of various composition was not limited by the overall availability of $\mathrm{N}$, the dynamic of decomposition of the added residues depended mostly on the soluble compounds, cellulose and lignin content, regardless of the $\mathrm{N}$ content of the residue itself. Similar results were also found in Trinsoutrot et al. (2000a) when evaluating the relationship between the fate of $\mathrm{C}$ and $\mathrm{N}$ from nearly 50 types of crop residues and their biochemical properties.

\section{Climate}

Several field studies have shown that temperature is a key factor controlling the rate of decomposition of plant residues. Decomposition normally occurs more rapidly in the tropics than in temperature areas (Bot and Benites, 2005). When evaluating the effect of 5 different woody residue species quality and climate on plant residue decomposition, Tian et al. (2007) found that the direct correlation between the decomposition rate of plant residues and their quality was only valid in agroeco-zones where there is no moisture stress. Similarly, the direct correlation between the decomposition rate of plant residues and moisture availability was only valid for plant residues with high quality. The decomposition of the low quality plant residue could increase from humid to arid zone in West Africa. In the arid zone, the low quality plant residue could also decompose faster than high quality plant residue.

\section{Plant residue management}

Tillage is one of the major practices that reduce the organic matter level in the soil. When ploughed, the residues are incorporated in the soil together with air and come into contact with many micro-organisms, which accelerates the carbon cycle. Cookson et al. (1998) 
reported that wheat straw from the incorporated treatment had the greatest net $\mathrm{N}$ immobilization in the early stages of decay (0-14 days) and the greatest net $\mathrm{N}$ mineralisation in the later stages of decays (90-150 days). When evaluating the rate of mineral $\mathrm{N}$ accumulation in soil under greenhouse conditions of Mucuna aterrima, Costa et al. (1990) found that its value was $60 \%$ higher when residue was incorporated to the soil. Whereas applied on the surface, they result a slow of carbon cycle. Similar results also were found in (Li et al., 2013) when conducted the trials on soybean and maize.

\section{Soil physical characteristics}

Soil organic matter tends to increase as the clay content increases. This increase depends on two mechanisms. First, bonds between the surface of clay particles and organic matter retard the decomposition process. Second, soils with higher clay content increase the potential for aggregate formation. Several researches reported that the net $\mathrm{N}$ mineralisability in size decreased in the order: clay > silt > sand (Christensen and Olesen, 1998; Hassink, 1992; Hassink et al., 1993). According to Gregorich et al. (1991), soil texture was important in controlling the rate of decomposition of substrate $\mathrm{C}$ and turnover of $\mathrm{C}$ through the microbial biomass during short period. Soils with high clay content had low amounts of microbial products, suggesting that clay provides an environment for closer interaction between microorganisms and products of their decay and promotes the transfer of nutrient to succeeding generations of microorganisms. Hassink (1994) found a negative relationship between the percentage of soil $\mathrm{N}$ mineralisation during incubation and the clay + silt content of the soil. The amount of organic $C$ was only positively correlated with soil texture in case of high water content and this relationship was small. Soil texture was not always the dominant factor determining the organic $\mathrm{C}$ content of soils and $\mathrm{C}$ mineralisation rates. Differences in $\mathrm{C}: \mathrm{N}$ ratio of the soil organic matter and the ground water table confused the relationship of the soil organic $C$ and the percentage of soil organic $C$ that mineralized with soil texture.

\section{Soil chemical characteristics}

In general, decomposition of plant residues proceeds more rapidly in neutral soil than in acid soil. Condron et al. (1993) reported that acid soils with lime increased the decomposition of 
plant residues. In particular, over 17 weeks of incubation, the total amounts of $\mathrm{CO}_{2}-\mathrm{C}$ evolved from the litter and litter plus lime treated soils accounted to $20 \%$ and $30 \%$ of the added C residues. When examining the effects of soil $\mathrm{pH}$ on decomposition of added plant residues in tropical forest soils ( $\mathrm{pH}$ ranged from 3.9 to 6.7), Motavalli et al. (1995) found a positive relationship between initial soil $\mathrm{pH}$ and cumulative $\mathrm{CO}_{2}$ release after 7 days of incubation and continued up to 270 days. It is also known that the addition of available nutrients such as nitrogen, phosphorus and potassium can accelerate the decomposition of soil organic matter (Muhammad et al., 2011; Recous et al., 1995). The use of some fertilizers, especially $\mathrm{N}$ fertilizers, and pesticides can boost micro-organism activity and thus decomposition of organic matter. The chemicals provide the microorganisms with easy-to-use $\mathrm{N}$ components. This is especially important where the $\mathrm{C}$ : $\mathrm{N}$ ratio of the soil organic matter is high and thus decomposition is slowed by a lack of $\mathrm{N}$. The percentage of soil $\mathrm{C}$ mineralisation in sandy soils was negatively correlated with the C:N ratio of the soil organic matter (Hassink, 1994).

\section{Soil water content}

Residue decomposition requires water for microbial growth and for the diffusion of nutrients during the breakdown process. Decomposition of organic matter occurs more slowly in poorly aerated soils, where existing the limitation of oxygen, compared with well aerated soils. In a permanently waterlogged soil, one of the major structural parts of plants, lignin, does not decompose at all. The ultimate consequence of extremely wet or swampy conditions is the development of organic (peat or muck) soils, with organic matter contents of more than 30 percent. Where soils are drained artificially for agricultural or other uses, the soil organic matter decomposes rapidly (Bot and Benites, 2005).

\subsection{The application of model in representing the $\mathrm{C}$ and $\mathrm{N}$ dynamics in soil - plant - atmosphere systems}

\subsubsection{Overview of some Soil Organic Matter (SOM) models}

Understanding the dynamics of soil organic matter which is mainly added from plant residues plays an important role to face with several issues of environmental and agricultural 
activities. Many of the issues cannot be explained by direct experimentation due to the long time periods involved, they also involve consideration climate change scenarios that cannot be reproduced on a large scale or because broad conclusions are required based on data from a limited number of sites. Modelling SOM changes is the only practical approach in many instances. A large number of models are now published in the wide possible range of environment. Using simulation models to predict the mineralisation of carbon and nitrogen in farming systems has been mentioned widely in various models such as APSIM, Century, STICS, DSSAT, CERES...(Mohanty et al., 2011; Probert et al., 2005; Justes et al., 2009; Nicolardot et al., 2001; Garnier et al., 2003; Corbeels et al., 2005; Jones et al., 2003). All models of nitrogen turnover in soil share some common features. They just differ in the complexity with which they deal with these processes. Below we will shortly describe some popular SOILN models that are being used and its important characteristics.

CANDY (CArbon- Nitrogen-DYnamics) is a modular system of simulation models and a data base system for model parameters, measurement values, initial values, weather data and soil management data (Franko, 1995; Franko et al., 1995). It simulates dynamics of soil $\mathrm{N}$, temperature and water in order to provide information about $\mathrm{N}$ uptake by crops, leaching and water quality. CANDY uses a semi-cohort system to track litter decay, and calculates a biologically active time to allow comparisons among sites.

CENTURY: The model simulates soil organic matter dynamics in natural or cultivated systems and represents the dynamics of $\mathrm{C}, \mathrm{N}, \mathrm{P}$, and $\mathrm{S}$ in the soil - plant system using a monthly time step. The model includes three soil organic matter pools (active, slow and passive) with different potential decomposition rates, above and below ground litter pools and a surface microbial pool which is associated with decomposing surface litter (Parton, 1996). At initialization of the simulation, the fractional ratio of these three pools is set, with SOM1 of only about $2 \%$ of total SOM, while SOM2 and SOM3 vary with the management history of the soil (grassland or cultivated) and the degree of depletion. CENTURY was developed with data from temperate regions, were not applicable for all cropping systems (Parton et al., 1988). 
DAISY: The model is adapted to the wet temperate climate of North Western Europe (Hansen et al., 1991). The soil organic matter submodel considers three organic pools as added organic matter (AOM), soil microbial biomass $(\mathrm{SMB})$, and soil organic matter (SOM = total organic matter $\mathrm{C}-\mathrm{SMB}-\mathrm{C}-\mathrm{AOM}-\mathrm{C}$ ), each pools are divided into two subpools: one with a slow turnover and one with a fast turnover. The decay rate constants are functions of soil temperature, soil water and soil clay content. The corresponding N-pools are calculated from the amount of $\mathrm{C}$ in the pools using a fixed $\mathrm{CN}$ ratio for each pool (default values). The soil organic matter (SOM) is subdivided into three subpools designated SOM0, SOM1 and SOM2. The subpool SOM0 can be neglected as it consists of almost inert organic matter. The rate of decomposition of SOM1 and SOM2 are simulated by first order reaction kinetics. The subpool SOM1 is assumed to consist of chemically stabilized organic matter, while the subpool SOM2 is assumed to consist of organic matter.

DNDC (denitrification and decomposition) model is used to predict emission of $\mathrm{CO}_{2}, \mathrm{~N}_{2} \mathrm{O}$ and $\mathrm{N}_{2}$ from agricultural soils. The organic matter was divided into three pools: decomposable residues (mainly plant residues), microbial biomass and humads, each pool has a labile and resistant component and decomposes independently. The residue pool is divided into three subpools based on its rate of decomposition. The passive organic phase, or stable humus, is assumed not to interact with the active phase during the short time span of the model (about 1 year). In the DNDC model, nitrogen uptake by vegetation is the key process linking crop growth with climate and soil status (Li et al., 1992; Li et al., 1994; Li, 1996). In DNDC, SOM pool consists of several sub-pools of labile/resistant litter, microbes, humads, and humus. Each sub-pool has its own C:N ratio. The size and quality (C:N ratio) of the SOM pools dominate the overall decomposition rate. When SOM decomposes from one sub-pool to another, available $\mathrm{N}$ may release from or be required by the decomposing process because of the deference in $\mathrm{C}: \mathrm{N}$ ratio between the two sub-pools.

NCSOIL model simulates C and N (total and tracers) transformations in soils (Molina, 1996; Molina et al., 1983). It comprises four organic pools: plant residues, microbial biomass with a 
labile $\left(0.33 \mathrm{~d}^{-1}\right)$ and a resistant $\left(0.04 \mathrm{~d}^{-1}\right)$ component, the humads and pool III which is considered as the stable organic matter (Nicolardot et al., 1994).

\subsubsection{Description of using model - SOILN in APSIM}

APSIM (Agricultural Production Systems Simulators) is a modelling framework which provides a flexible structure for the simulation of climatic and soil management effects on crop growth in farming systems and changes in the soil resource (Keating et al., 2003). The SoilN module in the APSIM describes the dynamics of both carbon and nitrogen in soil and it can be traced back via CERES models (Probert et al., 2005). The framework and the transformations considered in each layer are shown in Figure 1.6. In general, plant residues and roots added to the soil (sometimes referred as fresh organic matter (FOM)) are considered into three different pools (FPOOLs) and sometimes referred to as the carbohydrate-like (FPOOL 1), cellulose-like (FPOOL2) and lignin-like (FPOOL3) fractions of the residues (Probert et al., 2005). Each FPOOL has its own rate of decomposition, which is modified by factors to allow effects of soil temperature and soil moisture. In circumstances where there is inadequate mineral $\mathrm{N}$ to meet an immobilization demand, as can occur where the C:N ratio of the FOM pool is high, the decomposition process is limited by the $\mathrm{N}$ available to be immobilised. Decomposition of FOM results in formation of soil organic matter comprising the soil microbial biomass (BIOM) and humid (HUM) pools. The BIOM pool is notionally the more labile organic matter associated with soil microbial biomass, it has a higher rate of turnover than the bulk of the soil organic matter even though it makes up a relatively small part of the total soil organic matter. SOILN assumes that the pathway for synthesis of stable soil organic matter is predominantly through initial formation of BIOM, though some carbon may be transferred directly to the more stable pool (HUM). The model further assumes that the soil organic matter pools (BIOM and HUM) have C:N ratios that are unchanging through time. The $\mathrm{C}: \mathrm{N}$ ratio of the BIOM pool is typically set at 8 , while that of the HUM pool is based on the C:N ratio of the soil, which is an input at initialisation of a simulation. The formation of BIOM and HUM thus creates an immobilization demand that has to be met from the $\mathrm{N}$ released from the decomposing pools and/or by drawing on the mineral 
$\mathrm{N}$ (ammonium and nitrate) in the layer. Any release of $\mathrm{N}$ above the immobilisation demand during the decomposition process results in an increase in the ammonium- $\mathrm{N}$.

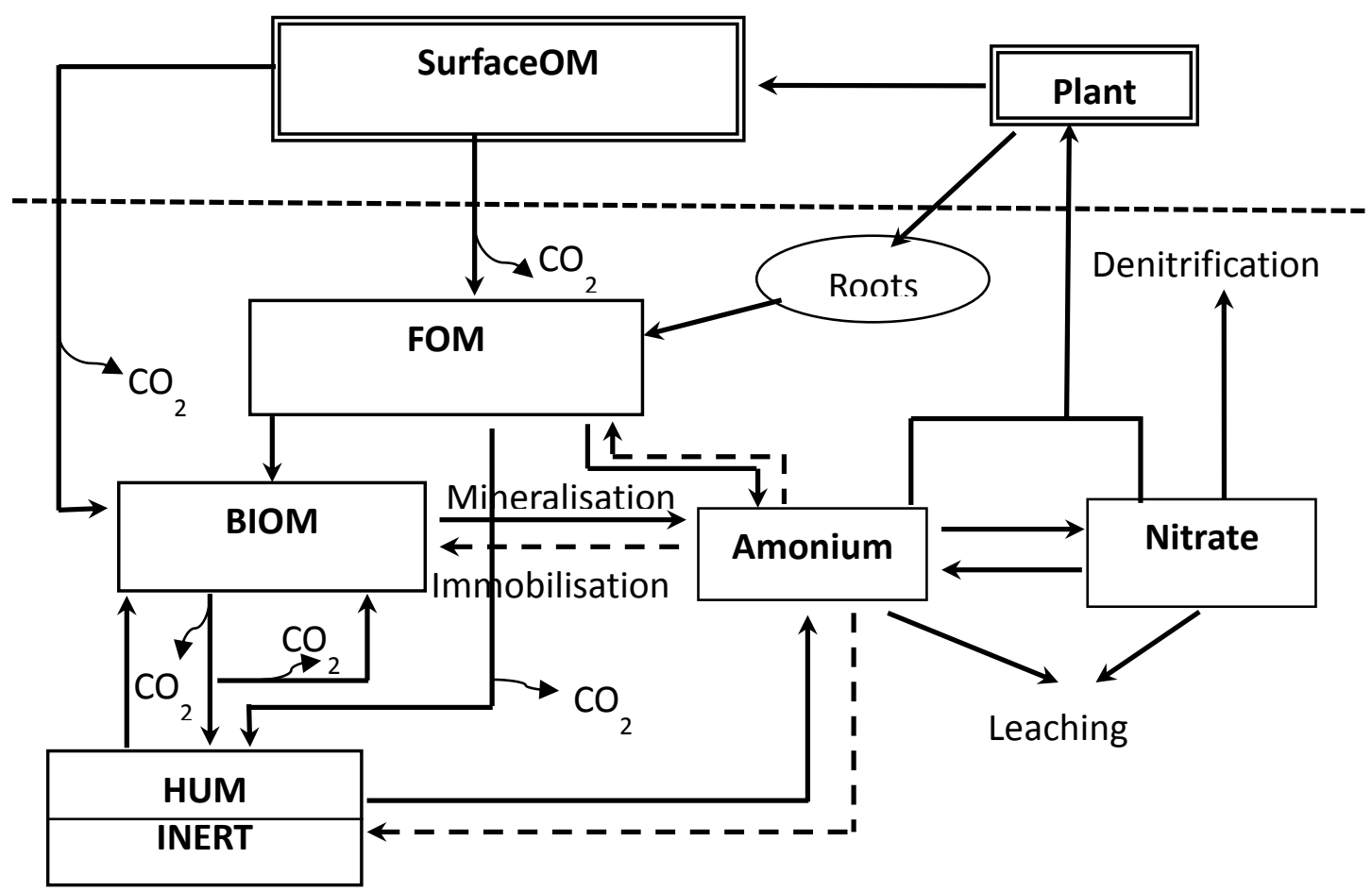

Figure 1.6. The framework of SOILN module and the transformation occurring in each layer.

\subsubsection{The application of SOILN in representing the dynamic of $\mathrm{C}$ and $\mathrm{N}$}

SOILN has been tested successfully in diverse plant residue to represent the decomposition of organic input, and the influence of residues quality on nitrogen release in different climate conditions of various organic materials and soil types. On a Vertosol soil in the Australian subtropics, the prediction of soil $\mathrm{N}$ and water dynamics following 2-year ley phases from APSIM is closely represented over 4 years of grain sorghum following grazed annual legume leys or a grass pasture systems (Whitbread and Clem, 2006). By simulation of hypothetical materials, Probert et al. (2005) shown that SOILN could be parameterized to simulate the general pattern of $\mathrm{N}$ mineralisation of various organic manures and feeds. By using modified values of added $C$ in the three FPOOLs from the default value as 0.2:0.7:0.1, SOILN could predict the $\mathrm{N}$ mineralisation from a wide range of materials having total $\mathrm{C}: \mathrm{N}$ ratio from $13-86$ (Probert et al., 2005). To specify different proportion of $\mathrm{C}$ and $\mathrm{N}$ in different FPOOLs, Probert 
et al. (2005) used $\mathrm{C}$ and $\mathrm{N}$ in the water soluble components for FPOOL1 and measured ADL to specify the $\mathrm{C}$ in FPOOL 3 . The C:N of FPOOL2 was estimated from measured data for $\mathrm{N}$ associated with ADF and NDF. However, it still remains a challenge that how to know appropriate parameters should be selected for a given source and/or how to derive the parameter values from other information. Using a similar approach, Mohanty et al. (2011) found an agreement between predicted N mineralisation from Gliricidia and farmyard manure by APSIM SOILN under different rates of application $\left(5 \mathrm{~g} \mathrm{~kg}^{-1}\right.$ and $10 \mathrm{~g} \mathrm{~kg}^{-1}$ on dry matter basis) and the observed data under incubation condition. Huth et al. (2010) found that APSIM -SOILN was able to adequately describe the major processes and resultant changes in soil $\mathrm{C}$ and $\mathrm{N}$ content within the surface soil layers $(0-30 \mathrm{~cm})$ when adjusting the denitrification rate coefficient and $\mathrm{C}: \mathrm{N}$ ratios in soil organic matter pools. When examining the performance of APSIM to predict the long term soil C dynamics under various agricultural practices at four semi-arid sites across the wheat-belt of eastern Australia, Luo et al. (2011) found that APSIM was able to predict soil C dynamics. Meier et al. (2006) reported that APSIM SOILN could simulate well the mineral $\mathrm{N}$ behavior of the 48-day incubations by using default values of three FPOOLs. Similar results were also reported in Thorburn et al. (2005), Thorburn et al. (2010) under sugarcane systems, in Archontoulis et al. (2014) under Midwestern production systems in America.

\subsection{Objectives of the study}

\section{Objectives}

The main objective of this thesis is to evaluate the dynamics of carbon and nitrogen mineralization from diverse plant residues in soil - plant systems by comparing measured data from laboratory and predicted data from modelling. In order to explain for this objective, some main sub-objectives are:

i) To determine the impact of biochemical quality of different added plant residues, soil types and residue application methods on the release of $\mathrm{C}$ and $\mathrm{N}$ under controlled conditions. 
ii) To evaluate the performance of original SOILN model and improve the model parameterization and assess the comprehensive decomposition model of $\mathrm{C}$ and $\mathrm{N}$ mineralisation in short term.

iii) To assess the impact of residue application, time of application, residue types on the gas fluxes $\left(\mathrm{CO}_{2}\right), \mathrm{N}$ mineralisation and ${ }^{15} \mathrm{~N}$ recovery to plant.

\section{Hypothesis}

The research question at the core of this work can be summarized as followed: How does the carbon and nitrogen dynamics react to different plant residues and can they be modeled? To answer this question, this thesis tests the following hypotheses:

i) For low input systems where plant residues play a major role in the supply of nutrients to crops, residue quality is the most important factor affected on nutrient release.

ii) Modelling $\mathrm{N}$ and $\mathrm{C}$ release from diverse residue and connecting to plant growth modelling is needed for low input tropical systems.

iii) Determining plant quality based on existing analytical techniques can be used as the basis for parameterizing a soil organic matter model to simulate the mineralisation/immobilization of $\mathrm{C}$ and $\mathrm{N}$ of a wide range of biochemical quality of residues under controlled conditions.

iv) In the long term of application, the $\mathrm{N}$ recovery from plant residues will be decreased and driven by their characteristics.

\subsection{Structure of the thesis}

This thesis is divided into 5 chapters. Following this general introduction chapter, next three chapters $(2,3,4)$ will focus on three main objectives above. Each chapter is written in the form of journal articles. In chapter 5 the research results will be generally assessed against the overall objectives and the conclusions from the study. 
Chapter 2 will present the effect of residue quality on $\mathrm{C}$ and $\mathrm{N}$ mineralisation in soils under controlled condition (objective 1). The decomposition of eight different plan residues with overall C:N ratio from 9 to 70 was tested on 3 different soil types.

Chapter $\mathbf{3}$ will present model parameterization and model performance in different scenarios of various plant residues (objective 2). With these modifications, the predictive ability of the model improved as indicated by modeling efficiency, a measure of goodness of fit between the simulated and observed data.

Chapter 4 will present $\mathrm{C}$ and $\mathrm{N}$ mineralisation and $\mathrm{N}$ recovery from ${ }^{15} \mathrm{~N}$ labelled plant residues in controlled conditions (objective 3). A long term experiment (7 months) was carried out to examine the $\mathrm{N}$ recovery from added residues in plant by different application. 


\subsection{References}

Archontoulis, S. V., Miguez, F. E., and Moore, K. J., Evaluating APSIM Maize, Soil Water, Soil Nitrogen, Manure, and Soil Temperature Modules in the Midwestern United States, 2014.

Aregheore, M., 'Voluntary intake and nutrient digestibility of crop-residue based rations by goats and sheep', Small Ruminant Research, Vol. 22, No. 1, 1996.

Baudron, F., Delmotte, S., Corbeels, M., Herrera, J. M., and Tittonell, P., 'Multi-scale trade-off analysis of cereal residue use for livestock feeding vs. soil mulching in the Mid-Zambezi Valley,

Zimbabwe', Biomass use trade-offs in cereal cropping systems:Lessons and implications from the developing world, Vol. 134, 2015.

Bending, G. D., Turner, M. K., and Burns, I. G., 'Fate of nitrogen from crop residues as affected by biochemical quality and the microbial biomass', Soil Biology and Biochemistry, Vol. 30, No. 14, 1998.

Bengtsson, J., Ahnström, J., and Weibull, A.-C., 'The effects of organic agriculture on biodiversity and abundance: a meta-analysis', Journal of Applied Ecology, Vol. 42, No. 2, 2005.

Bot, A., and Benites, J., The importance of soil organic matter. Key to drought-resistant soil and sustained food production, Food and Agriculture Organization of the United Nations, 2005.

Bowyer, J. L. \&. S. V. E., 'Agricultural residues: An exciting bio-based raw material for the global panels industry.', Forest Products Journal, Vol. 51, No. 1, 2001.

Brisson, N., Gary, C., Justes, E., Roche, R., Mary, B., Ripoche, D., Zimmer, D., Sierra, J., Bertuzzi, P., Burger, P., Bussière, F., Cabidoche, Y. M., Cellier, P., Debaeke, P., Gaudillère, J. P., Hénault, C., Maraux, F., Seguin, B., and Sinoquet, H., 'An overview of the crop model stics. Modelling Cropping Systems: Science, Software and Applications', European Journal of Agronomy, Vol. 18, 3-4, 2003.

Castellanos-Navarrete, A., Tittonell, P., Rufino, M. C., and Giller, K. E., 'Feeding, crop residue and manure management for integrated soil fertility management - A case study from Kenya', Biomass use trade-offs in cereal cropping systems:Lessons and implications from the developing world, Vol. 134, 2015.

Chen, Y., and Avnimelech, Y., The Role of Organic Matter in Modern Agriculture, Springer Netherlands, 1986.

Cherubini, F., and Ulgiati, S., 'Crop residues as raw materials for biorefinery systems - A LCA case study', Applied Energy, Vol. 87, No. 1, 2010.

Christensen, B. T., and Olesen, J. E., 'Nitrogen mineralization potential of organomineral size separates from soils with annual straw incorporation', European Journal of Soil Science, Vol. 49, No. 1, 1998.

Condron, L. M., Tiessen, H., Trasar-Cepeda, C., Moir, J. O., and Stewart, J. W. B., 'Effects of liming on organic matter decomposition and phosphorus extractability in an acid humic Ranker soil from northwest Spain', Biology and Fertility of Soils, Vol. 15, No. 4, 1993

Constantinides, M., and Fownes, J. H., 'Nitrogen mineralization from leaves and litter of tropical plants: Relationship to nitrogen, lignin and soluble polyphenol concentrations', Soil Biology and Biochemistry, Vol. 26, No. 1, 1994.

Cookson, W. R., Beare, M. H., and Wilson, P. E., 'Effects of prior crop residue management on microbial properties and crop residue decomposition', Applied Soil Ecology, Vol. 7, No. 2, 1998.

Corbeels, M., McMurtrie, R. E., Pepper, D. A., and O'Connell, A. M., 'A process-based model of nitrogen cycling in forest plantations: Part II. Simulating growth and nitrogen mineralisation of Eucalyptus globulus plantations in south-western Australia', Ecological Modelling, Vol. 187, No. 4, 2005.

Costa, F. J. S. A., Bouldin, D. R., and Suhet, A. R., 'Evaluation of N recovery from mucuna placed on the surface or incorporated in a Brazilian oxisol', Plant and Soil, Vol. 124, No. 1, 1990.

E Owen and M C N Jayasuriya, 'Use of crop residues as animal feeds in developing coutries', Research and development in Agriculture, Vol. 6, No. 3, 1989. 
Food and Agriculture Organisation of the United Nations, 'FAOSTAT database (FAOSTAT. 2013), available at http://faostat3.fao.org/download/G1/GA/E'

Fox, R. H., Myers, R. J. K., and Vallis, I., 'The nitrogen mineralization rate of legume residues in soil as influenced by their polyphenol, lignin, and nitrogen contents', Plant and Soil, Vol. 129, No. 2, 1990

Garnier, P., Néel, C., AITA, C., Recous, S., Lafolie, F., and Mary, B., 'Modelling carbon and nitrogen dynamics in a bare soil with and without straw incorporation', European Journal of Soil Science, Vol. 54, No. 3, 2003.

Gattinger, A., Muller, A., Haeni, M., Skinner, C., Fliessbach, A., Buchmann, N., Mäder, P., Stolze, M., Smith, P., Scialabba, N. E.-H., and Niggli, U., 'Enhanced top soil carbon stocks under organic farming', Proceedings of the National Academy of Sciences, Vol. 109, No. 44, 2012.

Gijsman, A. J., Hoogenboom, G., Parton, W. J., and Kerridge, P. C., 'Modifying DSSAT Crop Models for Low-Input Agricultural Systems Using a Soil Organic Matter-Residue Module from CENTURY', Agron. J, Vol. 94, No. 3, 2002.

Gregorich, E. G., Voroney, R. P., and Kachanoski, R. G., 'Turnover of carbon through the microbial biomass in soils with different texture', Soil Biology and Biochemistry, Vol. 23, No. 8, 1991.

Hansen, S., Jensen, H. E., Nielsen, N. E., and Svendsen, H., 'Simulation of nitrogen dynamics and biomass production in winter wheat using the Danish simulation model DAISY', Fertilizer Research, Vol. 27, 2-3, 1991.

Hassink, J., 'Effects of soil texture and structure on carbon and nitrogen mineralization in grassland soils', Biology and Fertility of Soils, Vol. 14, No. 2, 1992.

Hassink, J., 'Effects of soil texture and grassland management on soil organic $\mathrm{C}$ and $\mathrm{N}$ and rates of $\mathrm{C}$ and N mineralization', Soil Biology and Biochemistry, Vol. 26, No. 9, 1994.

Hassink, J., Bouwman, L. A., Zwart, K. B., Bloem, J., and Brussaard, L., 'Relationships between soil texture, physical protection of organic matter, soil biota, and $\mathrm{c}$ and $\mathrm{n}$ mineralization in grassland soils', Soil Structure/Soil Biota Interrelationships, Vol. 57, 1-2, 1993.

Hassink, J., Neutel, A. M., and ruiter, P. C. de, 'C and N mineralization in sandy and loamy grassland soils: The role of microbes and microfauna', Soil Biology and Biochemistry, Vol. 26, No. 11, 1994

Hole, D. G., Perkins, A. J., Wilson, J. D., Alexander, I. H., Grice, P. V., and Evans, A. D., 'Does organic farming benefit biodiversity?', Biological Conservation, Vol. 122, No. 1, 2005.

Huth, N., Thorburn, P., Radford, B., and Thornton, C., 'Impacts of fertilisers and legumes on N2O and $\mathrm{CO} 2$ emissions from soils in subtropical agricultural systems: A simulation study', Agriculture, Ecosystems \& Environment, Vol. 136, 3-4, 2010.

Jaleta, M., Kassie, M., and Erenstein, O., 'Determinants of maize stover utilization as feed, fuel and soil amendment in mixed crop-livestock systems, Ethiopia', Biomass use trade-offs in cereal cropping systems:Lessons and implications from the developing world, Vol. 134, 2015.

Johansson, T. B., and Goldemberg, J., Energy for sustainable development. A policy agenda, United Nations Development Programme, 2002.

Jones, J. W., Hoogenboom, G., Porter, C. H., Boote, K. J., Batchelor, W. D., Hunt, L. A., Wilkens, P. W., Singh, U., Gijsman, A. J., and Ritchie, J. T., 'The DSSAT cropping system model. Modelling Cropping Systems: Science, Software and Applications', European Journal of Agronomy, Vol. 18, 3-4, 2003.

Justes, E., Mary, B., and NICOLARDOT, B., 'Quantifying and modelling C and N mineralization kinetics of catch crop residues in soil: parameterization of the residue decomposition module of STICS model for mature and non mature residues', Plant and Soil, Vol. 325, 1-2, 2009.

Keating, B. A., Carberry, P. S., Hammer, G. L., Probert, M. E., Robertson, M. J., Holzworth, D., Huth, N. I., Hargreaves, J. N. G., Meinke, H., Hochman, Z., McLean, G., Verburg, K., Snow, V., Dimes, J. P., Silburn, M., Wang, E., Brown, S., Bristow, K. L., Asseng, S., Chapman, S., McCown, R. L., Freebairn, D. M., and Smith, C. J., 'An overview of APSIM, a model designed for farming systems simulation. Modelling Cropping Systems: Science, Software and Applications', European Journal of Agronomy, Vol. 18, 3-4, 2003. 
Kim, S., and Dale, B. E., 'Global potential bioethanol production from wasted crops and crop residues', Biomass and Bioenergy, Vol. 26, No. 4, 2004.

Kumar, K., and Goh, K. M., 'Crop Residues and Management Practices: Effects on Soil Quality, Soil Nitrogen Dynamics, Crop Yield, and Nitrogen Recovery', in Donald L. Sparks (ed.), Advances in Agronomy, Academic Press, 1999.

Lal, R., 'The Role of Residues Management in Sustainable Agricultural Systems', Journal of Sustainable Agriculture, Vol. 5, No. 4, 1995.

Lal, R., 'Carbon sequestration in dryland ecosystems of West Asia and North Africa', Land Degradation \& Development, Vol. 13, No. 1, 2002.

Lal, R., 'World crop residues production and implications of its use as a biofuel', Environment International, Vol. 31, No. 4, 2005.

Lal, R., 'Crop residues as soil amendments and feedstock for bioethanol production', Waste Management, Vol. 28, No. 4, 2008.

Lansink, A. O., lerland, E. C., and Best, G., 'Sustainable Energy in Agriculture: Issues and Scope', in E. C. lerland and A. O. Lansink (eds.), Economy \& Environment, Kluwer Academic Publishers, 2003.

Lascano, R. J., and Baumhardt, R. L., 'Effects of crop residue on soil and plant water evaporation in a dryland cotton system', Theoretical and Applied Climatology, Vol. 54, No. 1, 1996

Li, C., 'The DNDC Model', in D. Powlson, P. Smith and J. Smith (eds.), Evaluation of Soil Organic Matter Models, Springer Berlin Heidelberg, 1996.

$\mathrm{Li}, \mathrm{C}$., Frolking, S., and Frolking, T. A., 'A model of nitrous oxide evolution from soil driven by rainfall events: 1. Model structure and sensitivity', Journal of Geophysical Research: Atmospheres, Vol. 97, D9, 1992.

Li, C., Frolking, S., and Harriss, R., 'Modeling carbon biogeochemistry in agricultural soils', Global Biogeochemical Cycles, Vol. 8, No. 3, 1994.

Li, L.-J., Han, X.-Z., You, M.-Y., Yuan, Y.-R., Ding, X.-L., and Qiao, Y.-F., 'Carbon and nitrogen mineralization patterns of two contrasting crop residues in a Mollisol: Effects of residue type and placement in soils', European Journal of Soil Biology, Vol. 54, 2013.

Luo, Z., Wang, E., Sun, O. J., Smith, C. J., and Probert, M. E., 'Modeling long-term soil carbon dynamics and sequestration potential in semi-arid agro-ecosystems', Agricultural and Forest Meteorology, Vol. 151, No. 12, 2011.

Mader, P., 'Soil Fertility and Biodiversity in Organic Farming', Science, Vol. 296, No. 5573, 2002.

Meier, E. A., Thorburn, P. J., and Probert, M. E., 'Occurrence and simulation of nitrification in two contrasting sugarcane soils from the Australian wet tropics', Australian Journal of Soil Research, Vol. 44, No. 1, 2006.

Mohanty, M., Reddy, K. S., Probert, M., Dalal, R., Rao, A. S., and Menzies, N., 'Modelling N mineralization from green manure and farmyard manure from a laboratory incubation study', Ecological Modelling, Vol. 222, No. 3, 2011.

Molina, J. A. E., 'Description of the model NCSOIL', in D. Powlson, P. Smith and J. Smith (eds.), Evaluation of Soil Organic Matter Models, Springer Berlin Heidelberg, 1996.

Molina, J. A. E., Clapp, C. E., Shaffer, M. J., Chichester, F. W., and Larson, W. E., NCSOIL, A Model of Nitrogen and Carbon Transformations in Soil: Description, Calibration, and Behavior1, 1983.

Motavalli, P., Palm, C., Parton, W., Elliott, E., and Frey, S., 'Soil pH and organic C dynamics in tropical forest soils: Evidence from laboratory and simulation studies', Soil Biology and Biochemistry, Vol. 27, No. 12, 1995.

Muhammad, W., Vaughan, S., Dalal, R., and Menzies, N., 'Crop residues and fertilizer nitrogen influence residue decomposition and nitrous oxide emission from a Vertisol', Biology and Fertility of Soils, Vol. 47, No. 1, 2011.

Nicolardot, B., Molina, J. A. E., and Allard, M. R., 'C and N fluxes between pools of soil organic matter: Model calibration with long-term incubation data', Soil Biology and Biochemistry, Vol. 26, No. 2, 1994. 
Nicolardot, B., Recous, S., and Mary, B., 'Simulation of C and N mineralisation during crop residue decomposition: A simple dynamic model based on the C: $\mathrm{N}$ ratio of the residues', Plant and Soil, Vol. 228, No. 1, 2001.

Njie, M., and Reed, J. D., 'Potential of crop residues and agricultural by-products for feeding sheep in a Gambian village', Animal Feed Science and Technology, Vol. 52, 3-4, 1995.

Onwuka, C. F. I., Adetiloye, P. O., and Afolami, C. A., 'Use of household wastes and crop residues in small ruminant feeding in Nigeria', Small Ruminant Research, Vol. 24, No. 3, 1997.

Pacini, C., Wossink, A., Giesen, G., Vazzana, C., and Huirne, R., 'Evaluation of sustainability of organic, integrated and conventional farming systems: a farm and field-scale analysis', Agriculture, Ecosystems \& Environment, Vol. 95, No. 1, 2003.

Palm, C. A., and Sanchez, P. A., 'Nitrogen release from the leaves of some tropical legumes as affected by their lignin and polyphenolic contents', Soil Biology and Biochemistry, Vol. 23, No. 1, 1991.

Parthasarathy Rao, P., and Hall, A. J., 'Importance of crop residues in crop-livestock systems in India and farmers' perceptions of fodder quality in coarse cereals', Approaches to improve the utilization of food-feed crops, Vol. 84, 1-2, 2003.

Parton, W. J., 'The CENTURY model', in D. Powlson, P. Smith and J. Smith (eds.), Evaluation of Soil Organic Matter Models, Springer Berlin Heidelberg, 1996.

Parton, W. J., Stewart, J. W. B., and Cole, C. V., 'Dynamics of C, N, P and S in grassland soils: a model', Biogeochemistry, Vol. 5, No. 1, 1988.

Probert, M., Delve, R., Kimani, S., and Dimes, J., 'Modelling nitrogen mineralization from manures: representing quality aspects by varying C: $\mathrm{N}$ ratio of sub-pools', Soil Biology and Biochemistry, Vol. 37, No. 2, 2005.

Recous, S., Robin, D., Darwis, D., and Mary, B., 'Soil inorganic N availability: Effect on maize residue decomposition', Soil Biology and Biochemistry, Vol. 27, No. 12, 1995.

Shaver, T. M., Peterson, G. A., Ahuja, L. R., and Westfall, D. G., 'Soil sorptivity enhancement with crop residue accumulation in semiarid dryland no-till agroecosystems', Geoderma, Vol. 192, 2013.

Thorburn, P. J., Meier, E. A., and Probert, M. E., 'Modelling nitrogen dynamics in sugarcane systems: Recent advances and applications', Field Crops Research, Vol. 92, 2-3, 2005.

Thorburn, P., Biggs, J., Collins, K., and Probert, M., 'Using the APSIM model to estimate nitrous oxide emissions from diverse Australian sugarcane production systems', Agriculture, Ecosystems \& Environment, Vol. 136, 3-4, 2010.

Tian, G., Badejo, M. A., Okoh, A. I., Ishida, F., Kolawole, G. O., Hayashi, Y., and Salako, F. K., 'Effects of residue quality and climate on plant residue decomposition and nutrient release along the transect from humid forest to Sahel of West Africa', Biogeochemistry, Vol. 86, No. 2, 2007.

Tian, G., Kang, B. T., and Brussaard, L., 'Biological effects of plant residues with contrasting chemical compositions under humid tropical conditions-Decomposition and nutrient release', Soil Biology and Biochemistry, Vol. 24, No. 10, 1992.

Trinsoutrot, I., Recous, S., Bentz, B., Line'res, M., Che`neby, D., and NICOLARDOT, B., 'Biochemical Quality of Crop Residues and Carbon and Nitrogen Mineralization Kinetics under Nonlimiting Nitrogen Conditions', Soil Sci. Soc. Am. J, Vol. 64, No. 3, 2000 a.

Trinsoutrot, I., Recous, S., Mary, B., and NICOLARDOT, B., 'C and N fluxes of decomposing $13 \mathrm{C}$ and ${ }^{15} \mathrm{~N}$ Brassica napus L.: effects of residue composition and $\mathrm{N}$ content', Soil Biology and Biochemistry, Vol. 32, 11-12, 2000b.

Tuomisto, H. L., Hodge, I. D., Riordan, P., and Macdonald, D. W., 'Does organic farming reduce environmental impacts? - A meta-analysis of European research', Journal of Environmental Management, Vol. 112, 2012.

Urbaniec, K., and Bakker, R. R., 'Biomass residues as raw material for dark hydrogen fermentation - A review', International Journal of Hydrogen Energy, Vol. 40, No. 9, 2015.

Vahdat, E., Nourbakhsh, F., and Basiri, M., 'Lignin content of range plant residues controls $\mathrm{N}$ mineralization in soil', European Journal of Soil Biology, Vol. 47, No. 4, 2011. 
Valbuena, D., Erenstein, O., Homann-Kee Tui, S., Abdoulaye, T., Claessens, L., Duncan, A. J., Gérard, B., Rufino, M. C., Teufel, N., van Rooyen, A., and van Wijk, M. T., 'Conservation Agriculture in mixed crop-livestock systems: Scoping crop residue trade-offs in Sub-Saharan Africa and South Asia', Conservation Agriculture in Dry Areas, Vol. 132, 2012.

van S. J. Donk, D. L. M. S. I. S. R. M. J. L. P. D. R. D., 'Crop Residue Cover Effects On Evaporation, Soil Water Content, And Yield Of Deficit-Irrigated Corn In West-Central Nebraska', Transactions of the ASABE, Vol. 53, No. 6, 2010.

Ververis, C., Georghiou, K., Christodoulakis, N., Santas, P., and Santas, R., 'Fiber dimensions, lignin and cellulose content of various plant materials and their suitability for paper production', Industrial Crops and Products, Vol. 19, No. 3, 2004.

Whitbread, A. M., and Clem, R. L., 'Graze to grain-measuring and modelling the effects of grazed pasture leys on soil nitrogen and sorghum yield on a Vertosol soil in the Australian subtropics', Australian Journal of Agricultural Research, Vol. 57, No. 5, 2006.

Willke, T., and Vorlop, K.-D., 'Industrial bioconversion of renewable resources as an alternative to conventional chemistry', Applied Microbiology and Biotechnology, Vol. 66, No. 2, 2004. 


\section{Chapter 2. Evaluating the effect of residue quality on $\mathbf{C}$ and $\mathbf{N}$ mineralization in soils under controlled conditions}

\subsection{Introduction}

There can be no doubt that the use of residues as an alternative nutrient source is growing in agricultural farming systems throughout the tropics and subtropics. The role of residues is not only important for nutrient supply for plant growth in short-term (Whitbread et al., 2000a) but also for soil organic matter (SOM) maintenance in long-term (Mary et al., 1996; Whitbread et al., 2000b). The pattern of breakdown of residues can also affect the nutrient transitions in soil and soil microbial activities (Powlson, 1996). Losses of SOM have consequences for productivity, quality of agricultural produce and environmental quality (Whitbread et al., 1998; Blanco-Canqui and Lal, 2009).

The mineralisation of crop residue in soils is complex and is controlled by several factors, such as soil conditions and soil characteristics (Cookson et al., 2002; Aita et al., 1997; Khalil et al., 2005; Hassink, 1992; Khalil et al., 2007; Muhammad et al., 2011), residue characteristics and management (Angers and Recous, 1997; Coppens et al., 2007; Janzen and Kucey, 1988; Muhammad et al., 2011; Trinsoutrot et al., 2000a; Trinsoutrot et al., 2000b; Vanlauwe et al., 1996). Among the numerous factors affecting the decomposition of crop residues under field conditions, chemical composition is widely mentioned as an important factor (Trinsoutrot et al., 2000a; Tian et al., 1992). The C:N ratio has been mentioned as a good predictor of plant residue decomposition and net mineralisation or immobilization when applied to soils (Nicolardot et al., 2001; Qian and Schoenau, 2002). The N mineralized from residues was significantly and negatively correlated with high $\mathrm{C}: \mathrm{N}$ ratio of plant residues (Muhammad et al., 2011; Trinsoutrot et al., 2000a). Crop residues with C:N ratio less than 24 are expected to result in net $\mathrm{N}$ mineralisation, while those with $\mathrm{C}: \mathrm{N}$ ratios higher than 24 cause immobilization after times of application (Trinsoutrot et al., 2000a). The effect of the chemical composition of added residues on the release of $\mathrm{C}$ and $\mathrm{N}$ has been documented in several studies. The research of Powlson et al. (1996) showed that the different decomposition rate of added plant residues could be related to initial polyphenol/ $\mathrm{N}$ and 
polyphenol+lignin: $\mathrm{N}$ ratios. The cumulative $\mathrm{N}$ release could be predicted with the (polyphenol+lignin): $\mathrm{N}$ ratio of the initial substrate in the first 2 weeks of decomposition processes (Powlson et al., 1996). The role of lignin as a regulator in the decomposition process has been eluded to in studies by Tian et al. (1992), Müller et al. (2003), Palm and Sanchez (1991). Tian et al. (1992) found negative correlations between decomposition rate of some woody agroforestry plants and their $\mathrm{C}: \mathrm{N}$ ratio, percent lignin and polyphenol content. According to Palm and Sanchez (1991), the polyphenolic content played a more important role in influencing net $\mathrm{N}$ mineralization pattern for leguminous leaves than $\% \mathrm{~N}$ or lignin -to- $\mathrm{N}$ ratio. Furthermore, Vanlauwe et al. (1996) found the correlation between C mineralization of some leaves and roots of 3 agroforestry plants and lignin content, $\mathrm{C}: \mathrm{N}$ ratio and polyphenol-to- $\mathrm{N}$ ratio. High lignin content of plant residues could also enhance nutrient immobilization, especially nitrogen (Constantinides and Fownes, 1994).

Soil texture is mentioned as an indicator factor on nutrient cycling and decomposing of soil organic matter in somewhere else. Gilmour and Gilmour (1985) found the positive relationship between $\mathrm{CO}_{2}-\mathrm{C}$ evolution and clay content whereas the relationship between net nitrification and clay content was negative. Similarly results were also mentioned in Li et al.(1992), Pezeshki et al. (1997). However, in Hansen et al. (1991) study found an inversely result in which $\mathrm{N}$ dynamics were little affected by soil clay and silt contents. Moreover, Anderson and Domsch (1986) reported that the C mineralised and the net $\mathrm{N}$ mineralisation was greatest for the sand and least for the silt in incubation condition. Regarding to evaluate the effect of added residues application on the mineralisation and $\mathrm{C}$ and $\mathrm{N}$, Porter et al. (2010) reported that the cumulative $\mathrm{C}$ mineralization and cumulative mineral $\mathrm{N}$ was higher for residues placed on the soil surface than for residues incorporated into the soils after 56 days in constant condition. Nevertheless, in Chertov (1990) research, the results showed that the net $\mathrm{N}$ mineralization of mucuna residue was greater when mixed with soil rather than placed on the surface. Meanwhile, Li et al. (1992) reported that there was no significant difference of maize straw decomposition either mixed into the soil or applied on the surface after one year 
with the exception in soil fraction $>200 \mu \mathrm{m}$, the organic matter decomposed faster in mixed treatment.

For low input farming systems, for example under subsistence agriculture in developing countries or in organic farming systems in Europe, research is needed on how to manage nutrient release from organic inputs. The objectives of this study were to determine how biochemical quality of a wide range of crop residues affects the decomposition pattern in laboratory incubations using different soil types and residue application methods.

\subsection{Materials and methods}

\subsubsection{Soil and residue characteristics}

Two cultivated soils from South Australia were collected from the surface layer $(0-10 \mathrm{~cm})$, airdried and sieved through a $2 \mathrm{~mm}$ mesh to remove roots and other debris. One soil from Germany was collected from a subsoil $(20-40 \mathrm{~cm})$ and prepared the same way. For the closed chamber incubation study, $500 \mathrm{~g}$ of dry soil was weighed into $2 \mathrm{I}$ glass jars, wetted to $50 \%$ water holding capacity and pre-incubated at $25^{\circ} \mathrm{C}$ from 2 to 4 days to stimulate the initial flush of $\mathrm{CO}_{2}$ and $\mathrm{N}$ released as described by (Birch, 1964).

Eight crop residues were considered in this study. They differ either in the plant species, the plant organs or the growth stage at which they were sampled. Residues \# 1 to \#4 (Table 2.2) were grown in field condition under subtropical climate of South Australia, residues \# 6 to \# 8 were also grown in field condition but in temperate seasonal climate of Middle Germany. Residue \# 5 was grown in control condition in greenhouse. Most residues were harvested at a maturity stage. Residue \# 6 (lucerne) was sampled at flowering stage in summer. All residues were dried at $40^{\circ} \mathrm{C}$ and chopped to $2-5 \mathrm{~cm}$ lengths. Subsamples of residues were dried, ground for chemical analysis as outlined in Table 2.2. The total $\mathrm{C}$ and $\mathrm{N}$ concentration of residues were determined using a combustion technique (Elemental analyser). The Van Soet method was used to determine the acid detergent fiber (ADF), neutral detergent fiber (NDF) and acid detergent lignin (ADL) (van Soest, 1967; van Soest et al., 1991). 


\subsubsection{Treatments and laboratory incubation}

Three laboratory incubation experiments were carried out in order to evaluate the impact of varying factors (soil type, placement of residue, residue type) on $\mathrm{CO}_{2}$ and $\mathrm{N}$ mineralisation. In experiment 1, $3.8 \mathrm{~g}$ residues 1-4 (Table 2.2) were mixed into a sand or a clay soil and incubated for 63 days ( 4 residues $\times 2$ soils $\times 4$ replicates). Experiment 2 used $3.8 \mathrm{~g}$ residues 1-4 with the sand soil only, and the application of the residues were either as surface applied (mulch) or mixed (incorporated) into the soil and incubated for 126 days (4 residues $\times 2$ methods of application $\times 4$ replicates). The third incubation used $2 \mathrm{~g}$ residues 5-8 mixed with the subsoil and incubated for 126 days.

After pre-incubation, the soil water content was adjusted to and maintained at $75 \%$ for the clay and sand and to $60 \%$ for the subsoil. The jars were sealed and incubated at $25^{\circ} \mathrm{C}$ in the dark in the presence of a $\mathrm{CO}_{2}$ trap. A control treatment consisting of soil-only was included with the 3 incubation experiments and in all cases treatments were replicated 4 times.

Table 2.1. Some chemical and textural properties of soils used in 3 incubation experiments.

\begin{tabular}{|l|l|c|c|c|c|c|c|c|}
\hline $\begin{array}{l}\text { Soils } \\
\text { code }\end{array}$ & \multicolumn{1}{|c|}{ Soil type } & $\begin{array}{c}\mathbf{p H} \\
\left(\mathbf{C a C l}_{\mathbf{2}}\right)\end{array}$ & $\begin{array}{c}\mathbf{O C} \\
(\%)\end{array}$ & $\begin{array}{c}\mathbf{N} \\
(\%)\end{array}$ & $\begin{array}{c}\mathbf{N} \text { min } \\
\left(\mathbf{m g ~ k g}^{-1}\right. \\
\mathbf{s o i l})\end{array}$ & $\begin{array}{c}\text { Clay } \\
(\%)\end{array}$ & $\begin{array}{c}\text { Silt } \\
(\%)\end{array}$ & $\begin{array}{c}\text { Sand } \\
(\%)\end{array}$ \\
\hline Clay & Alfisol & 7.13 & 2.3 & 0.19 & 29.9 & 43.0 & 22.0 & 35.0 \\
\hline Sand & Calcaresol & 7.91 & 0.6 & 0.02 & 7.0 & 7.0 & 2.0 & 91.0 \\
\hline Subsoil & Podsol & 6.6 & 0.22 & 0.012 & 6.6 & 3.3 & 9.5 & 87.2 \\
\hline
\end{tabular}


Table 2.2. Chemical properties of residues used

\begin{tabular}{|l|l|l|l|l|l|l|l|l|}
\hline $\begin{array}{c}\text { Residues } \\
\text { Code }\end{array}$ & \multicolumn{1}{|c|}{$\begin{array}{c}\text { Residue } \\
\text { types }\end{array}$} & $\begin{array}{c}\text { Total } \\
\mathbf{C} \\
(\%)\end{array}$ & $\begin{array}{c}\text { Total } \\
\mathbf{N} \\
(\%)\end{array}$ & $\begin{array}{c}\text { C:N } \\
\text { ratio }\end{array}$ & $\begin{array}{c}\text { Carbohydrate }^{\mathbf{c}} \\
(\%)\end{array}$ & $\begin{array}{c}\text { Cellulose }^{\mathbf{a}} \\
(\%)\end{array}$ & $\begin{array}{c}\text { Hemicellulose }^{\mathbf{b}} \\
(\%)\end{array}$ & Lignin $^{\mathbf{d}}$ \\
\hline 1 & Mucuna & 41.0 & 2.9 & 14.1 & 54.6 & 15.1 & 10.9 & 19.5 \\
\hline 2 & Pea & 40.0 & 4.4 & 9.1 & 52.6 & 11.2 & 22.4 & 13.8 \\
\hline 3 & Wheat & 43.0 & 1.6 & 26.9 & 25.8 & 24.7 & 36.6 & 12.9 \\
\hline 4 & Canola & 43.0 & 1.0 & 43.0 & 34.4 & 35.7 & 6.9 & 23.0 \\
\hline 5 & Lablab & 41.3 & 1.9 & 21.7 & 57.2 & 19.2 & 16.2 & 7.4 \\
\hline 6 & Lucerne & 43.8 & 2.4 & 18.3 & 48.6 & 16.6 & 20.9 & 13.8 \\
\hline 7 & Maize & 37.7 & 1.9 & 19.8 & 42.4 & 11.0 & 21.1 & 25.5 \\
\hline 8 & Wheat & 42.7 & 0.6 & 71.2 & 28.3 & 36.6 & 24.8 & 10.3 \\
\hline
\end{tabular}

${ }^{\mathrm{a}}$ Calculated as: \%Acid detergent fiber (ADF) - \% Acid detergent lignin (ADL); ${ }^{\mathrm{b}}$ Calculated as: $\%$ Neutral detergent fiber (NDF) - \%ADF; ${ }^{d}$ Calculated as \%ADL; ${ }^{\circ}$ Calculated as: $100-d-a-b$.

\subsubsection{Analytical measurements}

The evolution of $\mathrm{CO}_{2}$ in each incubation jar containing soil (control) or soil plus residues was captured in a $\mathrm{CO}_{2}$ trap which was simply a small beaker containing $25 \mathrm{ml}$ of $0.4 \mathrm{M} \mathrm{NaOH}$ placed in each glass jar. Two glass jars without soil containing only a $\mathrm{CO}_{2}$ trap were included as blanks throughout each incubation experiment. For the $1^{\text {st }}$ experiment, samples were collected on days 1, 2, 4, 7 for the first week and on weekly basis thereafter for 9 weeks. In the $2^{\text {nd }}$ and $3^{\text {rd }}$ experiments, samples were collected on day $1,2,3,7,10,14$, and on weekly basis thereafter until the the emissions of $\mathrm{CO}_{2}$ became small after week $18^{\text {th }}$. The samples were precipitated with $\mathrm{BaCl}_{2}$ and then titrated with hydrochloric acid $(\mathrm{HCl})$ and the readings were used to calculate the amount of cumulative $\mathrm{C}$ released as $\mathrm{CO}_{2}-\mathrm{C}$.

Carbon mineralization (expressed in $\mathrm{mg} \mathrm{kg}^{-1}$ soil) from added residues was calculated from the different in cumulative amount of carbon release between amendment soil with residues and a control at each sampling time.

Cumulative $\mathrm{CO}_{2}-\mathrm{C}$ (residue) $=$ Cumulative $\mathrm{CO}_{2}-\mathrm{C}$ (treatment) - Cumulative $\mathrm{CO}_{2}-\mathrm{C}$ (control) 
The quantity of $\mathrm{C}$ evolved was expressed as a (\%) of added residues as follows:

$$
\text { net } \mathrm{C} \text { release }(\% \text { of total residue } \mathrm{C} \text { added })=\left[\frac{\sum \mathrm{CO}_{2}-\mathrm{C} \times 100}{\text { res } \times \text { OC }}\right]
$$

Where $\mathrm{SCO}_{2}-\mathrm{C}$ is the cumulative amount of $\mathrm{CO}_{2}-\mathrm{C}\left(\mathrm{mg} \mathrm{kg}^{-1}\right.$ soil) release at time $\mathrm{t}$ from only added residue, res is the amount of applied residue ( $\mathrm{mg} \mathrm{kg}^{-1}$ soil), OC is the dry organic matter of residue (\%).

Mineral nitrogen was determined on soil samples collected at weeks 1, 2, 4, 7 and 9 for the $1^{\text {st }}$ experiment and at weeks $1,2,4,8,14$ and 18 for $2^{\text {nd }}$ and $3^{\text {rd }}$ experiments. Fresh soil samples were prepared by removing any organic residue particles and extracting with potassium chloride $(\mathrm{KCl})$ solution by shaking for 1 hour, followed by filtering through a No. 42 Whatman filter paper. The extracts were analysed for $\mathrm{NH}_{4}^{+}$and $\mathrm{NO}_{3}^{-}$using thermal conductivity detection by Matejovic (1997) with mineral $\mathrm{N}$ being the addition of $\mathrm{NH}_{4}{ }^{+}-\mathrm{N}+\mathrm{NO}_{3}{ }^{-}$ $-\mathrm{N}$.

Net $\mathrm{N}$ mineralization from added residues was calculated as follow:

Net $\mathrm{N}$ min $\left(\mathrm{mg} \mathrm{kg}^{-1}\right.$ soil $)=$ mineral $\mathrm{N}$ in the treatment - mineral $\mathrm{N}$ in control

\subsection{Results}

\subsubsection{Biochemical quality of the residues}

The overall C:N ratio of residues used in this study varied widely ranging from 9.1 (pea \# 2) to 71.2 (wheat \# 8) (Table 2.2). The highest concentration of lignin (\%) was found in maize (25.5\%) followed by canola (23.0\%) and mucuna (19.5\%) meanwhile the carbohydrate content in this group was in intermediate (from 34.4 to $54.6 \%$ ). The highest carbohydrate content resulted from lablab (57.2\%) and the lowest was recognised in wheat (\#3) $(25.8 \%)$.

Among 4 different pools of $\mathrm{C}$ in residues as carbohydrate, cellulose, hemicelluloses and lignin, statistical analysis found that the carbohydrate like pool was inversely related to overall C:N ratio $\left(R^{2}=0.50\right)$ while cellulose-like pool was linearly related $\left(R^{2}=0.81\right)$ (Figure 2.1). The relationship between overall $\mathrm{C}: \mathrm{N}$ ratio and hemicellulose and lignin was not clear, $R^{2}$ values was of 0.002 and 0.027 , respectively. 


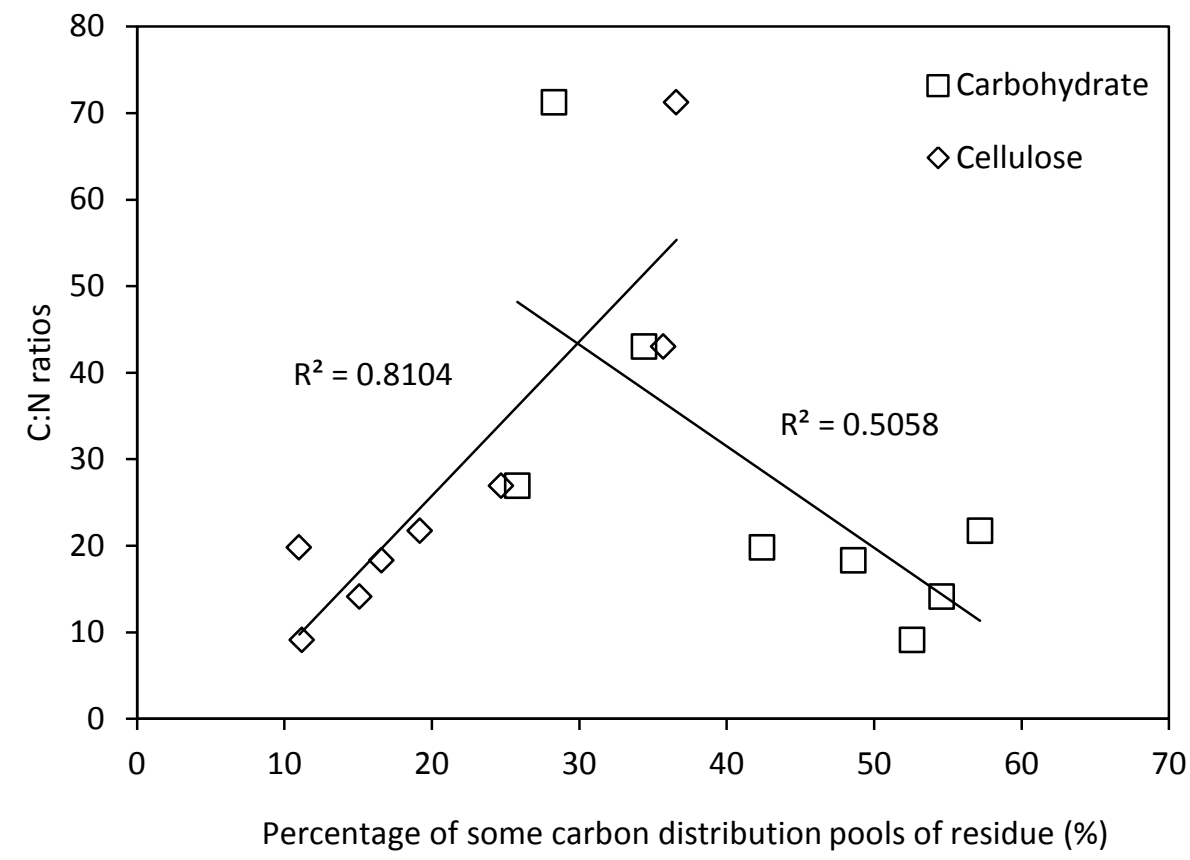

Figure 2.1. Linear regression between $\mathrm{C}: \mathrm{N}$ ratio of residue and some carbon distribution pools of residue.

\subsubsection{Carbon and nitrogen mineralisation of added residues from different soil types}

\section{a. Carbon mineralisation}

Regardless of residue addition, the quantity of $\mathrm{C}$ mineralisation was linearly related to soil $\mathrm{C}$ concentration (Figure $2.2 \mathrm{a}, \mathrm{b}, \mathrm{c}$ ). In the absence of residue, the amount of cumulative $\mathrm{CO}_{2}-\mathrm{C}$ release within 63 days of the incubation was $447.0,175.6$ and $47.3 \mathrm{mg} \mathrm{CO}_{2}-\mathrm{C} \mathrm{kg}^{-1}$ soil for clay, sand and subsoil, respectively and this was statistical difference at $P$ value $<0.05$. The release of $\mathrm{CO}_{2}-\mathrm{C}$ of added residues increases profoundly in the beginning of incubation. For example, in the first 7 days of incubation, $\mathrm{CO}_{2}-\mathrm{C}$ release from residues rapidly marked in all treatments to around $50 \%$ of total C mineralised in subsoil and continued increasing dramatically afterward (Figure 2.2c). The significant differences of the cumulative of $\mathrm{CO}_{2}-\mathrm{C}$ emission were recognised in all treatments with the exception between lablab and lucerne at $P$ value $<0.05$. The total amount of $\mathrm{CO}_{2}-\mathrm{C}$ emission from lablab and lucerne was much higher than from maize and wheat, about 592.6, 570.7, 376.9 and $267.8 \mathrm{mg} \mathrm{kg}^{-1}$ soil, respectively. After 4 weeks of incubation, the amount $\mathrm{CO}_{2}-\mathrm{C}$ lost increased slightly but the significant differences were found in all added residues. Higher production of $\mathrm{CO}_{2}-\mathrm{C}$ emission was found in lower $\mathrm{C}: \mathrm{N}$ ratio and small lignin content of added residues. Even though having similar $\mathrm{C}: \mathrm{N}$ ratio, maize produced less $\mathrm{CO}_{2}-\mathrm{C}$ than lucerne during 126 incubation days and was significant difference at $P$ value $<0.05$, about 1093.5 and $947.9 \mathrm{mg}$ $\mathrm{kg}^{-1}$ soil, respectively. 
When applying similar residues in different soils, the $\mathrm{C}$ mineralisation faster was recognised in soil having higher $\mathrm{OC}$ content (Figure 2.2a, b). In the first day of incubation, the statistical significant difference at $\mathrm{P}$ value $<0.05$ of $\mathrm{CO}_{2}-\mathrm{C}$ release from difference soils was only found in wheat and canola. Nevertheless, it was showed in all treatments after 1 week to the end of trial in which cumulative of $\mathrm{CO}_{2}-\mathrm{C}$ emission from clay was always significant higher than that in sand soil. For example, in the first 7 days of incubation, the largest amount of $\mathrm{CO}_{2}-\mathrm{C}$ release was found in pea, about $735.3 \mathrm{mg} \mathrm{kg}^{-1}$ soil when added in clay and this number decreased to $632.2 \mathrm{mg} \mathrm{kg}^{-1}$ soil when added in sand soil. Canola and wheat produced least $\mathrm{CO}_{2}-\mathrm{C}$ in the same time. In this both soils, the $\mathrm{CO}_{2}-\mathrm{C}$ release increased rapidly in the first 4 weeks of incubation and reached around a half of total $C$ mineralised. Afterward, the amount of $\mathrm{CO}_{2}-\mathrm{C}$ produced improved gradually. After 63 days of incubation, mucuna produced least significant of $\mathrm{CO}_{2}-\mathrm{C}$ comparison with other 3 residues, around $1152.1 \mathrm{mg} \mathrm{kg}^{-1}$ soil in sand and $1758.9 \mathrm{mg} \mathrm{kg}^{-1}$ soil in clay soil, respectively. In clay soil, after 28 days of incubation, there was no significant difference of cumulative $\mathrm{CO}_{2}-\mathrm{C}$ emission among wheat, canola and pea (Figure 2.2a). Meanwhile, the cumulative $\mathrm{CO}_{2}-\mathrm{C}$ emission from pea in sand soil after 63 days was lower significant at $P$ value $<0.05$ compared with wheat, about 2095.0 and 2142.9 $\mathrm{mg} \mathrm{kg}^{-1}$ soil, respectively. There was no significant difference between pea and canola.

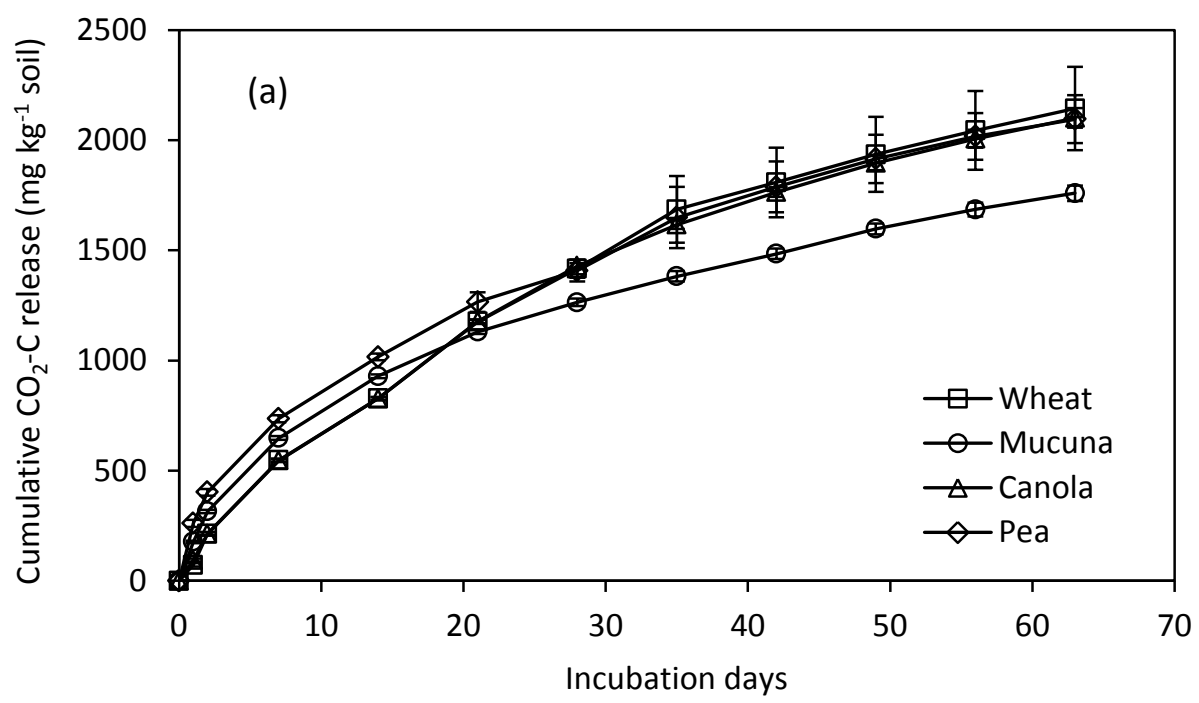



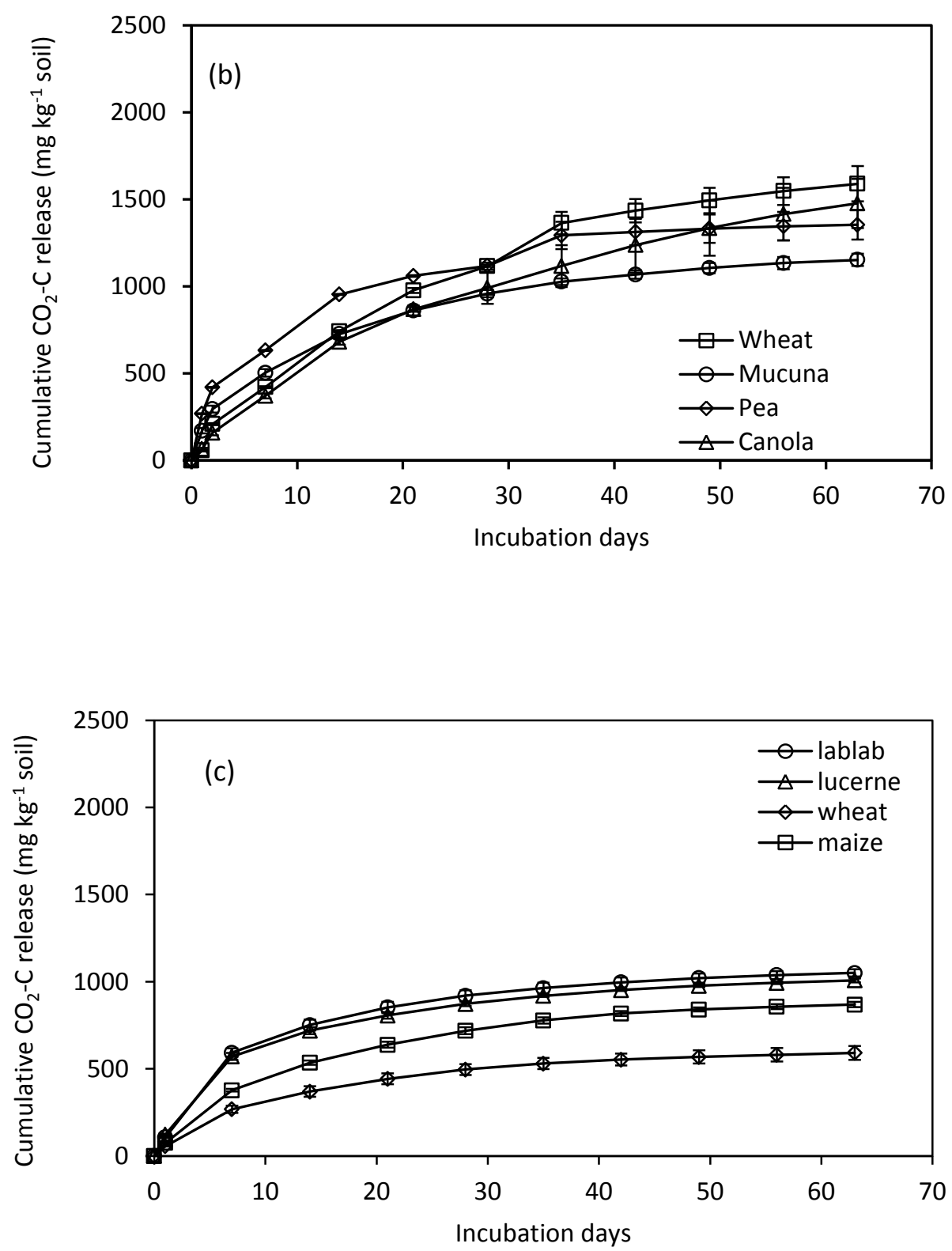

Figure 2.2. Cumulative $\mathrm{CO}_{2}-\mathrm{C}$ release from only residues in clay (a), sand (b) and subsoil (c). The error bars represented the standard deviation of 4 different replications. The incubation time from subsoil (2c) was actually for 126 days, however there was no change in the order of the residues and the same low rate of increase and moreover, to make sense when comparing to 2 others soils, the graph just presents in within 63 days of incubation. 


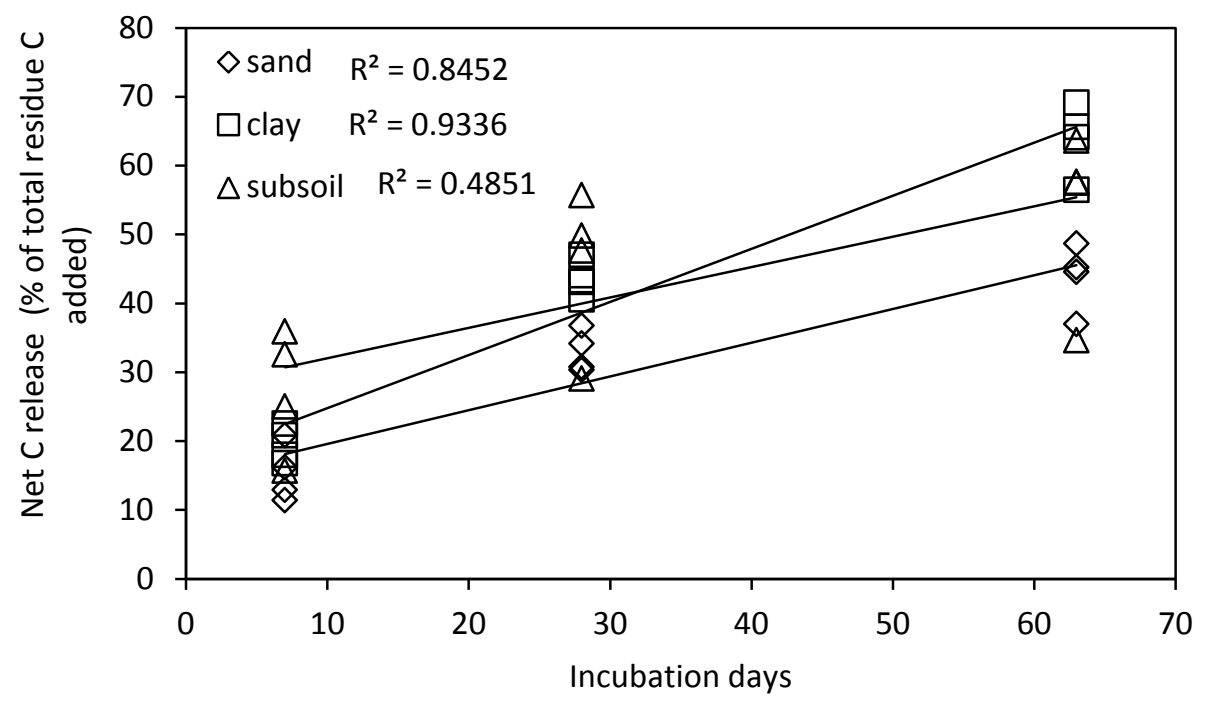

Figure 2.3. The relationships between net $\mathrm{C}$ release as percentage of total $\mathrm{C}$ input from only added residues (each point represented mean of 4 replications) and soil types after 7, 28 and 63 days of incubation.

The effect of added residues on net $C$ releases was positively related to the concentration of organic matter in soil or soil types at days 7, 28 and 63 of incubation (Figure 2.3), better $\mathrm{R}^{2}$ value being obtained with higher of soil organic matter. For subsoil, due to storing in a greenhouse for years, the microbial communities were lesser than normal condition and the organic carbon content much lower than other 2 soils, the overall coefficient of determination $\left(R^{2}\right)$ of this soil was much lower than those in other 2 soils (Figure 2.3). Statistic found a significant difference between clay and sand soil at day 28 and 63 at $P$ value $<0.05$ but not at day $7(P$ value $=0.105)$.

\section{b. Nitrogen mineralisation}

In the unamended soil only control treatments, there was continuous net $\mathrm{N}$ mineralisation with soil type a significant effect on the quantity of $\mathrm{N}$. Subsoil in which had the lowest amount of mineral $\mathrm{N}\left(6.6 \mathrm{mg} \mathrm{kg}^{-1}\right.$ soil, Table 2.1) produced lesser nitrogen mineralisation when comparison with 2 other soils. At 56 days, the amount of $\mathrm{N}$ release from clay soil was much significant higher than in sand and subsoil, about $88 \mathrm{mg} \mathrm{N} \mathrm{kg}^{-1}$ soil compared with $16 \mathrm{mg} \mathrm{N}$ $\mathrm{kg}^{-1}$ soil and $4 \mathrm{mg} \mathrm{N} \mathrm{kg}^{-1}$ soil, respectively.

The net $\mathrm{N}$ mineralised from added residues profoundly affected by the concentration of mineral $\mathrm{N}$ in soil. Sandy soil with low $\mathrm{N}$ concentration in soil (Table 2.1) resulted significant larger amount of net $\mathrm{N}$ min of same added residue than in clay soil. In particular of pea, it was about $122.5 \mathrm{mg} \mathrm{kg}^{-1}$ soil at 7 days in sandy soil and decreased to $65.9 \mathrm{mg} \mathrm{kg}^{-1}$ soil in 
clay soil. In next following weeks, similar progress occurred with a statistical significant difference $(P$ value $<0.05)$.

In all 3 soil types, the low C:N ratio residues such as pea (9.1), mucuna (14.1), lucerne (18.3) showed net $\mathrm{N}$ mineralisation during 56 days of incubation in clay and sand soil and in over 120 days in subsoil. In contrast, the addition of residues with $\mathrm{C}: \mathrm{N}$ ratio $>26.9$ resulted in net immobilisation. For example wheat $(\mathrm{C}: \mathrm{N}=26.9)$ and canola $(\mathrm{C}: \mathrm{N}=43.0)$ in clay and sand and wheat straw $(\mathrm{C}: \mathrm{N}=71.2)$ in subsoil (Figure 2.4a, b, c).

The highest amount of net $\mathrm{N}$ mineral was measured in the clay or sand with pea or mucuna residue additions, (123 and $81 \mathrm{mg} \mathrm{kg}^{-1}$ soil, respectively). Moreover, the strong net immobilisation showed in wheat and canola added to clay soil was a net mineralisation when added to the sand soil (Figure 2.4a and 2.4b). The amount of net $\mathrm{N}$ mineralisation/immobilisation in soil 3 varied from $-6.6 \mathrm{mg} \mathrm{kg}^{-1}$ soil in wheat to $18.3 \mathrm{mg} \mathrm{kg}$ soil in lucerne. The net $\mathrm{N}$ min from lablab and maize in this soil transferred from immobilisation to mineralisation after 20 days of incubation.

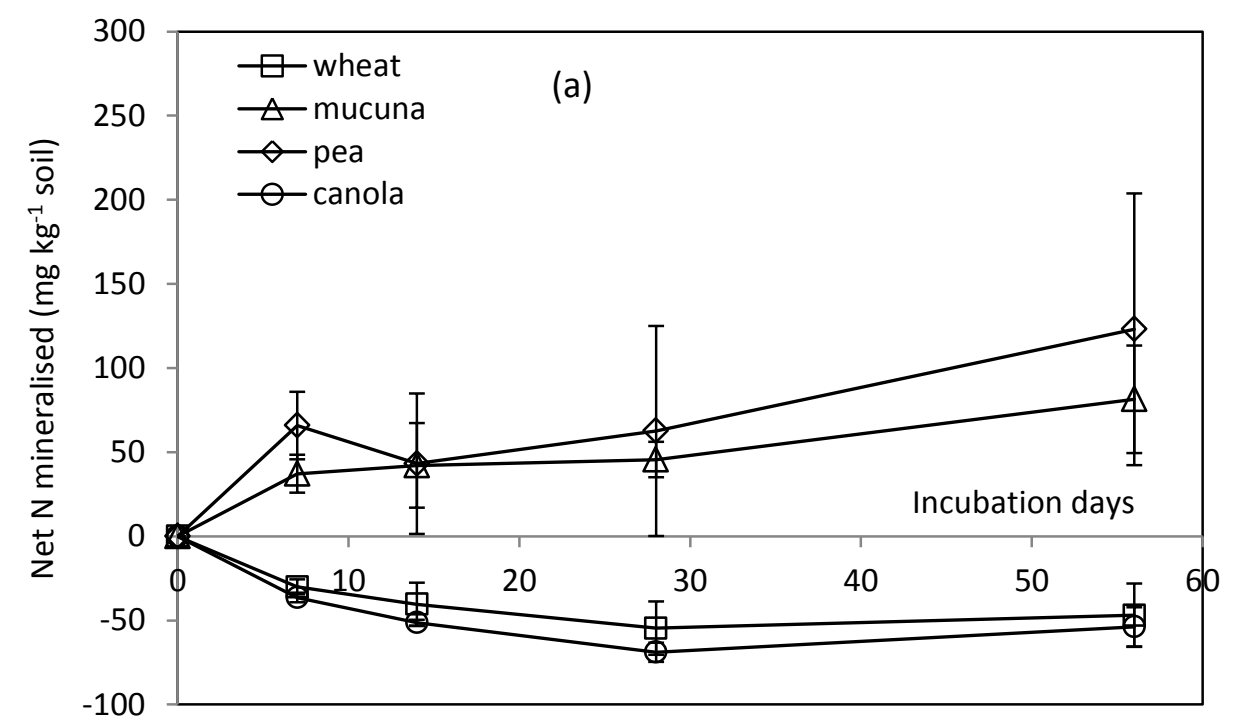



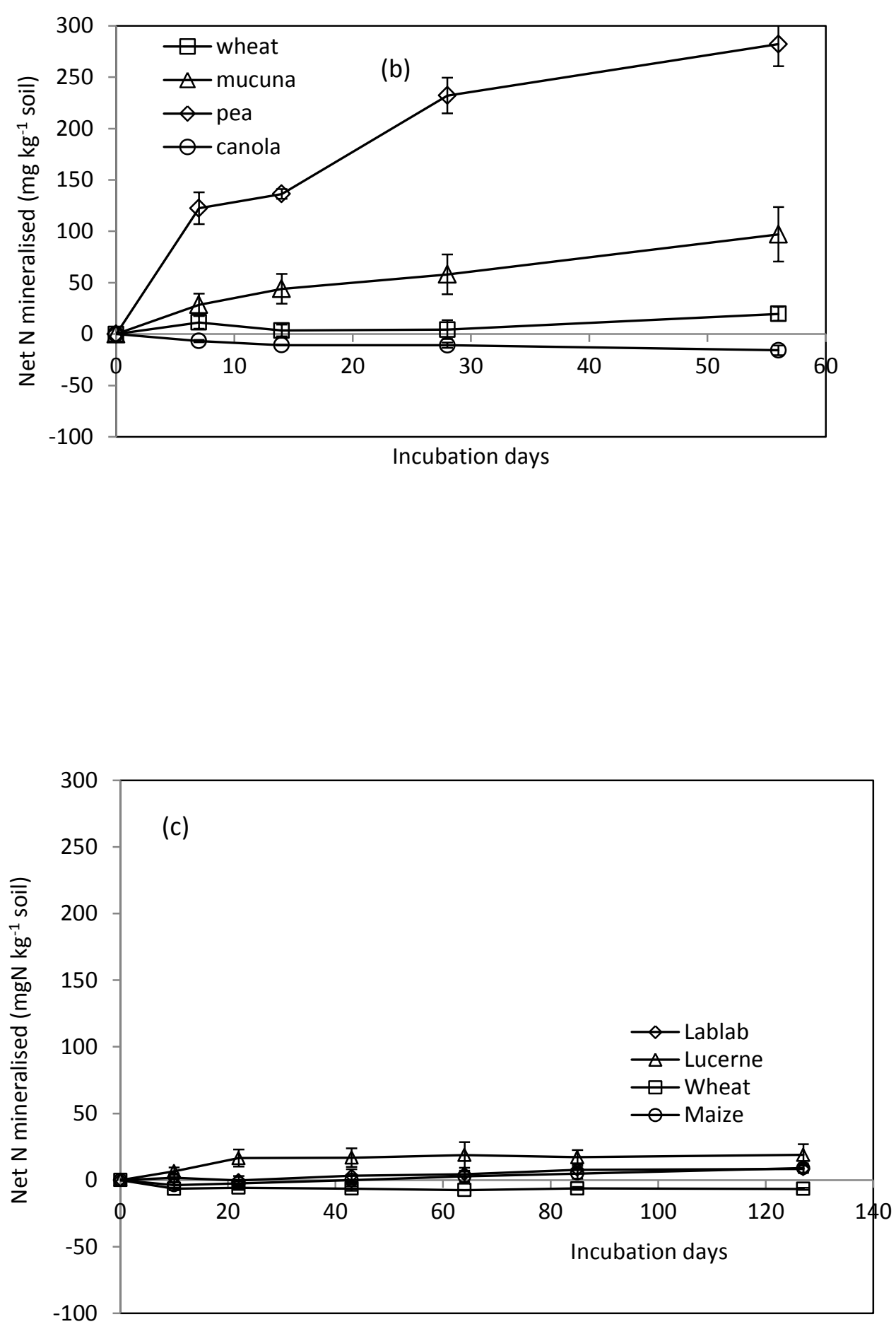

Figure 2.4. Net $\mathrm{N}$ mineralisation from only residues in clay (a), sand (b) and subsoil (c). The error bars represented the standard deviation of 4 different replications. 

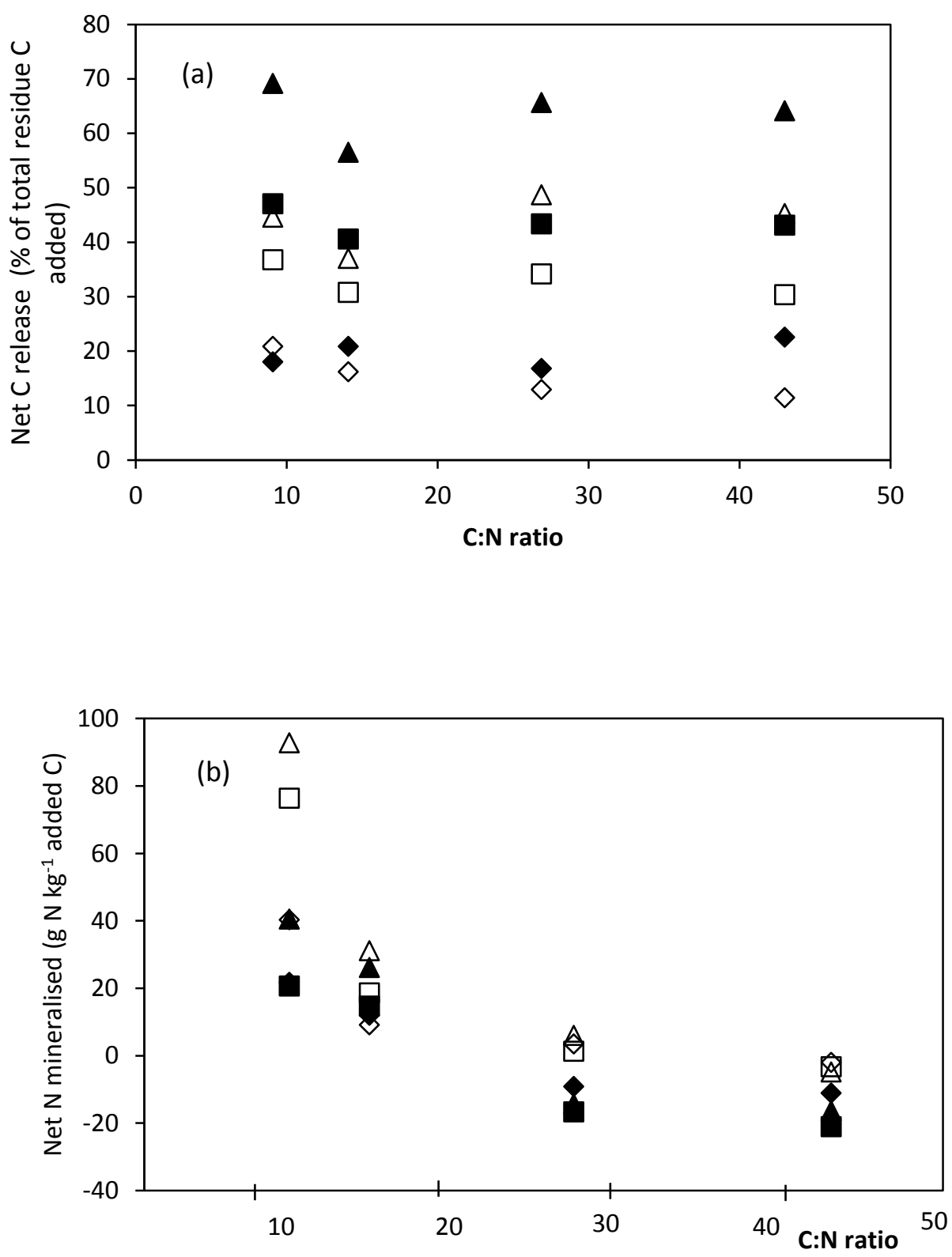

Figure 2.5. The relationship between overall $\mathrm{C}: \mathrm{N}$ ratio of residues and (a) net carbon mineralised (\% of total residue $\mathrm{C}$ added) and (b) net $\mathrm{N}$ mineralised ( $\mathrm{g} \mathrm{N} \mathrm{kg}^{-1}$ added $\mathrm{C}$ ) in clay

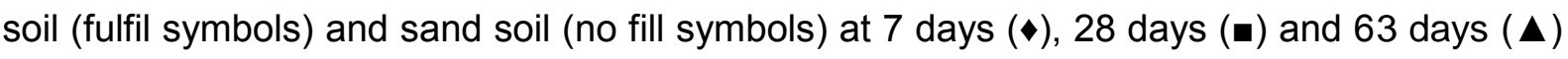
(for graph a and 56 days for graph b). Each point represented mean of 4 replications. 


\subsubsection{Carbon and nitrogen mineralisation from different residue application methods}

\section{a. Carbon mineralisation}

The effect of residue applications on carbon mineralisation was shown in Figure 2.6. In general, the $\mathrm{CO}_{2}-\mathrm{C}$ release from added residues was initially more rapid when placed on the surface rather than mixed with soil with exception of wheat. After 7 days, the amount of cumulative $\mathrm{CO}_{2}-\mathrm{C}$ emission from wheat was $956 \mathrm{mg} \mathrm{kg}^{-1}$ soil (approximately $29 \%$ of total C added) in incorporated treatment compared with $665 \mathrm{mg} \mathrm{kg}^{-1}$ soil (approximately $20 \%$ of total $C$ added) in mulched treatment which was a statistically significantly different $(p<0.05)$. For the residues mucuna and pea, cumulative $\mathrm{CO}_{2}-\mathrm{C}$ release was statistically higher at 14 and 21 days with surface application rather than with soil incorporation.

The effect of overall $\mathrm{C}: \mathrm{N}$ ratio of added residues on the release of $\mathrm{CO}_{2}-\mathrm{C}$ when using difference application was fluctuation. In particular, mucuna produced least $\mathrm{CO}_{2}-\mathrm{C}$ lost either placed on surface or mixed with soil after 21 days whereas the $\mathrm{CO}_{2}-\mathrm{C}$ release from wheat in mulched treatment was not significant difference compared with pea after 80 days to the end. Furthermore, when incorporated to soil, this figure from wheat was even statistical significant larger than from pea after 56 days of incubation. Before this time point, lower C:N ratio released significant larger amount of $\mathrm{CO}_{2}-\mathrm{C}$ emission.

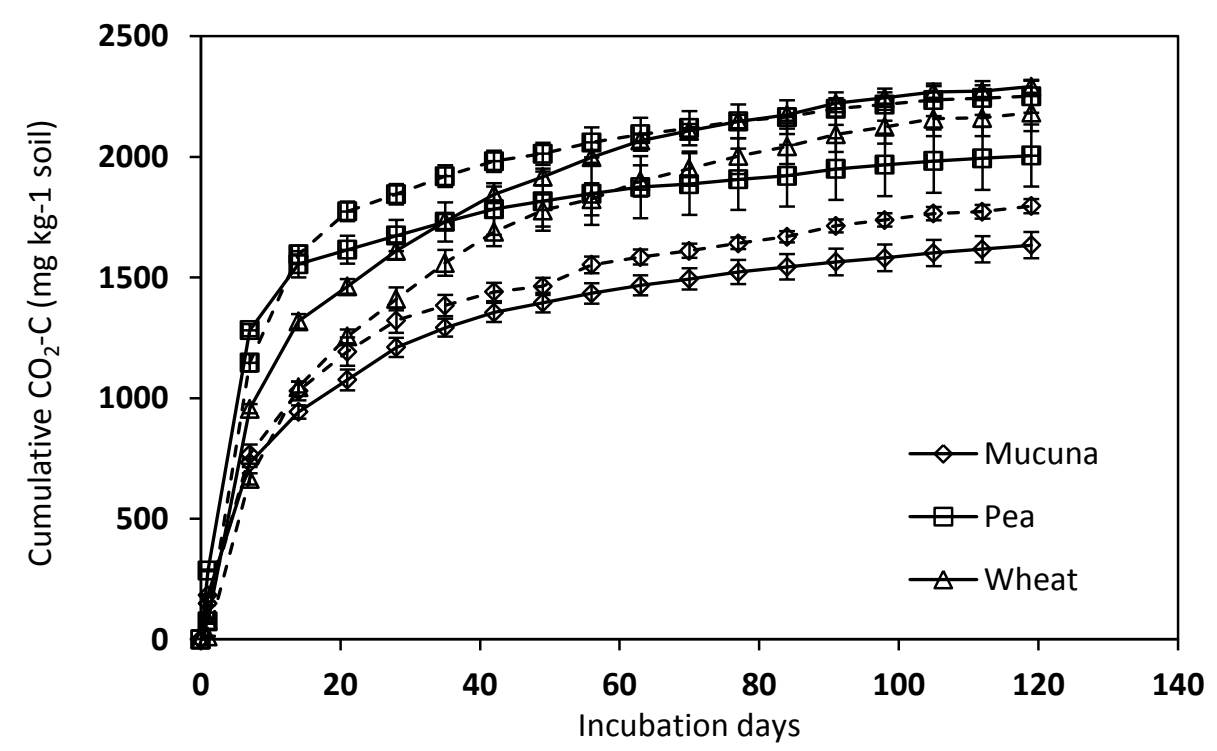

Figure 2.6. Cumulative $\mathrm{CO}_{2}-\mathrm{C}$ release from only residues in incorporated application (continuous line), and mulched application (dotted line). The error bars represented the standard deviation of 4 different replications. 


\section{b. Nitrogen mineralisation}

The net $\mathrm{N}$ mineralisation ranged from $40.7 \mathrm{mg} \mathrm{kg}^{-1}$ soil (wheat) to $299.6 \mathrm{mg} \mathrm{kg}^{-1}$ soil (pea) when incorporated to soil and ranged from $34.6 \mathrm{mg} \mathrm{kg}^{-1}$ soil (wheat) to $187.4 \mathrm{mg} \mathrm{kg}^{-1}$ soil (pea) in mulch treatment (Figure 2.7). In both residue applications, the net $\mathrm{N}$ mineralisation was the main trend for all residues from the first week of incubation.

In general, residue applications effected on the net $\mathrm{N}$ mineralisation depending on time of application and residue $\mathrm{C}: \mathrm{N}$ ratio. The net $\mathrm{N}$ mineralisation when placement on surface was statistical significant higher than mixed with soil in the $2^{\text {nd }}$ week in case of mucuna. Afterward, there was no significant difference of net $\mathrm{N}$ mineralised in any case of application in these residues. Nevertheless, it was inversion in pea in which no significant was found in the first two weeks. In the next week to the end, the net $\mathrm{N}$ mineralisation from incorporated treatment was much higher and statistical significant $(P$ value $<0.05)$.

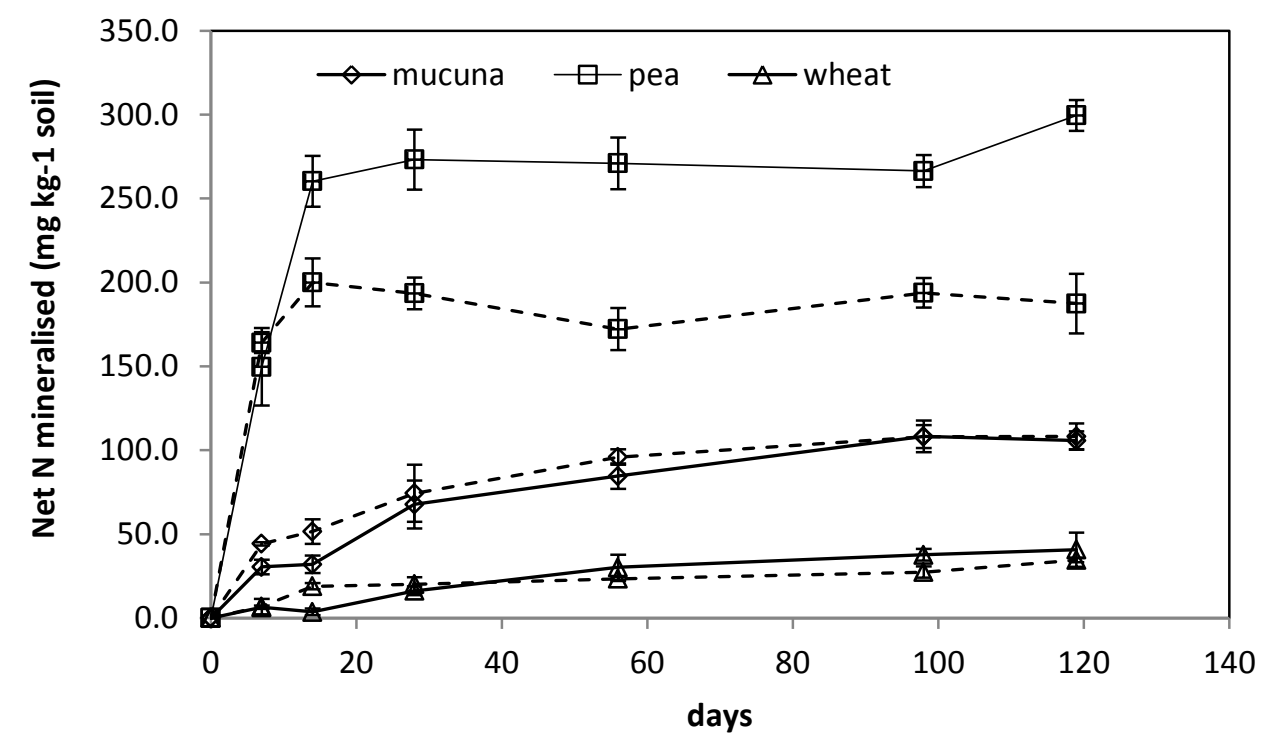

Figure 2.7. Net $\mathrm{N}$ mineralisation from only residues in incorporated application (continuous line), and mulched application (dotted line). The error bars represented the standard deviation of 4 different replications. 

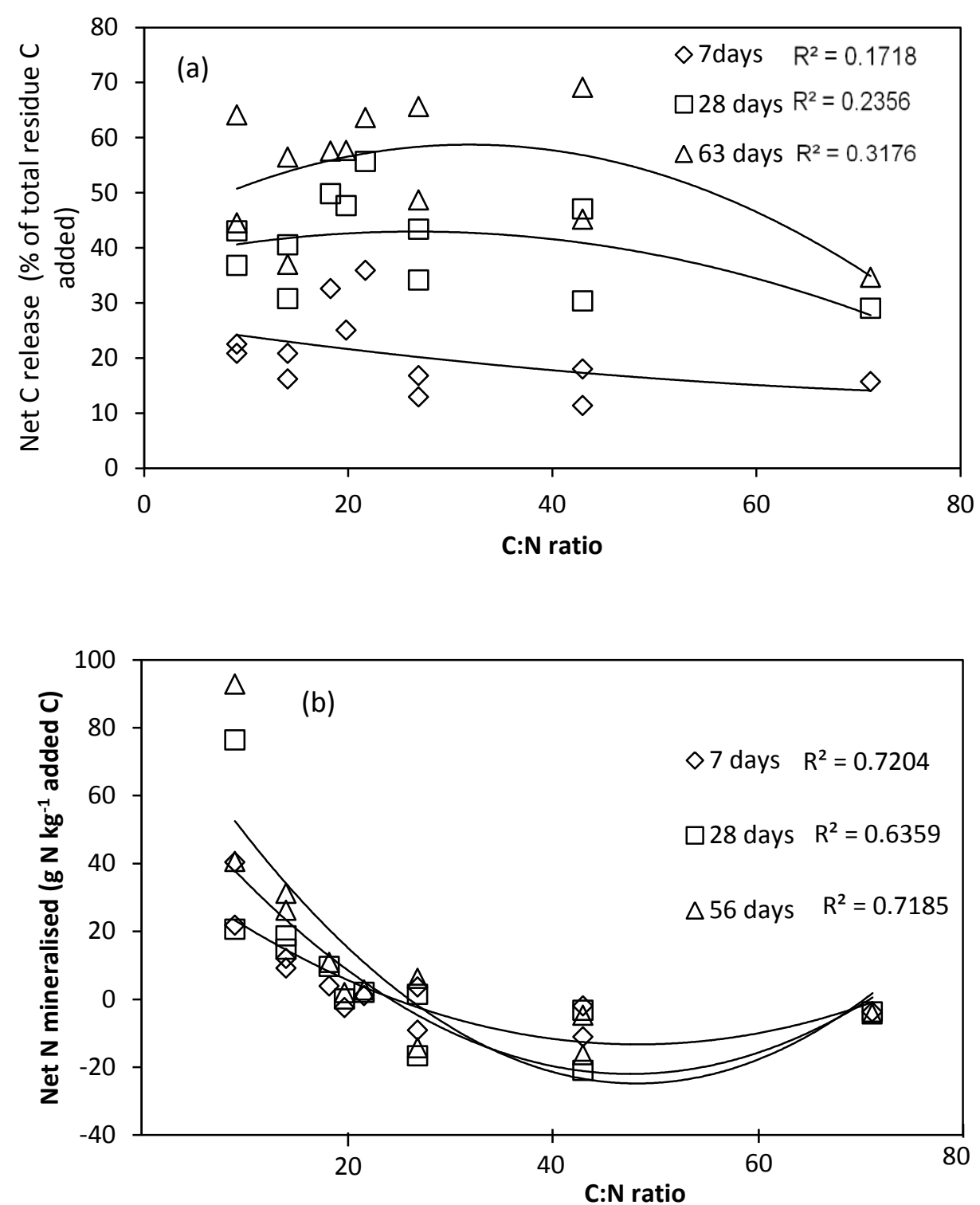

Figure 2.8. The relationship between overall $\mathrm{C}: \mathrm{N}$ ratio of residues and (a) net $\mathrm{C}$ release (\% of total residue $\mathrm{C}$ added) and (b) net $\mathrm{N}$ mineralised ( $\mathrm{g} \mathrm{N} \mathrm{kg}^{-1}$ added $\mathrm{C}$ ) of different residue materials at 7 days $(\diamond), 28$ days $(\square)$ and 63 days $(\Delta)$ 

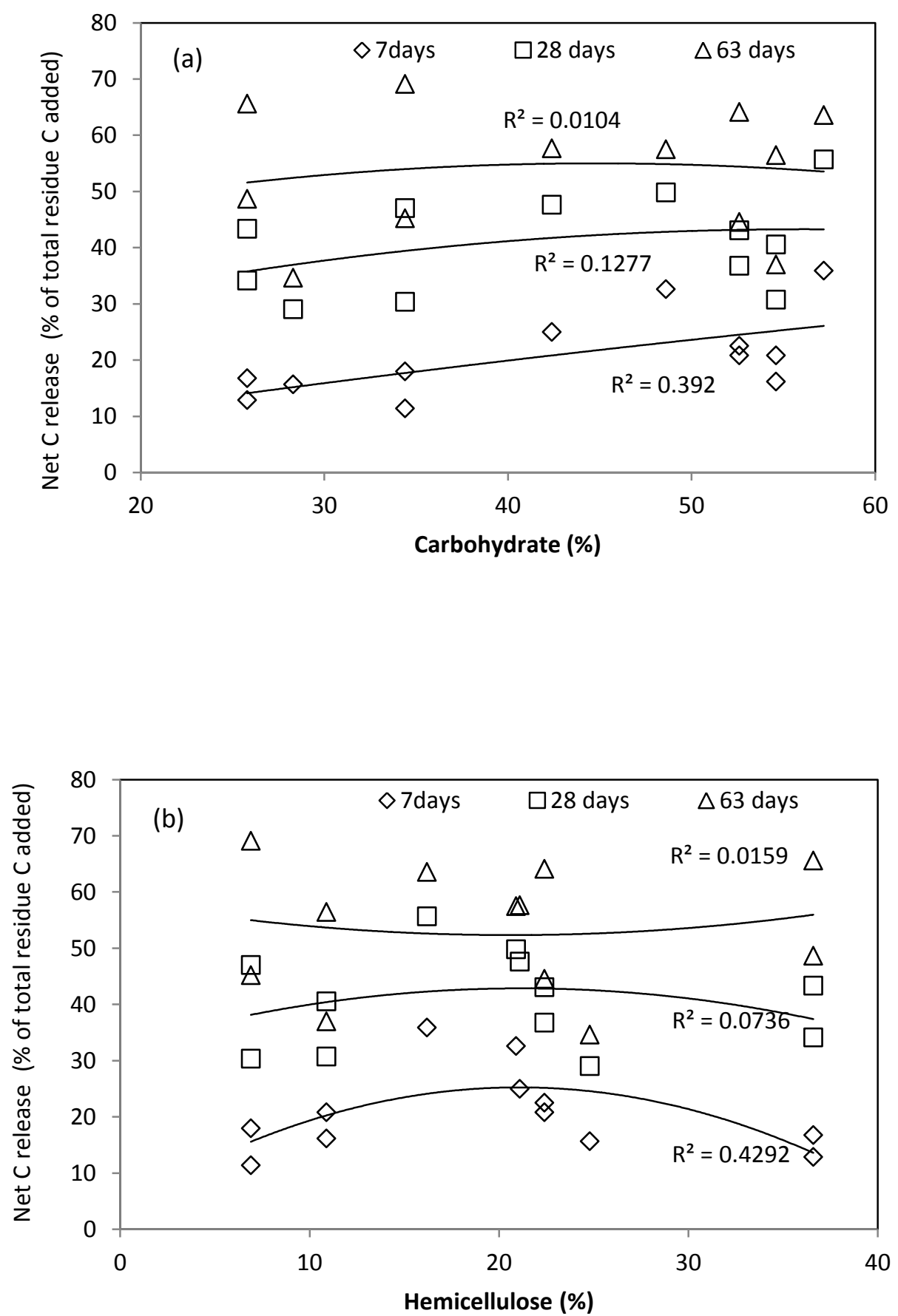

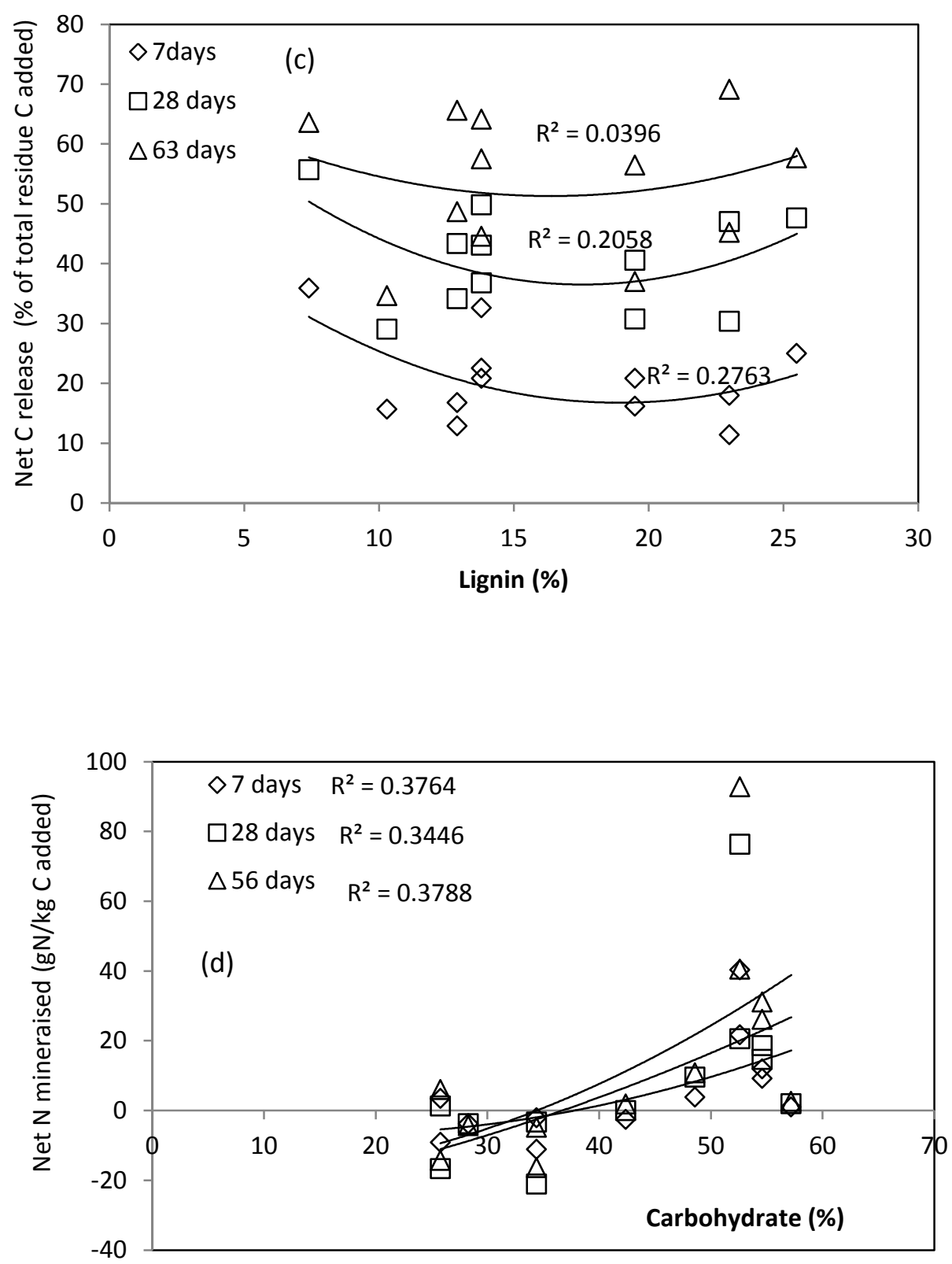

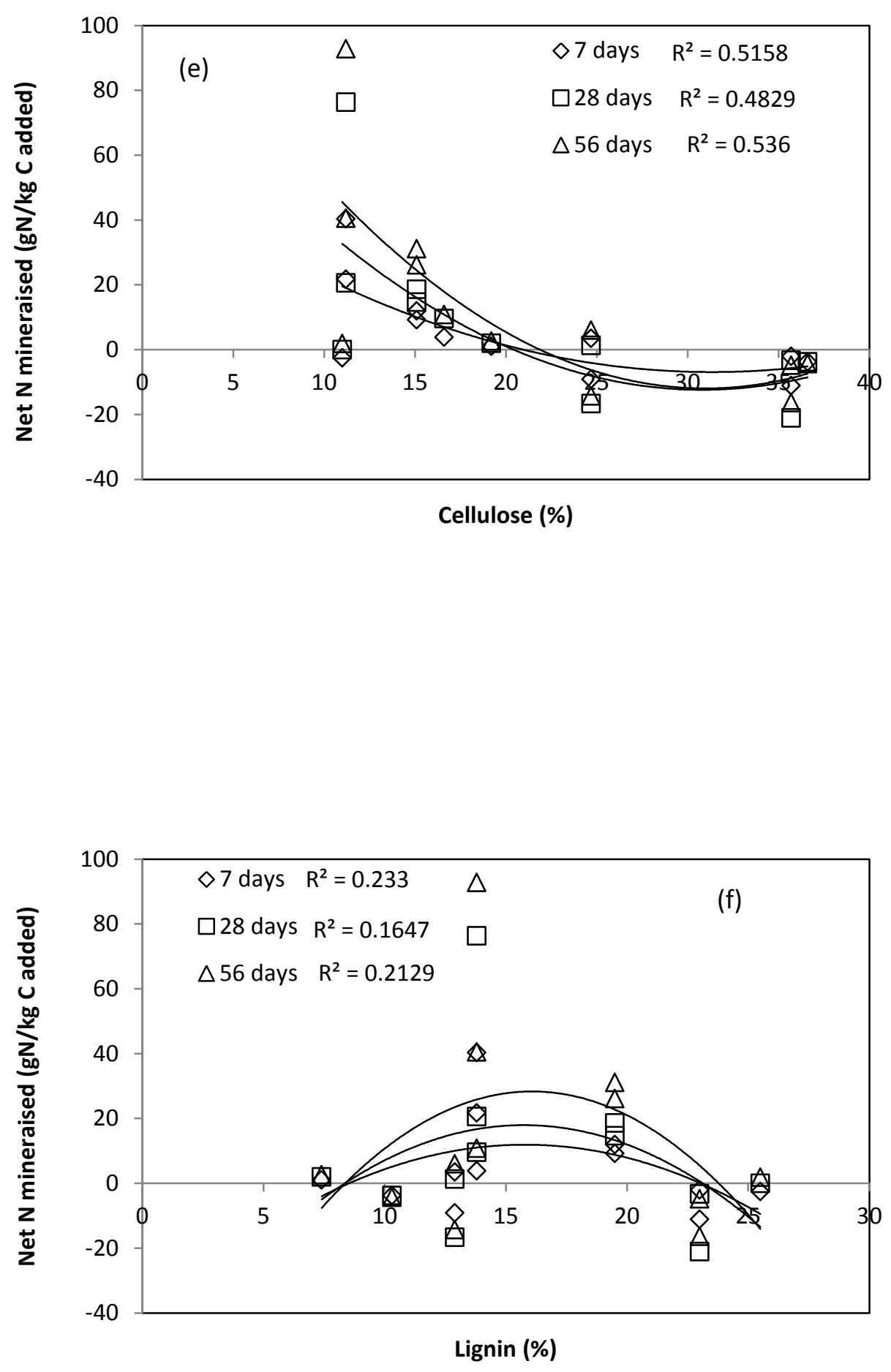

Figure 2.9. The relationship between different biochemical components and carbon mineralised (\%) $(\mathrm{a}, \mathrm{b}, \mathrm{c})$ and net $\mathrm{N}$ mineralised $\left(\mathrm{g} \mathrm{N} \mathrm{kg}^{-1}\right.$ added $\left.\mathrm{C}\right)(\mathrm{d}, \mathrm{e}, \mathrm{f})$ of different residue materials at 7 days $(\diamond), 28$ days $(\square)$ and 63 days $(\Delta)$. 


\subsection{Discussion}

\subsubsection{Biochemical quality of the residues}

As it is known that growth conditions, plant age or plant part composition have a marked impact on residue quality (Abiven et al., 2005; Parr and Papendick, 1978: Nicolardot et al., 2001), therefore it should be taken into account when comparing the observed residue quality with other reported values (Vanlauwe et al., 1996). In this research, the C:N ratio of wheat grown in subtropical climate (no. 3) was much lower than that grown in temperate seasonal climate (no.8) (Table 2.2). The reason led to this difference was the growth conditions, residue \#3 was grown and developed in glasshouse conditions whereas residue \#8 was grown and developed on field conditions. Huang et al. (2004) and Bending and Turner (1999) also showed a high C:N ratio of wheat in same growth condition.

Lignin content of all residues are considered intermediate to high according to Palm et al. (2001) and its value was almost higher than that usually observed in similar group (Muhammad et al., 2011; Kumar and Goh, 2003; Ibewiro et al., 2000; Adapa et al., 2009; Recous et al., 1995; Soon and Arshad, 2002). However, the $\mathrm{N}$ content did not show a similar trend. In legume group, published data shown a higher content of N (Ibewiro et al., 2000; Muhammad et al., 2011) with the exception of pea (Soon and Arshad, 2002; Kumar and Goh, 2003). Nevertheless, in cereal group like maize, wheat, canola, the $\mathrm{N}$ content was similar to other publish data (Martens, 2000; Soon and Arshad, 2002).

\subsubsection{Carbon and nitrogen mineralisation of added residues from different soil types}

\section{a. Carbon and nitrogen mineralisation from different soil types}

The $\mathrm{CO}_{2}$ evolution and $\mathrm{N}$ release from plant residues in different soil types used in this study varied depending on soil characteristics. In this study, the higher $\mathrm{C}$ mineralisation in clay soil than in the sand or sub-soils could be attributed to its higher organic $C$ content (Figure 5a). This is in agreement with observations by Martens (2000), Harrison-Kirk et al. (2013), Butterly et al. (2010). Martens (2000) found a simple regression between $\mathrm{CO}_{2}$ evolved from the treatments with or without residue and soil carbohydrate content. When maintaining at field capacity, the rate of $C$ mineralisation in soil increased with increases in soil organic carbon content (Harrison-Kirk et al., 2013).

Researching the effects of soil particle size on the dynamics of $C$, we found that sand soils were reported to release less $\mathrm{CO}_{2}$ than clay soils under incubations. In our study for example, the Alfisol had around $30 \%$ of sand particles but the amount of $\mathrm{CO}_{2}$ lost after 63 days of incubation was approximately 10 times higher than subsoil with mostly sand soil. These results contrast with those of previous studies. According to Parfitt and Salt (2001), the lowest proportion of $\mathrm{C}$ mineralised occurred in the silt fraction, and the greatest 
proportion occurred in the sand fraction. Thomsen et al. (2003) reported that the rate constants of $\mathrm{C}$ mineralisation for native and applied $\mathrm{C}$ were highest in the most sand soil. However, Hassink (1994) found that soil texture was not always the dominant factor determining the organic $C$ content of soils and $C$ mineralisation rates. A similar argument was also found in Gregorich et al. (1991). As with the $\mathrm{CO}_{2}-\mathrm{C}$ release, the microbial biomass $\mathrm{C}$ for clay soil was significantly higher that of the sand soil treatment (unpublished data). Differences in $\mathrm{C}$ mineralisation rates between different soil types could satisfactorily be explained by the differences in bacterial biomass (Hassink et al., 1994). Texture was important in controlling the rate of decomposition and turnover of $C$ through the microbial biomass during short periods. Soils with high clay content had low amounts of microbial products, suggesting that clay provides an environment for closer interaction between microorganisms and products of their decay and promotes the transfer of nutrients to succeeding generations of microorganisms (Gregorich et al., 1991). After 7 and 28 days of incubation, there was a slight difference of net $C$ mineralised in different soils but the difference became bigger afterwards (Figure 5a). Bending et al. (2002) reported that soil organic matter had little effect on mineralisation of $\mathrm{N}$ after 28 days, effects after 112 days were large for several materials. However, there was no observation on the effect of soil types on $\mathrm{C}$ mineralisation through time.

In the case of $\mathrm{N}$ mineralisation from different soil types, even though all soil types showed a net $\mathrm{N}$ mineralisation through time, the amount of net $\mathrm{N}$ mineralised from clay soil was much higher than in sand soil. This result was similar to the observation by Christensen and Olesen (1998) where net $\mathrm{N}$ mineralisation in size separates decreased in order: clay > silt > sand. Thomsen et al. (2003) also found that nitrification was lowest in the soil with most clay.

In the case of $\mathrm{N}$ mineralisation from crop residues, the effect of SOM content on this process depended on the nature of the residue incorporated, and the time of analysis (Bending et al., 2002). When applied residues, the results in our study were consistent with other studies (Parfitt and Salt, 2001; Izaurralde et al., 2006; Hansen et al., 1991). The net N mineralization/immobilization of added residues in sand soil was almost higher than in clay soil (Figure 5b). Parfitt and Salt (2001) showed a contrasty order of net N mineralisation as sand > clay > silt. Moreover, research on the $\mathrm{N}$ transformation from different ${ }^{15} \mathrm{~N}$-labelled crop residues Izaurralde et al. (2006) found that mineral $\mathrm{N}$ from sandy-loam was greater than in clay soil. Most research agreed that microbial activities in different soil texture affects significantly the mineralization/immobilization of nitrogen in soil-plant-atmosphere system (van Lieshout and Stoica, 2003; Parton et al., 1988). Microbial access to the residues in the sandy soil is usually higher than in clay soil because of binding by clay particles (Izaurralde et al., 2006) and this can affect the respiration of microbial community (Kirschbaum and Paul, 
2002) and therefore impact significantly on net $\mathrm{N}$ mineralization or denitrification (van Lieshout and Stoica, 2003; Kirschbaum and Paul, 2002).

\section{b. Carbon and nitrogen mineralisation from different residues types}

Decomposition and $\mathrm{N}$ release from plant residues used in this study vary over a wide range depending on their biochemical quality and the stage of decomposition. The greater increase in $\mathrm{CO}_{2}$ release and higher amount of net $\mathrm{N}$ mineralized following the lower $\mathrm{C}: \mathrm{N}$ ratio of plant residues application (such as pea residue) than other treatments (for instant, wheat \#8) is a good example to emphasize the effect of $\mathrm{C}: \mathrm{N}$ ratio on the breakdown of added residues. This result is consistent with previous observations (Muhammad et al., 2011; Powlson et al., 1996; Mueller et al., 1996; Trinsoutrot et al., 2000a; van Lieshout and Stoica, 2003). Even though both $\mathrm{C}$ and $\mathrm{N}$ release from residues relate to overall $\mathrm{C}: \mathrm{N}$ ratio, the relationship between overall C: $\mathrm{N}$ ratio and net $\mathrm{N}$ mineralized was much higher than that with the amount of $\mathrm{CO}_{2}$ release (Figure 2.8). In our study, the relationship between $\mathrm{CO}_{2}$ release and overall $\mathrm{C}: \mathrm{N}$ ratio became stronger in longer term (Figure 2.8a). This could be explained because of high correlation between percentage of $\mathrm{C}$ mineralization and stable components of residue such as cellulose and lignin (Figure 2.9b, c). Lignin is a constituent of crop residues that is resistant to decomposition by microorganisms (Parr and Papendick, 1978). When carried out the trials of 2 crop residues with contrasted biochemical and structural characteristics, Gaillard et al. (2003) reported the same proportion of $C$ mineralised due to having similar lignin content. In our experiment, as a legume crop with high $\mathrm{N}$ content and low $\mathrm{C}: \mathrm{N}$ ratio, mucuna was expected to have similar $\mathrm{CO}_{2}$ release with pea but in reality, mucuna released $\mathrm{CO}_{2}$ slower than pea. This could be attributed to higher lignin content of mucuna residues as also demonstrated by Konboon et al. 1996.

The net effect of added residues on the dynamics of soil mineral $\mathrm{N}$ was related mainly to the $\mathrm{C}: \mathrm{N}$ ratios of residues. This is agreement with other observations (Trinsoutrot et al., 2000b; Nicolardot et al., 2001). The net $\mathrm{N}$ mineralised from residues was significantly and negatively correlated with $\mathrm{CN}$ ratio of the residues (Figure 2.8b) and this result confirmed the work of Muhammad et al. (2011), Powlson et al. (1996), Mueller et al. (1996). In our study, all residues with a C:N ratio lower than 26.9 caused a net $\mathrm{N}$ mineralisation (with the exception of wheat \#3 in very low $\mathrm{N}$ mineral in soil). Several authors reported that residues with a $\mathrm{C}: \mathrm{N}$ ratio below 25 showed a net $\mathrm{N}$ mineralisation (Trinsoutrot et al., 2000b; Kumar and Goh, 1999). In earlier research, Fox et al. (1990) mentioned the impact of $\mathrm{N}$ concentration in plant on the dynamic of $\mathrm{N}$, the immobilisation occurred much more than mineralisation when $\mathrm{N}$ content less than $2 \%$ of total $\mathrm{N}$. Net $\mathrm{N}$ mineralisation occurred in the incubation where $\mathrm{N}$ content was higher than 1. 9\%. Therefore, the $\mathrm{C}: \mathrm{N}$ ratio and $\mathrm{N}$ content from added residues could be a good predictor of nitrogen dynamic in soils. 
In the early stages of decomposition, $\mathrm{N}$ release from the plant residues were correlated with the initial quality parameters as total $\mathrm{N}$ content, cellulose and the $\mathrm{C}: \mathrm{N}$ ratios. Unlike other research in which reported that lignin content was the most important in control the $\mathrm{N}$ mineralisation (Ibewiro et al., 2000; Fox et al., 1990; Vanlauwe et al., 1996), the lignin content in our studies showed a weak relationship with the net $\mathrm{N}$ mineralised (Figure 2.9f). Trinsoutrot et al. (2000a) also mentioned that some stable forms of residue $\mathrm{C}$ such as hemicelluloses, celluloses and lignin resulted slow decomposition in the beginning of application. The reason was that lignin was not the most important indicator of $\mathrm{N}$ mineralisation and microbial utilised it only slowly over the experiment. This could have led to the more readily degraded cellulose becoming the dominant residue derived $\mathrm{C}$ substrate used by the microbial community during the period of $\mathrm{N}$ mineralisation from the residues (Bending et al., 1998). This may explain why the relationship between celluloses content and net $\mathrm{N}$ mineralised became stronger after time of incubation (Figure 2.9f).

\section{c. Carbon and nitrogen mineralisation from different residues added methods}

In our study, the difference in C mineralisation between incorporated and mulched treatment depended on $\mathrm{C}: \mathrm{N}$ ratio and time of application. The significantly different was recognised in wheat residue after a week but it was delayed 1 week in mucuna and 2 weeks in pea. Cogle et al. (1987) reported that when incorporated wheat straw decomposed slightly more rapidly than surface straw during the first 5 months and this was consistent with our result in same residue. The increase of $\mathrm{CO}_{2}-\mathrm{C}$ release when incorporated into soil could be attributed to the closer contact with soil. This is in agreement with other observations (Powlson et al., 1996; Bosatta and Ågren, 1994). Nevertheless, the $\mathrm{CO}_{2}$ emissions from pea and mucuna after 2 weeks of incubation was greater when placed on the surface than mixed into the soil, especially in pea residue. Hasegawa et al. (1999) also reported similar result when testing with wheat litter $(\mathrm{C}: \mathrm{N}$ ratio $=19)$ or even though with higher $\mathrm{C}: \mathrm{N}$ ratio (Porter et al., 2010). Therefore, controlling condition in which moisture and temperature maintained as optimum, C from incorporated and surface placed residues was very similar (Powlson et al., 1996). Moreover, $\mathrm{N}$ content in plant always plays an important role either in different management practices or in different soil types in term of determining the decomposition processes.

The non-significant difference in mineral $\mathrm{N}$ with the application of wheat and mucuna after 4 months of incubation between different management practices could be due to the optimum moisture and temperature conditions of the environment. This was similar to the findings by Powlson et al. (1996) who reported that immobilisation of $\mathrm{N}$ occurred in incorporated and less change in mineral $\mathrm{N}$ with the surface placed of wheat, soybean and corn which had wide $\mathrm{C}: \mathrm{N}$ ratio. However Porter et al. (2010) reported that the cumulative mineral $\mathrm{N}$ for residues 
placed on the soil surface was higher than for residues incorporated into the soils where residues had C:N ratio higher than 25 and this totally contrasted with our result in pea (C:N ratio $=9.1$ ). The increased significant difference in net $\mathrm{N}$ mineralized with the incorporated than mulched in pea residue could be due to the direct contact of residues with the soil and $\mathrm{N}$ volatilisation of surface placed. This was supported by the results obtained by Chertov (1990) in which $\mathrm{N}$ increased more in incorporated than surface placed residues.

\subsection{Conclusion}

Decomposition processes of various added residues obtained from different climate conditions were related to soil type and to their biochemical quality. Soil organic carbon content and soil particle size play an important key in driving the dynamic of $\mathrm{C}$ and $\mathrm{N}$ of added in soil. A positive relationship between $\mathrm{C}: \mathrm{N}$ ratio and net $\mathrm{N}$ mineralization in this study could be used as an indicator to predict the pattern of $\mathrm{N}$ mineralisation. Residues with $\mathrm{C}: \mathrm{N}$ ratio lower than 27 may be lead to net $\mathrm{N}$ mineralisation. From results in this study we found that, placement residues on the surface of soil could enhance the decomposing processes, especially in low C:N residues. Furthermore, high correlation of determination between net $\mathrm{C}$ and $\mathrm{N}$ mineralization and stable components such as cellulose and lignin should take into account of in determining nutrient release patterns in low input systems. 


\subsection{References}

Abiven, S., Recous, S., Reyes, V., and Oliver, R., 'Mineralisation of C and N from root, stem and leaf residues in soil and role of their biochemical quality', Biology and Fertility of Soils, Vol. 42, No. 2, 2005.

Adapa, P., Tabil, L., and Schoenau, G., 'Compaction characteristics of barley, canola, oat and wheat straw', Biosystems Engineering, Vol. 104, No. 3, 2009.

AITA, C., Recous, S., and ANGERS, D. A., 'Short-term kinetics of residual wheat straw $\mathrm{C}$ and $\mathrm{N}$ under field conditions: characterization by ${ }^{13} \mathrm{C}^{15} \mathrm{~N}$ tracing and soil particle size fractionation', European Journal of Soil Science, Vol. 48, No. 2, 1997.

Anderson, T.-H., and Domsch, K. H., 'Carbon assimilation and microbial activity in soil', Zeitschrift für Pflanzenernährung und Bodenkunde, Vol. 149, No. 4, 1986.

Angers, D., and Recous, S., 'Decomposition of wheat straw and rye residues as affected by particle size', Plant and Soil, Vol. 189, No. 2, 1997.

Bending, G. D., and Turner, M. K., 'Interaction of biochemical quality and particle size of crop residues and its effect on the microbial biomass and nitrogen dynamics following incorporation into soil', Biology and Fertility of Soils, Vol. 29, No. 3, 1999.

Bending, G. D., Turner, M. K., and Burns, I. G., 'Fate of nitrogen from crop residues as affected by biochemical quality and the microbial biomass', Soil Biology and Biochemistry, Vol. 30, No. 14, 1998.

Bending, G. D., Turner, M. K., and Jones, J. E., 'Interactions between crop residue and soil organic matter quality and the functional diversity of soil microbial communities', Soil Biology and Biochemistry, Vol. 34, No. 8, 2002.

Birch, H. F., 'Mineralisation of plant nitrogen following alternate wet and dry conditions', Plant and Soil, Vol. 20, No. 1, 1964.

Blanco-Canqui, H., and Lal, R., 'Crop Residue Removal Impacts on Soil Productivity and Environmental Quality', Critical Reviews in Plant Sciences, Vol. 28, No. 3, 2009.

Bosatta, E., and Ågren, G. I., 'Theoretical analysis of microbial biomass dynamics in soils', Soil Biology and Biochemistry, Vol. 26, No. 1, 1994.

Butterly, C., Marschner, P., McNeill, A., and Baldock, J., 'Rewetting CO2 pulses in Australian agricultural soils and the influence of soil properties', Biology and Fertility of Soils, Vol. 46, No. 7, 2010.

Chertov, O. G., 'Specom - a single tree model of pine stand/raw humus soil ecosystem', Ecological Modelling, Vol. 50, 1-3, 1990.

Christensen, B. T., and Olesen, J. E., 'Nitrogen mineralization potential of organomineral size separates from soils with annual straw incorporation', European Journal of Soil Science, Vol. 49, No. 1, 1998.

Cogle, A. L., Strong, W. M., Saffigna, P. G., Ladd, J. N., and Amato, M., 'Wheat straw decomposition in subtropical Australia .II. Effect of straw placement on decomposition and recovery of added 15 N urea', Australian Journal of Soil Research, Vol. 25, No. 4, 1987.

Constantinides, M., and Fownes, J. H., 'Nitrogen mineralization from leaves and litter of tropical plants: Relationship to nitrogen, lignin and soluble polyphenol concentrations', Soil Biology and Biochemistry, Vol. 26, No. 1, 1994.

Cookson, W. R., Cornforth, I. S., and Rowarth, J. S., 'Winter soil temperature (2-15\&\#xa0; $\left.{ }^{\circ} \mathrm{C}\right)$ effects on nitrogen transformations in clover green manure amended or unamended soils; a laboratory and field study', Soil Biology and Biochemistry, Vol. 34, No. 10, 2002.

Coppens, F., Garnier, P., Findeling, A., Merckx, R., and Recous, S., 'Decomposition of mulched versus incorporated crop residues: Modelling with PASTIS clarifies interactions between residue quality and location', Soil Biology and Biochemistry, Vol. 39, No. 9, 2007. 
Fox, R. H., Myers, R. J. K., and Vallis, I., 'The nitrogen mineralization rate of legume residues in soil as influenced by their polyphenol, lignin, and nitrogen contents', Plant and Soil, Vol. 129, No. 2, 1990.

Gaillard, V., Chenu, C., and Recous, S., 'Carbon mineralisation in soil adjacent to plant residues of contrasting biochemical quality', Soil Biology and Biochemistry, Vol. 35, No. 1, 2003.

Gilmour, C. M., and Gilmour, J. T., 'Assimilation of carbon by the soil biomass', Plant and Soil, Vol. 86, No. 1, 1985.

Gregorich, E. G., Voroney, R. P., and Kachanoski, R. G., 'Turnover of carbon through the microbial biomass in soils with different texture', Soil Biology and Biochemistry, Vol. 23, No. 8, 1991.

Hansen, S., Jensen, H. E., Nielsen, N. E., and Svendsen, H., 'Simulation of nitrogen dynamics and biomass production in winter wheat using the Danish simulation model DAISY', Fertilizer Research, Vol. 27, 2-3, 1991.

Harrison-Kirk, T., Beare, M. H., Meenken, E. D., and Condron, L. M., 'Soil organic matter and texture affect responses to dry/wet cycles: Effects on carbon dioxide and nitrous oxide emissions', Soil Biology and Biochemistry, Vol. 57, No. 0, 2013.

Hasegawa, H., Labavitch, J. M., McGuire, A. M., Bryant, D. C., and Denison, R. F., 'Testing CERES model predictions of $\mathrm{N}$ release from legume cover crop residue', Field Crops Research, Vol. 63, No. 3, 1999.

Hassink, J., 'Effects of soil texture and structure on carbon and nitrogen mineralization in grassland soils', Biology and Fertility of Soils, Vol. 14, No. 2, 1992.

Hassink, J., 'Effects of soil texture and grassland management on soil organic $\mathrm{C}$ and $\mathrm{N}$ and rates of $\mathrm{C}$ and N mineralization', Soil Biology and Biochemistry, Vol. 26, No. 9, 1994.

Hassink, J., Neutel, A. M., and ruiter, P. C. de, 'C and N mineralization in sandy and loamy grassland soils: The role of microbes and microfauna', Soil Biology and Biochemistry, Vol. 26, No. 11, 1994.

Huang, Y., Zou, J., Zheng, X., Wang, Y., and Xu, X., 'Nitrous oxide emissions as influenced by amendment of plant residues with different C:N ratios', Soil Biology and Biochemistry, Vol. 36, No. 6, 2004.

Ibewiro, B., Sanginga, N., Vanlauwe, B., and Merckx, R., 'Nitrogen contributions from decomposing cover crop residues to maize in a tropical derived savanna', Nutrient Cycling in Agroecosystems, Vol. 57, No. 2, 2000.

Izaurralde, R. C., Williams, J. R., McGill, W. B., Rosenberg, N. J., and Jakas, M. C. Q., 'Simulating soil C dynamics with EPIC: Model description and testing against long-term data', Ecological Modelling, Vol. 192, 3-4, 2006.

Janzen, H. H., and Kucey, R. M. N., 'C, N, and S mineralization of crop residues as influenced by crop species and nutrient regime', Plant and Soil, Vol. 106, No. 1, 1988.

Khalil, M. I., Hossain, M. B., and Schmidhalter, U., 'Carbon and nitrogen mineralization in different upland soils of the subtropics treated with organic materials', Soil Biology and Biochemistry, Vol. 37, No. 8, 2005.

Khalil, M. I., Rahman, M. S., Schmidhalter, U., and Olfs, H.-W., 'Nitrogen fertilizer-induced mineralization of soil organic $\mathrm{C}$ and $\mathrm{N}$ in six contrasting soils of Bangladesh', Journal of Plant Nutrition and Soil Science, Vol. 170, No. 2, 2007.

Kirschbaum, M. U. F., and Paul, K. I., 'Modelling C and N dynamics in forest soils with a modified version of the CENTURY model', Soil Biology and Biochemistry, Vol. 34, No. 3, 2002.

Kumar, K., and Goh, K. M., 'Crop Residues and Management Practices: Effects on Soil Quality, Soil Nitrogen Dynamics, Crop Yield, and Nitrogen Recovery', in Donald L. Sparks (ed.), Advances in Agronomy, Academic Press, 1999.

Kumar, K., and Goh, K. M., 'Nitrogen Release from Crop Residues and Organic Amendments as Affected by Biochemical Composition', Communications in Soil Science and Plant Analysis, Vol. 34, 17-18, 2003.

Li, C., Frolking, S., and Frolking, T. A., 'A model of nitrous oxide evolution from soil driven by rainfall events: 1. Model structure and sensitivity', Journal of Geophysical Research: Atmospheres, Vol. 97, D9, 1992. 
Martens, D. A., 'Plant residue biochemistry regulates soil carbon cycling and carbon sequestration', Soil Biology and Biochemistry, Vol. 32, No. 3, 2000.

Mary, B., Recous, S., Darwis, D., and Robin, D., 'Interactions between decomposition of plant residues and nitrogen cycling in soil', Plant and Soil, Vol. 181, No. 1, 1996.

Matejovic, I., 'Determination of carbon and nitrogen in samples of various soils by the dry combustion', Communications in Soil Science and Plant Analysis, Vol. 28, 17-18, 1997.

Mueller, T., Jensen, L. S., Hansen, S., and Nielsen, N. E., 'Simulating soil carbon and nitrogen dynamics with the soil-plant-atmosphere system model DAISY', in D. Powlson, P. Smith and J. Smith (eds.), Evaluation of Soil Organic Matter Models, Springer Berlin Heidelberg, 1996.

Muhammad, W., Vaughan, S., Dalal, R., and Menzies, N., 'Crop residues and fertilizer nitrogen influence residue decomposition and nitrous oxide emission from a Vertisol', Biology and Fertility of Soils, Vol. 47, No. 1, 2011.

Müller, T., Magid, J., Jensen, L. S., and Nielsen, N. E., 'Decomposition of plant residues of different quality in soil-DAISY model calibration and simulation based on experimental data', Ecological Modelling, Vol. 166, 1-2, 2003.

NICOLARDOT, B., Recous, S., and Mary, B., 'Simulation of C and N mineralisation during crop residue decomposition: A simple dynamic model based on the $\mathrm{C}: \mathrm{N}$ ratio of the residues', Plant and Soil, Vol. 228, No. 1, 2001.

Palm, C. A., and Sanchez, P. A., 'Nitrogen release from the leaves of some tropical legumes as affected by their lignin and polyphenolic contents', Soil Biology and Biochemistry, Vol. 23, No. 1, 1991.

Palm, C. A., Gachengo, C. N., Delve, R. J., Cadisch, G., and Giller, K. E., 'Organic inputs for soil fertility management in tropical agroecosystems: application of an organic resource database', Agriculture, Ecosystems \& Environment, Vol. 83, 1-2, 2001.

Parfitt, R. L., and Salt, G. J., 'Carbon and nitrogen mineralisation in sand, silt, and clay fractions of soils under maize and pasture', Australian Journal of Soil Research, Vol. 39, No. 2, 2001.

Parr, J. F., and Papendick, R. I., 'Factors Affecting the Decomposition of Crop Residues by Microorganisms', Crop Residue Management Systems, asaspecialpubli, cropresiduemana, 1978.

Parton, W. J., Stewart, J. W. B., and Cole, C. V., 'Dynamics of C, N, P and S in grassland soils: a model', Biogeochemistry, Vol. 5, No. 1, 1988.

Pezeshki, S. R., DeLaune, R. D., and Meeder, J. F., 'Carbon assimilation and biomass partitioning in Avicennia germinans and Rhizophora mangle seedlings in response to soil redox conditions', Environmental and Experimental Botany, Vol. 37, 2-3, 1997.

Porter, C., Jones, J. W., Adiku, S., Gijsman, A. J., Gargiulo, O., and Naab, J. B., 'Modeling organic carbon and carbon-mediated soil processes in DSSAT v4.5', Operational Research, Vol. 10, No. 3, 2010.

Powlson, D., 'Why evaluate soil organic matter models?', in D. Powlson, P. Smith and J. Smith (eds.), Evaluation of Soil Organic Matter Models, Springer Berlin Heidelberg, 1996.

Powlson, D., Smith, P., and Smith, J. (eds.), Evaluation of Soil Organic Matter Models, Springer Berlin Heidelberg, 1996.

Qian, P., and Schoenau, J. J., 'Availability of nitrogen in solid manure amendments with different C:N ratios', Can. J. Soil. Sci, Vol. 82, No. 2, 2002.

Recous, S., Robin, D., Darwis, D., and Mary, B., 'Soil inorganic $\mathrm{N}$ availability: Effect on maize residue decomposition', Soil Biology and Biochemistry, Vol. 27, No. 12, 1995.

Soon, Y., and Arshad, M., 'Comparison of the decomposition and $\mathrm{N}$ and $\mathrm{P}$ mineralization of canola, pea and wheat residues', Biology and Fertility of Soils, Vol. 36, No. 1, 2002.

Thomsen, I. K., Schjønning, P., Olesen, J. E., and Christensen, B. T., ' $\mathrm{C}$ and $\mathrm{N}$ turnover in structurally intact soils of different texture', Soil Biology and Biochemistry, Vol. 35, No. 6, 2003.

Tian, G., Kang, B. T., and Brussaard, L., 'Biological effects of plant residues with contrasting chemical compositions under humid tropical conditions-Decomposition and nutrient release', Soil Biology and Biochemistry, Vol. 24, No. 10, 1992. 
Trinsoutrot, I., Recous, S., Bentz, B., Line`res, M., Che`neby, D., and NICOLARDOT, B., 'Biochemical Quality of Crop Residues and Carbon and Nitrogen Mineralization Kinetics under Nonlimiting Nitrogen Conditions', Soil Sci. Soc. Am. J, Vol. 64, No. 3, 2000a.

Trinsoutrot, I., Recous, S., Mary, B., and NICOLARDOT, B., 'C and N fluxes of decomposing ${ }^{13} \mathrm{C}$ and ${ }^{15} \mathrm{~N}$ Brassica napus L.: effects of residue composition and $\mathrm{N}$ content', Soil Biology and Biochemistry, Vol. 32, 11-12, 2000b.

van Lieshout, M. N. M., and Stoica, R. S., 'The Candy model: properties and inference', Statistica Neerlandica, Vol. 57, No. 2, 2003.

van Soest, P. J., 'Development of a Comprehensive System of Feed Analyses and its Application to Forages', Journal of Animal Science, Vol. 26, No. 1, 1967.

van Soest, P. J., Robertson, J. B., and Lewis, B. A., 'Methods for Dietary Fiber, Neutral Detergent Fiber, and Nonstarch Polysaccharides in Relation to Animal Nutrition', Journal of Dairy Science, Vol. 74, No. 10, 1991.

Vanlauwe, B., Nwoke, O. C., Sanginga, N., and Merckx, R., 'Impact of residue quality on the C and N mineralization of leaf and root residues of three agroforestry species', Plant and Soil, Vol. 183, No. 2, 1996.

Whitbread, A. M., Blair, G. J., and Lefroy, R. D. B., 'Managing legume leys, residues and fertilisers to enhance the sustainability of wheat cropping systems in Australia: 1 . The effects on wheat yields and nutrient balances', Soil and Tillage Research, Vol. 54, 1-2, 2000a.

Whitbread, A. M., Blair, G. J., and Lefroy, R. D. B., 'Managing legume leys, residues and fertilisers to enhance the sustainability of wheat cropping systems in Australia: 2 . Soil physical fertility and carbon', Soil and Tillage Research, Vol. 54, 1-2, 2000b.

Whitbread, A. M., Lefroy, R. D. B., and Blair, G. J., 'A survey of the impact of cropping on soil physical and chemical properties in north-western New South Wales', Australian Journal of Soil Research, Vol. 36, No. 4, 1998. 


\section{Chapter 3. Modelling carbon and nitrogen mineralisation from diverse plant residues in incubation studies}

\subsection{Introduction}

In low input farming systems where inputs are often limited, it is difficult to explain the interaction between the factors (e.g. temperature, soil moisture, litter quality) that drive nutrient release without the help of a model (Stöckle et al., 2003; Jones et al., 2003; Brisson et al., 2003; Hasegawa et al., 2000; Keating et al., 2003; Nendel et al., 2011). Such soil processes play an important role in the supply of nutrients for plant growth as well as influencing soil structural properties and soil biodiversity (Powlson et al., 1996b; BlancoCanqui and Lal, 2009). Using simulation models to predict the mineralisation of carbon and nitrogen from various residue applications has been mentioned widely using models such as APSIM (Mohanty et al., 2011; Probert et al., 2005; Whitbread et al., 2010; Whitbread and Clem, 2006; Huth et al., 2010; Meier et al., 2006; Probert et al., 1998), CENTURY (Falloon and Smith, 2002; Kirschbaum and Paul, 2002), STICS (Justes et al., 2009), DSSAT (Gijsman et al., 2002), CERES (Hasegawa et al., 1999; Godwin, 1991), NCSOIL (Molina, 1996; Nicolardot et al., 1994; Nicolardot and Molina, 1994), DNDC (Li, 1996; Li et al., 1992), CANDY (van Ittersum et al., 2003; Franko, 1996), DAISY (Hansen et al., 1991), PASTIS (Oorts et al., 2007; Garnier et al., 2003). Because some processes occur in soils over long time periods (e.g. changes in organic carbon content or soil structure for example), soil organic matter models are an essential tool and are the only possible way of extrapolating from current knowledge in both time and space (Powlson, 1996). For low input farming systems, the wide range of input materials (crop residues, leaf litters, manures) used as nutrient sources bring new challenges for modelling (Probert and Dimes, 2004). Although these models are able to adequately describe the release of carbon and nitrogen from residues where decomposition pattern is closely related to C:N ratio, however there have been limited attempts to model the decomposition pattern of diverse plant residues and connection to plant growth modelling. Some outstanding soil organic matter (SOM) models 
focus only on the transformations of $\mathrm{C}$ and $\mathrm{N}$ in soils such as NCSOIL (Molina, 1996; Molina et al., 1983), QSOIL (Powlson et al., 1996a; Bosatta and Ågren, 1994), RothC (Falloon and Smith, 2002) or CANDY (Franko et al., 1995). Others have been developed for specific regions: DAISY is adapted to the wet temperate climate of North Western Europe (Hansen et al., 1991;Mueller et al., 1996); CENTURY, DNDC were developed with data from temperate regions and were not applicable for all cropping systems (Parton et al., 1988; Li et al., 1994) or SOMM in SPECOM (Chertov, 1990) developed for forested ecosystems. The Agricultural Production Systems Simulator (APSIM) (Keating et al., 2003; Holzworth et al. 2014) is a modular modelling framework that has been developed by APSRU (Agricultural Production Systems Research Unit) in Australia. APSIM is internationally recognised as an advanced simulator of agricultural systems and has been widely applied in different regions and in response of cropping systems to climate and different management strategies (Asseng et al., 2000; Mohanty et al., 2012; Asseng et al., 2004; Robertson et al., 2005; Anwar et al., 2009; Carberry et al., 2002; Probert and Dimes, 2004; Gaydon et al., 2012). APSIM version 7.5 (http://www.apsim.info/AboutUs.aspx) is now be able to simulate 27 different crops with various management strategies from crop rotation, irrigation, fertilisation, organic application, and climate variability. Model users can then edit in a wide range of scenarios based on their purposes.

The SOILN module in APSIM simulates the decomposition processes of soil organic matter and the $\mathrm{N}$ supply available to a crop from the soil and residues/roots added from previous crops (Probert et al., 1998). The framework of SOILN model is generally similar to what is found in other soil organic matter models - i.e. conceptual pools representing $C$ fractions of varying sizes and potential decomposition rates. This framework has been tested successfully in different climate conditions of various organic materials and soil types. In the semi-arid tropics, APSIM is well suited to simulate the soil $\mathrm{N}$ supply in legume based rotational pasture crop system and perennial grass system (Whitbread and Clem, 2006). In a study by Nascimento et al. (2011), after calibration in potential decomposition rate (k) in SOILN, the model was able to estimate the decomposition and $\mathrm{N}$ mineralisation rates of 
some plant organic residues over 1 year. When compared with the performance of the established CENTURY model, Probert ME (1995) showed that APSIM was adequate for simulating the mineralisation of $\mathrm{N}$ and the decline in soil organic matter through time during individual fallows. Its performance also resulted accurately in long term of a diverse range of farming systems (from different tillage managements, nitrogen applications) (Probert et al., 1998) or in different soil types of aerobic incubations (Meier et al., 2006). By adjusting the denitrification rate coefficient and $\mathrm{CN}$ ratios in soil organic matter pools, Huth et al. (2010) found that APSIM adequately described the decline in soil $C$ and $N$ in the first $10 \mathrm{~cm}$ soil layer after clearing of a forest and subsequent cropping. By using a default value of SOILN, the performance of model worked well in some crop residue applications (tropical legumes, Lablab purpureus) (Whitbread and Clem, 2006) or in different soil types (Meier et al., 2006) or in farmers' residue management practices with cereal crops, cowpea and groundnut (MacCarthy et al., 2009).

In the majority of these studies, the decomposition process, as represented by soil organic $\mathrm{C}$ and mineral $\mathrm{N}$ dynamics, has been well simulated by parameterizing residue inputs based on $\mathrm{C}$ and $\mathrm{N}$ content $(\mathrm{C}: \mathrm{N}$ ratio) and following the standard soil parameterization/initialization routines (Nicolardot et al., 2001). However, in the case where plant residues or manures are added and decomposition pattern is strongly influenced by factors in addition to $\mathrm{C}: \mathrm{N}$ ratio (e.g secondary metabolites, leaf structure/composition) decomposition pattern is not well simulated. As suggested in several studies, the quantity and quality of crop residues will clearly influence the build-up of soil organic matter and the subsequent availability and timing of release of nutrients to following crops (Jarvis et al., 1996; Janzen and Kucey, 1988). Trinsoutrot et al. (2000b) reported that the initial rate of C mineralisation was strongly dependent upon the amounts of soluble C initially present in the residues. Moreover, Constantinides and Fownes (1994) also mentioned that initial N concentration strongly correlated with $\mathrm{N}$ accumulation at all time periods of 16 week incubation from different tropical plants. Tian et al. (1992) and Palm and Sanchez (1991) showed that decomposition rate constants of plant residues were correlated with $\mathrm{C}: \mathrm{N}$ ratio, lignin and polyphenols 
content. In order to evaluate model performance in such cases Probert et al. (2005) and Mohanty et al. (2011) modified SOILN to allow the distribution of carbon and the C:N ratios of three pools which constitute added organic matter to vary, the revised model was then better able to represent the nitrogen mineralisation from various materials.

The main objective of this paper is therefore to measure and model the decomposition process observed from the laboratory incubation of residues representing highly diverse qualities and decomposition dynamics as represented by mineral $\mathrm{N}$ and the $\mathrm{CO}_{2}$ release. The dataset of $\mathrm{C}$ and $\mathrm{N}$ mineralisation from residues was collected in various individual incubation treatments having C:N ratios from 9.1 to 148.40 and was used to: (1) evaluate the performance of original SOILN model (Probert et al., 1998); and (2) improve the model parameterization and assess the comprehensive decomposition model of $\mathrm{C}$ and $\mathrm{N}$ mineralisation in short term. A sensitivity analysis for driven model parameters was also tested for evaluation the impact of those parameters on the residue decomposition.

\subsection{Materials and Methods}

\subsubsection{Description of the APSIM SoilN module}

Within the APSIM framework, SOILN is a core module which simulates the transformations of carbon and nitrogen in soil organic matter (Probert et al., 1998; Keating et al., 2003) (Figure 3.1). Its development from original Probert et al. (1998) to modified versions Probert et al. (2005) reflects greater demands for application.

Similar to other soil organic matter models, SOILN is divided into pools based on potential decomposition rate (Figure 3.1). In general, residues (including from crops, leaf litters, roots or manures) added to the soil are designated as the fresh organic matter (FOM) pool. Consistent with the original model (CERES-N), the FOM pool comprises of three sub-pools (FPOOLS) in the proportions 0.2:0.7:0.1 with a potential decomposition rate constant of each FPOOL reflecting its turnover. (FPOOL1) has the fastest turnover $\left(r=0.02\right.$ day $\left.^{-1}\right)$ and represents the fraction of residue inputs that are the most labile and biochemically similar to carbohydrate compounds. FPOOL2 component of cellulose/hemicellulose are in sub-pool2 
(FPOOL2) and of lignin is in sub-pool3 (FPOOL3). Decomposition rate constant of the FPOOL2 was of 0.05 day $^{-1}$ and its value in FPOOL3 was 0.0095 day $^{-1}$ and these values were kept unchanged under non-limiting temperature and moisture condition. Decomposition of FOM results in the formation of soil organic carbon comprising of pools representing soil microbial biomass (BIOM) and humus (HUM). The BIOM pool is notionally the most labile organic C pool representing soil microbial biomass, and thus has a higher rate of turnover than the bulk of the soil organic matter even though it make up a relatively small part of the total soil organic matter. The HUM pool consists of stable organic matter and it will transfer into passive pool (INERT pool) after years of decomposing. The decomposition rate of BIOM and HUM was 0.0081 and 0.00015 day $^{-1}$ respectively. The dynamics of soil organic matter is simulated by first order reaction kinetics in all soil layers, with each pool having a different turnover time ranging from days to weeks for biomass to hundreds of years for passive organic matter.

Decomposition of any soil organic matter pools represents in evolution of carbon dioxide to the atmosphere and transfers of carbon to other pools (Probert et al., 1998). These flows are defined as the efficiency coefficient (ef) which indicates the proportion of carbon retained in the system and the fraction of the retained carbon synthesized into the biom pool (fr).

\subsubsection{Process for initialising SOILN to simulate diverse residues}

In the incubation studies where environmental conditions can be controlled, we assume that soil water and soil temperature has no effect on residue decomposition and it was set up as optimum condition. Using the modified model, we would like to improve prediction of carbon and nitrogen release from different soil types of diverse crop residues during close-chamber system, new parameterizations procedure was carried out as following steps:

(1) Using the tillage function as incorporated in the first day of simulation, all surface organic matter (SurfaceOM) was directly transferred to FOM. The SOILN module in APSIM version 7.5 (http://www.apsim.info/AboutUs.aspx) was used to simulate in this study. Additionally, because these incubations were carried out in closed system, the effect of leaching and denitrification was eliminated. 
(2) For the unamended soil, a fitting procedure was used to minimize the difference between predicted and measured values of individual control treatments. The proportion of $\mathrm{C}$ in $\mathrm{BIOM}$ and the proportion of inert carbon in soil were based on common values used in other simulations (Probert et al., 1998) (see. Appendix) and kept unchanged during the simulation. The C:N ratio and root weight in soil was fixed in each soil and corresponds to the usually measured in similar soil texture and OC (\%) content. The parameters (fraction of biomass $\mathrm{C}$ mineralized retained in system (ef_biom), fraction of humus $\mathrm{C}$ mineralized retained in system (ef_hum), and fraction of retained biomass C returned to biomass (fr_biom_biom) were optimized simultaneously. All parameters then were assumed as constants during the incubation.

(3) For simulations where residues are applied, parameterisation of FOM was applied. The fraction of FOM C mineralized retained in system (ef_fom) can be directly calculated by equation (1) and (3) (see. Appendix). The fraction of retained FOM C transferred to biomass (fr_fom_biom) could be verified after testing sensitivity analysis of available dataset from residues in both $\mathrm{C}$ and $\mathrm{N}$ mineralisation. The pool size of FOM, consisting of 3 FPOOLs representing carbohydrate, cellulose/hemicellulose and lignin -like pools, can be measured in laboratory by Van Soest method (van Soest et al., 1991) and maintain during the processes. FPOOL1 based on measured C as water soluble components, proportion of $\mathrm{C}$ in FPOOL3 based on measured ADL (Acid detergent lignin). FPOOL2 based on the different between neutral detergent fibre and ADL. Changing the pool sizes alone could not alter whether a source exhibits initial net $\mathrm{N}$ mineralisation or immobilization as it was determined by the C:N ratios of the substrate (Probert et al. 2005). Therefore the distribution of $N$ in 3 FPOOLs need to be modified.. The decomposition rates of the three FPOOLs were adopted from default version of APSIM (0.2, 0.05 and 0.0095 day $^{-1}$, respectively under non-limiting temperature and moisture conditions). 


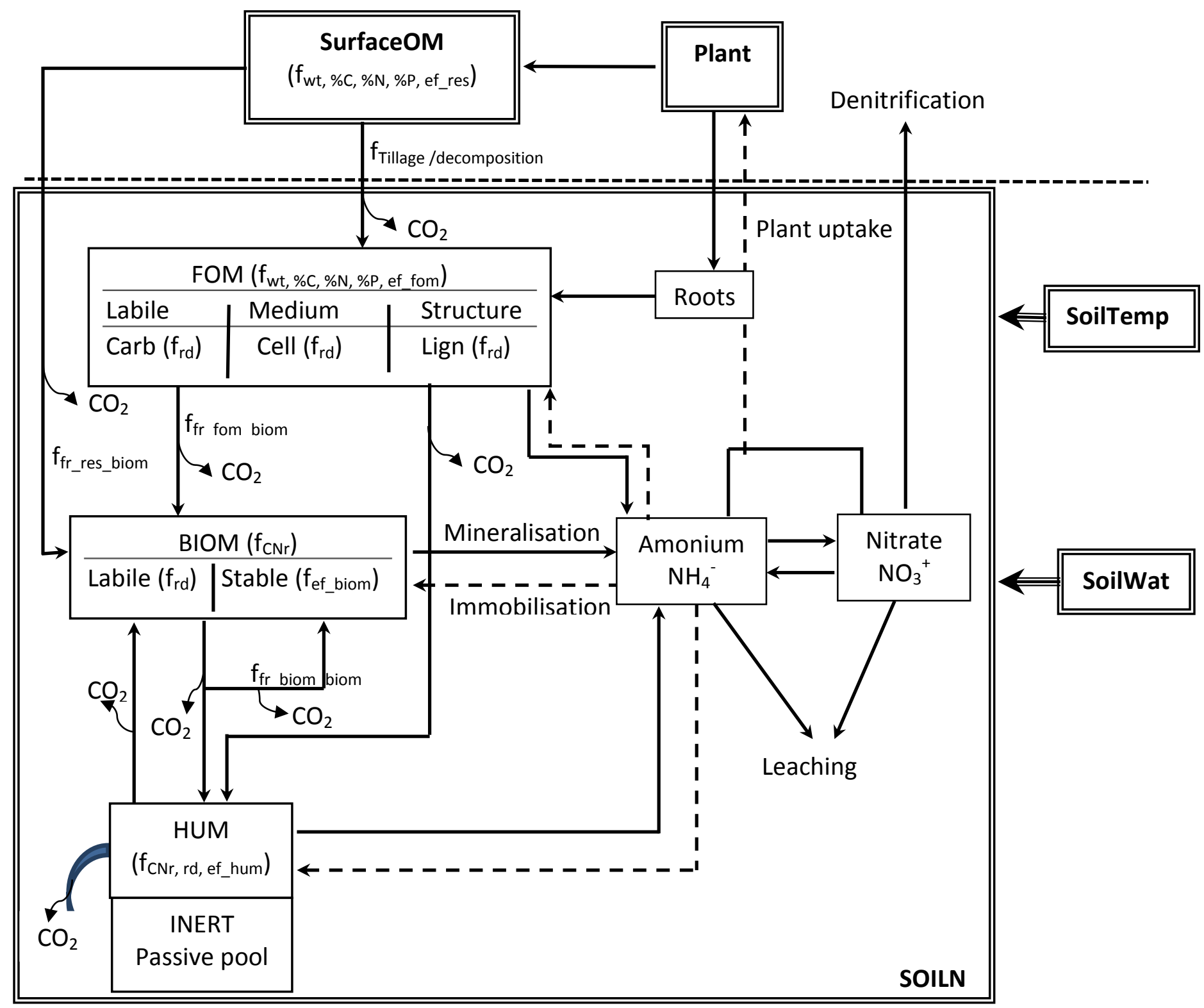

Figure 3.1 The framework of SOILN in relationship with other essential modules in APSIM. Double line box represents different modules in APSIM; $f_{i}$ is the function of factor $i$. Source: redrawn based on diagrams in Probert et al. (1998) 
(4) The performance of model was then evaluated by using an independent dataset from 3 individually different incubation trials. In this study we run the model in different scenarios based on changing FPOOLs.

- Scenario 1: Represent the results from default model in which FPOOL size was set as $0.2: 0.7: 0.1$ and $\mathrm{C}: \mathrm{N}$ ratio in each FPOOLs was similar to overall $\mathrm{C}: \mathrm{N}$ ratio of applied residues.

- Scenario 2: The distribution of carbon in FPOOLs was modified based on lab measurement but $\mathrm{C}: \mathrm{N}$ ratio in FPOOLs was equal to overall $\mathrm{C}: \mathrm{N}$ ratio of applied residues.

- Scenario 3: The FPOOLs size was set up as in scenario 2 but C:N ratio in each FPOOLs were set to enable the best fit of simulated and measured decomposition rate.

\subsubsection{Experimental data used for model performance}

To validate and evaluate the performance of the modified model in predicting changes of soil organic carbon and soil nitrogen mineralisation/immobilization, three different datasets of various residue biochemical quality (Table 3.1) and soil types from different incubation treatments were used (Table 3.2). All these treatments were carried out at controlled temperature and moisture conditions using aerobic soil.

Incubation 1 (unpublished data): Two laboratory incubation experiments were carried out in order to evaluate the impact of varying factors on $\mathrm{CO}_{2}$ and $\mathrm{N}$ mineralisation. A cultivated soil from South Australia were collected from the surface layer $(0-10 \mathrm{~cm})$, air-dried and sieved through a $2 \mathrm{~mm}$ mesh to remove roots and other debris. The other from Germany was collected from a subsoil $(20-40 \mathrm{~cm})$ and prepared the same way. Eight crop residues were considered in this study. They differ either in the plant species, the plant organs or the growth stage at which they were sampled. They were all dried at $40^{\circ} \mathrm{C}$ and chopped to $2-5 \mathrm{~cm}$ lengths. After pre-incubation, the water holding capacity was brought to $60 \%$ to $75 \%$ and carried out between 2 to 4 months of incubation. 
Incubation 2 (BN2000): This incubation trial based on data obtained from Trinsoutrot et al., (2000a) was carried out under non-limiting $N$ to evaluate the effects of biochemical characteristics of residues on kinetics of $\mathrm{C}$ and $\mathrm{N}$ mineralisation in a wide range of soil types and main arable crops of temperate regions (Trinsoutrot et al., 2000a). The residues were dried at $80^{\circ} \mathrm{C}$ and then incorporated into soil at an equivalent of $2 \mathrm{~g}$ residue $\mathrm{kg}^{-1}$ soil to $4 \mathrm{~g}$ residue $\mathrm{kg}^{-1}$ soil depending on residue type. Nitrogen fertilizer was added from 30 to $60 \mathrm{mg}$ $\mathrm{NO}_{3}^{-}-\mathrm{N} \mathrm{kg}^{-1}$ dry soil depending on the inorganic $\mathrm{N}$ concentration present in the soil and on the amount of added $\mathrm{C}$ to ensure that decomposition would not be limited by $\mathrm{N}$. The incubation temperature was from $12^{\circ} \mathrm{C}$ to $15^{\circ} \mathrm{C}$ based on treatments over 150 days.

Incubation 3 (BV96): This incubation trial was carried out at Ibadan, Nigeria in 56 days with 3 plant residues labeled by ${ }^{15} \mathrm{~N}$ in order to find out the impact of residue quality on the $\mathrm{C}$ and $\mathrm{N}$ mineralisation of leaf and root residues at $25^{\circ} \mathrm{C}$ by Vanlauwe et al. (1996). The residues were dried at $65^{\circ} \mathrm{C}$ and mixed with the soil to equivalent $2.827 \mathrm{~g}$ dry matter $\mathrm{kg}^{-1}$ dry soil. After 3,7 , 14, 28 and 56 days of incubation, soil samples were taken and analysed for $\mathrm{C}$ and $\mathrm{N}$. 
Table 3.1. Chemical properties of residues used in this study

\begin{tabular}{|c|c|c|c|c|c|c|c|c|c|c|}
\hline \multirow{2}{*}{ Crop residue } & \multirow{2}{*}{ Code } & \multirow{2}{*}{$\begin{array}{c}\text { Total } \\
\text { C } \\
(\%)\end{array}$} & \multirow{2}{*}{$\begin{array}{c}\text { Total } \\
\mathrm{N} \\
\text { (\%) }\end{array}$} & \multirow{2}{*}{$\begin{array}{c}\text { Overall } \\
\mathrm{C}: \mathrm{N}\end{array}$} & \multicolumn{3}{|c|}{ Fraction of carbon in FPOOLs } & \multicolumn{3}{|c|}{ C:N of FPOOLs* } \\
\hline & & & & & Pool $1^{a}$ & Pool $2^{b}$ & Pool $3^{c}$ & Pool 1 & Pool 2 & Pool 3 \\
\hline Lablab leaves & 1 & 41.3 & 1.9 & 21.9 & 57.2 & 35.4 & 7.4 & 28.1 & 45.4 & 4.0 \\
\hline Lucerne & 2 & 37.7 & 1.9 & 18.4 & 48.6 & 37.6 & 13.8 & 29.8 & 14.9 & 11.0 \\
\hline Maize leaves & 3 & 42.7 & 0.6 & 20.1 & 42.4 & 32.1 & 25.5 & 37.6 & 20.1 & 11.4 \\
\hline Mucuna & 4 & 41.0 & 2.9 & 14.1 & 54.6 & 26.0 & 19.4 & 9.5 & 19.3 & 45.9 \\
\hline Pea & 5 & 40.0 & 4.4 & 9.1 & 52.6 & 33.6 & 13.8 & 14.5 & 5.9 & 9.1 \\
\hline Canola & 6 & 43.0 & 1.0 & 43.0 & 34.4 & 42.6 & 23.0 & 43.0 & 42.9 & 43.1 \\
\hline Wheat08 & 7 & 43.0 & 1.6 & 26.9 & 25.8 & 61.3 & 12.9 & 42.2 & 26.4 & 15.0 \\
\hline Leucaena leaves & 8 & 37.4 & 2.9 & 12.9 & 78.6 & 13.0 & 8.4 & 26.2 & 5.0 & 5.5 \\
\hline Leucaena roots & 9 & 35.6 & 2.0 & 18.0 & 55.2 & 33.7 & 11.1 & 57.1 & 16.6 & 4.1 \\
\hline Dactyladenia leaves & 10 & 41.7 & 1.4 & 29.8 & 76.1 & 6.4 & 17.5 & 23.5 & 19.8 & 108.3 \\
\hline Dactyladenia roots & 11 & 42.9 & 1.0 & 41.7 & 49.9 & 19.5 & 30.6 & 20.8 & 51.1 & 333.1 \\
\hline Flemingia leaves & 12 & 39.6 & 2.6 & 15.1 & 70.5 & 20.9 & 8.6 & 11.8 & 25.8 & 47.6 \\
\hline Flemingia roots & 13 & 36.1 & 2.7 & 13.5 & 90.1 & 3.4 & 6.5 & 17.2 & 4.3 & 13.3 \\
\hline Rape seed stems & 14 & 46.2 & 0.33 & 140.0 & 26.6 & 60.6 & 12.8 & 549.8 & 422.7 & 19.2 \\
\hline Rape seed wall pods & 15 & 42.8 & 0.38 & 112.6 & 37.9 & 53.1 & 9.0 & 618.2 & 313.1 & 11.4 \\
\hline Rape seed leaves & 16 & 35.3 & 1.97 & 17.9 & 79.1 & 18.9 & 2.0 & 29.1 & 9.0 & 37.2 \\
\hline Rape seed stems & 17 & 43.7 & 0.39 & 112.4 & 31.3 & 59.1 & 9.6 & 141.1 & 84.5 & 97.6 \\
\hline Rape seed wall pods & 18 & 43.5 & 0.29 & 148.4 & 43.3 & 51.9 & 4.8 & 180.7 & 97.5 & 104.4 \\
\hline Rape seed leaves & 19 & 31.9 & 2.02 & 15.8 & 56.7 & 21.3 & 22.0 & 9.5 & 105.3 & 245.7 \\
\hline Rape seed & 20 & 43.4 & 0.44 & 98.9 & 35.5 & 56.8 & 7.7 & 381.2 & 65.4 & 51.1 \\
\hline
\end{tabular}

${ }^{\mathrm{a} C}$ Caculated as: $100-\mathrm{b}-\mathrm{c} ;{ }^{\mathrm{b}}$ Caculated as: \%Neutral detergent fibre (NDF) - \% Acid detergent lignin (ADL); ${ }^{\circ}$ Caculated as \%ADL + \% polyphenol. *: The $\mathrm{C}: \mathrm{N}$ ratio of each FPOOLs was taken from the best scenarios in which the model predicted best fit of decomposition as indicated by measured $\mathrm{CO}_{2}-\mathrm{C}$ release and nitrogen mineralisation (scenario 3). In scenario 1 and 2 in which the fraction of nitrogen was equal to fraction of carbon, the C:N ratio of each FPOOLs was similar to overall C:N ratio. 
Table 3.2. Soil characteristics and soil organic matter (0-10 cm layer).

\begin{tabular}{|c|c|c|c|c|c|c|c|c|c|}
\hline $\begin{array}{c}\text { Soil } \\
\text { type }\end{array}$ & $\begin{array}{c}\text { OC } \\
(\%)\end{array}$ & $\begin{array}{c}\text { C:N } \\
\text { ratio }\end{array}$ & $\begin{array}{c}\mathrm{N} \text { min } \\
\left(\mathrm{mg} \mathrm{kg}^{-1} \text { soil) }\right.\end{array}$ & $\begin{array}{c}\text { Fbiom } \\
(0-1)\end{array}$ & $\begin{array}{c}\text { Finert } \\
(0-1)\end{array}$ & $\begin{array}{c}\text { BiomC } \\
\left(\mathrm{kg} \mathrm{ha}^{-1}\right)\end{array}$ & $\begin{array}{c}\text { HumC } \\
\left(\mathrm{kg} \mathrm{ha}^{-1}\right)\end{array}$ & $\begin{array}{c}\text { InertC } \\
\left(\mathrm{kg} \mathrm{ha}^{-1}\right)\end{array}$ & Source \\
\hline 1 & 0.22 & 18.9 & 6.6 & 0.02 & 0.8 & 8.6 & 431.3 & 1760 & $\begin{array}{c}\text { Unpublished } \\
\text { data (NTH12) }\end{array}$ \\
\hline 2 & 2.3 & 12.1 & 29.9 & 0.035 & 0.4 & 466.7 & 13333 & 9200 & $\begin{array}{c}\text { Unpublished } \\
\text { data (NTH12) }\end{array}$ \\
\hline 3 & 1.81 & 10.6 & 55.8 & 0.04 & 0.4 & 417.7 & 10442.3 & 7240 & $\begin{array}{c}\text { Trinsoutrot et } \\
\text { al., (2000a) } \\
\text { (BN2000) }\end{array}$ \\
\hline 4 & 1.54 & 11 & 85 & 0.04 & 0.4 & 355.4 & 8884.6 & 6160 & $\begin{array}{c}\text { Vanlauwe et al., } \\
\text { (1996) (BV96) }\end{array}$ \\
\hline
\end{tabular}

\subsubsection{Carbon and nitrogen analysis and calculated SOILN}

The total $\mathrm{C}$ and $\mathrm{N}$ concentration of the crop residues were determined by using an elemental analyser. The ADF, NDF, and NDL were then determined based on van Soest et al. (1991) method. All experimental datasets determined $\mathrm{CO}_{2}$ release using a $\mathrm{NaOH}$ trap (concentrations of $2 \mathrm{~N}$ in BV96, $0.25 \mathrm{M}$ in BN2000, $0.4 \mathrm{M}$ in NTH12) to capture the $\mathrm{CO}_{2}$ gas released in the chamber and then titrated by $\mathrm{HCl}$.

The amount of simulated $C$ release was calculated as the sum of $C$ release from the FOM, BIOM and HUM pools. The decomposition speed of each pool depends on various conditions from biochemical component (affected by decomposition rate), fraction of carbon and nitrogen in each pool, and environment conditions (temperature and moisture) (see Appendix).

The soil samples were extracted by $\mathrm{KCl}$ and then analysed for $\mathrm{NH}_{4}{ }^{+}-\mathrm{N}$ and $\mathrm{NO}_{3}{ }^{-}-\mathrm{N}$ by using methods (A Skalar continuous flow analyser (IITA, 1982) in BV96, centrifugation (20 min at $5800 \mathrm{~g}$ ) in BN2000, or using stretophometer in $\mathrm{NTH12}$ ). Net $\mathrm{N}$ mineralisation during the incubation processes was calculated as follows:

Mineral $\mathrm{N}\left(\mathrm{mg} \mathrm{kg}^{-1}\right.$ soil $)=\mathrm{NH}_{4}{ }^{+}-\mathrm{N}+\mathrm{NO}_{3}^{-}-\mathrm{N}$

Net $\mathrm{N}$ mineralization from organic residues $\left(\mathrm{mg} \mathrm{kg}^{-1}\right.$ soil) $=$ mineral $\mathrm{N}$ in the treatment mineral $\mathrm{N}$ in control 


\subsubsection{Model evaluation}

The performance of APSIM simulation for prediction of $\mathrm{C}$ and $\mathrm{N}$ mineralisation from crop residues was evaluated by using commonly statistical methods (Smith et al., 1996) as follows:

Root mean square error (RMSE):

$$
\operatorname{RMSE}=\sqrt{\sum_{i=1}^{n}\left(\frac{(P i-O i)^{2}}{n}\right)}
$$

Mean difference (MD):

$\mathrm{MD}=\frac{1}{n}\left[\sum_{i=1}^{n}(O i-P i)\right]$

Modelling efficiency $(\mathrm{EF}): \quad \mathrm{EF}=1-\left[\frac{\sum_{i=1}^{n}(P i-O i)^{2}}{\sum_{i=1}^{n}(O i-\bar{O})^{2}}\right]$

Where $\mathrm{Pi}=$ predicted value, $\mathrm{Oi}=$ observed value, $\bar{O}=$ mean of the observed values, $\mathrm{n}=$ number of observation. The prediction of $\mathrm{C}$ and $\mathrm{N}$ release with $\mathrm{EF} \geq 0.7$ was consider to be a good prediction, and prediction with $0 \leq \mathrm{EF}<0.7$ was consider satisfactory, prediction with EF $<0$ was consider unsatisfactory.

\subsection{Result}

\subsubsection{Model parameterization}

In previous studies, parameters related to the flows of carbon during the decomposition (define can be found in Table 3.3a) in SOILN were assumed as a constant and used for several simulations. However, in specific situation, each of these parameters needed to be considered to get better simulation in realistic. In the absence of added residues where soil organic matter dominants the decomposition processes in soil, the fitting procedure firstly was applied in individual for 3 parameters (ef_biom, ef_hum and fr_biom_biom). A sensitivity analysis was also carried out with these parameters by added/subtracted $10 \%$ by default values to investigate which changes in the mode parameters affected the simulation results the most. In general, the fraction of biomass C mineralized retained in the system (ef_biom) profoundly affects the decomposition of soil organic matter and its value varied over a wide 
range from 0.35 to 0.7 whereas ef_hum and fr_biom-biom only slightly affected these processes. Therefore, to minimize the fitting procedure, both parameters remained at the default values. Moreover, without surface residue, the parameter of the proportion of carbon from residue in surface retained in the system (ef_res) and the fraction of the carbon retained in residue transferred to biomass (fr_res_biom) was eliminated. The values of 3 parameters obtained from fitting procedure were showed in Table 3.3a. The value of ef_biom was mainly depended on C content. Figure 3.2 showed model performance of different soil types without added residues with modified parameters. Statistical analysis showed that RMSE values of cumulative $\mathrm{CO}_{2}-\mathrm{C}$ varied from 5.29 to $51.84\left(\mathrm{mg} \mathrm{kg}^{-1}\right.$ dry soil) and from 2.29 to $28.45 \mathrm{mg} \mathrm{N}$ $\mathrm{kg}^{-1}$ dry soil from net $\mathrm{N}$ mineralisation. The model efficiency showed the goodness of fit in both $\mathrm{C}$ and $\mathrm{N}$ mineralisation (from 0.83 to 0.96 in cumulative $\mathrm{CO}_{2}-\mathrm{C}$ and from -1.23 to 0.95 in net $\mathrm{N}$ mineralised.

When residues were applied in the soil and became the dominant factor to fresh organic matter (FOM), 2 other parameters must be modifed: the fraction of fresh organic matter mineralized retained in the system (ef_fom) and the fraction of retained FOM transferred to biomass (fr_fom_biom). Depending on the percentage of $\mathrm{CO}_{2}-\mathrm{C}$ release from each residue, the ef fom could be calculated by combining equation (1) and (3) in Appendix (see Appendix). Its values vary from 0.12 (rape seed stem \# 14) to 0.68 (dactyladenia root \# 11). A fitting procedure was then undertaken for fr_fom_biom to obtain the best agreement between simulated and measured. Its value ranged from 0.5 to 0.9 based on biochemical quality of applied residues. 
Table 3.3a. Value of some modification parameters of SOILN

\begin{tabular}{|l|l|l|l|}
\hline Parameter & Description & Default value & Modified value \\
\hline ef_biom & Fraction of biomass C mineralized retained in system & 0.4 & $0.5 \pm 0.2$ \\
\hline ef_fom & Fraction of fresh organic matter C mineralized retained in system & 0.4 & $\begin{array}{l}\text { Eq. (1) and (2) } \\
\text { in Apendix }\end{array}$ \\
\hline ef_hum & Fraction of humic C mineralized retained in system & 0.4 & Default \\
\hline fr_fom_biom & Fraction of retained FOM C transferred to biomass & 0.9 & $0.7 \pm 0.2$ \\
\hline fr_biom_biom & Fraction of retained biomass C returned to biomass & 0.6 & Default \\
\hline
\end{tabular}
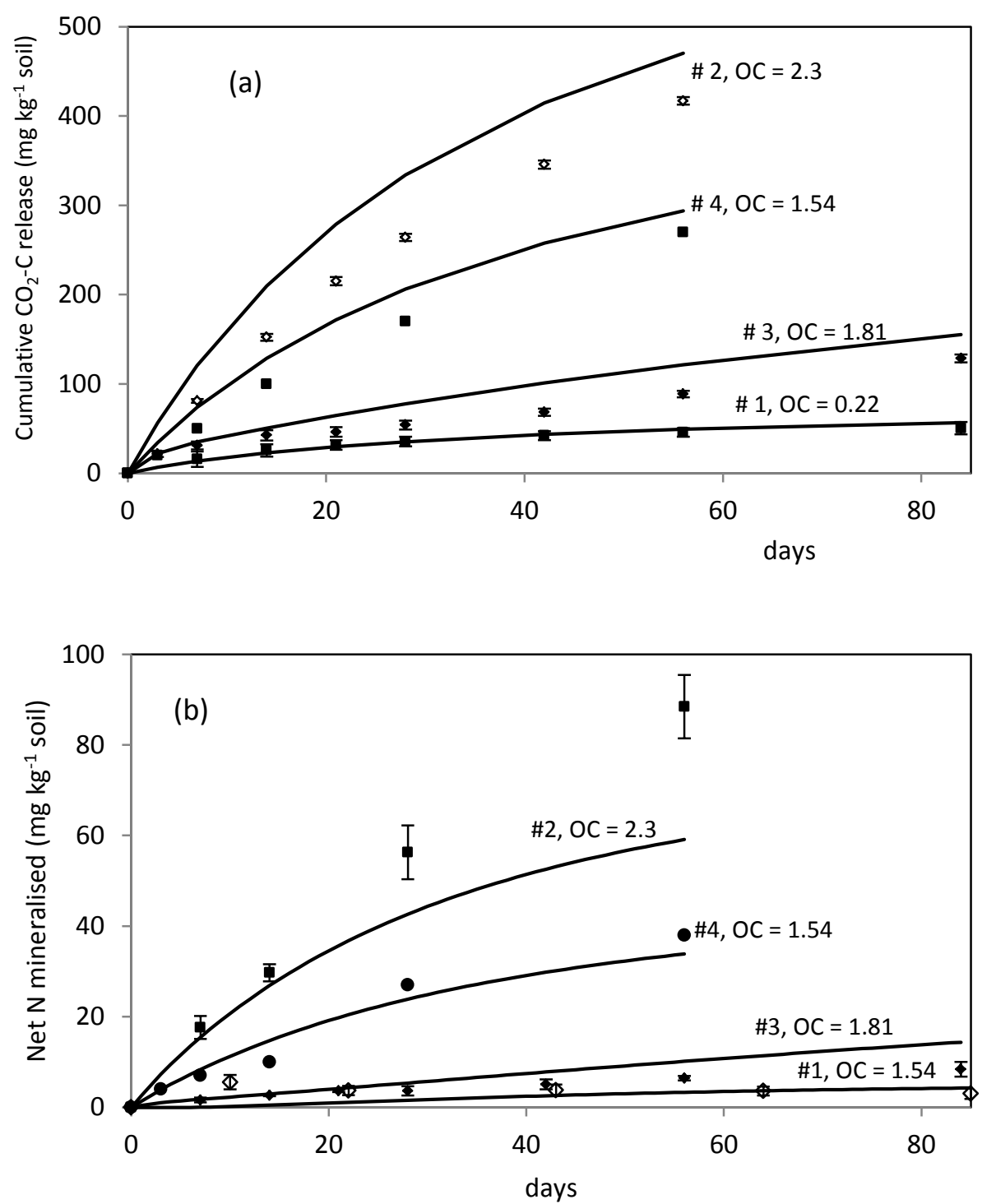

Figure 3.2. Cumulative $\mathrm{CO}_{2}-\mathrm{C}$ release (a) and net $\mathrm{N}$ mineralised (b) from unamended soil by individually fitting 3 parameters. Experimental data shown as symbols with bar representing \pm standard deviations of mean from four replicates. The continuous line is the output from the model. Soil types (\#) follow in Table 3.2. For comparative purposes, the incubation time is limited to 84 days. 
Table 3.3b. Statistical analysis of model performance from unamended soil

\begin{tabular}{|c|c|c|c|c|c|c|c|c|}
\hline \multirow{2}{*}{$\begin{array}{c}\text { Soil } \\
\text { type }\end{array}$} & \multicolumn{4}{|c|}{ Cumulative $\mathrm{CO}_{2}-\mathrm{C}\left(\mathrm{mg} \mathrm{kg}^{-1}\right.$ soil) } & \multicolumn{3}{c|}{ Net N mineralised $\left(\mathrm{mg} \mathrm{kg}^{-1}\right.$ soil) } \\
\cline { 2 - 9 } & $\mathrm{X}$ & RMSE & $\mathrm{EF}^{\star}$ & $\mathrm{MD}$ & $\mathrm{X}$ & $\mathrm{RMSE}$ & $\mathrm{EF}^{*}$ & $\mathrm{MD}$ \\
\hline 1 & 41.11 & 5.29 & 0.90 & -4.06 & 3.27 & 2.29 & -1.23 & 1.44 \\
\hline 2 & 221.51 & 51.84 & 0.89 & -45.26 & 53.73 & 28.45 & 0.59 & 18.94 \\
\hline 3 & 79.98 & 23.51 & 0.83 & -18.14 & 8.46 & 2.69 & 0.87 & 1.14 \\
\hline 4 & 128.15 & 44.46 & 0.85 & -33.38 & 9.52 & 3.87 & 0.84 & -2.42 \\
\hline 5 & 101.67 & 19.02 & 0.96 & -15.54 & 14.33 & 2.89 & 0.95 & 0.87 \\
\hline
\end{tabular}

( $X=$ mean of measurement; ${ }^{*}$ : ununit)

\subsubsection{Model performance in different scenarios}

The effect of changing the input by modifying the proportion of the $C$ in each of the FPOOLs was mentioned in Probert et al. (2005). In this study, the three FPOOLs sizes (carbohydrate, cellulose/hemicellulose and lignin -like pools) were modified based on observation analysis in laboratory (Table 3.1). Then the model performance was tested in three different scenarios as description in step (4). In terms of cumulative $\mathrm{CO}_{2}-\mathrm{C}$ release from residues, comparison with scenario 1, the modified models were showed a good agreement between measured data and predicted. In 3 different datasets, the model efficiency (EF) increased significantly. For example, the EF value was from 0.27 to 0.46 in BV96 and from 0.23 to 0.53 in BN2000. In 165 observations, the EF increased from 0.67 to 0.83 (Table 3.4a). Moreover, we found that the prediction of $\mathrm{CO}_{2}-\mathrm{C}$ release did not change significantly whether adjusted the $\mathrm{C}: \mathrm{N}$ ratios in each different FPOOLs. The distribution of $\mathrm{N}$ in each FPOOL in this case did not influence on the release of $\mathrm{CO} 2$ from residues.

Scatter plots were produced comparing predicted and measured of $\mathrm{CO} 2-\mathrm{C}$ cumulative of all datasets in different scenarios (Figure $3.3 \mathrm{a}$ and $\mathrm{b}$ ). In the best performance, the overall $\mathrm{R}^{2}$ value of 0.86 with a low bias ( $\alpha=0.97, \beta=59.17 \mathrm{mg} \mathrm{kg}^{-1}$ soil) provides strong evidence that the modified SOILN model is able to simulate a wide range of biochemical quality of residues for different soil types. The overall RMSE of $164.76 \mathrm{mg} \mathrm{kg}^{-1}$ soil, less than the overall standard deviation of measurement data $\left(402.10 \mathrm{mg} \mathrm{kg}^{-1}\right.$ soil) together with high overall EF value (0.73) suggests an acceptable model performance. Moreover, the Student's paired T- 
test (assuming non-equal variances) gave a significance of $P(t)=0.39$ indicating that there is no statistical difference between predicted and measured data at the $95 \%$ confidence level.
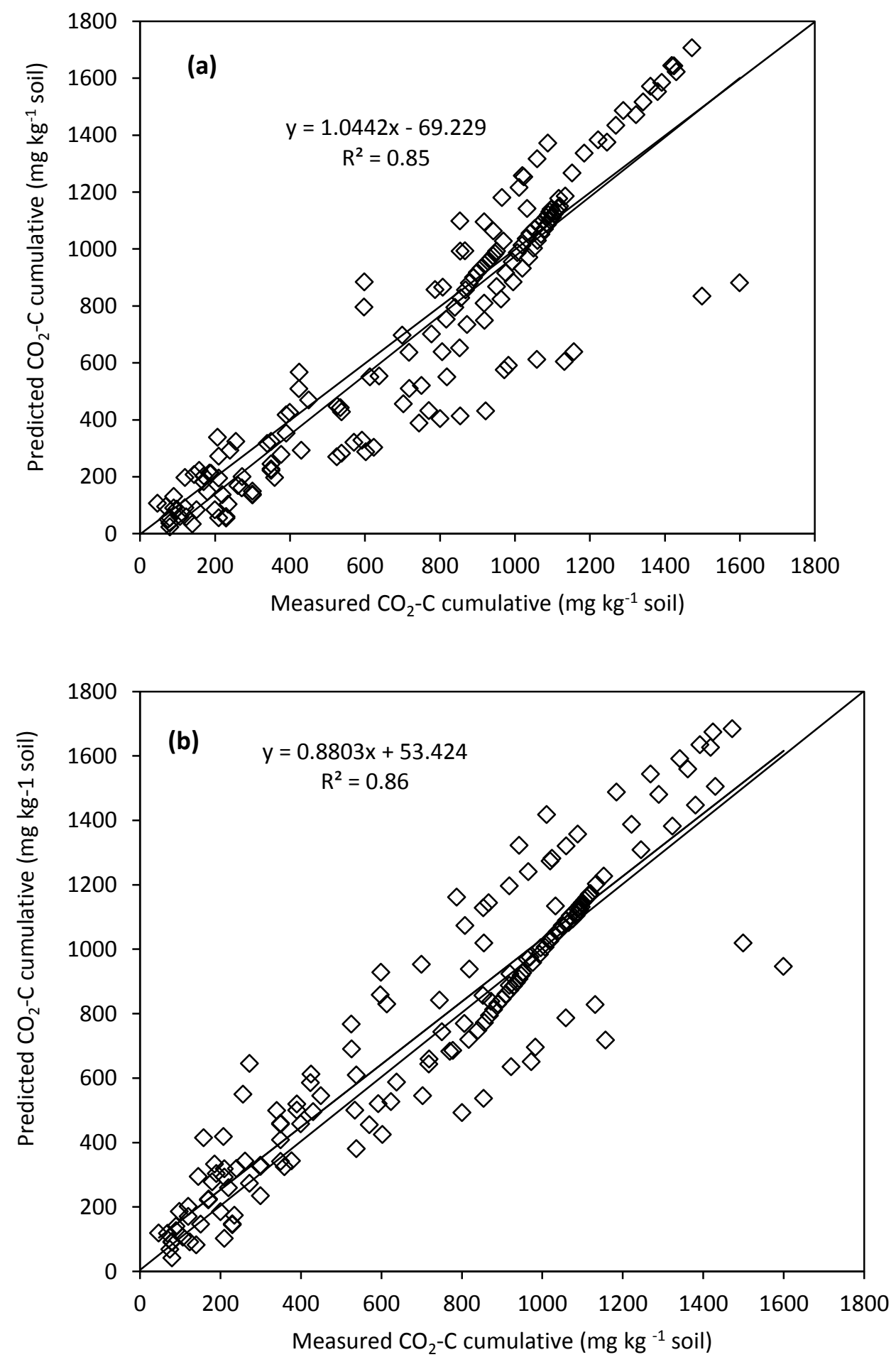

Figure 3.3. Scatter plots of the observation vs. measurement of cumulative $\mathrm{CO}_{2}-\mathrm{C}$ release from 20 residues applied in scenario 1 (a) and scenario 2 and 3 (b). 
Table 3.4a. Statistical analysis of cumulative $\mathrm{CO}_{2}-\mathrm{C}$ release from different dataset in the best scenario performance

\begin{tabular}{|c|c|c|c|c|c|c|c|c|c|c|}
\hline Dataset & $\mathrm{N}$ & $\begin{array}{c}\mathrm{X}_{\text {mea }}(\mathrm{SD}) \\
\left(\mathrm{mg} \mathrm{kg}^{-1} \text { soil }\right)\end{array}$ & $\begin{array}{c}\mathrm{X}_{\text {sim }}(\mathrm{SD}) \\
\left(\mathrm{mg} \mathrm{kg}^{-1} \text { soil) }\right.\end{array}$ & $\alpha$ & $\begin{array}{c}\beta \\
\left(\mathrm{mg} \mathrm{kg}^{-1} \text { soil }\right)\end{array}$ & $\mathrm{R}^{2}$ & $\begin{array}{c}\mathrm{RMSE} \\
\left(\mathrm{mg} \mathrm{k}^{-1} \text { soil }\right)\end{array}$ & $\mathrm{EF}$ & $\begin{array}{c}\mathrm{MD} \\
\left(\mathrm{mg} \mathrm{kg}^{-1} \text { soil }\right)\end{array}$ & $\mathrm{P}(\mathrm{t})$ \\
\hline BV96 & 30 & $239.7(110.7)$ & $279.1(150.2)$ & 1.22 & -12.27 & 0.80 & 80.05 & 0.46 & -39.46 & 0.25 \\
\hline BN 2000 & 28 & $673.6(404.9)$ & $596.7(211.3)$ & 0.42 & 312.67 & 0.65 & 271.55 & 0.53 & 76.92 & 0.38 \\
\hline NTH 12 & 107 & $890.3(331.9)$ & $960.0(382.6)$ & 1.09 & -11.56 & 0.90 & 144.10 & 0.81 & -69.65 & 0.16 \\
\hline Overall & 165 & $735.2(402.1)$ & $774.5(422.7)$ & 0.97 & 59.17 & 0.86 & 164.76 & 0.83 & -39.29 & 0.39 \\
\hline
\end{tabular}

$\mathrm{N}$ : number of data pairs; $X_{\text {mea }}$ : mean of measurement; $X_{\text {sim }}$ : mean of simulation; SD: standard deviation; $\alpha$ : slope of linear regression between simulated and measured values; $\beta$ : intercept of linear regression between simulated and measured values; $\mathrm{R}^{2}$ : square of linear correlation coefficient between simulated and measured values, $P(t)$ significance of Student's paired t-test assuming nonequal variances.

Concerning the net $\mathrm{N}$ mineralization from different residues, the model performance in 3 scenarios resulted in Figure 3.4 and Table 3.4b. Compared with scenario 1 and scenario 2, the modified model in scenario 3 showed a good agreement between measured data and predicted from the model. The model efficiency increased in all datasets. Within 112 dataset, the $\mathrm{EF}$ values risen from 0.60 in scenario 1 to 0.77 in the scenario 3 .

In contrast to $\mathrm{CO}_{2}$ release, the distribution of nitrogen in different Fpools significantly influenced the dynamic of nitrogen within soil organic matter system. In the case where C:N ratio in each FPOOLs differed from the overall C:N ratio (scenario 3) (Table 3.1), the model performance was better compared to the default model settings (scenario 1) and modified model in scenario 2. Probert et al. (2005) and Mohanty et al. (2011) also found similar results in their study.

Scatter plots were also produced comparing predicted and measured net $\mathrm{N}$ mineralisation of all datasets in different scenarios (Figure $3.4 \mathrm{a}, \mathrm{b}$ and $\mathrm{c}$ ). Similarly to $\mathrm{CO}_{2}-\mathrm{C}$ cumulative, in the best performance, the high value of $R^{2}(0.79)$ with a low bias $\left(\alpha=0.90, \beta=1.98 \mathrm{mg} \mathrm{kg}^{-1}\right.$ soil) and high EF value (0.77) convinced that SOILN in APSIM is able to capture the dynamic of nitrogen of different added residues in various soil types. The Student's paired T-test (assuming non-equal variances) reported a significance of $P(t)=0.49$ indicating that there is no statistical difference between predicted and measured data at the $95 \%$ confidence level. 

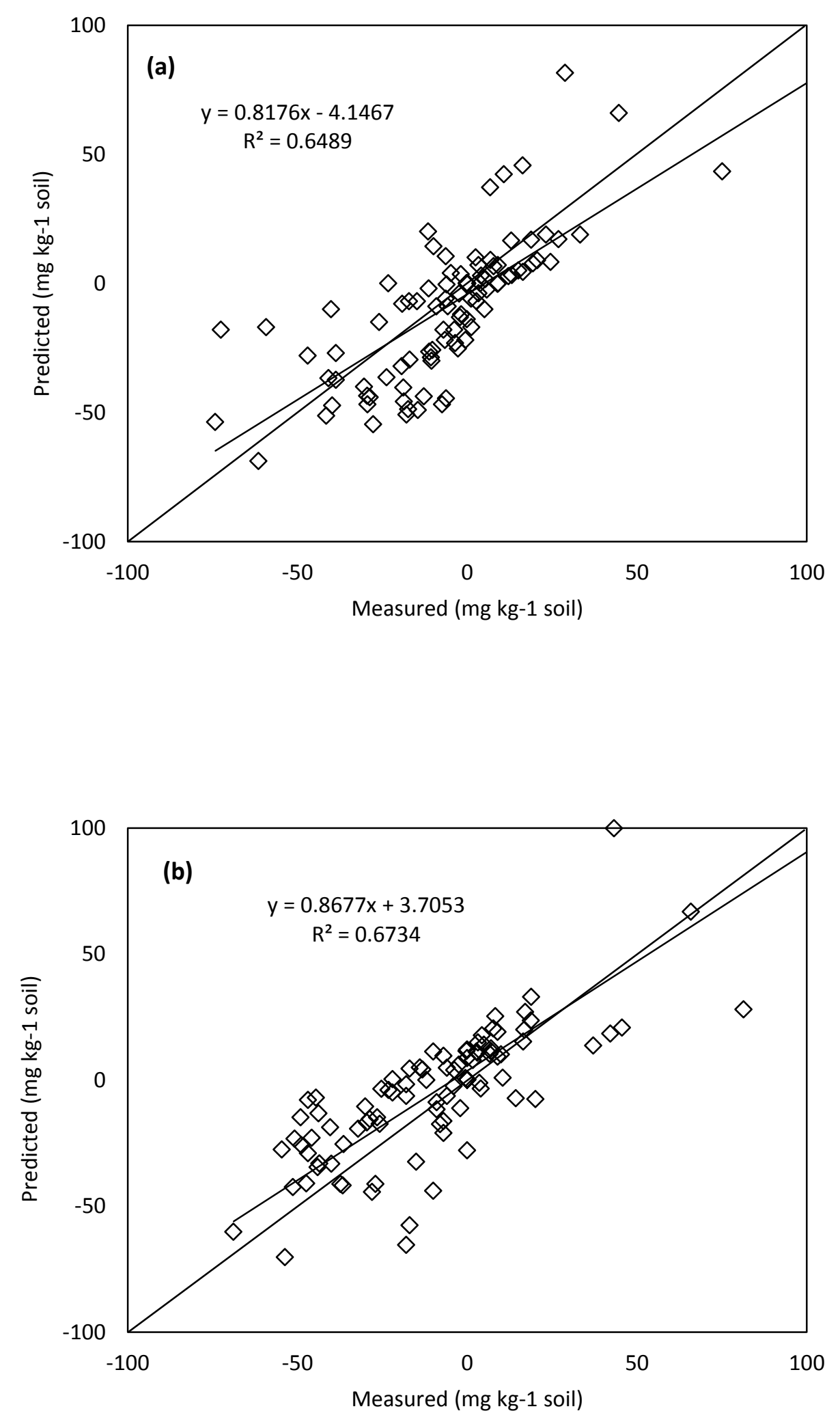


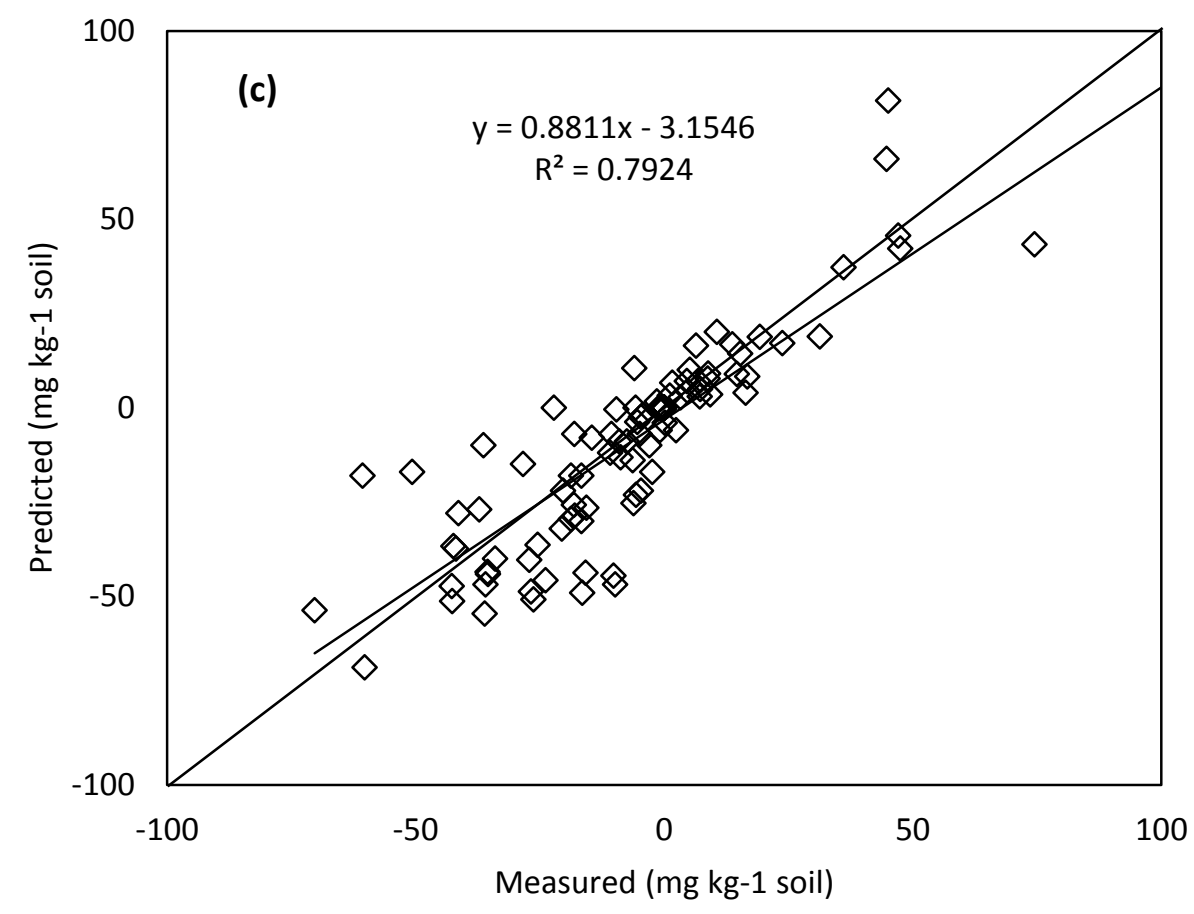

Figure 3.4. Scatter plots of the observation vs. measured of net $\mathrm{N}$ mineralised from 20 residues applied in scenario 1 (a) and scenario 2 (b) and scenario 3 (c).

Table 3.4b. Statistical analysis of net $\mathrm{N}$ mineralisation from different dataset in the best scenario performance

\begin{tabular}{|c|c|c|c|c|c|c|c|c|c|c|}
\hline Dataset & $\mathrm{N}$ & $\begin{array}{c}\mathrm{X}_{\text {mea }}(\mathrm{SD}) \\
\left(\mathrm{mg} \mathrm{kg}^{-1} \text { soil }\right)\end{array}$ & $\begin{array}{c}\mathrm{X}_{\text {sim }}(\mathrm{SD}) \\
\left(\mathrm{mg} \mathrm{kg}^{-1} \text { soil) }\right.\end{array}$ & a & $\begin{array}{c}\beta \\
\left(\mathrm{mg} \mathrm{kg}^{-1} \text { soil }\right)\end{array}$ & $R^{2}$ & $\begin{array}{c}\text { RMSE } \\
\text { ( } \mathrm{mg} \mathrm{kg}^{-1} \text { soil) }\end{array}$ & $E F$ & $\begin{array}{c}\mathrm{MD} \\
\left(\mathrm{mg} \mathrm{kg}^{-1} \text { soil }\right)\end{array}$ & $P(t)$ \\
\hline BV96 & 36 & $-7.3(9.9)$ & -10.9 (16.9) & 1.21 & -2.10 & 0.50 & 12.42 & -0.62 & 3.62 & 0.27 \\
\hline BN 2000 & 35 & $-21.3(22.0)$ & $-12.7(16.1)$ & 0.60 & 0.11 & 0.67 & 15.26 & 0.51 & -8.64 & 0.07 \\
\hline NTH 12 & 41 & 6.1 (37.7) & 9.2 (39.6) & 0.99 & 3.15 & 0.89 & 13.33 & 0.87 & -3.09 & 0.71 \\
\hline overall & 112 & $-6.8(28.6)$ & $-4.1(28.9)$ & 0.90 & 1.98 & 0.79 & 13.69 & 0.77 & -2.67 & 0.49 \\
\hline
\end{tabular}

$\mathrm{N}$ : number of data pairs; $\mathrm{X}_{\text {mea }}$ : mean of measurement; $\mathrm{X}_{\text {sim }}$ : mean of simulation; SD: standard deviation; a: slope of linear regression between simulated and measured values; $B$ : intercept of linear regression between simulated and measured values; $R^{2}$ : square of linear correlation coefficient between simulated and measured values. $\mathrm{P}(\mathrm{t})$ significance of Student's paired $\mathrm{t}$-test assuming nonequal variances. 


\subsubsection{Simulation $\mathrm{C}$ and $\mathrm{N}$ dynamic from SOILN model by using modified parameters}

Based on results from model in different scenarios, modified model was tested under varying conditions using several soil types (Table 3.2) and residue types (Table 3.1). The output was compared with cumulative $\mathrm{CO}_{2}-\mathrm{C}$ release and net $\mathrm{N}$ mineralization. Due to the amount of mineral nitrogen in soil, we separated into 3 different groups: low mineral $\mathrm{N}$ soils (less than 10 ppm mineral $\mathrm{N}$ ), medium mineral $\mathrm{N}$ soils (from 10 to $30 \mathrm{ppm}$ mineral $\mathrm{N}$ ) and high mineral $\mathrm{N}$ soils (above $30 \mathrm{ppm}$ mineral $\mathrm{N}$ ).

\section{a. In low mineral $N$ soils:}

This soil group had only $6.6 \mathrm{mg} \mathrm{N}$ min $\mathrm{kg}^{-1}$ soil. The model predicted well the $\mathrm{CO}_{2}-\mathrm{C}$ release from different residues quality in poor soil nutrient (Figure 3.5a). Though the model underestimated in case of maize, the higher value of EF in lablab and lucerne suggested a better representation of the pattern of $\mathrm{CO}_{2}-\mathrm{C}$ cumulative by the model (Figure 3.5a). The amount of $\mathrm{CO}_{2}$ release as predicted by the model from maize was much lower than that in lablab and lucerne. All these residues had similar overall $\mathrm{C}: \mathrm{N}$ ratio but the lignin content in maize was much higher than in lablab and lucerne (Table 3.1). The high EF value (0.96) from all datasets of these residues in this soil type was considered to be a good prediction of the model in capturing the release of $\mathrm{CO}_{2}$ in low $\mathrm{C}: \mathrm{N}$ ratio residue materials.

After 10 days of incubation, the pattern of net mineralisation predicted for the lablab and maize changed from immobilization to mineralisation and maintained until the end of incubation (Figure 3.5b). The model showed a goodness of fit when representing the dynamic of nitrogen in maize with high EF value (0.60). Nevertheless, the EF value decreased in lucerne and lablab (Figure 3.5b). Then we calculated the Student T-test $(P(t))$ (assuming unequal variances) to evaluate the significantly different between measured data and predicted data. The high result of $\mathrm{P}(\mathrm{t})$ ( 0.85 and 0.96 respectively for lablab and lucerne) with high value of correlation coefficient (respectively 0.84 and 0.62 ) suggests that there is no significant different in the $95 \%$ confidence level between predicted and measured data. Moreover, high value of EF (0.57) and correlation coefficient $R^{2}(0.78)$ obtained from the 
comparison between simulated and measured data of all residues suggested a satisfactory goodness of fit by the model in poor soil nutrient in high biochemical quality of plant residues.
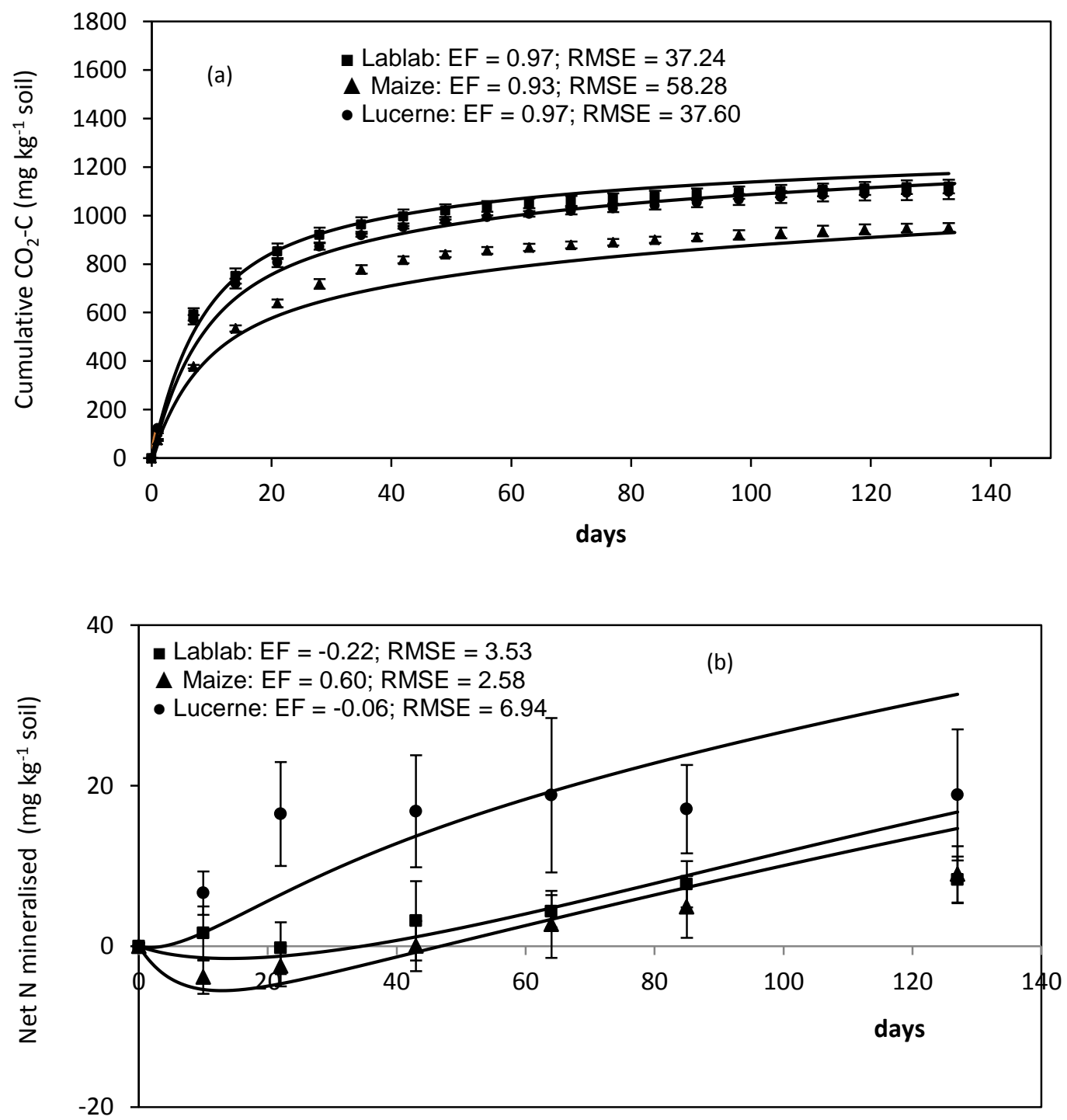

Figure 3.5. Cumulative $\mathrm{CO}_{2}-\mathrm{C}$ release (a) and Net $\mathrm{N}$ mineralized (b) from residues in soil type 1 by using modified parameters. Experimental data shown as symbols with bar representing \pm standard deviations of mean from four replicates. The continuous line is the output from the model.

b. In medium mineral $N$ soil:

This soil group had $29.9 \mathrm{mg} \mathrm{N} \mathrm{min} \mathrm{kg}^{-1}$ soil. Within a wide range of added residues quality, the model performance increased with the increase of overall $\mathrm{C}: \mathrm{N}$ ratio of residue. The EF 
value was of around 0.50 in low $\mathrm{C}: \mathrm{N}$ residues as pea and mucuna but rise significantly to above 0.80 in higher group (wheat and canola) (Figure 3.6a). The amount of $\mathrm{CO}_{2}$ release from the model after over 60 days of incubation was ordered as pea $>$ wheat $>$ canola $>$ mucuna. Mucuna with low C:N ratio (14.1) in this case predicted less $\mathrm{CO}_{2}$ than wheat and canola in which has higher $\mathrm{C}: \mathrm{N}$ ratio due to its high lignin content and high $\mathrm{C}: \mathrm{N}$ ratio in $\mathrm{POOL}$ 3 (Table 3.1). In general, comparison between observed and predicted data of all residues showed a high EF value (0.74) and $R^{2}$ value (0.95) suggesting an acceptable performance of the model when simulating the $\mathrm{CO}_{2}$ release from various added residues.

Over the 56 days of incubation, the model produced a immobilization for high $\mathrm{C}: \mathrm{N}$ ratio residues group (wheat (26.9) and canola (43.0)) and mineralisation for lower C:N ratio (mucuna (14.1) and pea (9.1)) (Figure 3.6b). In the low quality of residue group, the small bias of RMSE and high value of EF suggested a satisfactory simulation in this soil type when comparing between predicted and observed data. For the high quality of residue group, the model efficiency was acceptable, 0.01 for pea and 0.57 for mucuna. The model performed in mucuna much better than in pea.

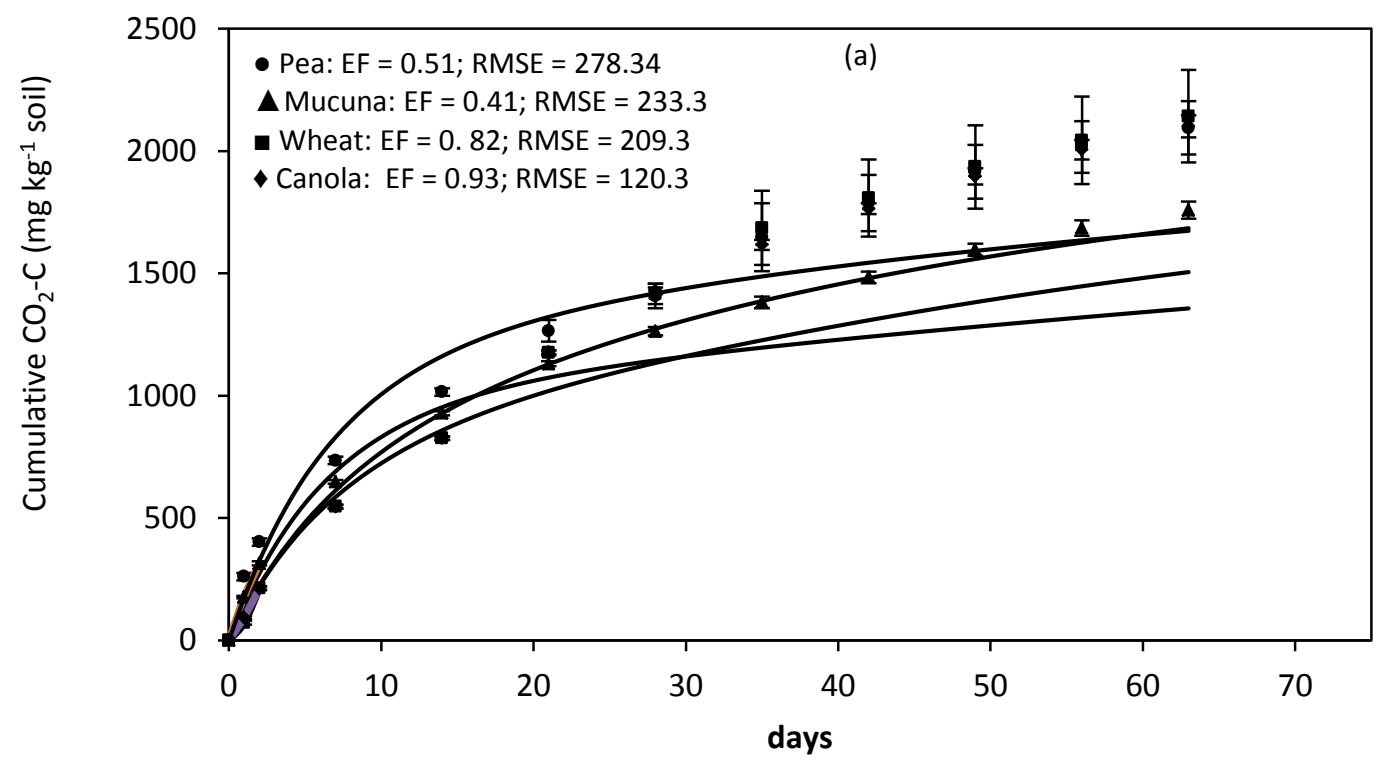




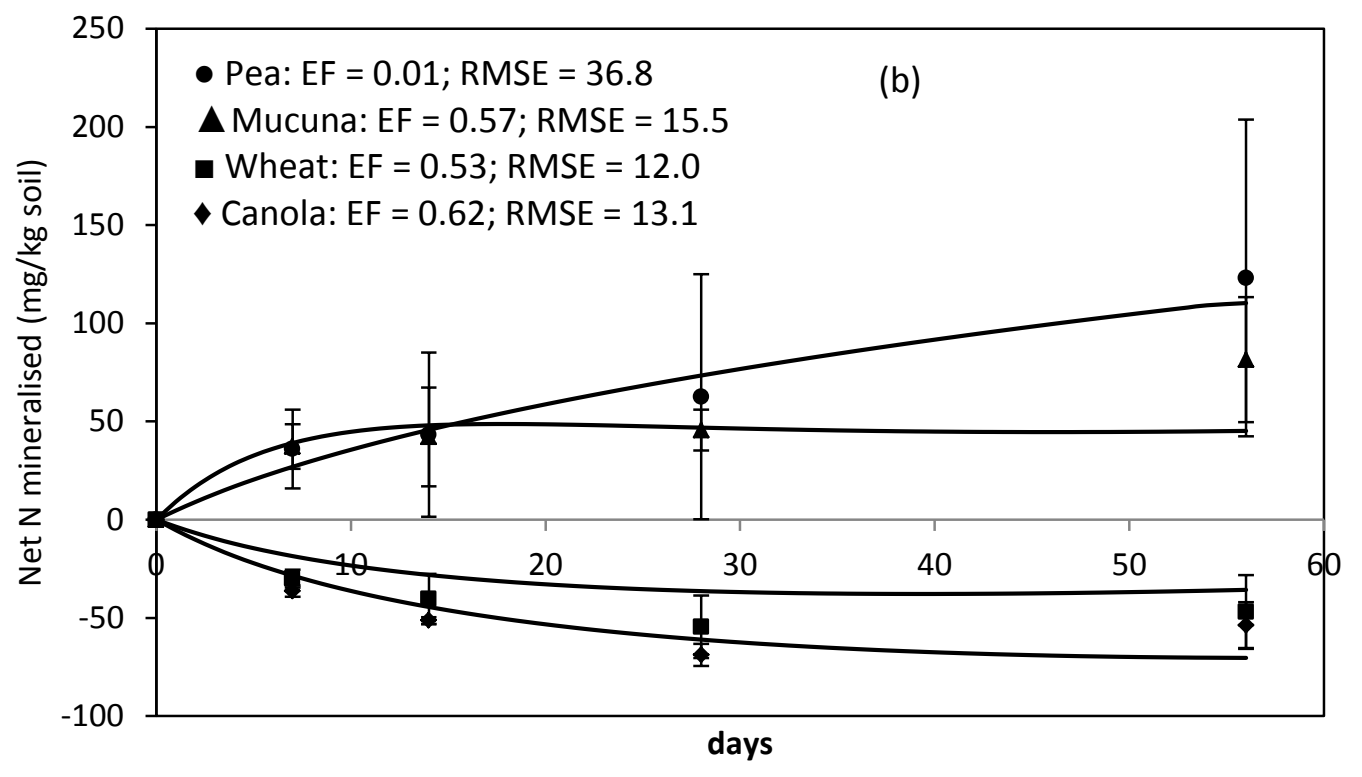

Figure 3.6. Cumulative $\mathrm{CO}_{2}-\mathrm{C}$ release (a) and Net $\mathrm{N}$ mineralized (b) from residues in soil type 2 by using modified parameters. Experimental data shown as symbols with bar representing \pm standard deviations of mean from four replicates. The continuous line is the output from the model.

\section{c. In high min N soil (above 30 ppm)}

This soil group had 2 different soil types. 6 different residues (from \#8 to \# 13) were tested with soil having $55.8 \mathrm{mg} \mathrm{N} \mathrm{kg}^{-1}$ soil and 7 different residues (from \#14 to \#20) were tested with soil having $85.0 \mathrm{mg} \mathrm{N} \mathrm{kg}^{-1}$ soil (Table 3.2). The biochemical quality of each residue and related parameters could be seen in Table 3.1.

Concerning simulation of $\mathrm{CO}_{2}-\mathrm{C}$ release from various residues, the model presented a goodness of agreement between predicted and measured data with EF values from 0.01 (\#11) to 0.88 (\#19). Comparison between 2 different soil types, the model performance was more satisfactory in soil having more $\mathrm{N}$ mineral even though the overall $\mathrm{C}: \mathrm{N}$ ratio of residues in this group much higher than the other (Figure 3.7a, 3.7c and Table 3.5a). 
Regarding to net $\mathrm{N}$ mineralized, the model produced the immobilization in almost applied residues with the exception of \# 13 and \#19. The residue \# 8 became mineralisation after 5 days of simulation and residue \# 16 switched from immobilization to mineralisation after 20 days of simulation (Figure 3.7b and 3.7d). Overall the simulation of both soil types, the model showed an acceptable performance via its statistical analysis (Table 3.5b), except residue \# 11. The model performed poorly in this residue with very low EF value $(-12.44)$
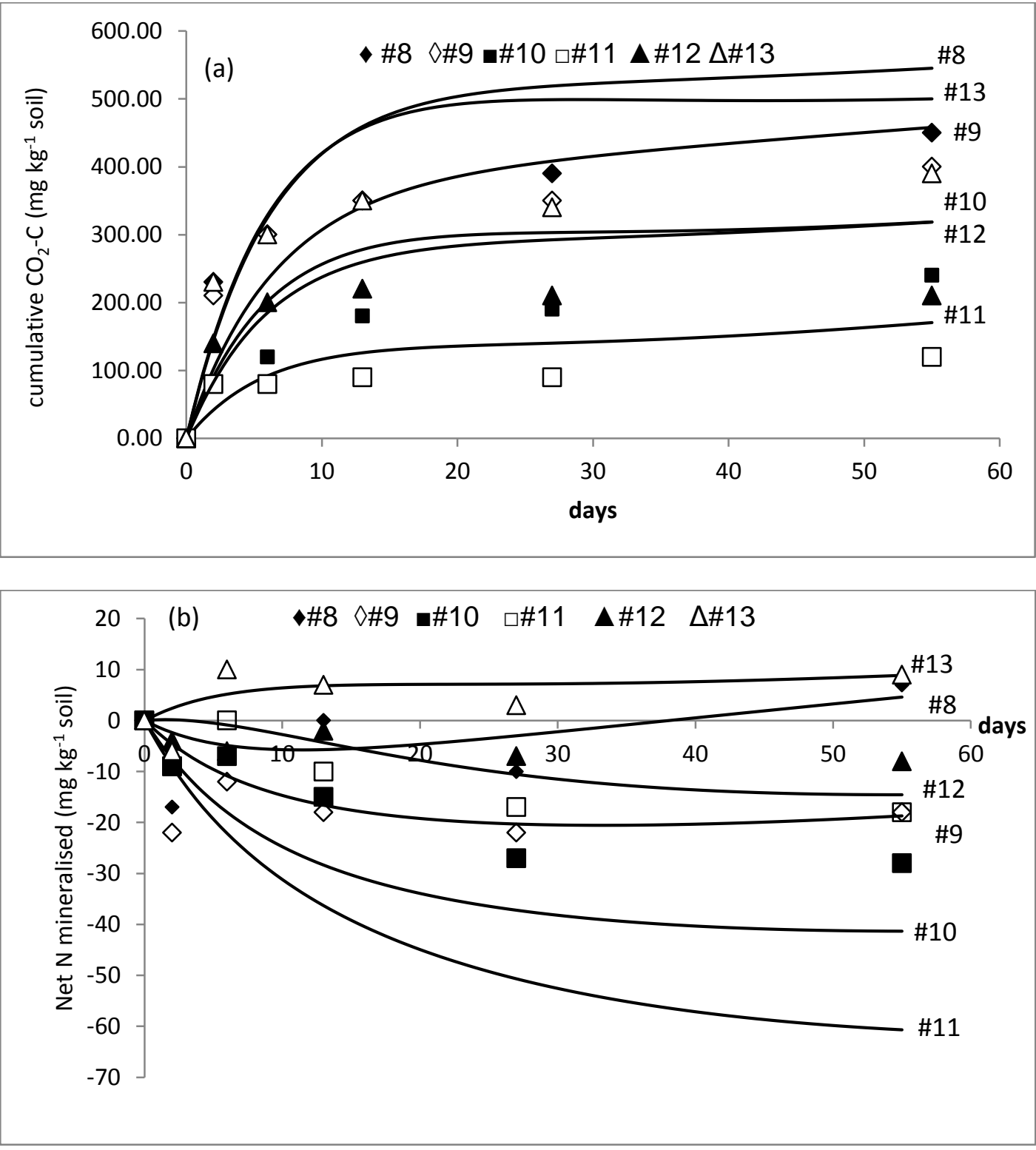

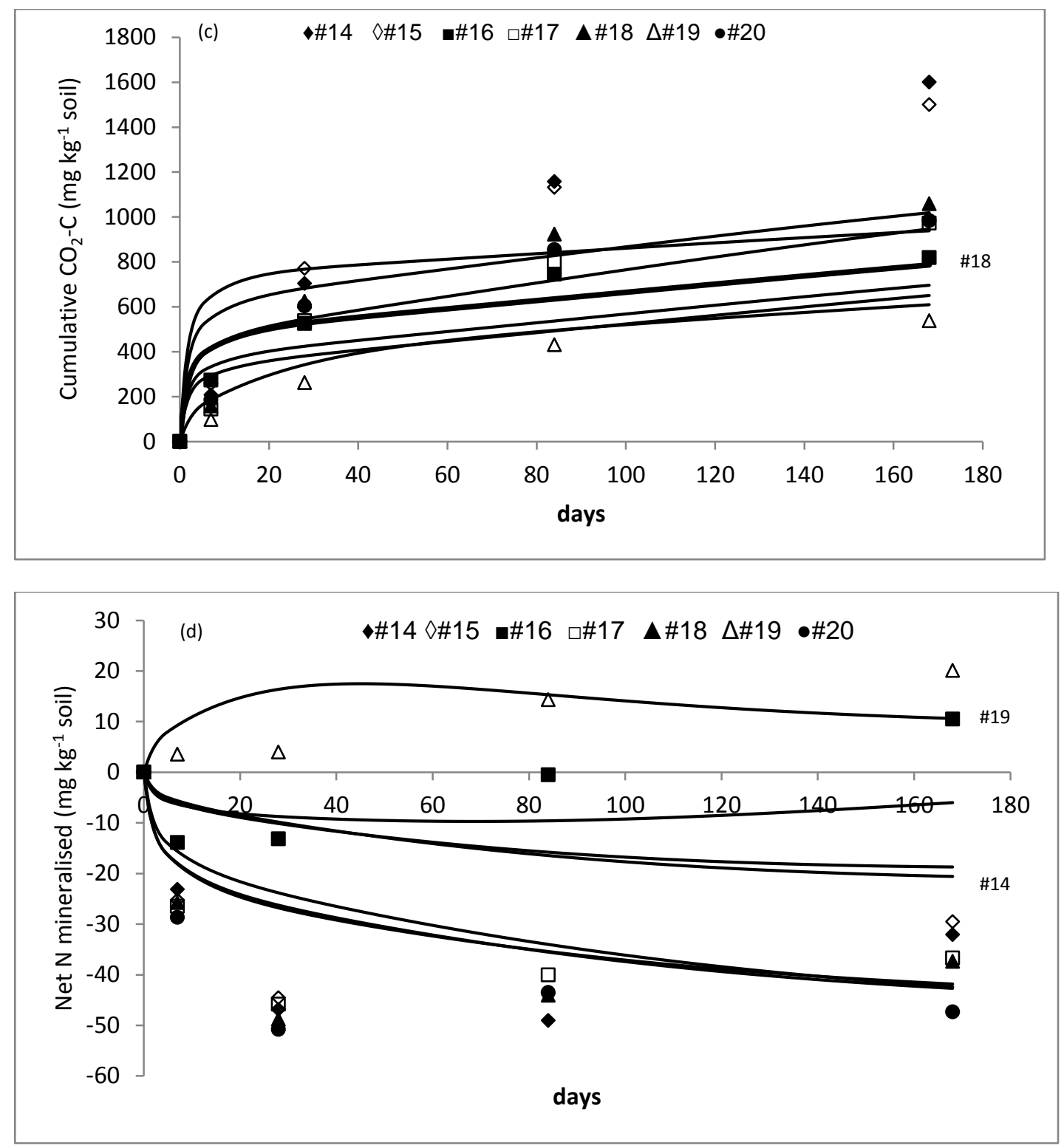

Figure 3.7. Cumulative $\mathrm{CO}_{2}-\mathrm{C}$ release and $\mathrm{Net} \mathrm{N}$ mineralized from residues in soil type 4 (a and b) and soil type 3 (c and d) by using modified parameters. Experimental data shown as symbols with bar representing \pm standard deviations of mean from four replicates. The continuous line is the output from the model. 

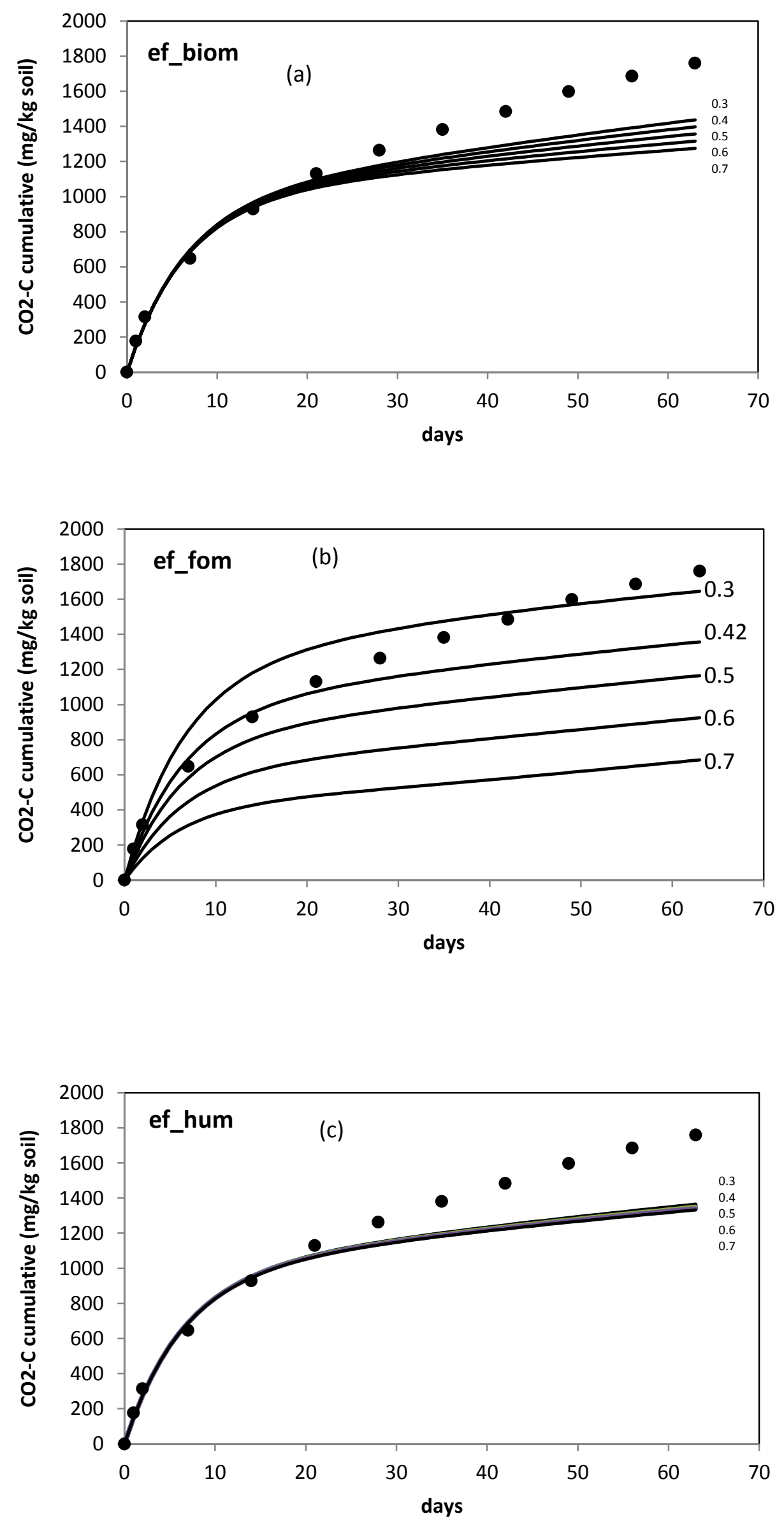

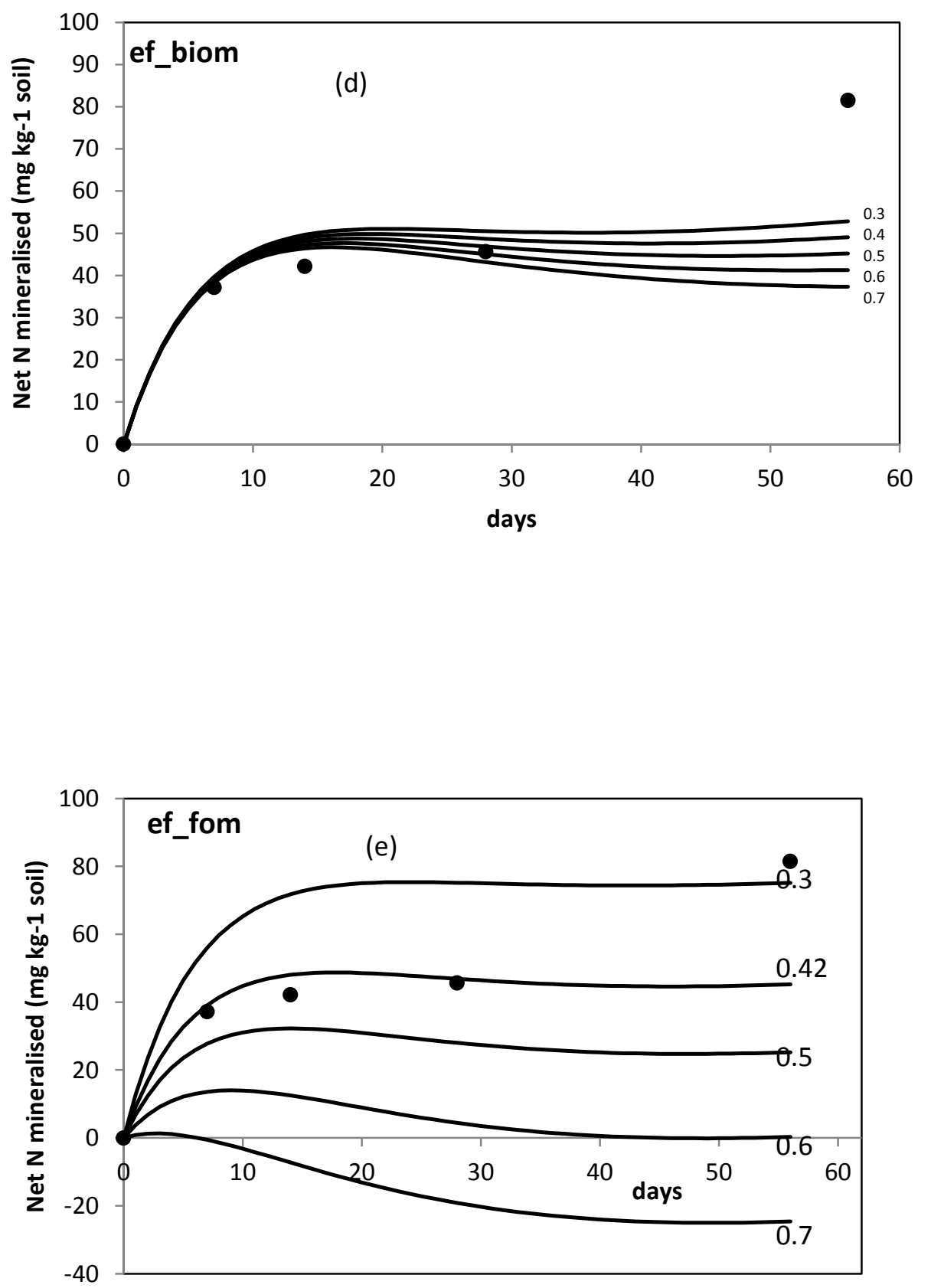


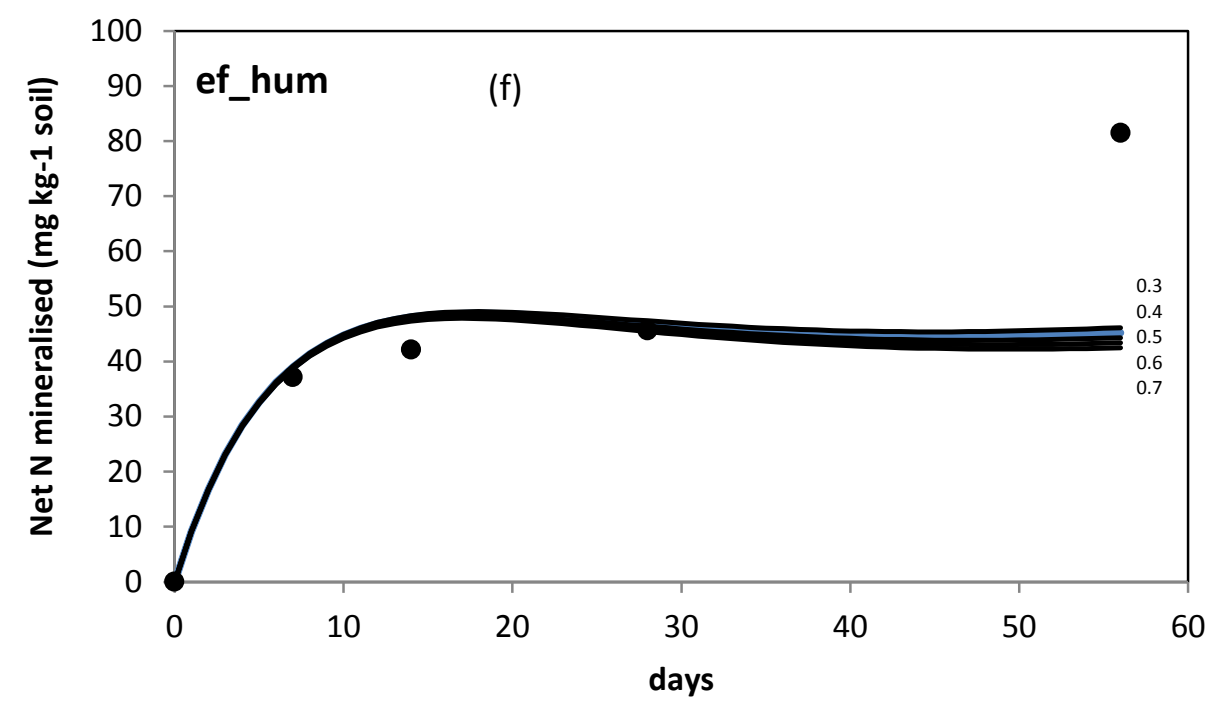

Figure 3.8. Sensitivity analysis to the variation of ef_biom, ef_fom and ef_hum parameters applied to mucuna residue (\#4) in soil type 2. The value of other parameters were maintained constant as in Table 3.1. The continuous line is the output from the model. Experimental data shown as symbols.

\subsection{Discussion}

According to Gilmour and Gilmour (1985) and Anderson et al. (1986), the fraction of C assimilated depends on soil quality and residue applied characteristics. Therefore, using the default values of each parameters of carbon flows (eg. ef_fom, fr_fom_biom) was unable to represent the dynamic of $\mathrm{C}$ and $\mathrm{N}$ release in a wide range of residues, especially in residues having high secondary metabolites. Sensitivity analysis with mucuna (\#4) which had high lignin content (Figure 3.8) indicated that using the default values of these parameters was inadequate to simulate both $\mathrm{C}$ and $\mathrm{N}$ dynamics.

In the absence of applied residues, the majority of soil organic matter decomposing exists in the inert and humic pools whereas the microbial biomass aggregate a small part of total soil organic carbon (Sparling, 1992; Schnürer et al., 1985; MacCarthy et al., 2009). Therefore, the breakdown of BIOM and HUM pools in soil significantly influence on the dynamic of $\mathrm{C}$ and $\mathrm{N}$ in soil. In other words, the pool size and the assimilation yield of microorganisms 
determine these processes. The pool size of BIOM and HUM was assumed from organic carbon content of different added soils and it differed from various soil types. The value of ef_biom modified in this study was always higher than default means and the assimilation yield of microorganisms was always higher than 0.6. This result is consistent with other authors who used the model to represent the $\mathrm{C}$ and $\mathrm{N}$ mineraisation of different crop residues. Justes et al. (2009) and Nicolardot et al. (2001) used similar value at 0.62 in different model approaches.

The next parameter correlated to the $\mathrm{C}$ and $\mathrm{N}$ dynamics in SOILN is the fraction of fresh organic matter C mineralized retained in the system (ef_fom). This is also a very sensitive parameter for the model (Figure 3.8b, e). Its values varied in a wide range and a higher value resulted smaller amount of $\mathrm{CO}_{2}$ release as well as the net $\mathrm{N}$ mineralized became immobilization. Statistic found a linear regression between overall C:N ratio and ef_fom with the exception of residue \# 14, 15, 17, 18 and \#20. These residues had extremely high $\mathrm{C}$ : $\mathrm{N}$ ratio but they also produced high amount of $\mathrm{CO}_{2}$. The similar results also were found in in Trinsoutrot et al. (2000a) in which showed a weak relation between the C:N ratio of the residues and the decomposition of added residues. The possibility of $\mathrm{N}$ limitation in those studies was eliminated by the initial addition to soil of a sufficient amount of mineral N. In our study, those residues were carried out in rich soil with high content of mineral N. Other residues show a good agreement with literatures.

In a previous study, Probert et al. (2005) mentioned that it is important to conceptualise the organic residues added as comprising discrete fractions to represent the complex patterns of mineralization/immobilization in soil in response to residue additions. By conceptually representing the added materials in terms of pools, the model can be parameterized to simulate the dynamics of $\mathrm{C}$ and $\mathrm{N}$ that are observed in a wide range of residues. When default values of FPOOLs (scenario 1) were applied for all residues, the model worked acceptably to capture the release of $\mathrm{CO}_{2}$ in all cases with the EF values varies from 0.02 to 0.94, except for residue \# 11 (Table 3.5a). The lignin content in this residue was extremely higher than others (over 30\%). Nevertheless, model performance was worse when 
simulating the $\mathrm{N}$ mineralization (Table $5 \mathrm{~b}$ ). Then the measurement fraction of carbon in FPOOLs was used to increase the capacity of the model. The distribution of $C$ in pool 1 and pool 3 fluctuated widely, from 25.8 to 90.1 in pool 1 and from 2.0 to 30.6 in pool 3 whereas the amount of $C$ in pool 2 much lower than default, range from 3.4 to 61.3 (Table 3.1). In this case, the model predicted more accurately net $\mathrm{N}$ mineralisation (Table $3.5 \mathrm{a}, 3.5 \mathrm{~b}$ ). In an attempt to improve the predictive performance of the model for net $\mathrm{N}$ mineralization, a series of simulations were carried out in which the $\mathrm{CN}$ ratios of each FPOOLs were changed by adding/subtracting $10 \%$ of original to obtain satisfactory fit with the observed data (Figure 3.5b, 6b, 7b, 7d; Table 3.5b). The output of C:N ratios in each FPOOLs were shown in Table 3.1. Surprisingly, the prediction of $\mathrm{CO}_{2}$ release did not differ from previous scenario where C:N ratios in FPOOLs were equal to overall $\mathrm{CN}$ ratios. Therefore, decomposition of $\mathrm{CO}_{2}$ from the model is mainly driven by the distribution of $C$ in each of the pools of fresh organic matter rather than the distribution of $\mathrm{N}$ in each FPOOLs whereas the prediction of $\mathrm{N}$ mineralization depends strongly on $\mathrm{CN}$ ratio in each FPOOLs. One issue that emerges, is how appropriate parameters should be selected for given source and how accurately the model could applied in a truly predictive way for anther residues. For the amount of $\mathrm{CO}_{2}$ release over time, the model performed satisfactorily when parameterized with laboratory defined pools for various residue application in same conditions. Probert et al. (2005) showed that by using values of $\mathrm{C}: \mathrm{N}$ ratios in FPOOLs which were estimated from measured data for $\mathrm{N}$ associated with ADF and NDF, the model performed unsatisfactorily than using optimization values.

Focusing on the impact of $\mathrm{N}$ on model performance, we found that the $\mathrm{N}$ mineral content in soil affects considerably on the ability of the mode to illustrate the dynamics of $\mathrm{C}$ and $\mathrm{N}$ in soil. Take residue \# 6 (canola, $\mathrm{CN}=43.0$ ) as an example, in low $\mathrm{N}$ mineral soil $(7.0 \mathrm{mg} \mathrm{N}$ mineral $\mathrm{kg}^{-1}$ soil), the model was not able to capture the decomposition process of this residue in any scenario. At higher soil $\mathrm{N}\left(\mathrm{N} \min =29.9 \mathrm{mg} \mathrm{kg}^{-1}\right.$ soil), the mode performance was acceptable in both $\mathrm{C}$ and $\mathrm{N}$ release. Janzen and Kucey (1988) found a high correlation between initial $\mathrm{N}$ concentration and amount of $\mathrm{CO}_{2}$ evolved. Knapp et al. (1983) reported that 
straw decomposition rate strongly depended on available $\mathrm{C}$ and $\mathrm{N}$ during initial decomposition. When the limitation of $\mathrm{N}$ appears, the excess available $\mathrm{C}$ apparently becomes immobilization.

Table 3.5a. Statistical analysis of cumulative $\mathrm{CO}_{2}-\mathrm{C}$ (mineral $\mathrm{kg}^{-1}$ soil) release from added residues in different scenarios

\begin{tabular}{|c|c|c|c|c|c|c|c|}
\hline \multirow{2}{*}{ Residue code } & \multirow{2}{*}{$\mathrm{x}$} & \multicolumn{3}{|c|}{ Scenario 1} & \multicolumn{3}{|c|}{ Scenario 2 and scenario 3} \\
\hline & & RMSE & $\mathrm{EF}^{*}$ & MD & RMSE & $\mathrm{EF}^{*}$ & MD \\
\hline 1 & 970.08 & 108.38 & 0.79 & 59.95 & 37.24 & 0.97 & -22.93 \\
\hline 2 & 938.43 & 95.47 & 0.82 & 41.24 & 37.60 & 0.97 & 5.43 \\
\hline 3 & 794.28 & 51.70 & 0.94 & 14.39 & 58.28 & 0.93 & 51.48 \\
\hline 4 & 898.28 & 199.28 & 0.84 & -184.37 & 209.29 & 0.82 & -194.77 \\
\hline 5 & 761.82 & 170.48 & 0.69 & -98.91 & 233.26 & 0.41 & -208.86 \\
\hline 6 & 960.21 & 158.09 & 0.84 & -85.67 & 278.34 & 0.51 & -236.45 \\
\hline 7 & 880.18 & 133.84 & 0.92 & -120.63 & 120.33 & 0.93 & -102.32 \\
\hline 8 & 286.67 & 103.44 & 0.49 & 73.75 & 87.26 & 0.64 & -45.63 \\
\hline 9 & 268.33 & 104.93 & 0.38 & 72.93 & 61.67 & 0.79 & 10.94 \\
\hline 10 & 135.00 & 34.20 & 0.81 & 4.97 & 76.96 & 0.05 & -63.89 \\
\hline 11 & 76.67 & 43.49 & -0.40 & -6.17 & 36.54 & 0.01 & -18.54 \\
\hline 12 & 163.33 & 76.95 & 0.02 & 42.85 & 62.84 & 0.34 & -26.44 \\
\hline 13 & 268.33 & 111.90 & 0.26 & 77.02 & 97.03 & 0.44 & -53.76 \\
\hline 14 & 733.58 & 415.52 & 0.51 & 270.59 & 371.23 & 0.61 & 207.75 \\
\hline 15 & 731.64 & 409.88 & 0.44 & 292.72 & 288.83 & 0.72 & 115.76 \\
\hline 16 & 472.38 & 231.95 & 0.42 & 190.39 & 210.36 & 0.52 & -166.27 \\
\hline 17 & 491.13 & 277.14 & 0.44 & 197.16 & 221.42 & 0.65 & 127.46 \\
\hline 18 & 552.75 & 331.00 & 0.36 & 238.94 & 215.34 & 0.73 & 80.06 \\
\hline 19 & 265.65 & 89.24 & 0.80 & 70.53 & 68.68 & 0.88 & -61.01 \\
\hline 20 & 525.15 & 299.22 & 0.37 & 224.01 & 217.58 & 0.67 & 126.98 \\
\hline
\end{tabular}

( $X=$ mean of measurement; *: ununit) 
Table 3.5b. Statistical analysis of net $\mathrm{N}$ mineralized (mineral $\mathrm{kg}^{-1}$ soil) from added residues in different scenarios

\begin{tabular}{|c|c|c|c|c|c|c|c|c|c|c|}
\hline \multirow{2}{*}{ Residue code } & \multirow{2}{*}{$x$} & \multicolumn{3}{|c|}{ Scenario 1} & \multicolumn{3}{|c|}{ Scenario 2} & \multicolumn{3}{|c|}{ Scenario 3} \\
\hline & & RMSE & $\mathrm{EF}^{*}$ & $\mathrm{MD}$ & RMSE & $\mathrm{EF}^{*}$ & $M D$ & RMSE & $\mathrm{EF}^{*}$ & $M D$ \\
\hline 1 & 3.57 & 10.30 & -9.43 & -8.97 & 11.57 & -12.17 & -10.35 & 3.53 & -0.22 & -0.55 \\
\hline 2 & 13.52 & 6.99 & -0.07 & -4.07 & 6.99 & -0.07 & -4.88 & 6.94 & -0.06 & -0.24 \\
\hline 3 & 1.48 & 8.68 & -3.50 & -7.95 & 8.12 & -2.94 & -7.49 & 2.58 & 0.60 & -0.61 \\
\hline 4 & -56.36 & 19.38 & -0.04 & -17.11 & -34.38 & -0.09 & -16.15 & 11.99 & 0.53 & -10.44 \\
\hline 5 & 80.56 & 33.26 & -0.65 & 28.73 & 41.28 & -0.37 & 20.96 & 15.51 & 0.57 & 3.50 \\
\hline 6 & -28.73 & 12.09 & 0.73 & -1.86 & -42.07 & 0.62 & 1.72 & 13.13 & 0.62 & 1.72 \\
\hline 7 & 50.64 & 29.86 & 0.44 & -16.96 & 58.97 & -1.51 & -42.33 & 53.92 & -1.21 & -32.48 \\
\hline 8 & -4.50 & 10.60 & -0.84 & -8.16 & 15.00 & -2.69 & -12.61 & 7.15 & 0.16 & -2.61 \\
\hline 9 & -15.33 & 13.70 & -2.22 & -12.05 & 14.88 & -2.80 & -13.19 & 7.19 & 0.11 & -3.49 \\
\hline 10 & -14.33 & 10.71 & -0.08 & 7.69 & 12.79 & -0.55 & 10.39 & 9.86 & 0.08 & 7.73 \\
\hline 11 & -9.00 & 32.16 & -19.15 & 25.03 & 31.23 & -18.00 & 25.47 & 26.26 & -12.44 & 20.80 \\
\hline 12 & -4.50 & 7.27 & -5.68 & 4.87 & 6.66 & -4.60 & 4.50 & 4.18 & -1.20 & 0.52 \\
\hline 13 & 3.83 & 4.60 & 0.32 & 0.85 & 5.90 & -0.12 & -4.08 & 4.31 & 0.40 & -1.24 \\
\hline 14 & -30.24 & 25.70 & -1.06 & -23.42 & 25.37 & -1.01 & -23.09 & 23.98 & -0.80 & -21.79 \\
\hline 15 & -28.63 & 24.89 & -1.36 & -22.97 & 24.36 & -1.26 & -22.43 & 22.15 & -0.87 & -20.39 \\
\hline 16 & -3.42 & 11.21 & -0.50 & -4.85 & 12.24 & -0.78 & -9.35 & 9.30 & -0.03 & -0.75 \\
\hline 17 & -29.82 & 14.74 & 0.17 & -13.05 & 12.09 & 0.44 & -10.31 & 11.59 & 0.49 & -9.74 \\
\hline 18 & -31.21 & 17.11 & 0.03 & -15.57 & 11.80 & 0.54 & -10.15 & 11.29 & 0.58 & -9.57 \\
\hline 19 & 8.39 & 18.38 & -4.93 & 9.60 & 16.19 & -3.60 & 8.45 & 7.44 & 0.03 & -4.78 \\
\hline 20 & -34.08 & 18.25 & 0.04 & -16.25 & 14.66 & 0.38 & -12.75 & 12.68 & 0.54 & -10.82 \\
\hline
\end{tabular}

( $X=$ mean of measurement; *: ununit)

\subsection{Conclusion}

The results from this study showed that using the default values, the SOILN model was not able to represent the kinetics of $\mathrm{C}$ and $\mathrm{N}$ in soil - plant systems, especial in low residue quality. When residues were applied into soil, several parameters such as the fraction of each substrate pools mineralized, retained or transferred to the other pools, the distribution of $\mathrm{C}$ and $\mathrm{N}$ in each substrate need to be modified to get better simulation. The performance of SOIN model then showed a satisfactory in capturing the dynamics of $\mathrm{C}$ and $\mathrm{N}$ from different applied residues with $\mathrm{C}: \mathrm{N}$ ratio from 9 to 148 . In case of high residue quality (in term of C:N ratio lower than 27), the model predicted well in both low and high soil $\mathrm{N}$ concentrations. Discover the essential role of initial parameter (eg ef_fom, ef_biom) need to be taken into consideration due to its effect on the decomposition of different residues which 
are very popular in low farming systems. Moreover, because of carrying out in close system in constant conditions, the model needs to be further evaluated for its ability to predict $\mathrm{C}$ and $\mathrm{N}$ dynamics in various climate and management. 


\subsection{References}

Anderson, T.-H., and Domsch, K. H., 'Carbon assimilation and microbial activity in soil', Zeitschrift für Pflanzenernährung und Bodenkunde, Vol. 149, No. 4, 1986.

Anwar, M. R., O'Leary, G. J., Rab, M. A., Fisher, P. D., and Armstrong, R. D., 'Advances in precision agriculture in south-eastern Australia. V. Effect of seasonal conditions on wheat and barley yield response to applied nitrogen across management zones', Crop and Pasture Science, Vol. 60, No. 9, 2009.

Asseng, S., Jamieson, P., Kimball, B., Pinter, P., Sayre, K., Bowden, J., and Howden, S., 'Simulated wheat growth affected by rising temperature, increased water deficit and elevated atmospheric CO2', Field Crops Research, Vol. 85, 2-3, 2004.

Asseng, S., van Keulen, H., and Stol, W., 'Performance and application of the APSIM Nwheat model in the Netherlands', European Journal of Agronomy, Vol. 12, No. 1, 2000.

Blanco-Canqui, H., and Lal, R., 'Crop Residue Removal Impacts on Soil Productivity and Environmental Quality', Critical Reviews in Plant Sciences, Vol. 28, No. 3, 2009.

Bosatta, E., and Ågren, G. I., 'Theoretical analysis of microbial biomass dynamics in soils', Soil Biology and Biochemistry, Vol. 26, No. 1, 1994.

Brisson, N., Gary, C., Justes, E., Roche, R., Mary, B., Ripoche, D., Zimmer, D., Sierra, J., Bertuzzi, P., Burger, P., Bussière, F., Cabidoche, Y. M., Cellier, P., Debaeke, P., Gaudillère, J. P., Hénault, C., Maraux, F., Seguin, B., and Sinoquet, H., 'An overview of the crop model stics. Modelling Cropping Systems: Science, Software and Applications', European Journal of Agronomy, Vol. 18, 3-4, 2003.

Carberry, P., Probert, M., Dimes, J., Keating, B., and McCown, R., 'Role of modelling in improving nutrient efficiency in cropping systems', Plant and Soil, Vol. 245, No. 1, 2002.

Chertov, O. G., 'Specom - a single tree model of pine stand/raw humus soil ecosystem', Ecological Modelling, Vol. 50, 1-3, 1990.

Constantinides, M., and Fownes, J. H., 'Nitrogen mineralization from leaves and litter of tropical plants: Relationship to nitrogen, lignin and soluble polyphenol concentrations', Soil Biology and Biochemistry, Vol. 26, No. 1, 1994.

Falloon, P., and Smith, P., 'Simulating SOC changes in long-term experiments with RothC and CENTURY: model evaluation for a regional scale application', Soil Use and Management, Vol. 18, No. 2, 2002.

Franko, U., 'Modelling approaches of soil organic matter turnover within the CANDY system', in D. Powlson, P. Smith and J. Smith (eds.), Evaluation of Soil Organic Matter Models, Springer Berlin Heidelberg, 1996.

Franko, U., Oelschlägel, B., and Schenk, S., 'Simulation of temperature-, water- and nitrogen dynamics using the model CANDY', Modelling of Geo-Biosphere Processes, Vol. 81, 1-3, 1995.

Garnier, P., Néel, C., AITA, C., Recous, S., Lafolie, F., and Mary, B., 'Modelling carbon and nitrogen dynamics in a bare soil with and without straw incorporation', European Journal of Soil Science, Vol. 54, No. 3, 2003.

Gaydon, D., Probert, M., Buresh, R., Meinke, H., and Timsina, J., 'Modelling the role of algae in rice crop nutrition and soil organic carbon maintenance', European Journal of Agronomy, Vol. 39, 2012.

Gijsman, A. J., Hoogenboom, G., Parton, W. J., and Kerridge, P. C., 'Modifying DSSAT Crop Models for Low-Input Agricultural Systems Using a Soil Organic Matter-Residue Module from CENTURY', Agron. J, Vol. 94, No. 3, 2002.

Gilmour, C. M., and Gilmour, J. T., 'Assimilation of carbon by the soil biomass', Plant and Soil, Vol. 86, No. $1,1985$.

Godwin, D. A. J. C., Nitrogen Dynamics in Soil-Plant Systems. In: Hanks, R. J; Ritchie, J. T.: Modeling plant and soil systems, American Society of Agronomy; Crop Science Society of America; Soil Science Society of America, 1991. 
Hansen, S., Jensen, H. E., Nielsen, N. E., and Svendsen, H., 'Simulation of nitrogen dynamics and biomass production in winter wheat using the Danish simulation model DAISY', Fertilizer Research, Vol. 27, 2-3, 1991.

Hasegawa, H., Bryant, D. C., and Denison, R. F., 'Testing CERES model predictions of crop growth and $\mathrm{N}$ dynamics, in cropping systems with leguminous green manures in a Mediterranean climate', Field Crops Research, Vol. 67, No. 3, 2000.

Hasegawa, H., Labavitch, J. M., McGuire, A. M., Bryant, D. C., and Denison, R. F., 'Testing CERES model predictions of $\mathrm{N}$ release from legume cover crop residue', Field Crops Research, Vol. 63, No. 3, 1999.

Holzworth, D. P., Huth, N. I., deVoil, P. G., Zurcher, E. J., Herrmann, N. I., McLean, G., Chenu, K., van Oosterom, E. J., Snow, V., Murphy, C., Moore, A. D., Brown, H., Whish, J. P. M., Verrall, S., Fainges, J., Bell, L. W., Peake, A. S., Poulton, P. L., Hochman, Z., Thorburn, P. J., Gaydon, D. S., Dalgliesh, N. P., Rodriguez, D., Cox, H., Chapman, S., Doherty, A., Teixeira, E., Sharp, J., Cichota, R., Vogeler, I., Li, F. Y., Wang, E., Hammer, G. L., Robertson, M. J., Dimes, J. P., Whitbread, A. M., Hunt, J., van Rees, H., McClelland, T., Carberry, P. S., Hargreaves, J. N. G., MacLeod, N., McDonald, C., Harsdorf, J., Wedgwood, S., and Keating, B. A., 'APSIM - Evolution towards a new generation of agricultural systems simulation', Environmental Modelling \& Software, Vol. 62, 2014.

Huth, N., Thorburn, P., Radford, B., and Thornton, C., 'Impacts of fertilisers and legumes on N2O and $\mathrm{CO} 2$ emissions from soils in subtropical agricultural systems: A simulation study', Agriculture, Ecosystems \& Environment, Vol. 136, 3-4, 2010.

Janzen, H. H., and Kucey, R. M. N., 'C, N, and S mineralization of crop residues as influenced by crop species and nutrient regime', Plant and Soil, Vol. 106, No. 1, 1988.

Jarvis, S. C., Stockdale, E. A., Shepherd, M. A., and Powlson, D. S., 'Nitrogen Mineralization in Temperate Agricultural Soils: Processes and Measurement', in Donald L. Sparks (ed.), Advances in Agronomy, Academic Press, 1996.

Jones, J. W., Hoogenboom, G., Porter, C. H., Boote, K. J., Batchelor, W. D., Hunt, L. A., Wilkens, P. W., Singh, U., Gijsman, A. J., and Ritchie, J. T., 'The DSSAT cropping system model. Modelling Cropping Systems: Science, Software and Applications', European Journal of Agronomy, Vol. 18, 3-4, 2003.

Justes, E., Mary, B., and NICOLARDOT, B., 'Quantifying and modelling C and N mineralization kinetics of catch crop residues in soil: parameterization of the residue decomposition module of STICS model for mature and non mature residues', Plant and Soil, Vol. 325, 1-2, 2009.

Keating, B. A., Carberry, P. S., Hammer, G. L., Probert, M. E., Robertson, M. J., Holzworth, D., Huth, N. I., Hargreaves, J. N. G., Meinke, H., Hochman, Z., McLean, G., Verburg, K., Snow, V., Dimes, J. P., Silburn, M., Wang, E., Brown, S., Bristow, K. L., Asseng, S., Chapman, S., McCown, R. L., Freebairn, D. M., and Smith, C. J., 'An overview of APSIM, a model designed for farming systems simulation. Modelling Cropping Systems: Science, Software and Applications', European Journal of Agronomy, Vol. 18, 3-4, 2003.

Kirschbaum, M. U. F., and Paul, K. I., 'Modelling C and N dynamics in forest soils with a modified version of the CENTURY model', Soil Biology and Biochemistry, Vol. 34, No. 3, 2002.

Knapp, E. B., Elliott, L. F., and Campbell, G. S., 'Carbon, nitrogen and microbial biomass interrelationships during the decomposition of wheat straw: A mechanistic simulation model', Soil Biology and Biochemistry, Vol. 15, No. 4, 1983.

Li, C., 'The DNDC Model', in D. Powlson, P. Smith and J. Smith (eds.), Evaluation of Soil Organic Matter Models, Springer Berlin Heidelberg, 1996.

Li, C., Frolking, S., and Frolking, T. A., 'A model of nitrous oxide evolution from soil driven by rainfall events: 1. Model structure and sensitivity', Journal of Geophysical Research: Atmospheres, Vol. 97, D9, 1992.

Li, C., Frolking, S., and Harriss, R., 'Modeling carbon biogeochemistry in agricultural soils', Global Biogeochemical Cycles, Vol. 8, No. 3, 1994. 
MacCarthy, D. S., Sommer, R., and Vlek, P. L. G., 'Modeling the impacts of contrasting nutrient and residue management practices on grain yield of sorghum (Sorghum bicolor (L.) Moench) in a semi-arid region of Ghana using APSIM', Field Crops Research, Vol. 113, No. 2, 2009.

Meier, E. A., Thorburn, P. J., and Probert, M. E., 'Occurrence and simulation of nitrification in two contrasting sugarcane soils from the Australian wet tropics', Australian Journal of Soil Research, Vol. 44, No. 1, 2006.

Mohanty, M., Probert, M., Reddy, K. S., Dalal, R., Mishra, A., Subba Rao, A., Singh, M., and Menzies, N., 'Simulating soybean-wheat cropping system: APSIM model parameterization and validation', Agriculture, Ecosystems \& Environment, Vol. 152, 2012.

Mohanty, M., Reddy, K. S., Probert, M., Dalal, R., Rao, A. S., and Menzies, N., 'Modelling N mineralization from green manure and farmyard manure from a laboratory incubation study', Ecological Modelling, Vol. 222, No. 3, 2011.

Molina, J. A. E., 'Description of the model NCSOIL', in D. Powlson, P. Smith and J. Smith (eds.), Evaluation of Soil Organic Matter Models, Springer Berlin Heidelberg, 1996.

Molina, J. A. E., Clapp, C. E., Shaffer, M. J., Chichester, F. W., and Larson, W. E., NCSOIL, A Model of Nitrogen and Carbon Transformations in Soil: Description, Calibration, and Behavior1, 1983.

Mueller, T., Jensen, L. S., Hansen, S., and Nielsen, N. E., 'Simulating soil carbon and nitrogen dynamics with the soil-plant-atmosphere system model DAISY', in D. Powlson, P. Smith and J. Smith (eds.), Evaluation of Soil Organic Matter Models, Springer Berlin Heidelberg, 1996.

Nascimento, A. F. d., Mendonca, E. S. de, Leite, L. F. C., and Neves, J. C. L., 'Calibration of the century, apsim and ndicea models of decomposition and $\mathrm{n}$ mineralization of plant residues in the humid tropics', Revista Brasileira de Ciencia do Solo, 35 (3), 2011.

Nendel, C., Berg, M., Kersebaum, K. C., Mirschel, W., Specka, X., Wegehenkel, M., Wenkel, K. O., and Wieland, R., 'The MONICA model: Testing predictability for crop growth, soil moisture and nitrogen dynamics', Ecological Modelling, Vol. 222, No. 9, 2011.

Nicolardot, B., Molina, J. A. E., and Allard, M. R., 'C and N fluxes between pools of soil organic matter: Model calibration with long-term incubation data', Soil Biology and Biochemistry, Vol. 26, No. 2, 1994.

Nicolardot, B., Recous, S., and Mary, B., 'Simulation of C and N mineralisation during crop residue decomposition: A simple dynamic model based on the C:N ratio of the residues', Plant and Soil, Vol. 228, No. 1, 2001.

Oorts, K., Garnier, P., Findeling, A., Mary, B., Richard, G., and NICOLARDOT, B., 'Modeling Soil Carbon and Nitrogen Dynamics in No-till and Conventional Tillage Using PASTIS Model', Soil Sci. Soc. Am. J, Vol. 71, No. 2, 2007.

Palm, C. A., and Sanchez, P. A., 'Nitrogen release from the leaves of some tropical legumes as affected by their lignin and polyphenolic contents', Soil Biology and Biochemistry, Vol. 23, No. 1, 1991.

Parton, W. J., Stewart, J. W. B., and Cole, C. V., 'Dynamics of C, N, P and S in grassland soils: a model', Biogeochemistry, Vol. 5, No. 1, 1988.

Powlson, D., 'Why evaluate soil organic matter models?', in D. Powlson, P. Smith and J. Smith (eds.), Evaluation of Soil Organic Matter Models, Springer Berlin Heidelberg, 1996.

Powlson, D., Smith, P., and Smith, J. (eds.), Evaluation of Soil Organic Matter Models, Springer Berlin Heidelberg, 1996a.

--, Evaluation of Soil Organic Matter Models, Springer Berlin Heidelberg, 1996b.

Probert ME, K. B. T. J. P. W., 'Modelling water, nitrogen, and crop yield for a long-term fallow management experiment', Australian Journal of Experimental Agriculture, Vol. 35, 1995.

Probert, M. E., Dimes, J. P., Keating, B. A., Dalal, R. C., and Strong, W. M., 'APSIM's water and nitrogen modules and simulation of the dynamics of water and nitrogen in fallow systems', Agricultural Systems, Vol. 56, No. 1, 1998.

Probert, M., and Dimes, J. P., Modelling Release of Nutrients from Organic Resources Using APSIM. In: Delve, R.J; Probert, M.E (eds): Modelling nutrient management in tropical cropping systems, Australian Centre for International Agricultural Research (ACIAR), 2004. 
Probert, M., Delve, R., Kimani, S., and Dimes, J., 'Modelling nitrogen mineralization from manures: representing quality aspects by varying C: $\mathrm{N}$ ratio of sub-pools', Soil Biology and Biochemistry, Vol. 37, No. 2, 2005.

Robertson, M., Sakala, W., Benson, T., and Shamudzarira, Z., 'Simulating response of maize to previous velvet bean (Mucuna pruriens) crop and nitrogen fertiliser in Malawi', Field Crops Research, Vol. 91, No. 1, 2005.

Schnürer, J., Clarholm, M., and Rosswall, T., 'Microbial biomass and activity in an agricultural soil with different organic matter contents', Soil Biology and Biochemistry, Vol. 17, No. 5, 1985.

Smith, J., Smith, P., and Addiscott, T., 'Quantitative methods to evaluate and compare Soil Organic Matter (SOM) Models', in D. Powlson, P. Smith and J. Smith (eds.), Evaluation of Soil Organic Matter Models, Springer Berlin Heidelberg, 1996.

Sparling, G. P., 'Ratio of microbial biomass carbon to soil organic carbon as a sensitive indicator of changes in soil organic matter', Australian Journal of Soil Research, Vol. 30, No. 2, 1992.

Stöckle, C. O., Donatelli, M., and Nelson, R., 'CropSyst, a cropping systems simulation model', Modelling Cropping Systems: Science, Software and Applications, Vol. 18, 3-4, 2003.

Tian, G., Kang, B. T., and Brussaard, L., 'Biological effects of plant residues with contrasting chemical compositions under humid tropical conditions-Decomposition and nutrient release', Soil Biology and Biochemistry, Vol. 24, No. 10, 1992.

Trinsoutrot, I., Recous, S., Bentz, B., Line'res, M., Che'neby, D., and NICOLARDOT, B., 'Biochemical Quality of Crop Residues and Carbon and Nitrogen Mineralization Kinetics under Nonlimiting Nitrogen Conditions', Soil Sci. Soc. Am. J, Vol. 64, No. 3, 2000a.

Trinsoutrot, I., Recous, S., Mary, B., and NICOLARDOT, B., 'C and N fluxes of decomposing ${ }^{13} \mathrm{C}$ and ${ }^{15} \mathrm{~N}$ Brassica napus L.: effects of residue composition and N content', Soil Biology and Biochemistry, Vol. 32, 11-12, 2000b.

van Ittersum, M. K., Leffelaar, P. A., van Keulen, H., Kropff, M. J., Bastiaans, L., and Goudriaan, J., 'On approaches and applications of the Wageningen crop models', Modelling Cropping Systems: Science, Software and Applications, Vol. 18, 3-4, 2003.

van Soest, P. J., Robertson, J. B., and Lewis, B. A., 'Methods for Dietary Fiber, Neutral Detergent Fiber, and Nonstarch Polysaccharides in Relation to Animal Nutrition', Journal of Dairy Science, Vol. 74, No. 10, 1991.

Vanlauwe, B., Nwoke, O. C., Sanginga, N., and Merckx, R., 'Impact of residue quality on the C and N mineralization of leaf and root residues of three agroforestry species', Plant and Soil, Vol. 183, No. 2, 1996.

Whitbread, A. M., and Clem, R. L., 'Graze to grain-measuring and modelling the effects of grazed pasture leys on soil nitrogen and sorghum yield on a Vertosol soil in the Australian subtropics', Australian Journal of Agricultural Research, Vol. 57, No. 5, 2006.

Whitbread, A. M., Robertson, M. J., Carberry, P. S., and Dimes, J. P., 'How farming systems simulation can aid the development of more sustainable smallholder farming systems in southern Africa', Cropping Systems Design: new methods for new challenges, Vol. 32, No. 1, 2010. 


\section{APPENDIX}

\section{Parameterisation}

If we call the "assimilation yield constant by microbial biomass" of soil organic matter pools is $Y$ (range from $0-1$ ), then the proportion of carbon retained when each soil organic matter pools decomposing is given as below:

$\mathrm{ef}_{\mathrm{i}}=1-\mathrm{Y}$

In fresh organic matter (FOM) pool, the value of $\mathrm{y}$ can be calculated by follow equation:

$$
\mathrm{Y}=\left[\frac{d C_{\mathrm{CO}_{2}}}{d t}\right]
$$

Where: $\mathrm{C}_{\mathrm{CO} 2}$ is the amount of $\mathrm{CO}_{2}$ release from FOM pool during time t. The value of $\gamma$ varies from 0 to 1. The value of $y$ in FOM of any added residue is calculated as follow:

$$
\mathrm{V}_{\mathrm{FOM}}=\left[\frac{\mathrm{CO}_{2} \times 100}{\operatorname{res} \times d m}\right]
$$

Where $\mathrm{SCO}_{2}$ is the amount of $\mathrm{CO}_{2}-\mathrm{C}$ release during time $\mathrm{t}\left(\mathrm{mg} \mathrm{kg}^{-1}\right.$ soil), res is the amount of applied residue ( $\mathrm{mg} \mathrm{kg}^{-1}$ soil), $\mathrm{dm}$ is the dry matter of residue (\%).

\section{Distribution of carbon in different pools soil}

At initialisation, total carbon content (TOC) is calculated as:

$\mathrm{TOC}=\mathrm{FOM}+\mathrm{OC}=\mathrm{FOM}+\mathrm{BIOM}+\mathrm{HUM}$

Where: OC is the organic carbon of soil $(\mathrm{kg} / \mathrm{ha}), \mathrm{BIOM}$ is the microbial biomass carbon ( $\mathrm{kg} / \mathrm{ha})$, HUM is the humic carbon $(\mathrm{kg} / \mathrm{ha})$.

In SOILN, a passive pool of soil organic carbon is considered as the inert part of HUM and is calculated as:

INERT $=$ Finert $\times$ OC

Where: Finert is the proportion of soil carbon that is inert, it is usually assumed depending on soil layer and total organic carbon content.

The BIOM in SOILN is defined in term of the HUM carbon as follow:

BIOM = Fbiom x (HUM - INERT $)$

Fbiom specifies the BIOM pool carbon as a fraction of the hum carbon that is subject to decomposition. Its values range from $0.06 \pm 0.04$ which are mainly depended on soil organic matter. Then,

$\mathbf{B I O M}=($ Fbiom $\times(\mathrm{OC}-\mathrm{INERT})) /(1+$ Fbiom $)$

The decomposition of each pools soil follows equations from $8-12$

\section{Decomposition of soil organic matter pools}


The rate of residue decomposition can be calculated as the following equation:

$\mathrm{dR} / \mathrm{dt}=-\mathrm{kR}$

where: $\mathrm{R}$ is the organic matter added per unit $\left(\mathrm{kg} \mathrm{ha}^{-1}\right)$ in time $\mathrm{t}$ and $\mathrm{k}$ is the decomposition coefficient given by:

$\mathrm{k}=\mathrm{rd}_{\max } \mathrm{F}_{\mathrm{C}: \mathrm{N}} \mathrm{F}_{\text {temp }} \mathrm{F}_{\text {moisture }}$

where: $\mathrm{rd}_{\max }$ is potential decomposition rate; $\mathrm{F}_{\mathrm{C}: \mathrm{N}}, \mathrm{F}_{\text {temp }}, \mathrm{F}_{\text {moisture, }}$ are factors on a scale from 0 to 1 representing the degree of limitation on decomposition imposed by residue $\mathrm{CN}$ ratio, temperature, moisture. The definitions of the factors are expressed mathematically as below:

$$
\begin{array}{lr}
\mathrm{F}_{\mathrm{C}: \mathrm{N}}=\exp \left(0.277\left(1-\mathrm{CN} / \mathrm{CN}_{\mathrm{opt}}\right)\right) & \mathrm{CN}>\mathrm{CN}_{\mathrm{opt}} \\
\mathrm{F}_{\text {temp }}=\mathrm{T} / \mathrm{T}_{\mathrm{opt}} & \mathrm{T} \leq \mathrm{T}_{\mathrm{opt}} \\
\mathrm{F}_{\text {moist }}=1-\left(\sum \mathrm{E}_{\mathrm{os}} / \mathrm{E}_{\mathrm{os}, \text { max }}\right) & \quad \sum \mathrm{E}_{\mathrm{os}}<\mathrm{E}_{\mathrm{os}, \max }
\end{array}
$$

Where: $T$ is the average daily air temperature, $E_{o s}$ is the potential daily soil evaporation, and the subscripts "opt" and "max" refer to the optimum and maximum parameter values, respectively. In SOIL N, the $\mathrm{CN}_{\text {opt }}$ was set to 25 and $\mathrm{T}_{\text {opt }}$ to 32 as default values that represent values in literature 


\section{Chapter 4. Carbon and nitrogen mineralisation and $\mathrm{N}$ recovery from ${ }^{15} \mathrm{~N}$ labelled plant residues under controlled conditions}

\subsection{Introduction}

Nutrient cycling in the soil - plant ecosystem is an essential component of sustainable productive agricultural activities. Although during the last 20 years inorganic fertilizer has played a dominant role of nutrient supply source for plant growth, plant residues also play an important role, especially in low agricultural farming systems in developing countries. Understanding of the decomposition processes occurring in soil, in particular of $\mathrm{C}$ and $\mathrm{N}$ mineralization patterns therefore will help farmers saving their budget for inputs.

The release of $\mathrm{C}$ and $\mathrm{N}$ from organic residues depends mainly on their chemical and physical properties, the environmental conditions and the decomposer communities. Several authors noted negative effects of high lignin and active polyphenol concentrations on the decomposing ability and $\mathrm{N}$ release from residues (Constantinides and Fownes, 1994, Palm and Sanchez, 1991, Fox et al., 1990, Handayanto et al., 1994, Trinsoutrot et al., 2000, Vahdat et al., 2011). When studying the effects of chemical composition of some tropical legumes on N release patterns, Palm and Sanchez (1991) showed that polyphenolic content could control the short term $\mathrm{N}$ release and availability from legumes. Vahdat et al. (2011) found a negative correlation between $\mathrm{N}$ release from two major plant families (Gramineae and Leguminoseae) and lignin, lignin: $\mathrm{N}$ contents or $\mathrm{C}: \mathrm{N}$ ratio of the plant residues.

Nitrogen recovery from plant residues varies widely depending on their characteristics and environmental conditions. Thomsen (2004) indicated that $\mathrm{N}$ recovery significantly depended on the season, for example the barley ${ }^{15} \mathrm{~N}$ recovery was $15 \%$ for winter-applied manure whereas this figure increased to $38 \%$ when applying in spring. Through years, the amount of $\mathrm{N}$ recovery decreased significantly. Thomsen (2004) found that ryegrass recoveries of ${ }^{15} \mathrm{~N}$ from manure and fertiliser were 4 to $6 \%$ in the second year and only 1 to $2 \%$ in the third year. Similar results were also found in Sisworo et al. (1990), Cadisch et al. (1998), Kumar and Goh (2002), Thomsen and Jensen (1994) which showed that the mean N recoveries from 
residues decreased with increasing time of subsequent crop without any added of residues. The effect of residue quality on the $\mathrm{N}$ recovery was reported in Cadisch et al. (1998) where cumulative $\mathrm{N}$ recovery by maize from 4 different legume prunings ranged from $9 \%$ to $44 \%$ under the same conditions. These materials differed significantly in their content of lignin, polyphenol and protein-binding capacity.

Long term $\mathrm{N}$ release may be of considerable practical interest. Holbeck et al. (2013) found that the recovery of fertiliser ${ }^{15} \mathrm{~N}$ was not significantly influenced by soil texture and soil organic matter content and suggested that management practices and biological recycling played a major role in nutrient recovery. When studying the recovery of nitrogen mineralisation from ${ }^{15} \mathrm{~N}$ labelled straw and ryegrass residues by spring barley over 3 years on field conditions, Thomsen and Jensen (1994) found that recovery of $\mathrm{N}$ derived from straw was not significantly different whether incorporated alone or in combination with ryegrass residue and the mean recovery of straw $\mathrm{N}$ was decrease in long term $(4.5 \%$ in the first barley crop and $2.7 \%$ and $1.1 \%$ in the second and third crop). When researching the effect of tillage method on fertilizer N dynamics in the soil, Giacomini et al. (2010) found a little effect between minimum tillage and conventional tillage. Plant ${ }^{15} \mathrm{~N}$ recovery accounted for $59-63 \%$ at flowering and harvest. Similar results were also recognized in Thomsen and Christensen (2007).

The use of nitrogen 15 isotopic techniques to evaluate the $\mathrm{N}$ recovery from added sources has been applied in many studies. In this study, by using ${ }^{15} \mathrm{~N}$ labelled plant residues, we focus mainly on: 1) the dynamic of carbon and nitrogen under incubation condition of several labelled plant residues and 2) to discover the effect of biochemical quality of added residues, the methods of application and season on the $\mathrm{N}$ recovery in a long term experiment in pot trial in greenhouse condition. 


\subsection{Materials and Methods}

\subsubsection{Soil}

The soil (Podsols) was collected from the North of Germany (Lüneburg $53^{\circ} 15^{\prime} 9^{\prime \prime} \mathrm{N}$, $\left.10^{\circ} 24^{\prime} 52^{\prime \prime} \mathrm{E}\right)$ from the surface layer $(0-20 \mathrm{~cm})$ of an annually cultivated field. Previously, the field was planned to annual crops such as carrots, potatoes and wheat. Soil was air-dried and sieved through a $2 \mathrm{~mm}$ mesh to remove roots and other debris and stored at room temperature. Some properties of the soil were: $\mathrm{pH}=6.6$, Clay $=6.2 \%$, Silt $=5.2 \%$, Sand $=$ 88.60\%; OC =1.44\%, $\mathrm{N}=0.06 \%, 5.10 \mathrm{NH}_{4}{ }^{+}-\mathrm{N}\left(\mathrm{mg} \mathrm{kg}^{-1}\right.$ soil), $2.40 \mathrm{NO}_{3}-\mathrm{N}$ (mg kg${ }^{-1}$ soil).

\subsubsection{Labelled plant residues}

Depending on the plant type 2 methods of application were used to enrich ${ }^{15} \mathrm{~N}$ in the plant residues used in this study. Foliar brushing was applied for the perennial cacao (Theobroma cacao) in some branches, the others including mucuna (Mucuna pruriens), lablab (Lablab purpureus), maize (Zea mays), and flemingia (Flemingia macrophylla) were sprayed in whole plant. All plants were grown and developed under controlled conditions in the glasshouse. The number of plants per pot was adjusted to allow normal development. In the beginning, 3-5 seeds of maize, lablab or mucuna were sown and thinned to 1-2 plants in each pot. The plants were continuously labelled with ${ }^{15} \mathrm{~N}$ either from $5 \mathrm{mM}$ of 98 atom\% ${ }^{15} \mathrm{NH}_{4}{ }^{15} \mathrm{NO}_{3}$ or from $5 \mathrm{mM}$ of 98 atom\% ${ }^{15} \mathrm{~N}_{2}$ urea (applied only in maize). Labelling was applied for 12 weeks to allow each pot receiving about $200-300 \mathrm{ml}{ }^{15} \mathrm{~N} 5 \mathrm{mM}$ solution in total. The wetting agent Proagro was added at $2.5 \mathrm{~mL} \mathrm{~L}^{-1}$ to ensure the contact between solution and leaves surface. After labelling, all above biomass were harvested and oven-dried at $40^{\circ} \mathrm{C}$, a subsample was ground at $0.8 \mathrm{~mm}$ for characteristic analysis (Table 4.1 ). The total $\mathrm{C}$ and $\mathrm{N}$ concentration of residues were determined using a combustion technique (Elemental analyser). The Van Soet method was used to determine the acid detergent fiber (ADF), neutral detergent fiber (NDF) and acid detergent lignin (ADL) (van Soest, 1967, van Soest et al., 1991). A soluable fertiliser containing essential macro and micro -nutrients, excluding $\mathrm{N}$ 
was also applied at the start of planting and weekly afterward in each pot experiment in order to satisfy plant nutrient requirements.

Table 4.1. Some biochemical quality of using plant residues (mean \pm standard deviation)

\begin{tabular}{|c|l|l|l|l|c|c|c|c|}
\hline Treatment & $\begin{array}{c}{ }^{15} \mathrm{~N} \\
(\mathrm{APE})\end{array}$ & $\begin{array}{c}\mathrm{N} \\
(\%)\end{array}$ & $\begin{array}{c}\mathrm{C} \\
(\%)\end{array}$ & \multicolumn{1}{c}{$\mathrm{C}: \mathrm{N}$} & $\begin{array}{c}\text { Carbohydrate }^{\mathrm{c}} \\
(\%)\end{array}$ & $\begin{array}{c}\text { Cellulose }^{\mathrm{a}} \\
(\%)\end{array}$ & $\begin{array}{c}\text { Hemicellulose }^{\mathrm{b}} \\
(\%)\end{array}$ & $\begin{array}{c}\text { Lignin }^{\mathrm{d}} \\
(\%)\end{array}$ \\
\hline Cacao & $\begin{array}{l}1.22 \pm \\
0.07\end{array}$ & $\begin{array}{l}2.88 \pm \\
0.23\end{array}$ & $\begin{array}{l}44.03 \pm \\
1.47\end{array}$ & $\begin{array}{l}15.40 \pm \\
1.74\end{array}$ & $38.6 \pm 2.4$ & $27.4 \pm 0.6$ & $11.9 \pm 3.0$ & $\begin{array}{c}22.1 \pm \\
1.5\end{array}$ \\
\hline Flemingia & $\begin{array}{l}1.26 \pm \\
0.08\end{array}$ & $\begin{array}{l}3.02 \pm \\
0.17\end{array}$ & $\begin{array}{l}43.05 \pm \\
0.39\end{array}$ & $\begin{array}{l}14.28 \pm \\
0.68\end{array}$ & $41.4 \pm 0.5$ & $22.0 \pm 1.0$ & $16.0 \pm 0.6$ & $\begin{array}{c}20.6 \pm \\
0.7\end{array}$ \\
\hline Lablab & $\begin{array}{l}2.22 \pm \\
0.10\end{array}$ & $\begin{array}{l}3.16 \pm \\
0.14\end{array}$ & $\begin{array}{l}41.57 \pm \\
0.59\end{array}$ & $\begin{array}{l}13.16 \pm \\
0.37\end{array}$ & $59.4 \pm 1.5$ & $24.3 \pm 0.7$ & $7.9 \pm 1.9$ & $\begin{array}{c}8.3 \pm \\
0.4\end{array}$ \\
\hline Maize & $\begin{array}{l}4.05 \pm \\
0.12\end{array}$ & $\begin{array}{l}2.38 \pm \\
0.16\end{array}$ & $\begin{array}{l}37.73 \pm \\
1.52\end{array}$ & $\begin{array}{l}15.86 \pm \\
1.18\end{array}$ & $32.8 \pm 0.6$ & $28.3 \pm 0.5$ & $34.7 \pm 0.8$ & $\begin{array}{c}4.1 \pm \\
0.1\end{array}$ \\
\hline Mucuna & 0.05 & 0.13 & 0.77 & $\begin{array}{l}11.67 \pm \\
0.47\end{array}$ & $59.1 \pm 0.7$ & $23.2 \pm 0.4$ & $8.4 \pm 1.1$ & $\begin{array}{c}9.2 \pm \\
0.2\end{array}$ \\
\hline
\end{tabular}

${ }^{a}$ Calculated as: \%Acid detergent fiber (ADF) - \% Acid detergent lignin (ADL); ${ }^{b}$ Calculated as: $\%$ Neutral detergent fiber (NDF) - \%ADF; ${ }^{d}$ Calculated as \%ADL; ${ }^{\circ}$ Calculated as: $100-d-a-b$.

\subsubsection{Trials}

\section{Pot trial:}

This trial was carried out in the Greenhouse of Crop Production System in the Tropics, Göttingen University from July 2014 to February 2015 . Five ${ }^{15} \mathrm{~N}$ labeled residue types (including leaves and stems) mentioned in part $2 \mathrm{~b}$ were used in this trial. Pots (height $17 \mathrm{~cm}$, diameter $14 \mathrm{~cm}$ ) were fulfilled with around $1.5 \mathrm{~kg}$ of $2 \mathrm{~mm}$ soil and mixed with $2 \mathrm{~g}$ of ${ }^{15} \mathrm{~N}$ residue throughout pot. The residues were cut at length 1-3 cm and were applied to soil with 2 different ways: incorporated (IN) or mulched (MU). In the IN treatment, the residues were completely and manually mixed into soil to ensure that no visible part of added residues remained on the surface. In the latter treatment $(\mathrm{MU})$, applied residues were maintained on the soil surface with no disturbance. In the same day of residues application, the pots were wet and kept running in 4 weeks. Alora, a variety of winter wheat (Triticum aestivum) from Schweiger Seed Production Company in Moosburg, Germany was used in this trial. Wheat 
seeds were germinated in the chamber for 5 days before transplanting seedlings into pots. Five plants per pot were maintained until harvesting. The experiment was a completely randomized design, replicated 3 times with 2 duplications. A control treatment without added residues was also run in the same time. The first duplication was harvested after 6 weeks of planting and the second one was harvested after 12 weeks of planting. After harvesting in each of duplication, new seedlings were immediately sown in same pots without re-mixing the soil and surface or mixed residues remained in the pots. Each of duplication was then grown and harvested at 6 weeks and 12 weeks of planting respectively for 3 continuous seasons and in totally of almost 7 months. In the harvesting time of each of duplication, all above biomass of 5 wheat plants was completely collected, weighted for biomass and ovendried at $40^{\circ} \mathrm{C}$ for dry matter. Plants samples then were prepared for further analyses. The light was ensured for normal development in greenhouse in winter time by artificial lighting system which was activated daily from 7 am to $5 \mathrm{pm}$.

\section{Incubation trial}

This trial used the same soil and residues type as in pot trial. An amount of $2 \mathrm{~g}$ residue was mixed with $500 \mathrm{~g}$ soil in $3 \mathrm{~L}$ closed-pot and incubated for 119 days (approximately equivalent to 3 tons per ha). In the beginning, the water holding capacity was adjusted to $50 \%$, the cover of the pots was opened and system was run as pre-incubation for 7 days at a constant temperature of $25^{\circ} \mathrm{C}$. In day 8 (day 0 ), water holding capacity was brought to $75 \%$ and kept unchanged during the treatment by controlling pot weight plus soil and water in every week. The pots were completely sealed, closed and incubated at $25^{\circ} \mathrm{C}$ in chamber. A control treatment consisting of soil-only was included in all incubations and in all cases 3 replicates of each treatment were used.

\subsubsection{Analytical measurement}

\section{Gas sampling and measurement}

Gas sampling was carried out only for incubation trial. It was collected every second day in the first 2 weeks, and then on a weekly basis over the next 8 weeks until completion (week $\left.17^{\text {th }}\right)$. At each sampling time, pots were opened for 1 hour, closed and $20 \mathrm{ml}$ of gas was 
sequentially sampled through a septum at 0,45 and $90 \mathrm{~min}$ and transferred to an evacuated vial for gas analysis. This gas sample was marked at time "zero". After 45 and 90 minutes thereafter, this process was replicated without opening the pot. The gas samples then were analysed for all $\mathrm{CH}_{4}, \mathrm{CO}_{2}$ and $\mathrm{N}_{2} \mathrm{O}$ by the automated gas chromatographic system equipped with a flame ionization and an electron capture detectors (WILLIAMS, 1946). Gas fluxes then were calculated from the linear increase of gas concentration as follow:

$$
\Phi=\frac{d c}{d t} \operatorname{IV}\left(\frac{\text { P.V.f }}{\text { R.T }}\right) \mathrm{M}
$$

Where $\Phi$ is the flux of either $\mathrm{N}_{2} \mathrm{O}-\mathrm{N}, \mathrm{CO}_{2}-\mathrm{C}$ or $\mathrm{CH}_{4}-\mathrm{C}\left(\mathrm{mg} \mathrm{h}^{-1}\right)$, dc/dt is the rate of gas concentration change within the incubation pot $\left(\mu \mathrm{L} \mathrm{L}^{-1} \mathrm{~h}^{-1}\right)$, Iv is the incubation pot volume $(\mathrm{L}), \mathrm{P}$ is the measured atmospheric pressure $\left(\mathrm{N} \mathrm{m}^{-2}\right), \mathrm{f}$ is the factor to convert measured gas volume from $\mu \mathrm{L}$ to $\mathrm{m}^{3}, \mathrm{R}$ is ideal gas constant $\left(8.314 \mathrm{~N} \cdot \mathrm{m} \mathrm{mol}{ }^{-1} \mathrm{~K}^{-1}\right)$, T is measured air temperature $(\mathrm{K})$ and $\mathrm{M}$ is molar mass of each gas fluxes $\left(\mathrm{mg} \mathrm{mol}^{-1}\right)$.

Gas flux then was expressed on soil mass basis per day $\left(\mu \mathrm{gg}^{-1}\right.$ soil day $\left.{ }^{-1}\right)$.

Carbon mineralization (expressed in $\mu \mathrm{g} \mathrm{kg}^{-1}$ soil) from added residues was calculated from the different in cumulative amount of carbon release between amendment soil with residues and a control at each sampling time.

Cumulative $\mathrm{CO}_{2}-\mathrm{C}$ (residue) $=$ Cumulative $\mathrm{CO}_{2}-\mathrm{C}$ (treatment) - Cumulative $\mathrm{CO}_{2}-\mathrm{C}$ (control)

\section{Soil sampling and nitrogen measurement}

Mineral nitrogen was measured on soil samples collected at week $0,3,6,9,12,15,18,22$, 25, 28 and 30 in the pot experiment and at week $0,1,2,3,5,7,10,13$ and 17 in the incubation experiment. The samples were extracted with potassium chloride $(\mathrm{KCl})$ solution by shaking for 1 hour and filtered through the No. 42 Whatman filter paper. The extracts were analysed for $\mathrm{NH}_{4}^{+}$and $\mathrm{NO}_{3}^{-}$using thermal conductivity detection by Matejovic (1997). Net $\mathrm{N}$ mineralisation during the incubation processes was calculated as follows:

Mineral $\mathrm{N}\left(\mathrm{mg} \mathrm{kg}^{-1}\right.$ soil $)=\mathrm{NH}_{4}{ }^{+}-\mathrm{N}+\mathrm{NO}_{3}^{-}-\mathrm{N}$

Net $\mathrm{N}$ mineralization from added residues was calculated as follows:

$\mathrm{Net} \mathrm{N} \min \left(\mathrm{mg} \mathrm{kg}^{-1}\right.$ soil $)=$ mineral $\mathrm{N}$ in the treatment - mineral $\mathrm{N}$ in control 


\section{Isotopic analysis}

About $2 \mathrm{mg}$ of ground plant samples were weighed into tin capsules. Samples then were analyzed by isotope ratio mass spectrometry (IRMS), using an elemental analyzer (NA1108, Fisons-Instruments, Rodano,Milano, Italy) coupled to a gas isotope ratio mass spectrometer (Delta C, Finnigan MAT, Bremen, Germany). An Acetanilid was used as a standard for ${ }^{15} \mathrm{~N}$ $(R=0.00367)$. Enrichment of plants in term of atom percent excess (APE) was calculated as follows:

$$
\operatorname{APE}=\left(\left(\frac{15_{N}}{15_{N}+14_{N}}\right)_{\text {labeled }}-\left(\frac{15_{N}}{15_{N}+14_{N}}\right)_{\text {standard }}\right) \times 100
$$

$\mathrm{N}$ derived from residues in percent $(\% \mathrm{NdfR})$ to plant samples was then estimated by using the equation:

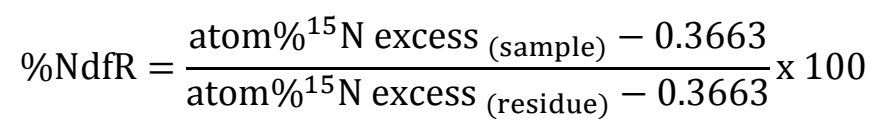

\subsubsection{Statistics}

The data on gas flux, net $\mathrm{N}$ mineralisation, dry matter and $\mathrm{N}$ derived from residues were analysed using analysis of variance (ANOVA) and tests of significance at $5 \%$ level of probability. Statistical analysis was performed by using R program and Excel program.

\subsection{Results}

\subsubsection{Residue quality and the recovery of ${ }^{15} \mathrm{~N}$ isotopic of plants}

Biochemical components of added residues were presented in Table 4.1. In general, there was no significant difference in overall $\mathrm{C}: \mathrm{N}$ ratio and cellulose content of the residues whereas the hemicellulose and lignin content varied in a wide range and was significantly different. The lowest lignin content was measured in maize (4.1\%) followed by lablab (8.3\%) and mucuna (9.2\%). Meanwhile the hemicellulose content of maize was the highest (34.7) and significant difference with the others. As a result of growth conditions, all residues had a low overall C: $\mathrm{N}$ ratio even in cacao and maize residue. 
Table 4.2. The recovery of ${ }^{15} \mathrm{~N}$ isotopic in atom percent excess (APE) of wheat plant from different ${ }^{15} \mathrm{~N}$ labelled residues in 3 consecutive seasons at 6 and 12 weeks after planting of 2 different residue applications (mean \pm standard deviation).

\begin{tabular}{|c|c|c|c|c|c|c|c|}
\hline \multirow{2}{*}{\multicolumn{2}{|c|}{ Residue }} & \multicolumn{3}{|c|}{ Incorporated } & \multicolumn{3}{|c|}{ Mulched } \\
\hline & & 1 & 2 & 3 & 1 & 2 & 3 \\
\hline \multirow{2}{*}{ Cacao } & 6 weeks & $0.42 \pm 0.007$ & $0.39 \pm 0.002$ & $0.39 \pm 0.004$ & $0.42 \pm 0.009$ & $0.38 \pm 0.000$ & $0.39 \pm 0.001$ \\
\hline & 12 weeks & $0.42 \pm 0.012$ & $0.40 \pm 0.004$ & $0.39 \pm 0.005$ & $0.40 \pm 0.009$ & $0.39 \pm 0.001$ & $0.39 \pm 0.003$ \\
\hline \multirow{2}{*}{ Flemingia } & 6 weeks & $0.46 \pm 0.009$ & $0.42 \pm 0.008$ & $0.43 \pm 0.004$ & $0.44 \pm 0.007$ & $0.41 \pm 0.007$ & $0.41 \pm 0.009$ \\
\hline & 12 weeks & $0.45 \pm 0.005$ & $0.46 \pm 0.012$ & $0.42 \pm 0.001$ & $0.45 \pm 0.01$ & $0.45 \pm 0.008$ & $0.41 \pm 0.002$ \\
\hline \multirow{2}{*}{ Lablab } & 6 weeks & $0.72 \pm 0.07$ & $0.48 \pm 0.014$ & $0.48 \pm 0.016$ & $0.60 \pm 0.027$ & $0.53 \pm 0.111$ & $0.47 \pm 0.026$ \\
\hline & 12 weeks & $0.66 \pm 0.008$ & $0.60 \pm 0.011$ & $0.48 \pm 0.026$ & $0.58 \pm 0.036$ & $0.60 \pm 0.044$ & $0.46 \pm 0.011$ \\
\hline \multirow{2}{*}{ Maize } & 6 weeks & $0.86 \pm 0.037$ & $0.56 \pm 0.053$ & $0.54 \pm 0.05$ & $0.96 \pm 0.133$ & $0.58 \pm 0.021$ & $0.53 \pm 0.005$ \\
\hline & 12 weeks & $0.84 \pm 0.078$ & $0.73 \pm 0.077$ & $0.53 \pm 0.017$ & $0.92 \pm 0.061$ & $0.69 \pm 0.02$ & $0.57 \pm 0.013$ \\
\hline \multirow{2}{*}{ Mucuna } & 6 weeks & $0.71 \pm 0.031$ & $0.49 \pm 0.034$ & $0.47 \pm 0.013$ & $0.57 \pm 0.012$ & $0.49 \pm 0.024$ & $0.48 \pm 0.011$ \\
\hline & 12 weeks & $0.70 \pm 0.049$ & $0.59 \pm 0.008$ & $0.48 \pm 0.019$ & $0.64 \pm 0.034$ & $0.61 \pm 0.016$ & $0.48 \pm 0.015$ \\
\hline
\end{tabular}

Through the seasons, recovery of ${ }^{15} \mathrm{~N}$ in wheat plants from the various residues decreased in both residue application treatments. In the first season, ${ }^{15} \mathrm{~N}$ recovery was similar for 6 and 12 week harvests (with exception of mucuna when placed on surface). Nevertheless, in the following season the amount of ${ }^{15} \mathrm{~N}$ recovery when harvesting at 12 weeks after planting (WAP) was significant higher than at 6 WAP in all treatments (except in lablab treatment when placed on surface). In the last season, the significances higher of ${ }^{15} \mathrm{~N}$ recovery in plant were on found in cacao and maize treatments (12 WAP > 6 WAP) when mulched in surface and in flemingia treatment ( 6 WAP $>12$ WAP) when mixed with soil (Table 4.2). 


\subsubsection{Gas fluxes and net $\mathrm{N}$ mineralisation from incubation trial}

Over 17 weeks of the incubation, cumulative $\mathrm{CO}_{2}-\mathrm{C}$ from the flemingia treatment was much higher than from other treatments, totalling $14325 \mu \mathrm{g} \mathrm{CO}_{2}-\mathrm{C} \mathrm{kg}^{-1}$ soil, significantly higher than the mucuna treatment which produced the lowest the amount (9654 $\mu \mathrm{g} \mathrm{CO}_{2}-\mathrm{C} \mathrm{kg}^{-1}$ soil). During the first 4 weeks of incubation, there was a rapid increase of $\mathrm{CO}_{2}-\mathrm{C}$ flux release from lablab, maize and mucuna accounting for $69.1 \%, 73.7 \%$ and $68.2 \%$, respectively compared with the total amount of $\mathrm{CO}_{2}-\mathrm{C}$ flux during treatment. Meanwhile this proportion in cacao and flemingia was much lower, about $41.7 \%$ and $42.6 \%$, respectively. After 28 days, the $\mathrm{CO}_{2}-\mathrm{C}$ flux cumulative from latter group increased gradually till the end of the trial whereas in the former group, it kept almost unchanged after 56 days (Figure 4.1).

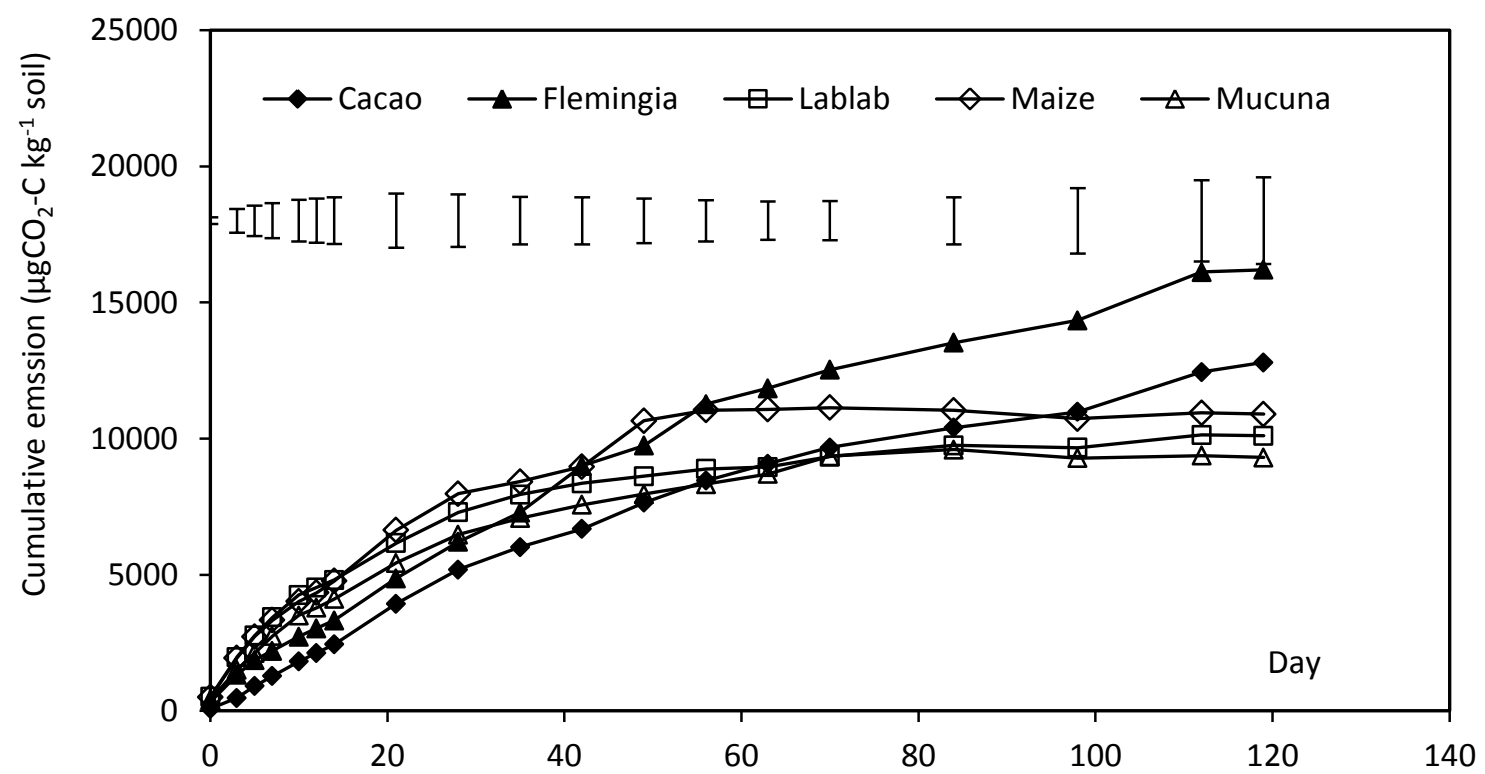

Figure 4.1. Cummulative $\mathrm{CO}_{2}-\mathrm{C}$ emissions from added residues in incubation trial. The error bars represented the least significant difference at $p<0.05$ between each treatment of 3 different replications.

When considering the relationship between biochemical characteristics of the residues (carbohydrate, cellulose, hemicellulose, lignin) and $\mathrm{CO}_{2}$ release, the linear regression was only found between lignin content and the $\mathrm{CO}_{2}$ release (Figure 4.2). A negative correlation 
was observed after 7 days of incubation whereas the positive relationship was found in the later of the decomposition.

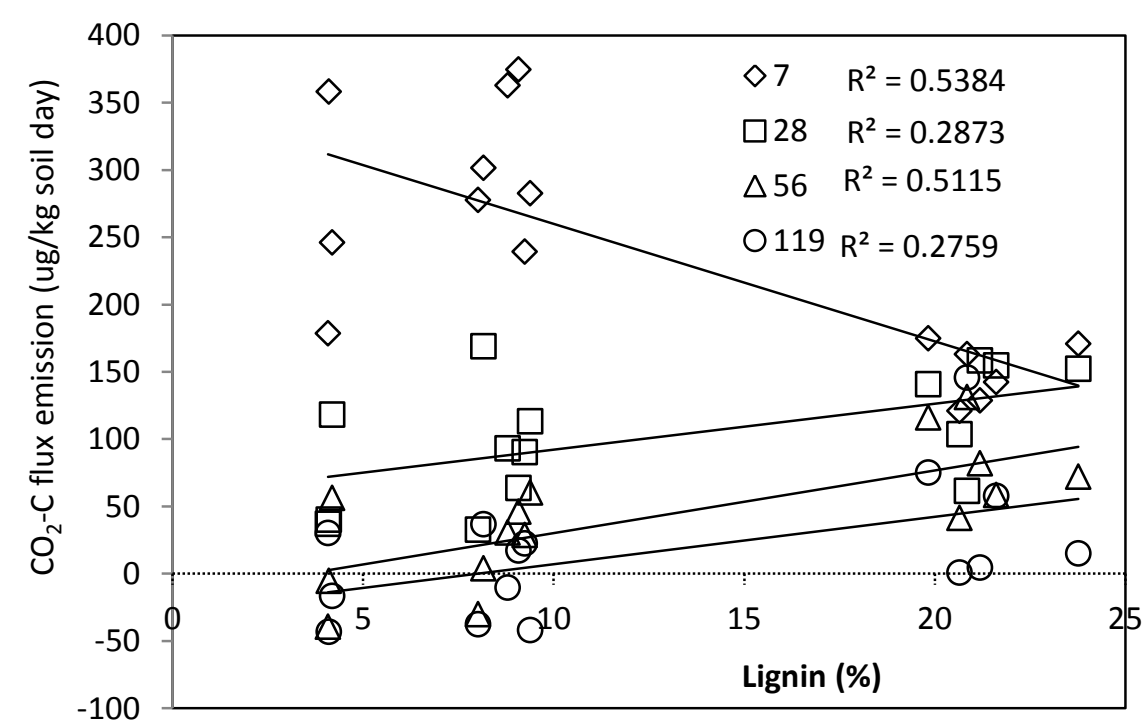

Figure 4.2. The relationship between lignin content and cumulative $\mathrm{CO}_{2}$ emission of different plant residues at 7 days $(\diamond), 28$ days $(\square), 56$ days $(\triangle)$ and 119 days $(O)$.

The net $\mathrm{N}$ mineralization was recognised from lablab and mucuna in the beginning of the incubation. Meanwhile this process was occurred after a short immobilisation (the first week of trial) in other residues (Figure 4.3). After the first week, the net $\mathrm{N}$ mineral from lablab was the largest, approximately $2.08 \mathrm{mg} \mathrm{N} \mathrm{kg}^{-1}$ soil and this was significant difference at $P$ value $<0.05$ compared to the net immobilisation following maize $\left(-4.15 \mathrm{mg} \mathrm{N} \mathrm{kg}^{-1}\right.$ soil), flemingia ($6.07 \mathrm{mg} \mathrm{N} \mathrm{kg}^{-1}$ soil) and cacao $\left(-4.94 \mathrm{mg} \mathrm{N} \mathrm{kg}^{-1}\right.$ soil). Later on, the net $\mathrm{N}$ mineralised was increased in all treatments to the end of trial in which mucuna and lablab was significant difference to the others (Figure 4.3). Cacao was recognised as the residue having the slowest mineralisation rate throughout the trial. In general, the percentage of $\mathrm{N}$ mineralised from added residues was increased with increase of biochemical quality based on the lignin content factor (Table 4.1). After 17 weeks of incubation, it was only about $5.5 \%$ in cacao to $21.2 \%$ in lablab. Mucuna, flemingia and maize was accounted for $18.3,12.3$ and $17.9 \%$, respectively. 


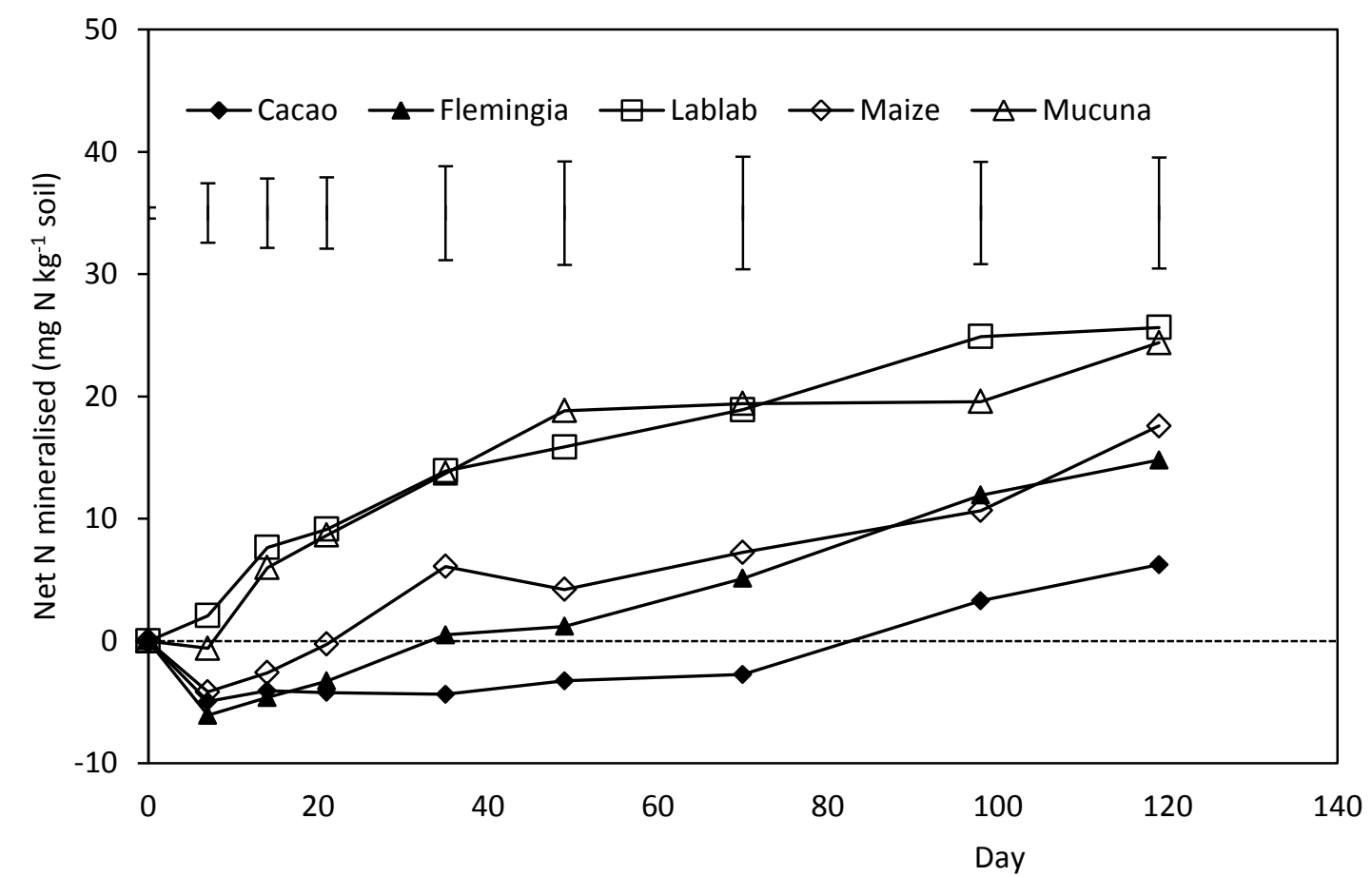

Figure 4.3. Net $\mathrm{N}$ mineralisation from added residues in incubation trial. The error bars represented the least significant difference at $p<0.05$ between each treatment of 3 different replications.

Statistical analysis only found a negative correlation between net $\mathrm{N}$ mineralisation and lignin content and overall C:N ratio of added residues at 7,21, 70 and 119 days of incubation. However this relationship was not strong as the $\mathrm{R}^{2}$ values were much lower than 0.5 and better value of determination correlation $\left(R^{2}\right)$ was being general observed in the later stages of decomposition.

\subsubsection{Dry matter of wheat plant from different applications and residues quality}

In order to evaluate the effect of residue application on dry matter in different of wheat stages, we found that: the dry matter of wheat plant in different residues application depends significantly on the characteristics of used residues. It was divided into 2 groups: maize and cacao group (with slightly higher $\mathrm{C}: \mathrm{N}$ ratio) and lablab, mucuna and flemingia group (with slightly lower C:N ratio). In the latter group, when added residues in surface of soil, dry matter of wheat at 6 WAP was much higher than when incorporated into soil in the first two seasons. Meanwhile, this number in the third season was higher when mixed residues with 
soil than mulched them on the surface. At 12 WAP, the dry matter in treatments incorporated residues into soil was much lower than that in which residues were laid on the surface in all 3 seasons with exception of mucuna in last season. Nevertheless, this trend was the opposite of the former group. The dry matter of plant when incorporated residues with soil was much higher than that when added them on the surface at 6 WAP in first season, but this number in latter application was higher in next consecutive seasons. This trend at 12 WAP was almost similar compared with what occurring to the other group with the exception of maize in first season. In particular, the dry matter of wheat at 6 WAP was about $58.2 \mathrm{~g} / \mathrm{m}^{2}$ and 22.3 $\mathrm{g} / \mathrm{m}^{2}$ when mixed lablab residue into soil in first two seasons but this number increased to $70.8 \mathrm{~g} / \mathrm{m}^{2}$ and $31.2 \mathrm{~g} / \mathrm{m}^{2}$ respectively when added this residue on the surface. However, this figure in latter application in third season was about $16.7 \mathrm{~g} / \mathrm{m}^{2}$ compared with $19.9 \mathrm{~g} / \mathrm{m}^{2}$ in the first application. At 12 WAP, the dry matter in mulch application of the same residue type (lablab) was about $93.5 \mathrm{~g} / \mathrm{m}^{2}, 58.5 \mathrm{~g} / \mathrm{m}^{2}, 45.5 \mathrm{~g} / \mathrm{m}^{2}$, statistical significant difference at $P$ value $<0.05$ compared with incorporation application which was about $84.2 \mathrm{~g} / \mathrm{m}^{2}, 57.2 \mathrm{~g} / \mathrm{m}^{2}, 34.9$ $\mathrm{g} / \mathrm{m}^{2}$, respectively.

In the first season, statistic found a significant difference of dry matter at 6 WAP at level $95 \%$ between treatments two groups. However, this difference was only recognised when residues were applied in the surface. When mixing residues into, in particular of flemingia and mucuna, the dry matter of wheat was even lower than maize and this difference was significant at $P$ value $<0.05$ (Figure 4.4b). It occurred similarly when residue was incorporated into soil (Figure 4.4b). In general, residue application time effected significantly on plant dry matter either added in the surface or mixed into the soil (Figure 4.4a, 4.4b). In 3 consecutive seasons, the dry matter of wheat plant decreased profoundly as a result of no further added of residues in following seasons. 

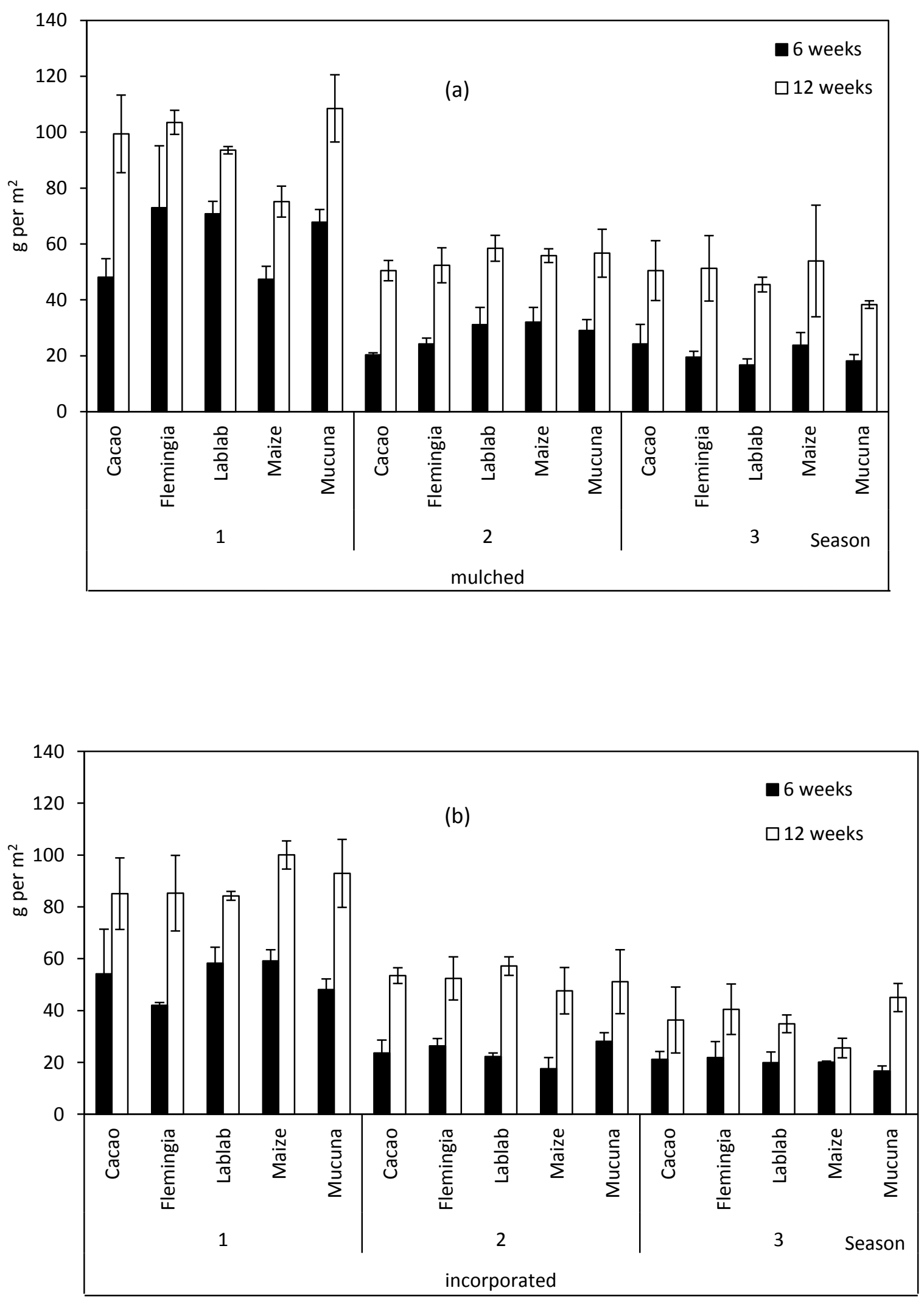

Figure 4.4. Dry matter of wheat at 6 WAP (-) and at 12 WAP ( $\square$ ) in $\mathrm{g} \mathrm{m}^{2-1}$ of different treatments from mulched (a) and incorporated (b) application in 3 consecutive seasons. The error bars represented the standard deviation of 3 different replications of each treatments. 


\subsection{4. $\mathrm{N}$ recovery from added labelled residues to plant}

In general, ${ }^{15} \mathrm{~N}$ recovery from added residues was significantly influenced by the harvested time and the season rather than by residue application when comparing in the same residue. The amount of ${ }^{15} \mathrm{~N}$ recovery in wheat plants at 6 WAP was higher significant than at 12 WAP either placed residues on the surface or mixed with soil. For instance, in the first season, over $18 \%$ of ${ }^{15} \mathrm{~N}$ isotope from labelled lablab was recovered to plant after 6 WAP but this figure was dropped to $12.9 \%$ after 12 WAP when incorporated to the soil. This number when placed them on the surface was $12.2 \%$ and $9.3 \%$, respectively. The smallest amount of ${ }^{15} \mathrm{~N}$ recovery was found in cacao residue, about $6.4 \%$ when mixed with soil and $5.8 \%$ when mulched on surface after 6 WAP. After 12 WAP this figure was about $4.4 \%$ and $2.9 \%$ respectively (Figure $4.5 \mathrm{a}, 4.5 \mathrm{~b})$.

With each crop, ${ }^{15} \mathrm{~N}$ measured in the wheat plants decreased. The largest amount of $\mathrm{N}$ recovery from plant residues was recognized in the first season whether applied on the surface or incorporated into the soil. For example, after 6 WAP in the first season, the total amount of ${ }^{15} \mathrm{~N}$ recovery in almost treatments was almost $50 \%$ higher and was significant difference compared with this amount in following seasons. Meanwhile, the total of $\mathrm{N}$ derived from residues in second season and in third season was almost the same, varied from $2 \%$ to $5.0 \%$. The residues application in general has not influenced on the $\mathrm{N}$ recovery, especially in the last season (Figure 4.5a, 4.5b).

After 3 seasons, we found that the total ${ }^{15} \mathrm{~N}$ recovery mainly depended on the residue types rather than the residue application and harvesting time (Figure 4.6). The highest amount of total ${ }^{15} \mathrm{~N}$ recovery came from lablab residue, approximately $28 \%$ when mixed with soil and about $24 \%$ when placed on surface. There was no significant difference when harvesting at 6 WAP or at 12 WAP. The amount of ${ }^{15} \mathrm{~N}$ from cacao recovered to plant was the least and was significant difference compared with other residues types in both residue applications (Figure 4.6). Among numeric of biochemical indicators of added residues such as carbohydrate, cellulose, hemicellulose and lignin, the total ${ }^{15} \mathrm{~N}$ derived from residues was influenced 
strongly by the lignin content. Statistical analysis found a negative relation between total ${ }^{15} \mathrm{~N}$ recovery and lignin content either at 6 WAP or at 12 WAP (Figure $4.7 a, 4.7 b$ ).
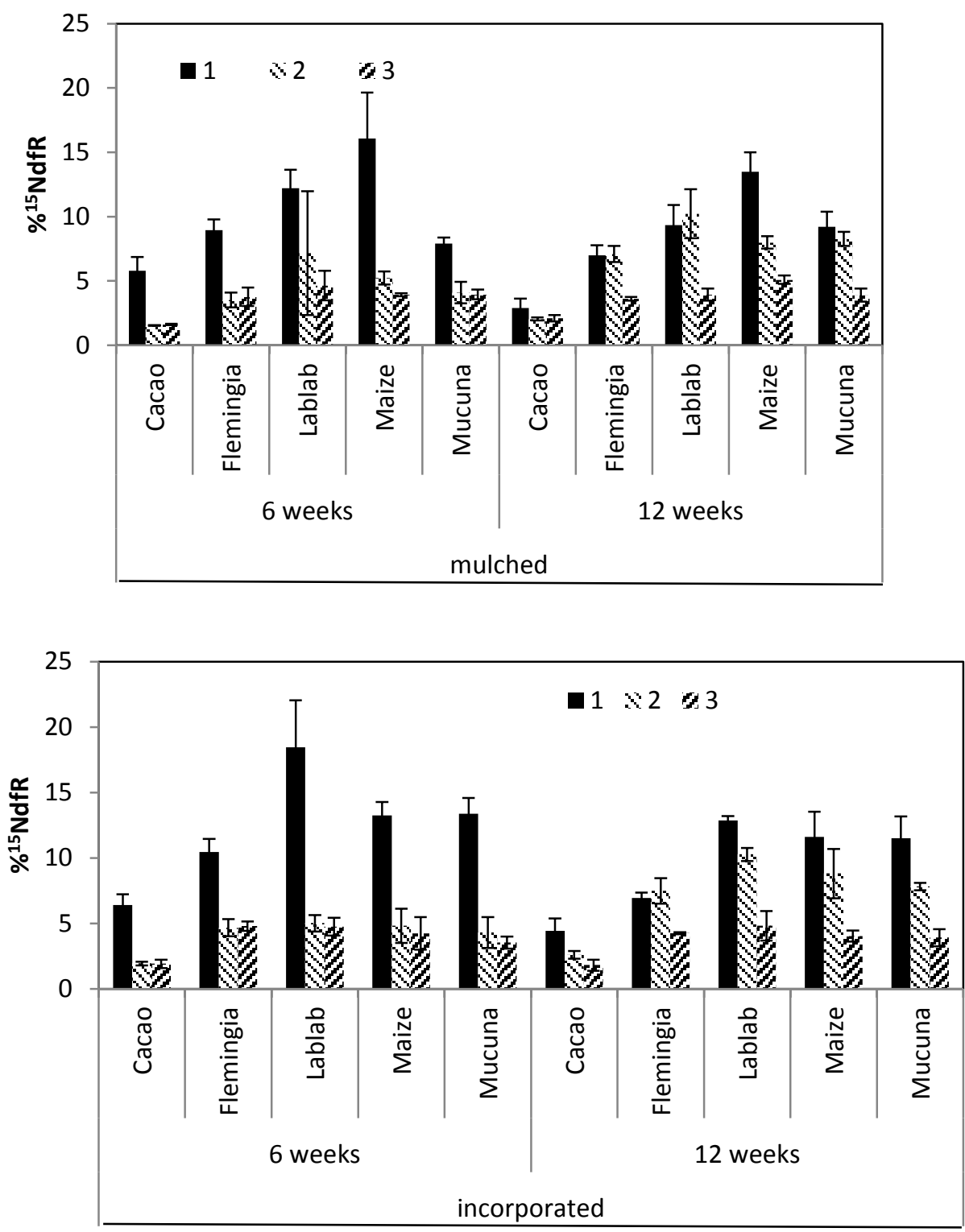

Figure $4.5 .{ }^{15} \mathrm{~N}$ recovery from different added residues to plant in various harvesting time and residues application in the first season ( $\mathbf{\square})$, second season ( $\mathbb{E}$ ) and third season ( $\mathbb{Z}$ ). The error bars represented the standard deviation of 3 different replications of each treatment. 


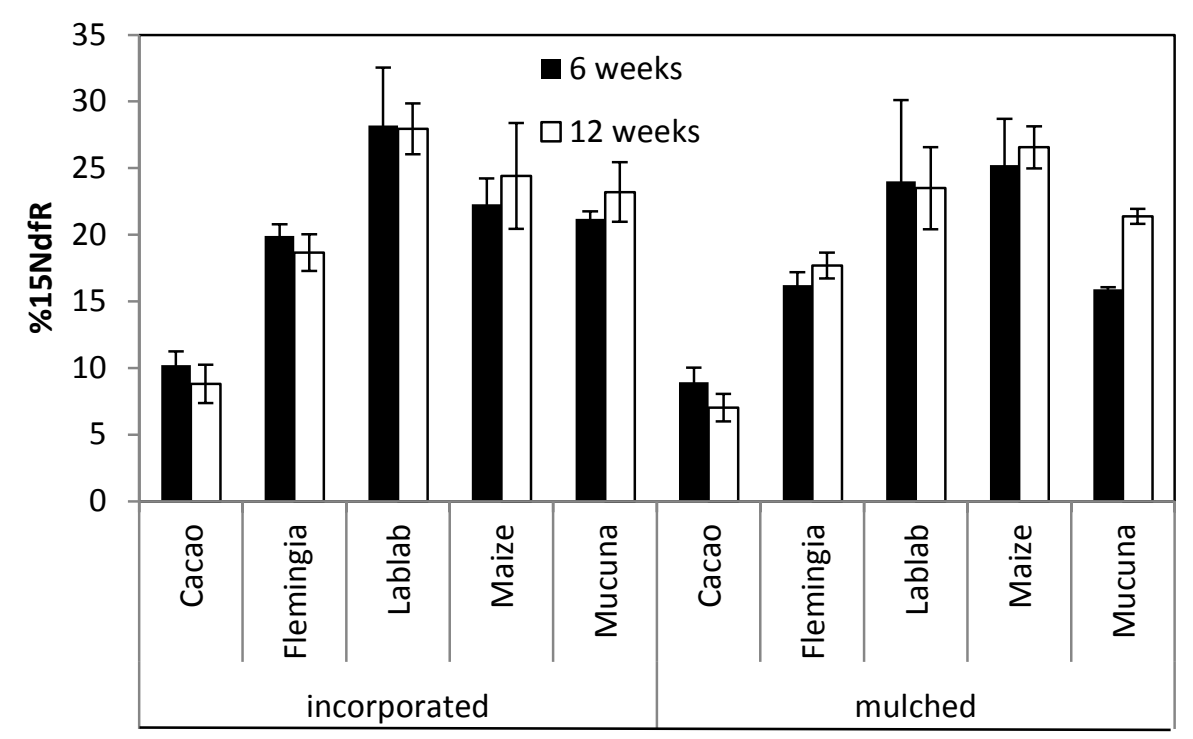

Figure 4.6. Total ${ }^{15} \mathrm{~N}$ recovery from different added residues to plant in different residues applications at 6 WAP (•) and at 12 WAP (口). The error bars represented the standard deviation of 3 different replications of each treatment.

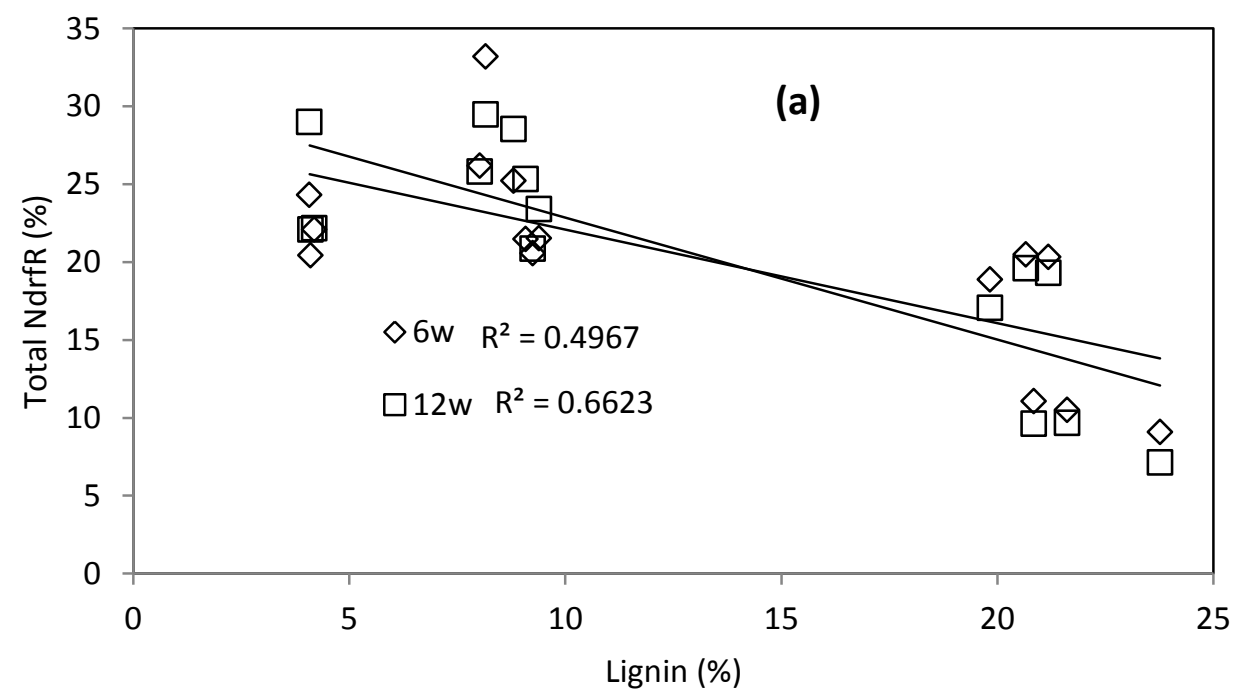




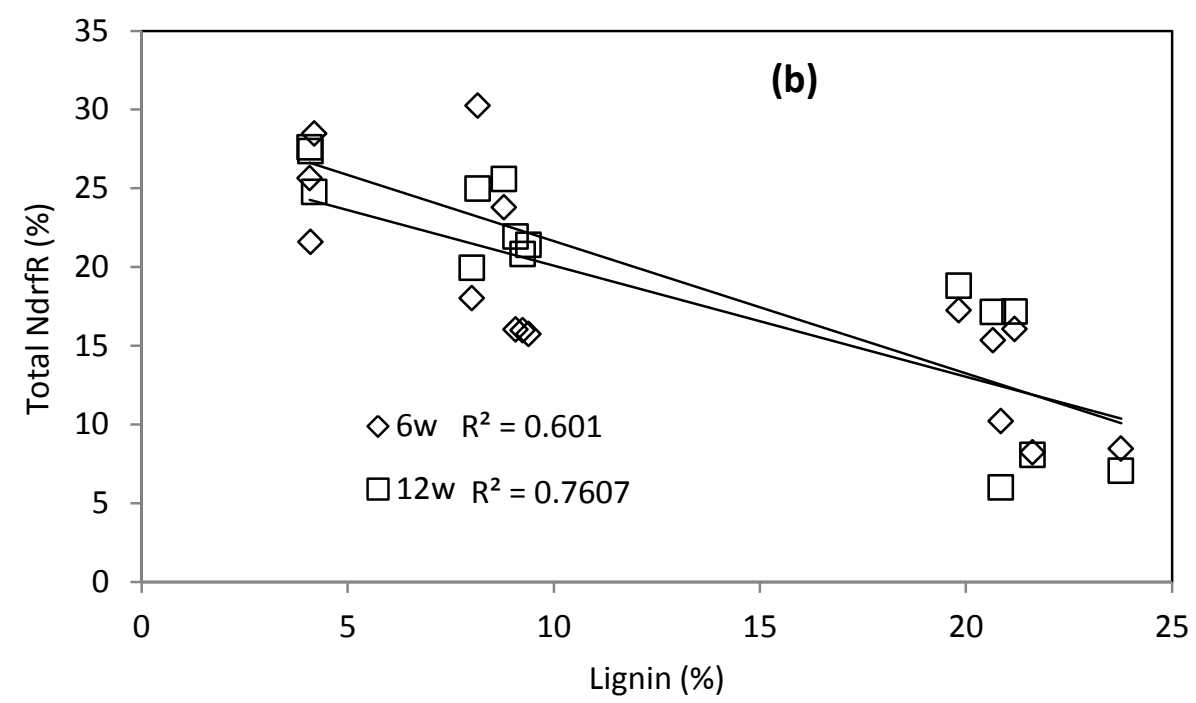

Figure 4.7. Relationship between total $15 \mathrm{~N}$ derived from residue and lignin content from incorporated (a) and mulched (b) application at 6 WAP $(\diamond)$ and at 12 WAP ( $\square)$

\subsubsection{Net $\mathrm{N}$ mineralisation from different residue types and application}

All residue-amended treatments resulted in similar immobilisation of $\mathrm{N}$ for the first 6 weeks either placed them on the surface or mixed with soil (Figure $4.8 \mathrm{a}, 4.8 \mathrm{~b}$ ). The amount of $\mathrm{N}$ immobilised varied and was significant difference between residues types. The lowest net $\mathrm{N}$ immobilised was found in maize (about $8.1 \mathrm{mg} \mathrm{N} \mathrm{kg}^{-1}$ soil) when incorporated with soil and in cacao (about $9.5 \mathrm{mg} \mathrm{N} \mathrm{kg}^{-1}$ soil) when mulched on the surface. The highest amount of net $\mathrm{N}$ immobilised came from mucuna residue when incorporated with soil and from lablab when placed on the surface, about 1.9 and $0.7 \mathrm{mg} \mathrm{N} \mathrm{kg}^{-1}$ soil, respectively. There was almost no initially significant in other 3 applied residues in two treatments, even though there was a slightly larger amount of $\mathrm{N}$ immobilisation when mixed with soil. It was varied from $3.9 \mathrm{mg} \mathrm{N}$ $\mathrm{kg}^{-1}$ soil in flemingia to $6 \mathrm{mg} \mathrm{N} \mathrm{kg}^{-1}$ soil in lablab for incorporation treatment and from $2.4 \mathrm{mg}$ $\mathrm{N} \mathrm{kg}^{-1}$ soil in mucuna to $4.9 \mathrm{mg} \mathrm{N} \mathrm{kg}^{-1}$ soil in maize for mulch treatment. After 6 weeks, following by a short mineralisation of $\mathrm{N}$, the net $\mathrm{N}$ immobilisation was mainly dominant in all added residues when mixed them with soil (Figure 4.8a). In contrast, there was a slightly net $\mathrm{N}$ mineralisation when applied residues on the surface after 12 weeks and this process maintained till the end of treatment (Figure 4.8b). 

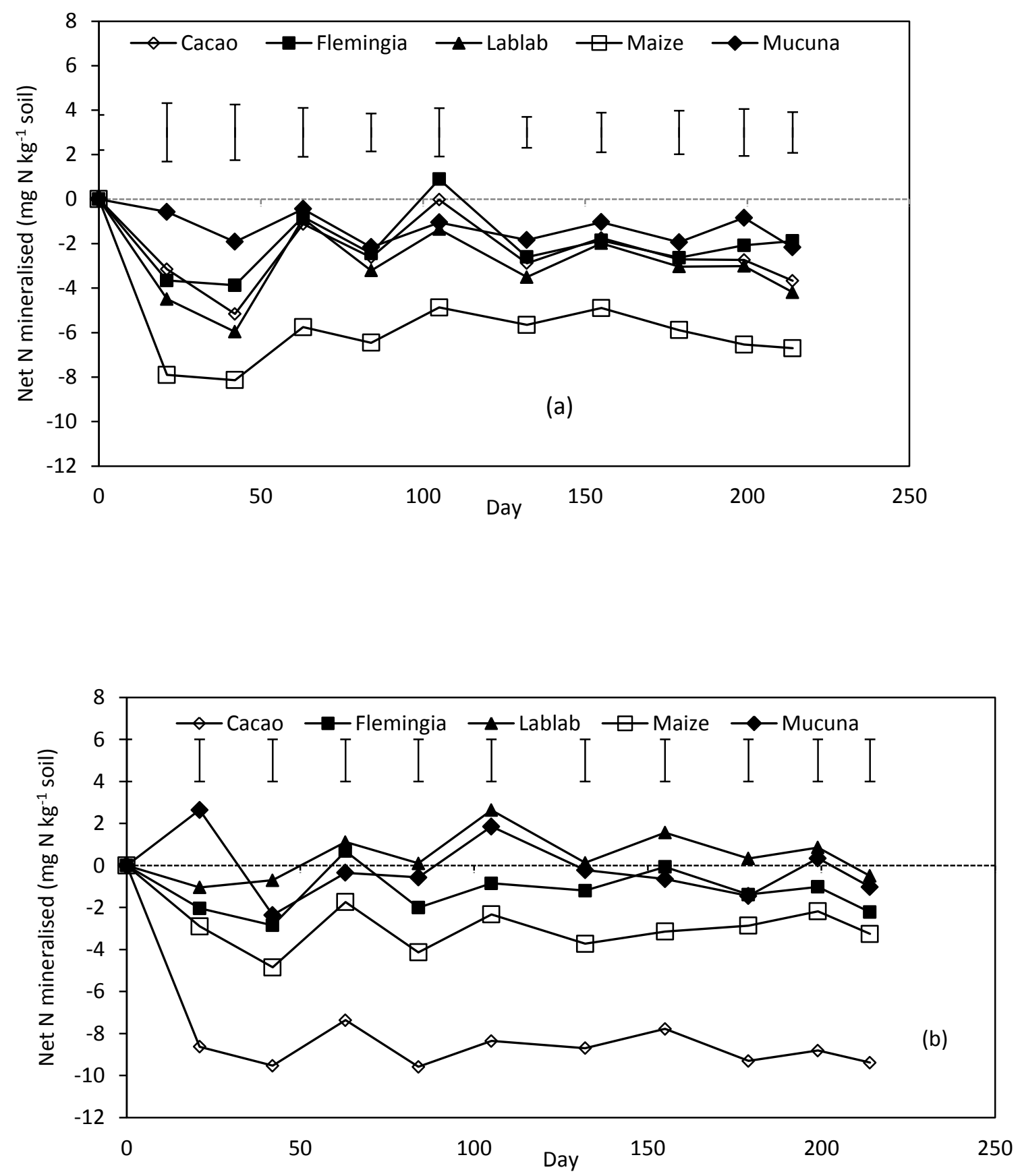

Figure 4.8. Net $\mathrm{N}$ mineralisation from added residues in pot trial when incorporated with soil

(a) or placed on the surface (b). The error bars represented the least significant difference at $p<0.05$ between each treatment of 3 different replications. 


\subsection{Discussion}

\subsubsection{The effect of residue quality on $\mathrm{CO}_{2}-\mathrm{C}$ emission}

The differences in $\mathrm{CO}_{2}-\mathrm{C}$ emission between five plant residues in this study were largely as expected according to their quality parameters. Although the residues had similar C:N ratios, carbohydrate, hemicellulose and lignin concentration varied widely (Table 4.1). The least $\mathrm{CO}_{2}-\mathrm{C}$ emission release was found in higher lignin content group, in this case was in cacao (lignin content of $22.1 \%$ ) and in flemingia (lignin content of $20.6 \%$ ). The group with the lowest lignin content (lablab, maize and mucuna) resulted in immediate release of $\mathrm{CO}_{2}-\mathrm{C}$ and produced almost two thirds of total released quantity of $\mathrm{C}$ after 4 weeks of incubation. This result was consistent with other research which indicated that lignin was one a key determinant of decomposition rate. Trinsoutrot et al. (2000) found that the kinetics of decomposition depended closely on the soluble compounds, cellulose and lignin content rather than the $\mathrm{N}$ content of the residue and similarly, Vanlauwe et al. (1996) found a significantly higher correlation between $\mathrm{C}$ mineralisation and both lignin content and $\mathrm{C}: \mathrm{N}$ ratio.

\subsection{2. $\mathrm{N}$ mineralisation/immobilisation in the different conditions}

Under incubated conditions, net $\mathrm{N}$ mineralisation occurred in all residues after a short time of immobilisation (the first week) except cacao. In this treatment, net immobilisation persisted to 70 days of the trial (Figure 4.3). Conversely for the pot experiment, , the net $\mathrm{N}$ immobilisation was mainly dominant through the time either placed residues on top or mixed with soil (Figure $4.8 \mathrm{a}$ and $4.8 \mathrm{~b}$ ). The reason led to this could be difference in temperature and moisture content. These conditions were well controlled as a constant in incubation trial whereas these conditions were much more difficult to maintain in greenhouse condition. The effect of temperature and moisture on the plant residue decomposition and soil organic matter was also mentioned in Tian et al. (2007), Plante et al. (2010), Cookson et al. (2002), Davidson and Janssens (2006), Leirós et al. (1999). Under laboratory conditions, Cookson et al. (2002) found a significantly increase of mineral $\mathrm{N}$ concentration with increasing 
temperature in amended soil. Similarly, Leirós et al. (1999) also found the combined effects of soil moisture and temperature on the mineralisation of organic matter and they could be estimated by multiple regression. Moreover, Tian et al. (2007) reported that the direct correlation between decomposition rate of plant residues and moisture availability was only valid for residues with high quality.

Regarding the effect of residues quality on the $\mathrm{N}$ dynamic, the results in this study were agreement with other authors. Bending et al. (1998) found that the quality components controlling net $\mathrm{N}$ mineralisation changed during decomposition, with water soluble phenolic and lignin content significantly correlated at early stages, and water soluble $\mathrm{N}$, followed by cellulose at later stages when carrying out a 6 months trials under controlled condition. Similar results were also mentioned in Palm and Sanchez (1991), Kumar and Goh (2003), Chaves et al. (2004), Abiven et al. (2005), Constantinides and Fownes (1994), and Vahdat et al. (2011). In our study, the amount of net $\mathrm{N}$ mineralisation from high quality residues (indicated by low lignin content in Table 4.1) was always higher than the other groups (Figure 4.3). However, in case of maize residue, even though its lignin content was quite low (4.1\%), the amount of net $\mathrm{N}$ mineralisation from this residue was not significantly difference with flemingia (lignin content about 20.6\%). It could be explained due to its high hemicellulose content. Among 5 different added residues, the hemicellulose of maize was the highest (34.7\%, Table 4.1). Similarly, the biochemical quality of residues also influenced significantly on the amount of net $\mathrm{N}$ immobilisation when mixed or placed on the surface in greenhouse condition (Figure 4.8a, 4.8b).

Concerning the effect of residue application on the release of $\mathrm{N}$, we found that: the amount of $\mathrm{N}$ decomposition when placed on the surface was slightly higher than that when incorporated them with soil. Li et al. (2013) suggested that crop residue with low C:N ratio could be incorporated into soils to immobilise $\mathrm{N}$ in comparison with crop residue placed on the soil surface. Similarly, when discover the effects of 3 different crop residues as wheat, barley and lupin management on crop residue decomposition, Cookson et al. (1998) found that wheat from the incorporated treatment had a greatest net $\mathrm{N}$ immobilisation in the early stages of 
decay (0-14 days) and the greatest net $\mathrm{N}$ mineralisation in the later stages. Whereas, there was no significant effects of prior residue management on decomposition of barley and lupin residues. This residue-specific response to management may be explained by a prior conditioning of the soil microbial community to wheat straw which has a more recalcitrant chemical composition such as high lignin content.

\subsubsection{Total ${ }^{15} \mathrm{~N}$ recovery}

Similarly to inorganic $\mathrm{N}$ fertilisers, the recovery of $\mathrm{N}$ from organic residues varies widely. Recovery of $\mathrm{N}$ from added residues by cereal crops depends significantly on biochemical characteristics and environment. When examining the recovery of nitrogen by spring barley following incorporation of ${ }^{15} \mathrm{~N}$ labelled straw and catch crop residues in 3 years on field condition, Thomsen and Jensen (1994) found that the C:N ratio and the lignin content affected significantly on $\mathrm{N}$ recovered. In particular, the first barley crop recovered more ryegrass $\mathrm{N}$ than straw $\mathrm{N}$. The C:N ratio of the former residues in this study was 4 times lesser than the latter one. The C:N ratio of residues using in our study was not much different but the lignin content was significantly difference (Table 4.1). This could be the reason to explain why the total ${ }^{15} \mathrm{~N}$ recovery from added residues (Figure 4.6) was much significantly difference between high lignin content residues (eg. Cacao) and low lignin content residues (eg. lablab and maize). In Cadisch et al. (1998) study, the authors found a good relationship between legume prunings quality (especially of protein binding capacity of polyphenol, \%N and C:N ratio) and the ${ }^{15} \mathrm{~N}$ labelled recovery in three crop cycles of maize (7 weeks for each cycle). Lignin content in this case just influenced on $\mathrm{N}$ recovery in the second and third crop cycles. The total ${ }^{15} \mathrm{~N}$ recovery by wheat in our study (varied from 10 to $30 \%$ ) was agreement with Cadisch et al. (1998), Thomsen (2004), Haynes (1997), Rees et al. (1993) but was relatively higher than report from Kumar and Goh (2002) and Thomsen (2001). It could be explained due to high quality of plant residues used in this study and the growth condition. All plant residues used in this study were grown in greenhouse condition and were harvest at young age. Moreover, this trial was carried out in pots in greenhouse and then it could provide a more favourable environment for residue decomposition than in the field. Furthermore, in the pot experiment, root growth was restricted 
to the volume of soil in which the residues had been applied, and then favouring efficient recovery of mineral $\mathrm{N}$. Keeping the temperature varied in a small range was also an important factor to get high $\mathrm{N}$ recovery in this study. For instance, the percentage of nitrogen recovery from manure by barley increased double to triple when applied in spring compared with in winter (Thomsen, 2004). Similar result was also found in Collins et al. (2007) in which showed that a warmer growing season led to higher $\mathrm{N}$ uptake.

The decrease of $\mathrm{N}$ recovery by plant through time was mentioned in several researches. Kumar and Goh (2002) found a small amount of the residual fertiliser was taken up by wheat and ryegrass in the first year and was decreased significantly in following years. Similarly results were also showed in Thomsen and Jensen (1994), Thomsen (2004), Thomsen (2001) when discovered the $\mathrm{N}$ uptake by barley on field condition. This was agreement with our result in this study in which the $\mathrm{N}$ recovery decreased profoundly in the second and the third season (Figure 4.5a, 4.5b). When carried out trials in pot condition, Cadisch et al. (1998) found a decrease of cumulative ${ }^{15} \mathrm{~N}$ recovery by maize from labelled pruning over three cropping cycles.

Moreover, in Kumar and Goh (2002) study, the authors did not find any significant influence between crop residue management practices (ploughed, rotary hoed, mulched or burned) and the $\mathrm{N}$ recovery. It is similar to our study in which no significant difference of total $\mathrm{N}$ recovery after 3 seasons was recognized in different residue application. This could be due to the experiment condition as it was carried out in close-system, water leaching from the pots was collected by plates and the re-water and thus the nitrogen lost from residue decomposition was elimination.

\subsection{Conclusion}

Finding the primary effect of biochemical quality, especially in the role of lignin content on the decomposition of various plant residues and nitrogen recovery in this study confirms the 
hypothesis that different plant residues will lead the dynamic of $\mathrm{C}$ and $\mathrm{N}$ in soil plant systems in several ways. Such high quality of residues (in term of low lignin content) decomposes faster and contributes large amount of initially nutrient in the beginning of plant growth and the $\mathrm{N}$ recovery from these plant residues was much higher than the others. Moreover, the net $\mathrm{N}$ mineralisation/immobilisation was profoundly influenced by the climate condition. In case of temperature and moisture was kept unchanged (in incubation condition), the net $\mathrm{N}$ mineralisation was main dominant but net immobilisation became main process when these characteristics could not maintain as a constant in greenhouse condition. In a longer term where no further plant residues application, the total $\mathrm{N}$ recovery decreased significantly through seasons, most of the total $\mathrm{N}$ was recovered in the first season. Furthermore, plant residues application did not effect on the total $\mathrm{N}$ recovery but it impact on $\mathrm{N}$ release. Incorporation plant residues with soil could decrease the loss of $\mathrm{N}$ through the mineralisation processes rather than placement them on the surface. 


\subsection{References}

Abiven, S., Recous, S., Reyes, V., and Oliver, R., 'Mineralisation of C and N from root, stem and leaf residues in soil and role of their biochemical quality', Biology and Fertility of Soils, Vol. 42, No. 2, 2005.

Bending, G. D., Turner, M. K., and Burns, I. G., 'Fate of nitrogen from crop residues as affected by biochemical quality and the microbial biomass', Soil Biology and Biochemistry, Vol. 30, No. 14, 1998.

Cadisch, G., Handayanto, E., Malama, C., Seyni, F., and Giller, K. E., 'N recovery from legume prunings and priming effects are governed by the residue quality', Plant and Soil, Vol. 205, No. 2, 1998.

Chaves, B., Neve, S. de, Hofman, G., Boeckx, P., and van Cleemput, O., 'Nitrogen mineralization of vegetable root residues and green manures as related to their (bio)chemical composition', European Journal of Agronomy, Vol. 21, No. 2, 2004.

Collins, H. P., Delgado, J. A., Alva, A. K., and Follett, R. F., 'Use of Nitrogen-15 Isotopic Techniques to Estimate Nitrogen Cycling from a Mustard Cover Crop to Potatoes', Agronomy Journal, Vol. 99, No. 1, 2007.

Constantinides, M., and Fownes, J. H., 'Nitrogen mineralization from leaves and litter of tropical plants: Relationship to nitrogen, lignin and soluble polyphenol concentrations', Soil Biology and Biochemistry, Vol. 26, No. 1, 1994.

Cookson, W. R., Beare, M. H., and Wilson, P. E., 'Effects of prior crop residue management on microbial properties and crop residue decomposition', Applied Soil Ecology, Vol. 7, No. 2, 1998.

Cookson, W. R., Cornforth, I. S., and Rowarth, J. S., 'Winter soil temperature (2-15\&\#xa0; $\left.{ }^{\circ} \mathrm{C}\right)$ effects on nitrogen transformations in clover green manure amended or unamended soils; a laboratory and field study', Soil Biology and Biochemistry, Vol. 34, No. 10, 2002.

Davidson, E. A., and Janssens, I. A., 'Temperature sensitivity of soil carbon decomposition and feedbacks to climate change', Nature, Vol. 440, No. 7081, 2006.

Fox, R. H., Myers, R. J. K., and Vallis, I., 'The nitrogen mineralization rate of legume residues in soil as influenced by their polyphenol, lignin, and nitrogen contents', Plant and Soil, Vol. 129, No. 2, 1990.

Giacomini, S., Machet, J., Boizard, H., and Recous, S., 'Dynamics and recovery of fertilizer ${ }^{15} \mathrm{~N}$ in soil and winter wheat crop under minimum versus conventional tillage', Soil and Tillage Research, Vol. 108, 1-2, 2010.

Handayanto, E., Cadisch, G., and Giller, K. E., 'Nitrogen release from prunings of legume hedgerow trees in relation to quality of the prunings and incubation method', Plant and Soil, Vol. 160, No. 2, 1994.

Haynes, R. J., 'Fate and recovery of ${ }^{15} \mathrm{~N}$ derived from grass/clover residues when incorporated into a soil and cropped with spring or winter wheat for two succeeding seasons', Biology and Fertility of Soils, Vol. 25, No. 2, 1997.

Holbeck, B., Amelung, W., Wolf, A., Südekum, K.-H., Schloter, M., and Welp, G., 'Recoveries of ${ }^{15} \mathrm{~N}$ labelled fertilizers (chicken manure, mushroom compost and potassium nitrate) in arable topsoil after autumn application to winter cover crops', Soil and Tillage Research, Vol. 130, 2013.

Kumar, K., and Goh, K., 'Recovery of ${ }^{15} \mathrm{~N}$-labelled fertilizer applied to winter wheat and perennial ryegrass crops and residual ${ }^{15} \mathrm{~N}$ recovery by succeeding wheat crops under different crop residue management practices', Nutrient Cycling in Agroecosystems, Vol. 62, No. 2, 2002.

Kumar, K., and Goh, K. M., 'Nitrogen Release from Crop Residues and Organic Amendments as Affected by Biochemical Composition', Communications in Soil Science and Plant Analysis, Vol. 34, 17-18, 2003.

Leirós, M. C., Trasar-Cepeda, C., Seoane, S., and Gil-Sotres, F., 'Dependence of mineralization of soil organic matter on temperature and moisture', Soil Biology and Biochemistry, Vol. 31, No. 3, 1999. 
Li, L.-J., Han, X.-Z., You, M.-Y., Yuan, Y.-R., Ding, X.-L., and Qiao, Y.-F., 'Carbon and nitrogen mineralization patterns of two contrasting crop residues in a Mollisol: Effects of residue type and placement in soils', European Journal of Soil Biology, Vol. 54, 2013.

Matejovic, I., 'Determination of carbon and nitrogen in samples of various soils by the dry combustion', Communications in Soil Science and Plant Analysis, Vol. 28, 17-18, 1997.

Palm, C. A., and Sanchez, P. A., 'Nitrogen release from the leaves of some tropical legumes as affected by their lignin and polyphenolic contents', Soil Biology and Biochemistry, Vol. 23, No. 1, 1991.

Plante, A. F., Conant, R. T., Carlson, J., Greenwood, R., Shulman, J. M., Haddix, M. L., and Paul, E. A., 'Decomposition temperature sensitivity of isolated soil organic matter fractions', Soil Biology and Biochemistry, Vol. 42, No. 11, 2010.

Rees, R. M., Yan, L., and Ferguson, M., 'The release and plant uptake of nitrogen from some plant and animal manures', Biology and Fertility of Soils, Vol. 15, No. 4, 1993

Sisworo, W., Mitrosuhardjo, M. M., Rasjid, H., and Myers, R. J. K., 'The relative roles of $\mathrm{N}$ fixation, fertilizer, crop residues and soil in supplying $\mathrm{N}$ in multiple cropping systems in a humid, tropical upland cropping system', Plant and Soil, Vol. 121, No. 1, 1990.

Thomsen, I. K., 'Recovery of nitrogen from composted and anaerobically stored manure labelled with ${ }^{15} \mathrm{~N}^{\prime}$, European Journal of Agronomy, Vol. 15, No. 1, 2001.

Thomsen, I. K., 'Nitrogen Use Efficiency of N-labeled Poultry Manure', Soil Science Society of America Journal, Vol. 68, No. 2, 2004.

Thomsen, I. K., and Christensen, B. T., 'Fertilizer ${ }^{15} \mathrm{~N}$ recovery in cereal crops and soil under shallow tillage', Soil and Tillage Research, Vol. 97, No. 1, 2007.

Thomsen, I. K., and Jensen, E. S., 'Recovery of nitrogen by spring barley following incorporation of ${ }^{15} \mathrm{~N}$-labelled straw and catch crop material', Agriculture, Ecosystems \& Environment, Vol. 49, No. 2, 1994.

Tian, G., Badejo, M. A., Okoh, A. I., Ishida, F., Kolawole, G. O., Hayashi, Y., and Salako, F. K., 'Effects of residue quality and climate on plant residue decomposition and nutrient release along the transect from humid forest to Sahel of West Africa', Biogeochemistry, Vol. 86, No. 2, 2007.

Trinsoutrot, I., Recous, S., Mary, B., and NICOLARDOT, B., 'C and N fluxes of decomposing $13 \mathrm{C}$ and ${ }^{15} \mathrm{~N}$ Brassica napus L.: effects of residue composition and N content', Soil Biology and Biochemistry, Vol. 32, 11-12, 2000.

Vahdat, E., Nourbakhsh, F., and Basiri, M., 'Lignin content of range plant residues controls $\mathrm{N}$ mineralization in soil', European Journal of Soil Biology, Vol. 47, No. 4, 2011.

Vanlauwe, B., Nwoke, O. C., Sanginga, N., and Merckx, R., 'Impact of residue quality on the C and N mineralization of leaf and root residues of three agroforestry species', Plant and Soil, Vol. 183, No. 2, 1996.

WILLIAMS, R. F., 'The Physiology of Plant Growth with Special Reference to the Concept of Net Assimilation Rate', Annals of Botany, Vol. 10, No. 1, 1946. 


\section{Chapter 5. General discussion and conclusion}

\subsection{General discussion}

The overall goal of this study was to explore the decomposition processes of various plant residues from cereal crops, legumes crops to perennial crops under controlled conditions. The research work was focused mainly on measuring and modelling $C$ and $N$ release from added residues in different experimental conditions.

\subsubsection{Residue quality and decomposition}

Application of organic matter plays a critical role in the productivity of most small farming systems in the tropics by providing nutrients availability in short term and substrates for the maintenance and synthesis of soil organic matter in long term. In the last two decades, research on plant residues decomposition and the relationship between plant litter quality and decomposition has been carried out and published widely either in laboratory scale or on field scale. From these studies, at least two general paradigms have emerged. First, the C:N ratio or the $\mathrm{N}$ concentration of the plant residue is accepted as a general index of quality (Seneviratne, 2000, Trinsoutrot et al., 2000a): mineralisation rates tend to decrease with increasing $\mathrm{C}: \mathrm{N}$ ratio. Second, lignin is considered as a natural recalcitrant which exerts a control on the overall biodegradability of plant residue in soil (Vahdat et al., 2011) and contributes to the recalcitrance of plant litter to decomposition by occluding more easily decomposable polysaccharides. Furthermore, Tian et al. (1995) developed an equation to calculate a plant residue quality index (PRQI) in the sub and humid tropics by using the C:N ratio and lignin and polyphenol concentration of plant residues. After testing with 18 different plant species, authors suggested that the PRQI could be used as a tool for projecting rates of plant residue decomposition. Physical components of litter quality have received somewhat less attention in research on litter quality. Recent research has shown that particle size and surface area to mass characteristics can markedly affect decomposition rates (Angers and Recous, 1997, Li et al., 2013). 
As presented in chapter 2, decomposition processes of various added residues were related to soil type and to their biochemical quality. The $\mathrm{C}$ mineralisation faster was recognised in soil having higher $\mathrm{OC}$ content. The rapidly evolution of $\mathrm{C}$ from residues (about $50 \%$ in the first 7 days of incubation from the clay soils) could be taken into consideration of residue practice management on the field. For example, high decomposition rate from lower $\mathrm{C}: \mathrm{N}$ ratio and low lignin content suggests an option of using residue for nutrient supply or for enrichment soil quality. Another important finding was that the at $\mathrm{C}: \mathrm{N}$ ratio lower than $27, \mathrm{~N}$ mineralisation was mainly dominance. Residue management practice also plays an important role in decomposing of residues. Mulching practice could enhance the amount of $\mathrm{CO}_{2}$ procedure than incorporation management. Moreover, residue quality also plays a dominant role in the recovery of nitrogen to plant, especially the lignin content (chapter 4). A statistical analysis showed a negative correlation between total nitrogen recovery and lignin content with relatively high of $R^{2}$ (varied from 0.5 to 0.75 ). Without addition of residue, the $N$ derived from residues significantly decline through seasons after 7 months of experiment.

The Organic Resource Database (ORD) which contains information on organic resource quality parameters including macronutrient, lignin and polyphenol contents of fresh leaves, litter, stems and/or roots from almost 300 species found in tropical ecosystems has been established by Palm et al. (2001a). Through comparative review of the data, an attempt to quantitatively define high and low quality organic matter materials as they impact to nitrogen release has been proposed. Based on these critical values, a simple decision tree for biomass transfer of plant residues for soil fertility management has been suggested (Figure 5.1). It could be used for testing the contribution of different organic materials categories (Table 5.1) on nutrient availability in soil in short term or the effect of organic resource quality on soil organic matter maintenance and composition. The findings in our study once again convinced the possibility of application of results representing in Figure 5.1 and Table 5.1 into the realistic, especially in low input farming systems. The residues with $\mathrm{N}$ content lower than 2.5 and $\mathrm{C}: \mathrm{N}$ ratio higher than 27 in almost cases decomposed slowly and therefore their role in nutrient contribution to plant was not so important in short term. However, if their lignin 
content was low (for example in lablab residues in chapter 2, lignin content was about $7 \%$ ) could be taken into consideration as a nutrient supply in short term as it decomposed fast.

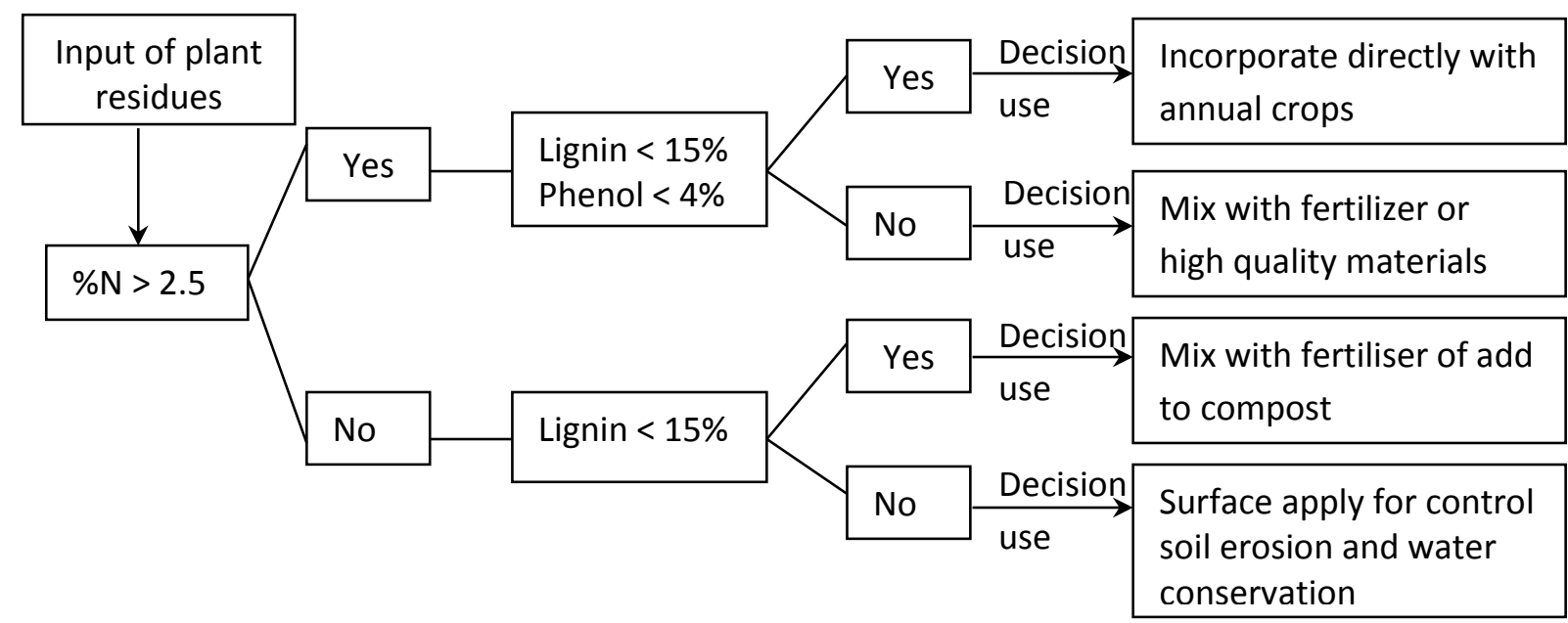

Figure 5.1. Decision tree of plant residues application as determined by their litter quality (adapted from Palm et al., 2001a)

Table 5.1. Different categories of organic materials based on biochemical quality and their effects on nitrogen supply and soil organic matter (adapted from Palm et al., 2001b)

\begin{tabular}{|l|l|l|l|}
\hline Categories & Parameters $\left(\mathrm{g} \mathrm{kg}^{-1}\right)$ & Nitrogen availability & Soil organic matter formation \\
\hline High quality & $\begin{array}{l}\mathrm{N}>25, \text { lignin }<150, \\
\text { polyphenol }<40\end{array}$ & High and immediate & $\begin{array}{l}\text { Little or negative effect on total } \\
\text { SOM, increased active pool (soil } \\
\text { microbial biomass }\end{array}$ \\
\hline $\begin{array}{l}\text { Intermediate-High } \\
\text { quality }\end{array}$ & $\begin{array}{l}\mathrm{N}>25, \text { lignin }>150, \\
\text { polyphenol }>40\end{array}$ & $\begin{array}{l}\text { Delayed, short or long } \\
\text { term }\end{array}$ & $\begin{array}{l}\text { Increased particulate and } \\
\text { passive pools in SOM }\end{array}$ \\
\hline $\begin{array}{l}\text { Intermediate-Low } \\
\text { quality }\end{array}$ & $\begin{array}{l}\mathrm{N}<25, \text { lignin }<150, \\
\text { polyphenol }<40\end{array}$ & $\begin{array}{l}\text { Low and short term } \\
\text { immobilization }\end{array}$ & Little effect on total SOM \\
\hline Low quality & $\begin{array}{l}\mathrm{N}<25, \text { lignin }>150, \\
\text { polyphenol }>40\end{array}$ & $\begin{array}{l}\text { Very low and possible } \\
\text { long term } \\
\text { immobilization }\end{array}$ & $\begin{array}{l}\text { Increased particulate and } \\
\text { passive pools. }\end{array}$ \\
\hline
\end{tabular}

\subsubsection{Potential application of soil organic matter models}

Integration of plant litter decomposition into soil - plant ecosystem models has been used widely elsewhere. The model has been successfully applied to representing the nitrogen mineralization from common crop residues (cereals and legumes) based on the overall $\mathrm{C}: \mathrm{N}$ 
ratio (Trinsoutrot et al., 2000b). However they could not be able to represent the more complex pattern of mineralisation/immobilization when residues decompose slower than what their C:N suggests. In order to capture these patterns, the organic matter input needs to be divided as comprising discrete fractions that differ not only their decomposition rates but also in their biochemical component (such as carbohydrate, cellulose and lignin contents). In almost soil organic matter (SOM) models, plant residues incorporated to soil is usually represented by two or more pools depending on its decomposition rate. Kinetically defined pools are conceptual substrate fractions that are determined by fitting the decomposition model to experimental data on substrate. However, most of the conceptual pools in all current SOM models do not correspond directly with experimentally measurable fractions of SOM. For example in Probert et al. (2005), even though the authors achieved some success in simulating the different patterns of $\mathrm{N}$ mineralization from various organic manures and feeds by using SOILN model, it remained a challenge to know how appropriate parameters should be selected and how to derive these values from literature. Within 3 different fresh organic matter (FOM) pools, an individual fitting procedure was applied for at least 2 parameters to give a goodness of fit between simulated $\mathrm{N}$ mineralisation and measured data. In chapter 3, the pools' size of FOM could be measured in laboratory by Van Soest method and this fraction was maintained during processes. However, the distribution of $\mathrm{N}$ in 3 FPOOLs (the C:N ratio in each FPOOLs) (Table 3.1) needed to be adjusted to get better represent of model. The obtained values of these parameters used in chapter 3 were in good agreement with those in Probert et al. (2005), except those in the residues dactyladenia roots (\#11), rape seed stems (\#14) and rape seed wall pods (\#15) (Table 3.1). Moreover, in order to get better fit, using default values for some essential parameters was not appropriate. Therefore, sensitivity analysis was tested under available dataset from residues of $\mathrm{C}$ and $\mathrm{N}$ mineralisation in some parameters such as fraction of biomass $\mathrm{C}$ mineralized retained in system (ef_biom), fraction of humus C mineralized retained in system (ef_hum), fraction of retained biomass C returned to biomass (fr_biom_biom), and fraction of retained FOM C transferred to biomass (fr_fom_biom). The performance of SOILN using modified 
parameters simulated well the kinetics of $\mathrm{C}$ and $\mathrm{N}$ from various residue types ( $\mathrm{C}: \mathrm{N}$ ratio from 9 to 150). The model could be also predicted well for high residues quality (in term of C:N ratio lower than 27) even in very poor soil nutrient.

A new approach to replace the conceptual pools in order to reduce uncertainty related to model initialization was presented in Luo et al. (2014). In this study, the conceptual SOM pools were transformation to measured SOM pools. Instead of dividing FOM pool into 3 different pools, a new framework model divided FOM into 2 different pools: particulate organic matter (POM) and difference between FOM and POM (DPM). However, changes in SOM pools require new calibration of the potential decomposition rates for each new pool. Under the measured SOM pools model, decomposition rate of POM ( $\mathrm{d}_{\mathrm{POM}}$ ) and HOM (humic SOM) ( $d_{\text {Hом }}$ ) was allowed to vary depended on the research site (for example, the coefficient of variation of $d_{\text {Ром }}$ and $d_{\text {Hом }}$ was about 18 and $69 \%$, respectively) and they were much lower than default values in the original model (which were used in chapter 3). With these modifications, the model got some success in prediction the variation in observed total soil organic carbon and the dynamics of the measured soil organic carbon at the three sites in Australia. However, soil nitrogen in this model was overestimated. Therefore, in order to increase the accuracy of simulation carbon and nitrogen dynamics by SOILN either in the original model Probert et al. (1998) or in new approach Luo et al. (2014), the understanding the different patterns of SOM pools, particularly their C:N ratio and the distribution of $\mathrm{C}$ and $\mathrm{N}$ in different sub-pools, the mechanisms controlling their decomposition and transformation among different pools are needed to be considered.

\subsection{Conclusions and recommendations}

\subsubsection{Conclusions}

- Finding the primary effect of residue quality, especially of lignin content on the decomposition of various plant residues and nitrogen recovery in this study confirms 
the hypothesis that such quality indicators can be used to understand $\mathrm{C}$ and $\mathrm{N}$ dynamics in soil plant systems.

- Mulching practice could promote the processes of residue breakdown in soil. In a longer term, incorporation plant residues with soil could decrease the loss of $\mathrm{N}$ through the mineralisation processes rather than placement them on the surface.

- Decomposition processes of diverse plant residues also depended significantly on soil organic carbon content, soil texture. Faster $\mathrm{C}$ and $\mathrm{N}$ mineralisation was recognised in soil having higher OC content. Moreover, soil that consists of more sandy particles releases less $\mathrm{CO}_{2}$ and nitrogen than high clay content soil.

- When evaluating the performance of SOILN module by using 4 independent datasets, we found that: the distribution of nitrogen in different FPOOLs of fresh organic matter profoundly influenced on the prediction of nitrogen release from the model. Therefore, it is very important to modified fraction of nitrogen in each FPOOLs to get better goodness of fit from the model. Whereas this modification did not effect on release of $\mathrm{CO}_{2}$. The model could also capture well the $\mathrm{C}$ mineralisation from residue when only modified the distribution of $\mathrm{C}$ in each FPOOLs.

- Available nitrogen content in soil influenced significantly on the performance of the model. For low residues quality, the modified model did not perform well in very poor nutrient in soil.

\subsubsection{Suggestions for future research related to the findings of this thesis.}

Learning from the research limitation, some corresponding suggestions are recommended for future work on the topic as follows:

- As far as the decomposition processes of plant residues are strongly influenced by the environmental conditions such as temperature and soil moisture, soil organisms' activities.... further examinations on kinetics of decomposition from several of plant 
species need to be carried out on field conditions under different climate regions to get better understand of these processes.

- The sensitivity of some initial parameters used in this study also takes into consideration when evaluating the model performance under various environmental conditions and residue practice management.

- The $\mathrm{N}$ availability in soil need to be taken into consideration when testing the effect of soil types on the dynamics of $\mathrm{C}$ and $\mathrm{N}$ from plant residues.

- We did not analyzed the $\mathrm{N}$ derived from plant residues to soil and the amount of $\mathrm{N}$ denitrification from the systems to the air, therefore these processes also need to be examined in order to get better understand of $\mathrm{N}$ cycle in soil - plant systems. 


\subsection{References}

Angers, D., and Recous, S., 'Decomposition of wheat straw and rye residues as affected by particle size', Plant and Soil, Vol. 189, No. 2, 1997.

Kögel-Knabner, I., '13C and 15N NMR spectroscopy as a tool in soil organic matter studies', NMR in Soil Science, Vol. 80, 3-4, 1997.

Li, L.-J., Han, X.-Z., You, M.-Y., Yuan, Y.-R., Ding, X.-L., and Qiao, Y.-F., 'Carbon and nitrogen mineralization patterns of two contrasting crop residues in a Mollisol: Effects of residue type and placement in soils', European Journal of Soil Biology, Vol. 54, 2013.

Luo, Z., Wang, E., Fillery, I. R., Macdonald, L. M., Huth, N., and Baldock, J., 'Modelling soil carbon and nitrogen dynamics using measurable and conceptual soil organic matter pools in APSIM', Agriculture, Ecosystems \& Environment, Vol. 186, 2014.

Palm, C. A., Gachengo, C. N., Delve, R. J., Cadisch, G., and Giller, K. E., 'Organic inputs for soil fertility management in tropical agroecosystems: application of an organic resource database', Agriculture, Ecosystems \& Environment, Vol. 83, 1-2, 2001a.

Palm, C. A., Giller, K. E., Mafongoya, P. L., and Swift, M. J., 'Management of organic matter in the tropics: translating theory into practice', in C. Martius, H. Tiessen and P. L. G. Vlek (eds.), Managing Organic Matter in Tropical Soils: Scope and Limitations: Proceedings of a Workshop organized by the Center for Development Research at the University of Bonn (ZEF Bonn) - Germany, 7-10 June, 1999, Springer Netherlands, 2001b.

Probert, M. E., Dimes, J. P., Keating, B. A., Dalal, R. C., and Strong, W. M., 'APSIM's water and nitrogen modules and simulation of the dynamics of water and nitrogen in fallow systems', Agricultural Systems, Vol. 56, No. 1, 1998.

Probert, M., Delve, R., Kimani, S., and Dimes, J., 'Modelling nitrogen mineralization from manures: representing quality aspects by varying C:N ratio of sub-pools', Soil Biology and Biochemistry, Vol. 37, No. 2, 2005.

Seneviratne, G., 'Litter quality and nitrogen release in tropical agriculture: a synthesis', Biology and Fertility of Soils, Vol. 31, No. 1.

Tian, G., Brussaard, L., and Kang, B. T., 'An index for assessing the quality of plant residues and evaluating their effects on soil and crop in the (sub-) humid tropics', Applied Soil Ecology, Vol. 2, No. 1, 1995.

Trinsoutrot, I., Recous, S., Bentz, B., Line`res, M., Che`neby, D., and NICOLARDOT, B., 'Biochemical Quality of Crop Residues and Carbon and Nitrogen Mineralization Kinetics under Nonlimiting Nitrogen Conditions', Soil Sci. Soc. Am. J, Vol. 64, No. 3, 2000 a.

Trinsoutrot, I., Recous, S., Mary, B., and NICOLARDOT, B., 'C and N fluxes of decomposing $13 \mathrm{C}$ and $15 \mathrm{~N}$ Brassica napus $\mathrm{L}$.: effects of residue composition and $\mathrm{N}$ content', Soil Biology and Biochemistry, Vol. 32, 11-12, $2000 \mathrm{~b}$.

Vahdat, E., Nourbakhsh, F., and Basiri, M., 'Lignin content of range plant residues controls $\mathrm{N}$ mineralization in soil', European Journal of Soil Biology, Vol. 47, No. 4, 2011. 


\section{Summary}

Nutrient cycling in the soil - plant ecosystem is an essential component of sustainable productive agricultural activities. Although during the last 20 years inorganic fertilizer have played a dominant role of nutrient supply source for plant growth, plant residues also play an important role, especially in low agricultural farming systems in developing countries. Understanding the dynamics of soil organic matter which is mainly added from plant residues plays an important role to face with several issues of both environmental and agricultural aspects. The aim of this dissertation is to explore the kinetics of carbon and nitrogen mineralization from diverse plant residues and to evaluate the performance of soil organic matter model in capturing these processes. Several plant residue species such as cereal crops, legumes crops to perennial crops were used under short-term experiments in closed chambers incubation in laboratory and pots in greenhouse. Furthermore, integration of plant litter decomposition into soil - plant ecosystem models has been used widely and applied successfully in some common crop residues (cereals and legumes). One of the most applicable models has been the SOILN in APSIM (Agricultural Production Systems Simulator) framework, which has been tested successfully in diverse plant residue to represent the decomposition of organic input, and the influence of residues quality on nitrogen release in different climate conditions of various organic materials and soil types.

In order to evaluate the effect of residue quality on $\mathrm{C}$ and $\mathrm{N}$ dynamics in soils under controlled conditions, eight different plan residues with overall C:N ratio varied from 9 to 70 was tested on 3 different soil types (chapter 2). Plant residues using in this study differed in species (legumes crop like mucuna, pea, lablab, lucerne; cereal crops like wheat and maize; energy crop like canola), plant organs, and growth condition. These materials were used in 3 different incubation trials at $25^{\circ} \mathrm{C}$ in $60-75 \%$ of water holding capacity from 63 days to 126 days. Decomposition processes of various plant residues in this study were driven mainly by their quality and soil types rather than by residues practice management. Higher production of $\mathrm{CO}_{2}$ release was recognized in low $\mathrm{C}: \mathrm{N}$ ratio, small lignin content in high soil organic carbon 
content. Moreover, the $\mathrm{CO}_{2}$ release increased rapidly in the first 4 weeks of incubation and reached around $40 \%$ to three fourths of total C mineralized, especial in very poor nutrient soil (Podsol, N\% $=0.012$ ) it reached up to $50 \%$ only in the first weeks. In all 3 soil types, a positively related was found between the net $\mathrm{C}$ release from added residues and the concentration of organic matter in soil. The net $\mathrm{N}$ mineralized from plant residues profoundly influenced by the concentration of mineral $\mathrm{N}$ in soil and the residue quality. When applying the same residue type, the larger amount of net $\mathrm{N}$ min was found in sandy soil with low $\mathrm{N}$ concentration (7 mg N kg${ }^{-1}$ soil) compared with clay soil (30 mg N kg-1 soil). Furthermore, residues with overall $\mathrm{C}: \mathrm{N}$ ratio lower than 27 resulted a net mineralisation and the net immobilization occurred in residues having overall $\mathrm{C}: \mathrm{N}$ ratio higher than this value.

In chapter 3, the APSIM's SOILN model (version 7.5, http://www.apsim.info/) was used to predict the kinetics of $\mathrm{C}$ and $\mathrm{N}$ mineralisation of plant residues from 3 independent dataset. New parameters used for model performance were obtained as following steps: (1) changing FPOOLs size based on measured data from default values as $0.2: 0.7: 0.1$; (2) allowing the $\mathrm{C}: \mathrm{N}$ ratios in each FPOOL vary, depending on $\mathrm{N}$ content which was determined by optimization; (3) the proportion of the $\mathrm{C}$ decomposed from FOM pool that could be retained in the system based on biochemical quality of residues; (4) the proportion of the C decomposed from BIOM and HUM pools retained in the system based on soil characteristics; (5) re-formulation the fraction of retained biomass returned to biomass; (6) re-formulation the fraction of retained FOM transferred to biomass. With these modifications, the model was able to provide reasonable estimates of both $\mathrm{C}$ and $\mathrm{N}$ release from a wide range of plant residues (C:N ratio varied from 9 to 148). Moreover, the available nitrogen content in soil influenced significantly on the performance of the model. However, for low residues quality, the modified model could not perform well in very poor nutrient in soil.

In the last chapter, five different ${ }^{15} \mathrm{~N}$ labelled plant residues from legumes crops (lablab, flemingia and mucuna), cereal crop (maize) and perennial crop (cacao) were used discover the effect of biochemical quality of added residues, the methods of application and season on the $\mathrm{N}$ recovery in a long term experiment in pot trial in greenhouse condition and 
examined the decomposition processes of those residues in incubation condition. In greenhouse condition, the net $\mathrm{N}$ immobilization was mainly dominant during 7 months of experiment either placed residues on the surface or mixed them with soil. Conversely for the incubation trial, net $\mathrm{N}$ mineralisation occurred in all residues after a short time of immobilization (1 week) except cacao in which net immobilization persisted until 70 days. The differences in $\mathrm{CO}_{2}-\mathrm{C}$ emission between five plant residues in incubation study were largely as expected according to their quality parameters. For example, the cumulative $\mathrm{CO}_{2}-\mathrm{C}$ emission from cacao and flemingia (lignin content over 20\%) accounted for over $40 \%$ during 4 weeks of incubation but this figure increased to around $70 \%$ in lablab, maize and mucuna (lignin content less than $10 \%$ ) eventhough these residues had similar C:N ratios. The residue quality also strongly influenced on the total $\mathrm{N}$ recovery to plant. Statistical analysis found a negative relationship between total ${ }^{15} \mathrm{~N}$ recovery and lignin content after 7 months under greenhouse condition with relatively high of coefficient determination $\left(R^{2}>0.5\right)$. Furthermore, ${ }^{15} \mathrm{~N}$ recovery from added residues was significantly influenced by the harvested time and the season rather than by residue application when comparing in the same residue. The amount of ${ }^{15} \mathrm{~N}$ recovery in wheat plants at 6 WAP was higher significant than at 12 WAP either placed residues on the surface or mixed with soil. The largest amount of $\mathrm{N}$ recovery from plan residues was recognised in the first season and drop suddenly in next following seasons. The residues application in general has not influenced on the $\mathrm{N}$ recovery, especially in controlled conditions. 


\section{Acknowledgements}

I would like to express my sincere gratitude to my supervisor Prof. Dr. Anthony Whitbread, formerly head of division "Crop Production Systems in the Tropics", now with ICRISAT in India, for his patient guidance and enthusiastic encouragement. I have particularly appreciated his willingness to give his time so generously to support me, from the planning to the development and accomplishment of this work. I am deeply thankful for his understanding and encouragement when I got married and had a baby in the last two years of the study and sometimes I did not follow his trace on time. Without my priceless mentor, I would never have finished my dissertation.

I would also like to thank Prof. Dr. Klaus Dittert (Institute of Applied Plant Nutrient) and Dr. Marife Corre (Soil Science of Tropical and Subtropical Ecosystems) for being the second and third examiner of my oral examination, respectively. Special thanks to Dr. John Hargreaves (CRISO) for his training and supporting me in understanding of APSIM modelling, Prof. Dr. Jürgen Hummel and Dr. Tobias Gorniak from Ruminant Nutrition Group for their help in fibre analysis and Dr. Norman Loftfield from Soil Science of Temperate and Boreal Ecosystems for his help in gases measurement. Many thanks also to Dr. Sara Hueso Martos and Seshuhla Rebinah Sasa for their help in arrangement incubation trial, collecting data and samples analyzing.

I wish to thank the staff of the Crop Production Systems in the Tropics (Dr. Ronald Kühne, Dr. Martin Worbes, Dr. Esther Fichtler, Heike Francoli, Birgitt Bode, Ute Fürchtenicht, Thomas Österreich) for their valuable assistance in technical issues, lab, and greenhouse as well as their sharing and supporting during the approximately four years. Also thanks to my PhD colleagues: Munir, Anne, Ami, Gabriel, William.

I am very thankful to the Vietnamese International Education Development (VIED) - Ministry of Education and Training of Vietnam for the funding granted for my Ph.D. Program in Göttingen, Germany.

I wish to acknowledge the forward-looking support and my many colleagues at the Hue University of Agriculture and Forestry, Vietnam, and also my dear friends in Göttingen and in Vietnam for their support and encouragement throughout my Ph.D. journey.

I am also incredibly grateful to my family: my parents, my brothers and sisters, my fatherin-law, and my wife's family. My deepest thanks are given to my wife, Nguyen Thi Hong Trinh, who has travelled countless times up and down from Hamburg to Göttingen and her help and care not only for our little daughter but for me as well. 


\section{Publications}

\section{Paper}

1. Nguyen Trung Hai et al. (2010). Development of Viet Nam coffee industry in recent years. Ecological Economic Journal, vol 36, 2010, p90 - 96.

2. Nguyen Trung Hai et al. (2010). Study on Chemical characteristics of Alluvial soil growing leaf vegetables at Huong Tra district, Thua Thien Hue province. Journal of Agriculture and Rural Development, vol 153, 2010, p27 - 31.

3. Nguyen Trung Hai (2010). Effect of various ferrous components on rice growth and soil characteristics on sandy soil at Thua Thien Hue. Summary record of scientific research, vol 1, Hue university of Agriculture and Forestry.

\section{Proceeding and poster presentation}

1. Nguyen Trung Hai, M.E. Probert, A.M. Whitbread (2014). Modeling carbon and nitrogen mineralisation from diverse crop residues measured from incubation. Poster presentation at $20^{\text {th }}$ World Congress of Soil Science, "Soils Embrace life and Universe", Jeju, Korea 2014

2. Nguyen Trung Hai, Rebina S. Sasa, Vadakattu V.S.R Gupta, A.M. Whitbread (2012). Measuring and Modelling the Decomposition Dynamics of Diverse Crop. Poster presentation at Tropentag conference in Goettingen University from 19-21 Sep 2012 "Resilience of agricultural systems against crises". 


\section{Curriculum Vitae}

\section{Personal information:}

Name: NGUYEN TRUNG HAI

Day of birth: 17.10 .1984

Place of birth: Thua Thien Hue, Viet Nam

Nationality: Vietnamese

\section{Educational background:}

December 2011 - May 2016: Georg - August - Universität Göttingen

PhD student at Crop Production Systems in the Tropics, Faculty of Agricultural Sciences.

Topic: Measuring and modelling the dynamics of carbon and nitrogen mineralization from diverse plant residues in soil - plant systems

Degree: Doctor scientiarum agrariarum (Dr. sc. agr.)

Funding: MOET scholarship

September 2006 - September 2008: Hue University of Agriculture and Forestry

Master student at Agronomy Faculty.

Topic: The correlation between Iron and Phosphorus on coastal sandy soils at Thua

Thien Hue province, Vietnam

Degree: Master of Applied Science in Agriculture

September 2002 - June 2006: Hue University of Agriculture and Forestry

Undergraduate student at Agronomy Faculty

Topic: Study on growth and development characteristics of high quality rice groups on Alluvial soil at Thua Thien Hue province in winter-spring season.

Degree: Bachelor

September 1999 to June 2002: Aluoi High school, Thua Thien Hue province.

Degree: High school Diploma

\section{Job experience:}

2008-2011: Lecturer at Faculty of Land Resources and Agricultural Environment, Hue University of Agriculture and Forestry

2007- 2008: Teaching assistant at Faculty of Land Resources and Agricultural Environment, Hue University of Agriculture and Forestry 


\section{Declarations}

1. I, hereby, declare that this Ph.D. dissertation has not been presented to any other examining body either in its present or a similar form. Furthermore, I also affirm that I have not applied for a Ph.D. at any other higher school of education.

Göttingen,

(Signature)

(Name in block capitals)

2. I, hereby, solemnly declare that this dissertation was undertaken independently and without any unauthorised aid.

Göttingen,

(Signature)

(Name in block capitals) 